UNIVERSIDAdE DE SÃo PAULO - USP

ESCOLA DE ENGENHARIA DE SÃO CARLOS

Departamento de Engenharia ElÉtrica e de ComputaÇão

Programa de Pós-GRAduAÇÃo EM ENGENHARIA ElÉtriCA

Paulo Estevão Teixeira Martins

\title{
Alocação Otimizada de Medidores em Sistemas de Distribuição visando à redução da Múltipla Localização de Faltas
}





\section{Paulo Estevão Teixeira Martins}

\section{Alocação Otimizada de Medidores em Sistemas de Distribuição visando à redução da Múltipla Localização de Faltas}

Dissertação apresentada ao Programa de Pós-Graduação em Engenharia Elétrica da Escola de Engenharia de São Carlos, como parte dos requisitos para obtenção do título de Mestre em Ciências.

Área de Concentração: Sistemas Elétricos de Potência

Orientador: Prof. Assoc. Mário Oleskovicz

São Carlos - SP

2019 
AUTORIZO A REPRODUÇÃO TOTAL OU PARCIAL DESTE TRABALHO, POR QUALQUER MEIO CONVENCIONAL OU ELETRÔNICO, PARA FINS DE ESTUDO E PESQUISA, DESDE QUE CITADA A FONTE.

Ficha catalográfica elaborada pela Biblioteca Prof. Dr. Sérgio Rodrigues Fontes da EESC/USP com os dados inseridos pelo(a) autor(a).

Eduardo Graziosi Silva - CRB - 8/8907 


\section{FOLHA DE JULGAMENTO}

Candidato: Engenheiro PAULO ESTEVÃO TEIXEIRA MARTINS.

Título da dissertação: Alocação otimizada de medidores em sistemas de distribuição visando à redução da múltipla localização de faltas".

Data da defesa: 19/02/2019.

Comissão Julgadora:

Resultado:

Prof. Associado Mario Oleskovicz

ARROVADO

(Orientador)

(Escola de Engenharia de São Carlos/EESC)

Prof. Dr. Fábio Bertequini Leão

APROVADO

(Universidade Estadual Paulista "Júlio de Mesquita Filho"/UNESP - Ilha Solteira)

Profa. Dra. Fernanda Caseño Trindade Arioli

APROVADO

(Universidade Estadual de Campinas/UNICAMP)

Coordenador do Programa de Pós-Graduação em Engenharia Elétrica: Prof. Titular Luis Fernando Costa Alberto

Presidente da Comissão de Pós-Graduação:

Prof. Titular Luis Fernando Costa Alberto 

Aos meus pais, José e Nazaré, pelo apoio durante toda a trajetória.

Aos meus irmãos, Marcos Vinícius e Thalita, que mesmo longes de São Carlos estiveram perto em todos os momentos.

Ao Prof. Mário Oleskovicz, pela orientação e disponibilidade constante. Sempre presente, sanando dúvidas e ajudando a direcionar o trabalho para o seu formato final.

Aos professores Benvindo e José Carlos, que contribuíram muito durante a qualificação. Suas dicas e questionamentos foram cruciais para o direcionamento e finalização deste trabalho.

Ao pessoal do Laboratório de Sistemas de Energia Elétrica (LSEE), por criarem esse ambiente de trabalho tranquilo e cooperativo, essencial para o desenvolvimento desta pesquisa.

Aos meus amigos, do LSEE, de outros laboratórios, e mesmo da cidade de São Carlos, que acompanharam bem de perto as minhas aflições e dificuldades encontradas pelo caminho. Obrigado também pelas horas de descontração juntos.

Aos meus amigos de Medeiros, por todos os momentos de diversão e conversa, que me ajudaram em tempos de descanso.

Ao Conselho Nacional de Desenvolvimento Científico e Tecnológico (CNPq), pela bolsa.

E, por fim, à todos que de alguma forma contribuíram para que este trabalho fosse concluído. 



\section{RESUMO}

MARTINS, P. E. T.. Alocação Otimizada de Medidores em Sistemas de Distribuição visando à redução da Múltipla Localização de Faltas. 125 p. Dissertação de Mestrado - Escola de Engenharia de São Carlos, Universidade de São Paulo, São Carlos, 2019.

Essa pesquisa propõe abordar o problema da alocação de medidores em sistemas de distribuição, de forma a reduzir os custos, garantindo o monitoramento dos distúrbios que afetam a qualidade da energia elétrica, mas também de obter alocações de medidores que facilitem a localização do curto-circuito. O problema de otimização é formulado por meio da programação linear inteira e resolvido por meio de algoritmos adequados para implementar cada modelagem matemática. São considerados sistemas testes com diferentes características, com destaque para a presença de linhas monofásicas e/ou bifásicas, linhas heterogêneas e geradores distribuídos acoplados na rede de distribuição principal. O problema de otimização clássico (reduzir custos garantindo o monitoramento) é retomado e é proposta uma modelagem mais geral, aplicável também a sistemas de distribuição com a presença de ramais monofásicos e/ou bifásicos. A parte da modelagem voltada para o problema da localização de faltas visa à redução das situações de múltipla estimação do local da falta, caracterizadas pela existência de múltiplos pontos no sistema com a mesma distância elétrica até a subestação. Esses dois modelos foram resolvidos separadamente, como dois problemas de otimização mono-objetivo, e em conjunto, sendo portanto, um problema multi-objetivo. As instâncias testadas incluem conjuntos de faltas de todos os tipos, simuladas ao longo das linhas do sistema, considerando a variação da impedância de falta. Os resultados apresentaram soluções de monitoramento para os dois sistemas testes considerados contendo entre 2 e 7 medidores. As soluções alcançadas são atrativas para a concessionária, pois requerem baixo custo de investimento e manutenção dos equipamentos e da infraestrutura de comunicação. A metodologia proposta apresentou alocações dispostas estrategicamente que garantem o monitoramento da qualidade da energia elétrica e minimizam o problema da múltipla estimação da falta, possibilitando o seu uso como suporte a um sistema localizador de faltas.

Palavras-chave: Qualidade da Energia Elétrica. Alocação de Medidores. Otimização Linear Inteira. Sistemas de Distribuição. Curtos-Circuitos. 



\section{ABSTRACT}

MARTINS, P. E. T.. Optimized Monitors Allocation in Distribution Systems aiming to reduction of the Multiple Fault Location. 125 p. Master Dissertation - São Carlos School of Engineering, University of São Paulo, São Carlos, 2019.

This research proposes to address the monitors allocation problem in distribution systems, aiming to reduce costs, ensuring the monitoring of disturbances affecting the power quality, but also to obtain monitoring systems that facilitate the process of fault location. The optimization problem is formulated through integer linear programming and solved by suitable algorithms for each mathematical modeling. Test systems with different characteristics, emphasis on the presence of single-phase and/or biphasic lines, heterogeneous lines and distributed generators were considered. The classic optimization problem (reduce costs by ensuring disturbance monitoring) is covered and a more general modeling is proposed, also applicable to distribution systems with the presence of single-phase and/or biphasic branches. The process of fault location is supported through the reduction of the multiple estimation of fault location, characterized by the existence of multiple points in the system with the same electrical distance to the substation. These two models were solved separately, as two mono-objective optimization problems, and together, in a multi-objective perspective. The tested instances include sets of faults of all types, simulated along the lines of the system, considering the fault impedance variation. The results presented monitoring solutions for the two test systems considered containing between 2 and 7 meters. The solutions achieved are attractive to the utility, as they require low investment and maintenance costs for equipment and communication infrastructure. The proposed methodology presented allocations strategically placed that guarantee the power quality monitoring and minimize the multiple estimation problem, allowing its use as support to a faults locator system.

Keywords: Power Quality. Monitors Allocation. Integer Linear Optimization. Distribution Systems. Electric Faults. 



\section{LISTA DE ILUSTRAÇÕES}

Figura 1 - Características de um afundamento de tensão.

Figura 2 - Fluxograma das 4 principais etapas da metodologia proposta para a alocação de PQMs. . . . . . . . . . . . . . . . . . . 24

Figura 3 - Sistema europeu de média tensão modificado de 15 barras. . . . . . . . . . 27

Figura 4 - Circuito equivalente representando o sistema antes da falta. . . . . . . . . 27

Figura 5 - Circuito equivalente representando o sistema durante a falta. . . . . . . . 28

Figura 6 - Circuito equivalente $1 \ldots \ldots \ldots \ldots \ldots$

Figura 7 - Circuito equivalente $2 \ldots \ldots \ldots \ldots \ldots \ldots$

Figura 8 - Diagrama de impedâncias do sistema europeu de 15 barras e de média tensão modificado. . . . . . . . . . . . . . . . . 30

Figura 9 - Diagrama de impedâncias do sistema de 15 barras europeu de média tensão modificado após a inserção do GD. . . . . . . . . . . . . . . . 32

Figura 10 - Conjunto de pontos de faltas definidos por meio da metodologia proposta. . 37

Figura 11 - MTDF resultante para o sistema de 15 barras durante a ocorrência de faltas trifásicas francas sem o GD . . . . . . . . . . . . . . . . . . 39

Figura 12 - MTDF resultante para o sistema de 15 barras durante a ocorrência de faltas trifásicas francas com o GD. . . . . . . . . . . . . . . . 39

Figura 13 - MO para o sistema de 15 barras com um valor de $\tau=0,6$ p.u. sem o GD. $\quad 41$

Figura 14 - MO para o sistema de 15 barras com um valor de $\tau=0,6$ p.u. com o GD. . 41

Figura 15 - Exemplo de um caso de simetria presente no sistema estudado sem o GD e sob a ocorrência de faltas trifásicas francas nas barras. . . . . . . . . . . . . 46

Figura 16 - Exemplo de como a disposição dos PQMs é capaz de resolver o problema da simetria. . . . . . . . . . . . . . . . . . 4 47

Figura 17 - Representação do conjunto de parâmetros $\sigma(8, i, \bar{i})$ para faltas trifásicas francas nas barras do sistema europeu de média tensão sem o GD instalado. . . . 50

Figura 18 - Solução obtida para a resolução do Modelo 1 considerando o sistema CIGRÉ. 55

Figura 19 - Sistema teste de distribuição do IEEE de 123 barras. . . . . . . . . . . . . . 57

Figura 20 - Curto-circuito monofásico AT. . . . . . . . . . . . . . . . . . . . . 109

Figura 21 - Curto-circuito bifásico BC . . . . . . . . . . . . . . . . 112

Figura 22 - Curto-circuito BCT. . . . . . . . . . . . . . . 115

Figura 23 - MTDF da fase A para o sistema de 15 barras durante a ocorrência de faltas monofásicas AT francas sem o GD . . . . . . . . . . . . . . . . 121 
Figura 24 - MTDF da fase B para o sistema de 15 barras durante a ocorrência de faltas monofásicas AT francas sem o GD . . . . . . . . . . . . . . . . . . 122

Figura 25 - MTDF da fase C para o sistema de 15 barras durante a ocorrência de faltas monofásicas AT francas sem o GD . . . . . . . . . . . . . . . . . 122

Figura 26 - MTDF da fase A para o sistema de 15 barras durante a ocorrência de faltas bifásicas BC francas sem o GD . . . . . . . . . . . . . . . . . . . 123

Figura 27 - MTDF da fase B para o sistema de 15 barras durante a ocorrência de faltas bifásicas BC francas sem o GD . . . . . . . . . . . . . . . . . . 123

Figura 28 - MTDF da fase C para o sistema de 15 barras durante a ocorrência de faltas bifásicas BC francas sem o GD. . . . . . . . . . . . . . . . . . . . 124

Figura 29 - MTDF da fase A para o sistema de 15 barras durante a ocorrência de faltas bifásicas BCT francas sem o GD . . . . . . . . . . . . . . . . 124

Figura 30 - MTDF da fase B para o sistema de 15 barras durante a ocorrência de faltas bifásicas BCT francas sem o GD. . . . . . . . . . . . . . . . . . 125

Figura 31 - MTDF da fase C para o sistema de 15 barras durante a ocorrência de faltas bifásicas BCT francas sem o GD . . . . . . . . . . . . . . . . . . 125 
Quadro 1 - Classificação das variações de tensão de curta duração. . . . . . . . . . . . 2

Quadro 2 - Resumo dos trabalhos relatados e correlatos ao tema de alocação de medidores. 21

Quadro 3 - Valores de tensão durante uma falta do tipo BC medidos na barra 11 do sistema do CIGRÉ. . . . . . . . . . . . . . . . . . . . . . . . 62

Quadro 4 - Valores de tensão durante uma falta do tipo BCT medidos na barra 11 do sistema do CIGRÉ. . . . . . . . . . . . . . . . . . . . 65 

Tabela 1 - Resultados para todos os cenários de falta $\left(Z_{f}=0 \Omega\right.$ e $\tau=0,6$ p.u. $)$. . . 58

Tabela 2 - Resultados para o cenário de faltas trifásicas $\left(Z_{f}=0 \Omega\right)$. . . . . . . . 59

Tabela 3 - Resultados para o cenário de faltas trifásicas com $Z_{f}=25$ e $50 \Omega$. . . . 60

Tabela 4 - Resultados para o cenário de faltas do tipo $A T\left(Z_{f}=0 \Omega\right) \ldots \ldots$. . . . . 60

Tabela 5 - Resultados para o cenário de faltas do tipo $B C\left(Z_{f}=0 \Omega\right)$. . . . . . . . 61

Tabela 6 - Resultados para o cenário de faltas do tipo $B C T\left(Z_{f}=0 \Omega\right)$. . . . . . . . 63

Tabela 7 - Resultados para o cenário de faltas bifásicas $B C T\left(Z_{f}=25 \Omega\right)$. . . . . . 63

Tabela 8 - Resultados para o cenário de faltas bifásicas $B C T\left(Z_{f}=50 \Omega\right)$. . . . . . 64

Tabela 9 - Resultados para o cenário de faltas trifásicas considerando o GD conectado à rede principal $\left(Z_{f}=0 \Omega\right) \ldots \ldots \ldots \ldots 6$

Tabela 10 - Resultados para o cenário de faltas trifásicas considerando o GD conectado à rede principal $\left(Z_{f}=25\right.$ e $\left.50 \Omega\right) . \ldots \ldots \ldots 6 \ldots$

Tabela 11 - Resultados para o cenário de faltas do tipo $A T$ considerando o GD conectado à rede principal $\left(Z_{f}=0 \Omega\right) \ldots \ldots \ldots \ldots$. . . . . . . . . . 67

Tabela 12 - Resultados para o cenário de faltas do tipo $B C$ considerando o GD conectado

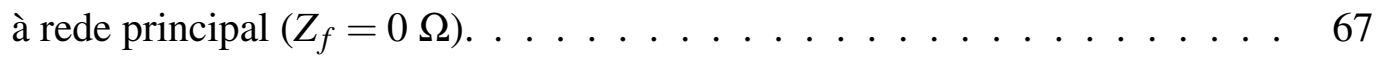

Tabela 13 - Resultados para o cenário de faltas bifásicas $B C$ considerando o GD conectado à rede principal $\left(Z_{f}=50 \Omega\right) . \ldots \ldots \ldots \ldots$

Tabela 14 - Resultados para o cenário de faltas do tipo BCT considerando o GD conectado à rede principal $\left(Z_{f}=0 \Omega\right) \ldots \ldots \ldots \ldots$

Tabela 15 - Resultados para o cenário de faltas bifásicas $B C T$ considerando o GD conectado à rede principal $\left(Z_{f}=25 \Omega\right) . \ldots \ldots$. . . . . . . . . . 68

Tabela 16 - Resultados para o cenário de faltas bifásicas $B C T$ considerando o GD conectado à rede principal $\left(Z_{f}=50 \Omega\right) \ldots \ldots \ldots \ldots$

Tabela 17 - Resultados para o cenário de faltas trifásicas $\left(Z_{f}=0 \Omega\right)$. . . . . . . . 69

Tabela 18 - Resultados para o cenário de faltas trifásicas $\left(Z_{f}=25\right.$ e $\left.50 \Omega\right)$. . . . . . 70

Tabela 19 - Resultados para o cenário de faltas do tipo $A T\left(Z_{f}=0 \Omega\right)$. . . . . . . . 70

Tabela 20 - Resultados para o cenário de faltas do tipo $A T\left(Z_{f}=25 \Omega\right)$. . . . . . . . 70

Tabela 21 - Resultados para o cenário de faltas do tipo $A T\left(Z_{f}=50 \Omega\right)$. . . . . . . 71

Tabela 22 - Resultados para o cenário de faltas do tipo $B T\left(Z_{f}=0 \Omega\right)$. . . . . . . 71

Tabela 23 - Resultados para o cenário de faltas do tipo $B T\left(Z_{f}=25 \Omega\right)$. . . . . . . 71

Tabela 24 - Resultados para o cenário de faltas do tipo $B T\left(Z_{f}=50 \Omega\right)$. . . . . . . 72

Tabela 25 - Resultados para o cenário de faltas do tipo $C T\left(Z_{f}=0 \Omega\right)$. . . . . . . . 72 
Tabela 26 - Resultados para o cenário de faltas do tipo $C T\left(Z_{f}=25 \Omega\right) \ldots \ldots \ldots$

Tabela 27 - Resultados para o cenário de faltas do tipo $C T\left(Z_{f}=50 \Omega\right)$. . . . . . . . 73

Tabela 28 - Resultados para o cenário de faltas do tipo $A B\left(Z_{f}=25 \Omega\right)$. . . . . . . 73

Tabela 29 - Resultados para o cenário de faltas do tipo $A B\left(Z_{f}=50 \Omega\right)$. . . . . . . . 73

Tabela 30 - Resultados para o cenário de faltas bifásicas $A B\left(Z_{f}=0 \Omega\right)$. . . . . . . . 74

Tabela 31 - Resultados para o cenário de faltas do tipo $A C\left(Z_{f}=25 \Omega\right)$. . . . . . . 75

Tabela 32 - Resultados para o cenário de faltas do tipo $A C\left(Z_{f}=50 \Omega\right)$. . . . . . . 75

Tabela 33 - Resultados para o cenário de faltas bifásicas $A C\left(Z_{f}=0 \Omega\right)$. . . . . . . . 76

Tabela 34 - Resultados para o cenário de faltas do tipo $B C\left(Z_{f}=25 \Omega\right)$. . . . . . . . 77

Tabela 35 - Resultados para o cenário de faltas do tipo $B C\left(Z_{f}=50 \Omega\right)$. . . . . . . 77

Tabela 36 - Resultados para o cenário de faltas bifásicas $B C\left(Z_{f}=0 \Omega\right)$. . . . . . . 78

Tabela 37 - Resultados para o cenário de faltas do tipo $A B T\left(Z_{f}=0 \Omega\right)$. . . . . . . 79

Tabela 38 - Resultados para o cenário de faltas bifásicas $A B T\left(Z_{f}=25 \Omega\right)$. . . . . . 79

Tabela 39 - Resultados para o cenário de faltas bifásicas $A B T\left(Z_{f}=50 \Omega\right)$. . . . . . . 80

Tabela 40 - Resultados para o cenário de faltas do tipo ACT $\left(Z_{f}=0 \Omega\right)$. . . . . . . . 80

Tabela 41 - Resultados para o cenário de faltas bifásicas $A C T\left(Z_{f}=25 \Omega\right)$. . . . . . 81

Tabela 42 - Resultados para o cenário de faltas bifásicas $A C T\left(Z_{f}=50 \Omega\right)$. . . . . . 81

Tabela 43 - Resultados para o cenário de faltas do tipo $B C T\left(Z_{f}=0 \Omega\right)$. . . . . . . . 82

Tabela 44 - Resultados para o cenário de faltas bifásicas $B C T\left(Z_{f}=25 \Omega\right)$. . . . . . 82

Tabela 45 - Resultados para o cenário de faltas bifásicas $B C T\left(Z_{f}=50 \Omega\right)$. . . . . . 83

Tabela 46 - Resultados para todos os cenários de falta considerando o sistema CIGRÉ e o GD desconectado da rede principal $\left(Z_{f}=0 \Omega\right)$. . . . . . . . . . . 84

Tabela 47 - Resultados para todos os cenários de falta no sistema CIGRÉ considerando o GD conectado à rede principal $\left(Z_{f}=0 \Omega\right) \ldots \ldots \ldots$. . . . . . . 86

Tabela 48 - Resultados para o cenário de faltas trifásicas $\left(Z_{f}=0 \Omega\right)$. . . . . . . 87

Tabela 49 - Resultados para o cenário de faltas monofásicas do tipo $C T\left(Z_{f}=0 \Omega\right)$. . 88

Tabela 50 - Resultados para o cenário de faltas bifásicas do tipo $A B\left(Z_{f}=0 \Omega\right)$. . . . 89

Tabela 51 - Resultados para o cenário de faltas bifásicas do tipo $A C\left(Z_{f}=0 \Omega\right)$. . . . . 90

Tabela 52 - Resultados para o cenário de faltas bifásicas do tipo $B C\left(Z_{f}=0 \Omega\right)$. . . . 91

Tabela 53 - Resultados para o cenário de faltas bifásicas do tipo $A B T\left(Z_{f}=0 \Omega\right)$. . . . 91

Tabela 54 - Resultados para o cenário de faltas bifásicas do tipo ACT $\left(Z_{f}=0 \Omega\right)$. . . 92

Tabela 55 - Resultados para o cenário de faltas bifásicas do tipo $B C T\left(Z_{f}=0 \Omega\right)$. . . . 92 
AG Algoritmo Genético

ANOVA Analysis of Variance

ABCDO Algorithm for Bicriteria Discrete Optimization

CEMIG Companhia Energética de Minas Gerais

cGA Compact Genetic Algorithm

CLONALG Clonal Selection Algorithm

FMRA Fuzzy Monitor Reach Area

GRASP Greedy Randomized Adaptive Search Procedure

GD Gerador Distribuído

IEEE Institute of Electrical and Electronics Engineers

MRA Monitor Reach Area

MP Monitor Placement Vector

MVR Multivariable Regression

MTDF Matriz de Tensão Durante a Falta

MO Matriz de Observabilidade

MEAT Multi-objective Evolutionary Algorithm with Tables

p.u. por unidade

PQM Power Quality Monitor

PLI Programação Linear Inteira

PSO Particle Swarm Optimization

QEE Qualidade da Energia Elétrica 
SEP Sistema Elétrico de Potência

SEM State Enumeration Method

TMRA Topological Monitor Reach Area

THDv Total Harmonic Distortion of a Voltage Wave

PMU Phasor Measurement Unit

VTCD Variação de Tensão de Curta Duração

VNS Variable Neighborhood Search 
1 INTRODUÇÃo . . . . . . . . . . . . . . . . . . . 1

1.1 Qualidade da energia elétrica . . . . . . . . . . . . . . . . 1

1.1.1 Variações de tensão de curta duração . . . . . . . . . . . . . . . . 2

1.1.1.1 Impactos das variações de tensão de curta duração . . . . . . . 3

1.1.2 Importância do monitoramento para a localização de faltas . . . . . . . . 4

1.2 Objetivos e principais contribuições desta pesquisa . . . . . . . . . . . . . . 5

1.3 Apresentação do documento . . . . . . . . . . . . . . . . 6

2 REVISÃo dA literATURA . . . . . . . . . . . . . . . . . . . 7

2.1 Trabalhos relacionados ao problema abordado . . . . . . . . . . . . . 7

2.1.1 Metodologia baseada em simulação de faltas . . . . . . . . . . . . . . 7

2.1.2 Metodologia baseada na análise do circuito elétrico . . . . . . . . . . . 16

2.1.3 Metodologia baseada na divisão do sistema em clusters . . . . . . . . 18

2.1.4 Metodologia baseada na representação do sistema por meio de grafos . 19

2.1.5 Resumo dos trabalhos relatados . . . . . . . . . . . . . . . . . 20

2.2 Considerações finais . . . . . . . . . . . . . . . . . . . . . 22

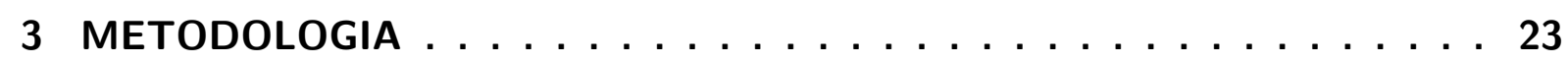

3.1 Passo 1: Leitura dos dados topológicos do sistema . . . . . . . . . . . . . 23

3.2 Passo 2: Construção das matrizes impedância de barras . . . . . . . . . . . . . 25

3.2.1 Análise do sistema de distribuição durante a falta . . . . . . . . . . . . . 26

3.2.2 Análise de faltas usando a matriz impedância de barras . . . . . . . . 29

3.2.2.1 Matriz impedância de barras antes da inserção do GD . . . . 29

3.2.2.2 Matriz impedância de barras após a inserção do GD . . . . . 31

3.3 Passo 3: Obtenção das matrizes de tensão durante a falta . . . . . . . . . . . 34

3.3.1 Definição do passo de aplicação das faltas . . . . . . . . . . . . . . 35

3.3.2 Exemplo de conjunto de dados para as faltas trifásicas . . . . . . . . . 36

3.4 Passo 4: Modelagem do problema de otimização . . . . . . . . . . . . . . . . . 40

3.4.1 Modelo clássico idealizado para sistemas de transmissão: Modelo 1 . . 40

3.4.1.1 Ajuste no modelo clássico para sistemas de distribuição com linhas monofásicas e bifásicas . . . . . . . . . . . . . . 42

3.4.1.2 Modelo modificado considerando todos os tipos de falta . . . 44

3.4.2 Modelagem matemática visando à localização de falta: Modelo 2 . . . 45 
3.4.2.1 Definição de um intervalo de simetria adaptativo . . . . . . . 46

3.4.2.2 Modelo de otimização para identificação de eventos . . . . . 49

3.5 Considerações finais . . . . . . . . . . . . . . . . . . . . . . . . . 51

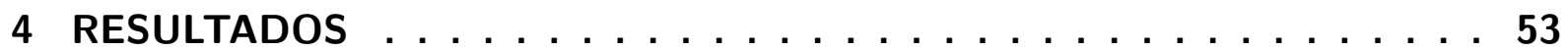

4.1 Problema de minimização da quantidade de PQMs: Modelo 1 . . . . . . . . . 54

4.1.1 Análise dos resultados para o sistema CIGRÉ . . . . . . . . . . . . . . 54

4.1.2 Análise dos resultados para o sistema IEEE 123 barras . . . . . . . . . 56

4.2 Problema de maximização da quantidade de eventos identificados: Modelo 2 . 58

4.2.1 Análise dos resultados para o sistema CIGRÉ . . . . . . . . . . . . . . 59

4.2.1.1 Cenário para faltas trifásicas . . . . . . . . . . . . . . . . 59

4.2.1.2 Cenário para faltas monofásicas AT . . . . . . . . . . . . . 60

4.2.1.3 Cenário para faltas bifásicas BC . . . . . . . . . . . . . . 61

4.2.1.4 Cenário para faltas bifásicas BCT . . . . . . . . . . . 63

4.2.1.5 Cenário para faltas trifásicas considerando o GD conectado . 65

4.2.1.6 Cenário para faltas monofásicas AT considerando o GD conectado . . . . . . . . . . . . . . 66

4.2.1.7 Cenário para faltas bifásicas BC considerando o GD conectado 67

4.2.1.8 Cenário para faltas bifásicas BCT considerando o GD conectado 68

4.2.2 Análise dos resultados para o sistema IEEE 123 barras . . . . . . . . . 69

4.2.2.1 Cenário para faltas trifásicas . . . . . . . . . . . . . 69

4.2.2.2 Cenário para faltas monofásicas AT . . . . . . . . . . . . 70

4.2.2.3 Cenário para faltas monofásicas BT . . . . . . . . . . . . . 71

4.2.2.4 Cenário para faltas monofásicas CT . . . . . . . . . . . . . . 72

4.2.2.5 Cenário para faltas bifásicas $A B$. . . . . . . . . . . . 73

4.2.2.6 Cenário para faltas bifásicas $A C$. . . . . . . . . . . . 75

4.2.2.7 Cenário para faltas bifásicas BC . . . . . . . . . . . . . . 77

4.2.2.8 Cenário para faltas bifásicas ABT . . . . . . . . . . . . . . . 79

4.2.2.9 Cenário para faltas bifásicas ACT . . . . . . . . . . . . . . . 80

4.2.2.10 Cenário para faltas bifásicas BCT . . . . . . . . . . . . 81

4.3 Abordagem multiobjetivo: Modelo $1+$ Modelo $2 \ldots$. . . . . . . . . . . . 83

4.3.1 Análise dos resultados para o sistema CIGRÉ . . . . . . . . . . . . . . 83

4.3.1.1 Análise considerando o GD desconectado . . . . . . . . . . . 84

4.3.1.2 Análise considerando o GD conectado . . . . . . . . . . . 85

4.3.2 Análise dos resultados para o sistema do IEEE 123 barras . . . . . . . 86

4.3.2.1 Cenário para faltas trifásicas . . . . . . . . . . . . 87

4.3.2.2 Cenário para faltas monofásicas CT . . . . . . . . . . . 87

4.3.2.3 Cenário para faltas bifásicas $A B \ldots \ldots$. . . . . . . . . . . . . . 88

4.3.2.4 Cenário para faltas bifásicas AC . . . . . . . . . . . . . . . . . . 89

4.3.2.5 Cenário para faltas bifásicas BC . . . . . . . . . . . . . . 90 
4.3.2.6 Cenário para faltas bifásicas ABT . . . . . . . . . . . . . . . 91

4.3.2.7 Cenário para faltas bifásicas ACT . . . . . . . . . . . . . . 92

4.3.2.8 Cenário para faltas bifásicas BCT . . . . . . . . . . . . . . . 92

4.4 Considerações finais . . . . . . . . . . . . . . . . . . . . . . . . . . . . . . 92

5 CONSIDERAÇÕES FINAIS . . . . . . . . . . . . . . . . . . 95

5.1 Publicações decorrentes desta pesquisa . . . . . . . . . . . . . . . . . . . 96

5.2 Publicações correlatas a esta pesquisa . . . . . . . . . . . . . . . . . . . 97

REFERÊNCIAS . . . . . . . . . . . . . . . . . . 99

APÊNDICE A ANÁlISE dE FALTAS ASSIMÉtRICAS . . . . . . . . . 105

A.1 Matrizes de transformação . . . . . . . . . . . . . . . . . . 105

A.1.1 Circuito equivalente monofásico da fase A . . . . . . . . . . . . . 105

A.1.2 Circuito equivalente monofásico da fase B . . . . . . . . . . . . . . 107

A.1.3 Circuito equivalente monofásico da fase C . . . . . . . . . . . . . . 108

A.2 Curtos-circuitos monofásicos . . . . . . . . . . . . . . . . . . . . . . . . 108

A.2.1 Curto-circuito monofásico AT . . . . . . . . . . . . . . . . . . . . . 108

A.2.2 Curto-circuito monofásico BT . . . . . . . . . . . . . . . . . . . 110

A.2.3 Curto-circuito monofásico CT . . . . . . . . . . . . . . . . . . . 111

A.3 Curtos-circuitos bifásicos . . . . . . . . . . . . . . . . . . . . . . . . . . . . . 112

A.3.1 Curto-circuito bifásico BC . . . . . . . . . . . . . . . . . . . 112

A.3.2 Curto-circuito bifásico AC . . . . . . . . . . . . . . . . . . . . . . . . 114

A.3.3 Curto-circuito bifásico AB . . . . . . . . . . . . . . . . . . . . . . . . 114

A.4 Curtos-circuitos bifásicos-terra . . . . . . . . . . . . . . . . . . . . . 115

A.4.1 Curto-circuito BCT . . . . . . . . . . . . . . . . . 115

A.4.2 Curto-circuito ACT . . . . . . . . . . . . . . . . . . . . . . . . . . . . 118

A.4.3 Curto-circuito ABT . . . . . . . . . . . . . . . . . . . . . . . . . . . . . 119

APÊNDICE B MATRIZES DE TENSÃO DURANTE A FALTA . . . . . . . . 121 



\section{1}

\section{INTRODUÇÃO}

Este capítulo apresenta uma contextualização sobre a temática da pesquisa realizada. Os distúrbios a serem estudados são abordados, ressaltando seus impactos em equipamentos com a sua consequência econômica. Na sequência, uma outra visão é mostrada com relação aos sistemas de monitoramento, vislumbrando seu uso para a localização de faltas. São expostos os objetivos almejados durante a elaboração do trabalho, bem como suas contribuições. Por fim, apresenta-se a estruturação deste documento.

\subsection{Qualidade da energia elétrica}

O adequado acompanhamento e atendimento aos índices que refletem a Qualidade da Energia Elétrica (QEE) são motivos constantes de preocupação por parte das distribuidoras e consumidores finais da energia elétrica (DUGAN et al., 2012, p. 1).

Mesmo assim, verifica-se na literatura correlata, que o conceito de QEE permeia distintas frentes de interpretação na comunidade técnico-científica.

Por exemplo, segundo (IEEE, 2005; IEEE, 2009), a QEE é entendida como o conceito de alimentação e aterramento do equipamento eletrônico de tal forma que é adequada à operação do equipamento e compatível com a instalação elétrica e outros equipamentos conectados. Essa definição é adequada em relação aos equipamentos eletrônicos, mas não só este tipo de equipamento pode ser afetado por problemas de QEE.

Uma definição um pouco mais abrangente é a ausência de qualquer problema manifestado na tensão, corrente ou desvio de frequência, que resulta em falha ou má operação nos equipamentos dos consumidores (DUGAN et al., 2012, p. 3). No entanto, não somente os equipamentos dos consumidores são afetados pela má QEE. Transformadores de distribuição com conexão delta-estrela, por exemplo, podem ser alvos de componentes harmônicos circulando no lado delta, o que produz aquecimento nos enrolamentos e redução da vida útil destes equipamentos. 
Ademais, transformadores com outros tipos de conexões também são afetados em razão do aquecimento dos respectivos núcleos.

Sendo assim, uma definição mais completa deve levar em conta a interação entre a carga e a fonte, como a apresentada em (BHATTACHARYA; BOLLEN; DAALDER, 2001, p. 254): a qualidade da energia elétrica é a combinação da qualidade da corrente e qualidade da tensão, envolvendo a interação entre o sistema e a carga. A qualidade da tensão diz respeito ao desvio da forma de onda da tensão da senoidal ideal, com magnitude e frequência constantes. A qualidade da corrente é um termo complementar e diz respeito ao desvio da forma de onda da corrente da senoidal ideal, com magnitude e frequência constantes. A qualidade da tensão envolve o desempenho do sistema de potência em relação à carga, enquanto a qualidade da corrente envolve o comportamento da carga com relação ao sistema de potência.

Esta pesquisa se situa no contexto da QEE, mas é restrita a apenas uma das classes de distúrbios que a afetam: as Variações de Tensão de Curta Duração (VTCDs). Esses distúrbios serão abordados com maior detalhe na próxima seção.

\subsubsection{Variações de tensão de curta duração}

Segundo (IEEE, 2009), as VTCDs são variações no valor eficaz da tensão ou corrente em relação ao seu valor nominal por um tempo maior que 0,5 ciclo da frequência fundamental, porém, menor ou igual a 1 min. Quando a variação no valor eficaz é com relação à tensão, podem ser subdivididas de acordo com o valor de tensão residual (remanescente), entre: afundamentos, se o valor da tensão permanecer entre 0,1 e 0,9 por unidade (p.u.); elevações, caso a tensão remanescente for de 1,1 a 1,8 p.u.; e interrupções, caso decrescer abaixo de 0,1 p.u. (DUGAN et al., 2012, p. 20). Além disso, pode ser considerado um modificador indicando a duração da variação, como indicado no Quadro 1:

Quadro 1 - Classificação das variações de tensão de curta duração.

\begin{tabular}{|c|c|c|c|}
\hline \multicolumn{2}{|c|}{ Classificação } & \multicolumn{2}{c|}{ Valores Típicos } \\
\hline $\begin{array}{c}\text { Quanto ao nível de } \\
\text { tensão remanescente }\end{array}$ & $\begin{array}{c}\text { Quanto à duração do } \\
\text { evento }\end{array}$ & Duração & Amplitude da tensão \\
\hline \multirow{3}{*}{ Afundamento } & Instantânea & $0,5-30$ ciclos & $0,1-0,9$ p.u. \\
& Momentânea & 30 ciclos $-3 \mathrm{~s}$ & $0,1-0,9$ p.u. \\
& Temporária & $3 \mathrm{~s}-1$ min & $0,1-0,9$ p.u. \\
\hline \multirow{3}{*}{ Elevação } & Instantânea & $0,5-30$ ciclos & $1,1-1,8$ p.u. \\
& Momentânea & 30 ciclos $-3 \mathrm{~s}$ & $1,1-1,4$ p.u. \\
& Temporária & $3 \mathrm{~s}-1$ min & $1,1-1,2$ p.u. \\
\hline \multirow{3}{*}{ Interrupção } & Instantânea & $0,5-30$ ciclos & $<0,1$ p.u. \\
& Momentânea & 30 ciclos $-3 \mathrm{~s}$ & $<0,1$ p.u. \\
& Temporária & $3 \mathrm{~s}-1$ min & $<0,1$ p.u. \\
\hline
\end{tabular}

Fonte: Adaptado de Dugan et al. (2012, p. 14). 
As VTCDs são distúrbios eletromagnéticos representados por mais de um parâmetro. Normalmente, costuma-se representar uma VTCD por meio da sua magnitude e duração. A magnitude é o valor eficaz da tensão remanescente observada em algum ponto do sistema, ou seja, o menor valor que a tensão atinge durante o evento. A duração é o tempo que o valor eficaz da tensão permanece abaixo de um valor limiar previamente configurado para a medição. A Figura 1 ilustra esses parâmetros em um exemplo de afundamento de tensão observado em uma determinada fase do sistema.

Figura 1 - Características de um afundamento de tensão.

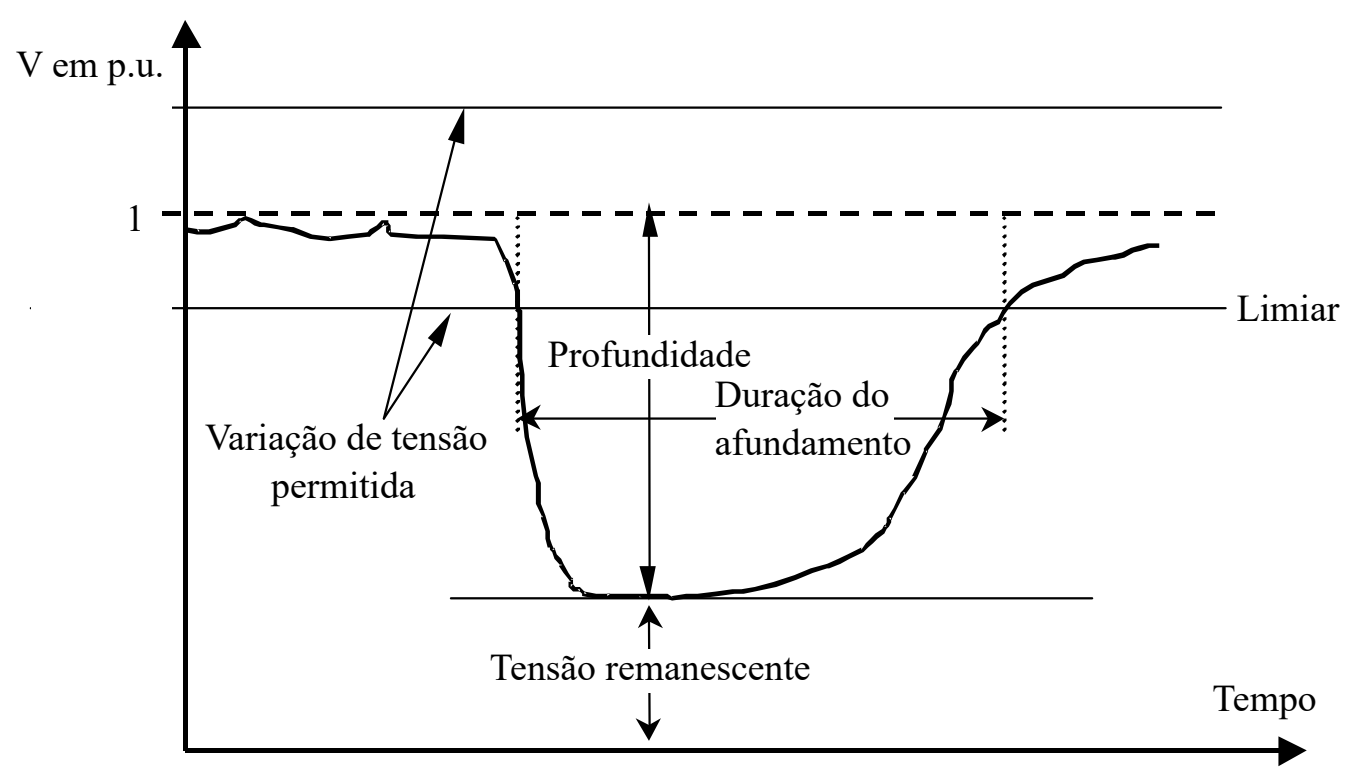

Fonte: Adaptado de Olguin (2005, p. 4).

\subsubsection{Impactos das variações de tensão de curta duração}

Dentre os três distúrbios associados às VTCDs, os afundamentos de tensão são os mais frequentes e podem causar mau funcionamento em equipamentos sensíveis ao nível de tensão, principalmente nos consumidores industriais, o que pode chegar a interromper todo o processo em execução (ZAMBRANO et al., 2017). Por exemplo, conforme encontrado em Zambrano et al. (2017), o prejuízo estimado para cada afundamento de tensão em uma fábrica de semicondutores é de 3,8 milhões de euros, e para uma indústria automobilística a perda é estimada em 10 milhões de dólares. Por essa razão, este trabalho focará nos afundamentos de tensão, sendo que a sigla VTCDserá utilizada genericamente para se referenciar aos afundamentos de tensão no restante deste documento.

Em razão dos prejuízos econômicos que as VTCDs podem causar e do melhor acompanhamento das agências reguladoras quanto à QEE fornecida, é importante para as distribuidoras de energia o constante monitoramento desses eventos em suas redes elétricas, para comprovar a qualidade do produto energia e, principalmente, a qualidade do serviço prestado com o objetivo 
de solucionar possíveis problemas e conflitos decorrentes com os clientes (ALMEIDA; KAGAN, 2010).

As VTCDs podem ser causadas por faltas elétricas (curtos-circuitos) ou acionamento de grandes blocos de cargas, como a partida de motores de grande porte e a energização de transformadores (OLGUIN, 2005, p. 4). Tecnicamente estas duas últimas causas são mais bem controladas e conhecidas. Já os curtos-circuitos são os fenômenos que mais causam VTCDs, apresentando características inerentes a uma adequada operação dos sistemas. Por esses motivos, nesta pesquisa, serão consideradas somente as VTCDs causadas pelos curtos-circuitos. Estes ocorrem de forma aleatória no sistema elétrico, em decorrência das intempéries ou demais acidentes e/ou problemas de qualquer natureza (queimadas, queda de árvores, etc.) (KINDERMANN, 1997, p. 138). Nesse sentido, em razão da imprevisibilidade dos curtos-circuitos, é apontado na literatura correlata que um monitoramento eficiente deve ter uma duração significativa (DUGAN et al., 2012, p. 466).

Portanto, é de interesse das distribuidoras o monitoramento permanente (constante) desses eventos, sendo necessário, além da instalação dos medidores, a instalação de transformadores para medição, e a configuração de um sistema de coleta de informação automática sobre os eventos registrados, com canais de comunicação à uma central de tratamento e armazenamento de dados (ELDERY et al., 2006). Portanto, a decisão de se instalar mais de um ponto de medição no sistema de monitoramento envolve muitos custos, sendo desejado utilizar o menor número possível, de forma a ainda garantir o monitoramento de todos os eventos passíveis de ocorrência na rede elétrica.

\subsubsection{Importância do monitoramento para a localização de faltas}

As distribuidoras têm interesse não só em armazenar um histórico de ocorrências das VTCDs, mas também usar os dados registrados no momento do fenômeno para determinar com exatidão o local onde ocorreu o curto-circuito. Dessa forma, em casos de curtos-circuitos permanentes, o tempo de reparo e do restabelecimento da operação do sistema pode ser consideravelmente reduzido, o que implica em uma melhoria na qualidade do serviço e nos índices de avaliação da distribuidora junto à agência reguladora e aos consumidores finais (DZAFIC et al., 2018).

Contudo, para uma correta localização do evento de curto-circuito, com as posteriores tentativas de retornar o sistema à sua operação normal, e garantir um adequado registro histórico, um problema usualmente enfrentado é a presença de simetria entre condições de faltas distintas. Duas situações de falta são consideradas distintas se existe diferença (variação) em pelo menos uma de suas 3 principais características: ponto (local) da falta, tipo da falta ou impedância da falta. Essa simetria pode ser refletida nas medições das tensões remanescentes com valores muito próximos em relação a um determinado ponto de medição, mas que realmente são causadas por situações de faltas diferentes (MARTINS et al., in press). Essa característica dificulta a 
localização do ponto de falta e impacta, consequentemente, no problema da estimação de afundamentos de tensão.

Um caso particular de simetria é a múltipla estimação da localização de falta, o qual é observado em sistemas de distribuição radiais com vários ramais laterais (ZHU; LUBKEMAN; GIRGIS, 1997; MORA-FLÓREZ; MORALES-ESPAÑA; PÉREZ-LONDOÑO, 2009; MORALES-ESPAÑA; MORA-FLÓREZ; VARGAS-TORRES, 2009; KRISHNATHEVAR; ENG, 2012; TRINDADE; FREITAS; VIEIRA, 2014; TRINDADE; FREITAS, 2017; ROSSINI et al., 2017). Este problema acontece quando o algoritmo localizador de falta calcula a distância da falta até a subestação e retorna múltiplas possibilidades para o ponto de falta. Em redes com esta topologia, a mesma impedância pode representar variados caminhos para a corrente de falta. Desconsiderando a corrente de carga, a tensão em qualquer barra está relacionada com sua impedância até a subestação. Em outras palavras, as múltiplas localizações estimadas podem ser simétricas com relação a um certo ponto de medição. Então, instalar medidores em pontos estratégicos na rede elétrica pode reduzir essas ocorrências de simetrias e melhorar as respostas dos algoritmos localizadores de falta. Portanto, neste caso particular, a condição de simetria ocorre entre duas faltas que se distinguem pelo local de falta, estando localizadas sempre em ramais diferentes do sistema de distribuição. Ademais, esta necessidade de uma alocação de medidores voltada para a localização de faltas também foi ressaltada em (TRINDADE; FREITAS; VIEIRA, 2014).

\subsection{Objetivos e principais contribuições desta pesquisa}

Embora muito tenha sido explorado no sentido de contornar o problema da múltipla estimação da falta, todos os esforços foram direcionados ao problema da localização de falta em específico. Esta pesquisa propõe abordar o problema clássico de monitoramento de VTCDs, mas além disso, utilizar-se dos mesmos medidores para o propósito da localização da falta. Em outras palavras, o problema da múltipla estimação será já tratado durante o problema de alocação dos medidores na rede elétrica, de tal forma que a falta possa ser mais bem localizada por um algoritmo, baseado, por exemplo, no método do cálculo da impedância. Acredita-se que, este seja o principal diferencial e contribuição deste trabalho, visto que o problema de alocação de medidores ainda foi pouco explorado com o foco no problema da localização de faltas.

Um outro ponto que merece destaque é o tratamento a ser dado aos sistemas de distribuição com impedâncias das linhas desequilibradas, ou seja, com a presença de linhas monofásicas e/ou bifásicas. Nos trabalhos sobre alocação de medidores incluídos na revisão bibliográfica desta monografia, e cujo foco são os sistemas de distribuição, nenhum deles levou em consideração este aspecto.

Por último, pretende-se também considerar a presença de geração distribuída na rede de distribuição e verificar o impacto da mesma no problema da alocação de medidores. Estes dois 
últimos pontos destacados são importantes, visto que aproximam as características do sistema a ser estudado de um sistema de distribuição real e com características atuais. A consideração da geração distribuída neste trabalho também é um grande diferencial, dado que não se encontrou até o momento, qualquer trabalho de alocação de medidores que também atendesse ao novo cenário resultante.

\subsection{Apresentação do documento}

Esta dissertação está dividida em 5 capítulos, sendo que este primeiro capítulo apresentou uma introdução ao trabalho, mostrando uma contextualização na linha de pesquisa em que o mesmo se insere. Alguns conceitos básicos, definições, e vocabulários indispensáveis para o entendimento do restante do documento também foram apresentados. O propósito desta pesquisa foi mostrado, bem como as contribuições deste trabalho para o meio técnico-científico. Os capítulos seguintes são brevemente descritos a seguir:

- Capítulo 2: Revisão da literatura

Este capítulo faz uma discussão dos principais trabalhos reportados e considerados até o momento sobre o problema da alocação de medidores, fazendo uma linha cronológica desde os trabalhos pioneiros até os mais recentes.

- Capítulo 3: Metodologia

Este capítulo descreve toda a metodologia proposta para abordar o problema da alocação de medidores, incorporando alguns elementos de trabalhos anteriores e adaptando outros para obter o tratamento desejado do problema aplicado nos sistemas de distribuição.

- Capítulo 4: Resultados

Neste capítulo são apresentados os resultados obtidos nesta pesquisa, abordando todos os modelos de otimização formulados no capítulo 3 em sistemas de distribuição com diversas características.

- Capítulo 5: Conclusões

Este capítulo sintetiza as conclusões obtidas por meio da análise e discussão dos resultados, e também apresenta possibilidades para se dar continuidade à pesquisa apresentada nesta dissertação. 
Neste capítulo são abordados os trabalhos técnico-científicos analisados nesta pesquisa e que tratam do tema da alocação de medidores em Sistemas Elétricos de Potência (SEPs), sendo os medidores, por exemplo, voltados à qualidade da energia (Power Quality Monitors (PQMs)), ou unidades de medição fasorial (Phasor Measurement Units (PMUs)), ou qualquer outro equipamento capaz de realizar a medição dos valores eficazes trifásicos de tensão e/ou corrente em algum ponto da rede elétrica. Na seção 2.1 são discutidos os principais trabalhos dentro deste tema, desde os pioneiros até pesquisas mais recentes. Por fim, na seção 2.2, são definidos alguns elementos que foram utilizados na pesquisa aqui proposta, relacionando os trabalhos reportados e os conceitos adotados para abordar o problema da alocação voltado para a redução da múltipla estimação em sistemas de distribuição.

\subsection{Trabalhos relacionados ao problema abordado}

Nesta seção são discutidos trabalhos que tratam o problema de alocação de medidores. Os mesmos foram subdivididos de acordo com a metodologia empregada para a resolução do problema de alocação. Desta forma é possível separar as linhas de pesquisas, bem como evidenciar as suas tendências.

\subsubsection{Metodologia baseada em simulação de faltas}

Um dos primeiros trabalhos encontrados sobre o problema de alocar dispositivos de medição foi o relatado em (PEREIRA; SILVA; MANTOVANI, 2004). Os autores consideraram o problema da alocação de PMUs em sistemas de distribuição visando à localização de faltas. $\mathrm{O}$ problema foi modelado usando Programação Linear Inteira (PLI) onde a alocação ótima é a que minimiza o número de pares de locais de falta imprecisos. Em outras palavras, para cada par de barras em situação isolada de falta (faltas não simultâneas nas duas barras), é calculada a soma 
de todas as diferenças de tensão observadas e medidas em relação ao ponto de instalação de cada medidor. Como são sempre considerados pares de faltas em locais diferentes, são comparados valores de tensão medidos em relação à primeira falta e calculados em relação à segunda falta. $\mathrm{O}$ modelo de otimização proposto sugere que valores diferentes entre tensões medidas e calculadas refletem em uma melhor disposição das PMUs para a localização de faltas. Essas diferenças de tensões são utilizadas para determinar uma variável de decisão binária, a qual deve ser minimizada. O problema de otimização é resolvido por meio da técnica heurística Busca Tabu e testado em uma rede de distribuição radial real com 141 barras. Nessa rede foram avaliadas faltas do tipo monofásicas considerando a resistência de falta para cada barra em que foram aplicadas. Os autores concluíram que para essa rede são necessários pelo menos 4 PMUs para garantir $100 \%$ de acerto no processo de localização das faltas. Conforme colocado pelos autores, essa proposta necessita das informações de medições de correntes de pré-falta e durante a falta na subestação, e também de medições das tensões durante a falta em barras monitoradas pelas PMUs. Essas medições devem estar disponíveis para garantir um adequado desempenho do algoritmo proposto.

Olguin, Vuinovich e Bollen (2006) por sua vez abordaram a alocação ótima de PQMs, e deram atenção ao monitoramento de um distúrbio que afeta a QEE: as VTCDs. Olguin, Vuinovich e Bollen (2006) consideraram apenas as faltas elétricas (curtos-circuitos) como as fontes das VTCDs (o que é uma consideração coerente, visto que a maioria das VTCDs de fato ocorrem devido à faltas), e simularam várias condições de falta no sistema teste a fim de construir um banco de dados para melhor caracterizar as VTCDs. Assumindo um limiar de disparo (ativação) para o PQM começar a registrar o evento de VTCD, os autores caracterizaram uma matriz binária que reúne as informações de todos os eventos e o alcance que cada ponto de medição (barra do sistema) teria caso houvesse um PQM instalado na barra. Essa matriz foi chamada de Monitor Reach Area (MRA) e, a partir dela, os autores definiram que uma VTCD era observável se pelo menos um PQM instalado no sistema fosse capaz de registrar (observar) o evento. $\mathrm{O}$ problema foi então modelado de acordo com a PLI, cujo objetivo foi de minimizar a quantidade de PQMs necessários (custo) para garantir a observabilidade de todos os eventos simulados. Foi utilizado um algoritmo exato Branch \& Bound para encontrar a solução para o problema de otimização. Contudo, foi observada a existência de múltiplas soluções ótimas para o problema de minimização. Então, para a exploração do espaço de soluções, utilizou-se de um Algoritmo Genético (AG) e, por meio de alguns índices de classificação, essas soluções foram comparadas entre si. A metologia foi testada em uma rede de transmissão de 87 barras, onde foram simuladas faltas simétricas nas barras. Um limiar de 0,9 p.u. foi utilizado para os PQMs começarem a registrar os afundamentos de tensão (uma das subclasses de distúrbio associada às VTCDs). Cabe ressaltar que esse trabalho é muito importante pelo seu pioneirismo, visto que, a partir deste, vários outros seguiram essa mesma metodologia para tratar o problema de alocação de PQMs.

Assim como Olguin, Vuinovich e Bollen (2006), Haghbin e Farjah (2009) também 
abordaram o problema de alocação visando ao monitoramento das VTCDs. Da mesma forma, simularam condições de falta trifásicas ao longo das barras do sistema para obter um banco de dados das VTCDs representativo. Os autores introduziram a definição de Fuzzy Monitor Reach Area (FMRA), a qual aprimora a MRA, que é construída segundo uma lógica booleana. Para a construção da FMRA, um sistema de inferência Fuzzy determina o grau de pertinência de cada falta à área de observação de cada barra. Dessa forma, os autores conseguem incorporar as incertezas de medição dentro do modelo matemático, principalmente próximo do limiar do PQM, região onde as pequenas variações na leitura de tensão poderiam incluir ou excluir o evento da MRA do medidor. É utilizado um outro sistema Fuzzy para calcular a função objetivo de cada sistema de monitoramento, com base na quantidade requerida de PQMs e em um índice de observação de cada barra (observation index). A restrição do modelo de otimização é a mesma definida em (OLGUIN; VUINOVICH; BOLLEN, 2006), utilizando também como base a MRA: a observabilidade de todas as faltas por pelo menos um PQM. Os autores utilizaram um AG para resolver o problema de otimização, e exploraram os resultados aplicando o método proposto em um sistema de transmissão de grande porte (sistema teste Institute of Electrical and Electronics Engineers (IEEE) de 118 barras).

A metodologia proposta por Olguin, Vuinovich e Bollen (2006) limitou-se às faltas trifásicas nas barras da rede elétrica. Espinosa-Juarez, Hernandez e Olguin (2009) generalizaram o método para todos os tipos de faltas, aplicando as situações de curtos-circuitos também ao longo das linhas. O modelo de otimização discreta permaneceu quase o mesmo de Olguin, Vuinovich e Bollen (2006), com a exceção da inclusão de novas restrições para atender os demais tipos de faltas. O problema foi resolvido também de forma exata, por meio do algoritmo Branch \& Bound, aplicado a dois sistemas de transmissão (IEEE de 24 e 118 barras). Os autores compararam os resultados da alocação de PQMs com o método original (faltas aplicadas somente nas barras), e também com faltas em pontos discretos do sistema (faltas nas barras e em 1 ou 2 pontos ao longo das linhas). Os mesmos concluíram que os métodos baseados em faltas em pontos discretos requerem uma quantidade menor de PQMs para monitorar o sistema, porém, ficam limitados ao monitoramento apenas das faltas simuladas. Ao considerar trechos de linhas ao invés de simular faltas em pontos discretos, os autores garantem o monitoramento completo do sistema perante afundamentos de tensão. Para considerar também as faltas desequilibradas os autores sugeriram uma MRA diferente para cada tipo de falta, partindo da ideia de que cada PQM possui uma área de alcance diferente ao se variar o tipo de falta. Faltas trifásicas, por serem mais severas, correspondem às MRAs maiores, por exemplo. Os autores fizeram uma análise de sensibilidade, comparando a alocação de PQMs obtida ao se considerar todos os tipos de falta no conjunto de restrições com a alocação considerando apenas um tipo de falta individualmente. Observaram que as faltas do tipo monofásicas-terra precisaram de um número maior de PQMs, sendo este número próximo (ou igual) à quantidade necessária ao se considerar todos os tipos de faltas como restrição. Portanto, considerando que esse tipo de falta é a mais recorrente nos SEPs, obter sistemas de monitoramento considerando apenas as faltas monofásicas 
é interessante como uma análise preliminar do sistema, ou mesmo como uma boa aproximação para o monitoramento de todos os tipos de falta. Os autores também fizeram uma análise de sensibilidade do parâmetro que ativa (dispara) o registro dos PQMs, e consideraram a existência de um PQM previamente instalado em uma barra do SEP. Valores de limiares (disparos) menores que 0,9 p.u. deixaram mais nítida a diferença entre a quantidade de PQMs requerida pelos diferentes métodos, principalmente para a rede de maior porte testada.

O trabalho de Almeida e Kagan (2010) também seguiu a mesma linha do trabalho de Olguin, Vuinovich e Bollen (2006), utilizando a mesma metodologia e modelo de otimização para o problema de alocação de PQMs. Porém, os autores propuseram a utilização de um algoritmo baseado em AG e conjuntos Fuzzy para a solução do problema de otimização, no sentido de dar mais flexibilidade à inclusão de novas restrições ao problema, como, por exemplo, na priorização de barras para a instalação de PQMs ou na restrição de barras onde já existem PQMs instalados. Para a simulação das faltas os autores utilizaram um simulador para redes elétricas chamado SINAP, ao invés de utilizarem a abordagem baseada em expressões analíticas (OLGUIN; VUINOVICH; BOLLEN, 2006; HAGHBIN; FARJAH, 2009; ESPINOSA-JUAREZ; HERNANDEZ; OLGUIN, 2009). Apesar de já considerarem faltas desequilibradas ocorrendo também ao longo das linhas, estas foram aplicadas em pontos discretos. Em outras palavras, a metodologia é mais precisa, porém, ainda podem existir trechos de linha que não pertencem à MRA de nenhum PQM. Por outro lado, os autores analisaram a influência da variação do parâmetro de impedância de falta, o que até o momento não havia sido feito. Almeida e Kagan (2010) aplicaram a metodologia em sistemas de transmissão, sendo um deles real de 154 barras (o qual faz parte do sistema brasileiro interligado), e o outro, um sistema teste de 30 barras do IEEE. Os autores utilizaram esta última rede para comparar os locais encontrados pelo método proposto com os encontrados em (ELDERY et al., 2006). Os locais de instalação foram diferentes e a quantidade utilizada foi inferior à obtida por Eldery et al. (2006). Os autores apontaram que o método proposto por Eldery et al. (2006) sobre-dimensiona os sistemas de monitoramento, e que para observar todos os eventos nem sempre é necessário garantir a estimação de todas as variáveis de estado da rede.

Salim e Nor (2010) também analisaram o problema de alocação de PQMs por meio da metodologia proposta por Olguin, Vuinovich e Bollen (2006). Consideraram faltas equilibradas e desequilibradas, porém, apenas nas barras, e não mencionaram o parâmetro de impedância da falta. As faltas foram simuladas por meio de um simulador de redes elétricas comercial. Quanto ao modelo do problema de otimização, os autores se basearam no modelo clássico (OLGUIN; VUINOVICH; BOLLEN, 2006), porém alteraram a restrição de monitoramento para garantir a observabilidade de todos os curtos-circuitos por pelo menos três PQMs. Além disso, adicionaram mais duas restrições ao problema. A primeira delas determina que as barras escolhidas para alocar os PQMs devem observar o maior número de eventos possível, e a segunda diz que as barras candidatas devem ter um número mínimo de quatro linhas de conexão (podendo esta quantidade ser reduzida a depender do sistema em análise). Os autores testaram o método em 
duas redes de transmissão do IEEE, de 30 e de 300 barras, e compararam seus resultados com Olguin, Vuinovich e Bollen (2006), Eldery et al. (2006), encontrando sistemas de monitoramento com uma quantidade menor de PQMs.

Trabalhando com sistemas de distribuição, Cebrian, Almeida e Kagan (2010) analisaram a variação dos principais parâmetros que caracterizam as condições de faltas: a localização, o tipo e a impedância de falta. Para definir o conjunto de faltas simuladas os autores propuseram um método estocástico híbrido, utilizando o Método de Monte Carlo e o método de enumeração de estados (State Enumeration Method (SEM)). Dessa forma, a quantidade de curtos-circuitos simulados depende das distribuições de probabilidade de cada variável envolvida na condição de falta. Esse método garante que o conjunto final obtido será composto apenas pelas condições de falta mais prováveis de acontecer. O problema de alocação de PQMs visando monitorar as VTCDs é modelado segundo uma PLI, com um objetivo, que combina dois índices (observabilidade e redundância). Um AG foi utilizado para obter os melhores sistemas de monitoramento em uma rede de distribuição real.

Ibrahim, Mohamed e Shareef (2011) sugeriram uma modificação na MRA proposta por Olguin, Vuinovich e Bollen (2006) para deixar a metodologia aplicável a sistemas de distribuição radiais. Os autores incorporaram a topologia desse tipo de rede na matriz, que ficou conhecida como Topological Monitor Reach Area (TMRA). Dessa forma, a TMRA consegue tratar bem a questão de vários pontos observarem uma tensão de 0 p.u., mesmo nem todos sendo o real ponto de falta. Os autores sugerem que esse método facilita a localização da falta, quando utilizados sistemas de monitoramento obtidos por essa metodologia. Foram consideradas faltas equilibradas e desequilibradas (simuladas por meio de software comercial). Porém, as situações de faltas foram aplicadas apenas nas barras e sem a variação da impedância de falta. Foi utilizada uma modelagem matemática similar à proposta por Olguin, Vuinovich e Bollen (2006), trocando apenas a matriz MRA pela TMRA na restrição do problema. Um AG foi usado para a exploração do espaço de busca, obtendo várias configurações de PQMs com quantidade reduzida. Dentre as configurações foram elencadas as melhores com base em um índice de severidade definido pelos autores. Os mesmos concluíram que ao se considerar a TMRA, utilizando um limiar de 0,9 p.u. para os PQMs, a metodologia proposta por Olguin, Vuinovich e Bollen (2006) sugere uma quantidade maior de PQMs para a monitoração das VTCDs em sistemas radiais. Utilizando a MRA, muitas das vezes era necessário apenas um PQM para o monitoramento de toda a rede. Porém, este não fornecia informação suficiente para um sistema localizador de falta. Com a utilização da TMRA esse problema pode ser contornado.

Os mesmos autores avançaram na metodologia ao definirem melhor o índice de severidade e utilizarem mais um índice que quantiza a redundância na medição de cada alocação de PQMs (IBRAHIM et al., 2012). Em seguida, incorporaram esses dois índices, juntamente com a quantidade de PQMs, em uma mesma função objetivo, por meio de uma soma dos índices, ponderando a redundância pela quantidade de PQMs (IBRAHIM et al., 2011a; IBRAHIM et 
al., 2011b; IBRAHIM; MOHAMED; SHAREEF, 2012a; IBRAHIM; MOHAMED; SHAREEF, 2012b; IBRAHIM; MOHAMED; SHAREEF, 2014; WONG et al., 2014). Em todos estes últimos trabalhos citados, o modelo mono-objetivo de PLI foi resolvido por meio de diferentes técnicas meta-heurísticas, e aplicado à diversas redes de distribuição radiais e de transmissão.

O trabalho apresentado em Haghbin, Farjah e Mazaherifar (2013) deu sequência à pesquisa iniciada em Haghbin e Farjah (2009). Por meio de um AG, os autores encontraram todas as soluções ótimas para o problema de otimização definido em Olguin, Vuinovich e Bollen (2006) e utilizaram três índices para ranquear as soluções. O primeiro deles é baseado no conceito de FMRA, e valoriza sistemas de monitoramento com faltas mais próximas dos centros de cada FMRA. Um sistema Fuzzy é usado para calcular esse índice (Fuzzy Index), tendo como entradas o afundamento de tensão mais ameno medido e a média de todos os afundamentos. O segundo índice (Separability Index) calcula a separabilidade dos afundamentos de tensão causados por diferentes pontos de falta. Os autores sugerem que arranjos de medidores que conseguem diferenciar melhor os grupos de afundamentos de tensão de faltas diferentes são melhores no sentido de utilizar suas medições para a localização de faltas. Os pesquisadores utilizaram o método Analysis of Variance (ANOVA), que calcula a variância dos dados dentro de cada grupo e entre grupos de afundamentos para cada monitor. Um sistema Fuzzy foi utilizado para avaliar cada alocação de PQMs com base nas avaliações de cada medidor. O último índice definido (Overlap Index) propõe mensurar o grau de sobreposição das FMRAs de cada arranjo de PQMs. Os autores valorizam essa redundância da medição pois faltas nas fronteiras da FMRA podem produzir características muito semelhantes nos afundamentos de tensão, sendo assim, pontos fracos para o medidor. A cobertura desses pontos por outro PQM é favorecida por meio desse índice. O seu cálculo é feito por meio da soma ponderada das distâncias dos afundamentos para todas as combinações de faltas nas fronteiras de PQMs diferentes. Dispondo dos valores desses três índices para cada solução obtida pelo AG, o melhor sistema de monitoramento é o que possui maior valor da soma dos índices. A metodologia proposta foi testada no sistema de transmissão do IEEE de 24 barras, considerando faltas trifásicas em todas as barras. A solução obtida pelo método reflete as características desejadas por cada índice.

Um outro trabalho que segue a abordagem de Olguin, Vuinovich e Bollen (2006) para o problema de alocação de PQMs visando monitorar VTCDs é o proposto por Guerra, Cardoso e Manso (2013). Os autores utilizam uma técnica híbrida para resolver o problema de otimização definido em Olguin, Vuinovich e Bollen (2006), aliando uma heurística de busca gulosa composta de um elemento adaptativo (Greedy Randomized Adaptive Search Procedure (GRASP)) com um processo de busca local (Variable Neighborhood Search (VNS)). Foram simuladas faltas de todos os tipos em pontos discretos (barras e linhas) de duas redes de transmissão teste, utilizando um software comercial de simulação de redes elétricas. Dentre as soluções ótimas obtidas foram também valorizadas as que possuem maior redundância nas medições. A técnica proposta foi comparada com outras duas meta-heurísticas, provando ser mais rápida e eficiente. 
Kazemi et al. (2013) propuseram um método baseado no AG e Mallow's Cp (critério estatístico baseado no conceito do erro quadrático médio dos valores ajustados) para determinar o número mínimo e local de PQMs para monitoração de VTCDs. O AG é utilizado para obter as melhores posições dos monitores Monitor Placement Vectors (MPs) considerando a estimação da tensão em barras não monitoradas e a teoria Multivariable Regression (MVR). Dentre as várias soluções encontradas pelo AG, os MPs com menor número de PQMs são selecionados e, a partir dos valores de $\mathrm{Cp}$ de Mallows calculados, o que apresenta $\mathrm{Cp}$ de Mallows mais próximo de $\mathrm{P}$ (número de variáveis independentes mais 1) é selecionado como melhor configuração de monitores para esta falta específica. São obtidos MPs ótimos para as faltas em todas as barras, usando o mesmo procedimento. Então, utilizando novamente o critério Mallow's Cp, é determinado o melhor MP dentre todos os gerados pra cada falta. Após a obtenção da solução, é feita uma análise de redundância, possibilitando uma redução adicional na quantidade de PQMs. Os autores simularam, por meio de software comercial, faltas monofásicas, bifásicas e trifásicas na rede de transmissão do IEEE de 30 barras. Os mesmos afirmam que este método responde tanto para sistemas de transmissão como de distribuição, e mostraram que o mesmo é independente do limiar de ativação definido para os PQMs.

Kempner, Oleskovicz e Santos (2014) seguiram a abordagem de Olguin, Vuinovich e Bollen (2006), obtendo conjuntos de faltas simuladas por meio de expressões analíticas, assim como Espinosa-Juarez, Hernandez e Olguin (2009), Haghbin e Farjah (2009), Haghbin, Farjah e Mazaherifar (2013), mas dessa vez trabalhando com um sistema de distribuição radial (IEEE de 37 barras). Foram simuladas faltas equilibradas e desequilibradas nas barras, utilizando a decomposição em componentes simétricos para o cálculo das tensões residuais. O modelo de otimização assemelha-se ao definido em (OLGUIN; VUINOVICH; BOLLEN, 2006), com a exceção da adição de pesos associados a cada variável de decisão, sendo estes aplicados com base na MRA (área de vulnerabilidade) de cada PQM. Diferentemente de Espinosa-Juarez, Hernandez e Olguin (2009), os autores utilizaram uma matriz binária para cada fase ao considerar as faltas desequilibradas. Além disso, variaram o limiar do PQM de 0,1 até 0,9 p.u., obtendo nove matrizes para cada fase, resultando no total de 27 para cada tipo de falta. Em cada uma delas, os elementos de cada linha foram somados, a fim de determinar a quantidade de faltas detectadas por cada barra. Os vetores resultantes de cada limiar foram somados, elemento a elemento, obtendo um único vetor para cada fase. Então, foram elencados os melhores pontos para instalação de PQMs (maiores áreas de vulnerabilidade) e, atribuídos pesos inversamente proporcionais a todas as barras candidatas. O problema de PLI foi resolvido para cada tipo de falta nove vezes, uma para cada valor de limiar, obtendo alocações com diversos números de PQMs. Dentre todas elas foram definidas as que são capazes de observar os afundamentos de tensão devidos a todos os tipos de falta.

Chen, Xu e Cao (2014) abordaram o problema de alocação de PQMs assim como Olguin, Vuinovich e Bollen (2006), resolvendo o mesmo modelo de PLI. Porém, ao invés de apresentar apenas a solução ótima, os autores obtiveram um conjunto contendo todas as soluções existentes 
com esse número de PQMs. Utilizando as leituras referentes aos afundamentos de tensão dos medidores, os autores definiram a equação a ser resolvida para encontrar a posição da falta (fonte do distúrbio) (CHEN; XU; CAO, 2014). Com base nessa informação, e no conjunto combinado gerado, foi definida uma nova matriz binária que informa se uma determinada posição de falta pode ser localizada por um dos sistemas de monitoramento do conjunto. Então, o problema de otimização foi reformulado em um novo modelo de PLI e a sua solução forneceu os melhores sistemas de monitoramento para localizar faltas dentre os sistemas selecionados. Assim como Pereira, Silva e Mantovani (2004), os autores não somente alocaram os medidores, mas também localizaram a posição da falta. Da mesma forma, a dificuldade da proposta reside na prévia informação dos afundamentos de tensão registrados pelos medidores de QEE.

Martins et al. (2016) exploraram o problema de alocação de PQMs para a detecção de VTCDs segundo a abordagem de Olguin, Vuinovich e Bollen (2006). Os autores aplicaram um algoritmo de seleção clonal (Clonal Selection Algorithm (CLONALG)) para resolver o problema de minimização. O conceito de simetria entre curtos-circuitos é estudado nesse trabalho, permitindo apontar condições de falta diferentes que produzem valores similares de tensão remanescente em uma barra. Martins et al. (2016) mostraram que a disposição dos PQMs na rede podem incluir barras que conseguem diferenciar esses casos de simetria, o que é desejado em métodos de localização de faltas que fazem uso das medições de PQMs. Os autores utilizaram a quantidade de simetrias entre eventos como informação auxiliar, ajudando na decisão de qual arranjo de PQMs é melhor, em caso de soluções com o mesmo valor de função objetivo. A técnica proposta foi testada em um sistema elétrico de potência constituído por uma malha de transmissão e uma sub-rede de distribuição primária. Foram aplicadas faltas simétricas e desequilibradas com impedância de falta variável em pontos discretos da rede (incluindo barras e linhas). Os autores trataram o caso das faltas desequilibradas utilizando o menor valor de tensão das três fases para a construção da matriz binária, assim como Espinosa-Juarez, Hernandez e Olguin (2009).

Bertho et al. (2016) por sua vez também abordaram faltas equilibradas e desequilibradas, porém todas francas e aplicadas apenas nas barras. O tratamento dado para a construção da matriz binária foi como o apresentado por Kempner, Oleskovicz e Santos (2014), ou seja, obtendo uma MRA associada à cada fase faltosa (fases onde se apresentam os afundamentos de tensão) e resolvendo um problema de PLI para cada uma delas. Além disso, os autores variaram o valor do limiar dos PQMs, obtendo vários arranjos de PQMs que atendem aos diversos tipos de falta e valores de limiares selecionados para os afundamentos de tensão. O problema foi modelado segundo a abordagem clássica de Olguin, Vuinovich e Bollen (2006) e resolvido por meio da meta-heurística enxame de partículas (Particle Swarm Optimization (PSO)). A restrição de observabilidade foi tratada como uma penalidade na função objetivo do problema.

Kempner, Oleskovicz e Gomes (2017) apresentaram melhorias na metodologia proposta em (KEMPNER; OLESKOVICZ; SANTOS, 2014), sendo todas voltadas para reduzir o esforço 
computacional. Os autores consideraram apenas as fases onde estão presentes os afundamentos de tensão, gerando apenas seis matrizes por limiar (considerando todos os tipos de falta). Kempner, Oleskovicz e Santos (2014) obtiveram matrizes binárias para cada fase, totalizando vinte e sete para cada tipo de falta, considerando todos os nove valores de limiar. Em (KEMPNER; OLESKOVICZ; GOMES, 2017) esse número foi reduzido para cinquenta e quatro matrizes, já considerando todos os tipos de falta. Além disso, os autores definiram uma matriz resultante que englobasse todos os tipos de falta, utilizando uma lógica binária AND elemento a elemento das matrizes. Dessa forma, foi necessária apenas uma matriz para cada limiar, reduzindo de cinquenta e quatro para nove matrizes. Esse novo tratamento do problema se mostrou bastante vantajoso, visto que com uma única execução do algoritmo de otimização se obtém uma solução que já garante a observação de qualquer tipo de falta, dispensando a execução do algoritmo por várias vezes a fim de se obter uma solução que atenda a todos os tipos de falta. Um redução adicional na complexidade do problema foi atingida ao se reduzir a matriz resultante por meio da identificação de barras com a mesma área de vulnerabilidade, ou seja, linhas da matriz idênticas. Os autores mantiveram apenas uma linha em cada conjunto de repetições, salvando esses conjuntos em um vetor. Com essa abordagem, uma vez que uma solução ótima é obtida, outras soluções podem ser obtidas facilmente trocando os locais de monitoramento por barras com mesma observabilidade. Para se obter todas as soluções ótimas segundo Kempner, Oleskovicz e Santos (2014) seria necessário executar o algoritmo de forma extensiva, o que implicaria mais uma vez no aumento do esforço computacional. Utilizando essa nova metodologia, Kempner, Oleskovicz e Gomes (2017) alteraram a forma de calcular o vetor de pesos para a função objetivo. A prioridade dos locais de instalação foi dada com base na área de vulnerabilidade que já engloba todos os tipos de falta, ou seja, com base na soma dos elementos de cada linha da matriz resultante já reduzida.

Martins et al. (in press) retomaram o conceito de simetria abordado por Martins et al. (2016) e formularam ele dentro de um modelo de PLI por meio da ideia de identificação de evento (curto-circuito), a qual diz que uma condição de curto-circuito é identificável caso seja possível eliminar a simetria entre essa condição e todas as outras dentro de um conjunto de condições avaliado. Os autores retomaram o modelo de monitoramento de VTCDs (OLGUIN; VUINOVICH; BOLLEN, 2006) e abordaram o problema de alocação de PQMs em uma formulação bi-critério, onde um dos objetivos é a minimização da quantidade de PQMs a se instalar e o segundo objetivo é a maximização da quantidade de eventos identificáveis. Dessa forma, eles introduziram o conceito de simetria (de forma indireta) como um dos objetivos do problema de otimização, e não como um critério de desempate durante a seleção da melhor solução (MARTINS et al., 2016). O problema multi-objetivo foi resolvido por meio do Algorithm for Bicriteria Discrete Optimization (ABCDO) em instâncias geradas para vários sistemas teste de transmissão do IEEE e da malha de transmissão do sistema interligado brasileiro. O conjunto de situações de falta apresenta variações no ponto de falta (barras e linhas), tipo da falta e impedância da falta. Os resultados apresentaram soluções com baixa quantidade de PQMs e alta identificação de eventos, sendo necessário a tomada de decisão com base nos interesses da concessionária de energia. 


\subsubsection{Metodologia baseada na análise do circuito elétrico}

Uma outra vertente na pesquisa sobre alocação de medidores surgiu a partir do trabalho de Eldery et al. (2006). Esse estudo aborda a questão da observabilidade do sistema elétrico de uma maneira mais geral que a pesquisa reportada por Olguin, Vuinovich e Bollen (2006), pois procura sistemas de monitoramento que sejam capazes de monitorar as tensões e correntes em toda a rede, e não com o objetivo de monitorar algum problema de QEE em específico. $\mathrm{Na}$ prática, esse trabalho assume que sejam instalados medidores de forma permanente nas barras da rede elétrica, e que seja necessária, portanto, uma infraestrutura de rede de comunicação capaz de coletar e enviar todas as medições para uma central de tratamento dos dados. O problema foi representado como de recobrimento (do inglês covering), objetivando, portanto, encontrar posições estratégicas para os medidores de forma a monitorar (cobrir) todo o sistema. Os autores trataram o problema de otimização por meio da PLI, com um único objetivo (reduzir o custo) e uma restrição (observabilidade total do sistema). Diferentemente de Olguin, Vuinovich e Bollen (2006), foi considerado um custo variável em cada ponto do sistema, dependendo de outros fatores além do próprio medidor. Em (OLGUIN; VUINOVICH; BOLLEN, 2006) o custo foi considerado unitário para todos os pontos de instalação, procurando por consequência, reduzir a quantidade de medidores a serem utilizados. No trabalho de Eldery et al. (2006) a matriz binária representando a observabilidade do sistema foi construída com base nas leis fundamentais da análise de circuitos elétricos, diferentemente de Olguin, Vuinovich e Bollen (2006), que foi baseada na simulação de curtos-circuitos. A metodologia proposta foi testada em uma rede de 6 barras, e em outros três sistemas teste de transmissão do IEEE: de 30, 118 e 300 barras. Os autores concluíram que a economia no sistema de monitoramento aumenta à medida em que a complexidade da rede testada se eleva. Os trabalhos de Olguin, Vuinovich e Bollen (2006) e Eldery et al. (2006) se diferenciam do trabalho de Pereira, Silva e Mantovani (2004) pelo fato de ambos levarem em consideração a redução do custo do sistema de monitoramento e a observabilidade da rede elétrica, o que este último não considerou.

Um trabalho que seguiu a mesma proposta de Eldery et al. (2006) foi o trabalho de Reis et al. (2008). Neste estudo, os autores utilizaram a mesma metodologia e modelagem propostas em (ELDERY et al., 2006). Porém, analisaram a possibilidade da existência de medidores previamente instalados em certas barras devido à sua importância para o SEP. Esse detalhe foi inserido no modelo de otimização por meio de uma restrição do modelo matemático. $\mathrm{O}$ problema também foi resolvido de forma exata, por meio de um algoritmo Branch \& Bound. A metodologia foi testada nas redes teste de transmissão do $\operatorname{IEEE~(14,~30,~} 57$ e 118 barras), além de uma rede real de transmissão da Companhia Energética de Minas Gerais (CEMIG) de 154 barras.

Kumar, Singh e Singh (2012) estudaram a alocação de PQMs em sistemas de distribuição radiais e não-radiais com o objetivo de monitorar as distorções harmônicas. A escolha dos pontos para a instalação dos PQMs foi feita baseada na sensitividade das barras à distorção 
harmônica total da tensão (Total Harmonic Distortion of a Voltage Wave (THDv)). Um sistema Fuzzy foi utilizado para escolher os pontos de alocação, o qual recebe entradas correspondentes à variação da tensão e da potência com relação à $T H D_{V}$ ao longo do dia. Os sistemas de monitoramento obtidos foram testados com relação à observabilidade total da rede, utilizando a mesma abordagem proposta por Eldery et al. (2006). Dessa forma, o sistema Fuzzy vai adicionando PQMs até que a rede seja observável. Um outro trabalho abordou o monitoramento das distorções harmônicas (ALMEIDA et al., 2012), utilizando o sistema de transmissão teste do IEEE de 14 barras. Foi aplicada a mesma metodologia de Eldery et al. (2006), e o problema de PLI foi resolvido por meio do algoritmo Branch \& Bound. Uma vez obtida a alocação, as tensões e correntes monitoradas foram utilizadas em um estimador de estado harmônico, considerando o terceiro nível de distorção. As variáveis estimadas foram comparadas com seus valores reais, validando a metodologia de alocação de PQMs para distorção harmônica.

Oleskovicz et al. (2012) propuseram uma abordagem multi-objetivo para o problema da alocação de medidores, que até então foi modelado sempre com um único objetivo. Os autores observaram que além do custo do sistema de monitoração, um outro aspecto importante do problema deveria ser avaliado: a redundância nas medições. Diferentemente de Ibrahim et al. (2011a), que sugeriram minimizar as interseções das MRAs dos medidores, Oleskovicz et al. (2012) decidiram maximizar as redundâncias. Ibrahim et al. (2011a) julgaram que ao minimizar essas interseções das MRAs seriam obtidos sistemas de monitoramento mais bem distribuídos na rede elétrica. Oleskovicz et al. (2012), por sua vez, apontaram que essas sobreposições de MRAs são benéficas, no sentido de que deixam o sistema de monitoramento mais confiável. Os autores definiram um índice para quantificar a redundância de cada sistema de monitoramento, sendo a maximização desse índice um dos objetivos. O outro objetivo é a minimização do custo, da mesma forma que em Eldery et al. (2006). Oleskovicz et al. (2012) observaram que esses dois objetivos são conflitantes, visto que à medida em que se reduz a quantidade de medidores também é reduzida a redundância na medição. Portanto, o tratamento adequado para o problema deve ser a modelagem multi-objetivo. A restrição de observabilidade do sistema elétrico também foi inclusa no modelo de otimização utilizando a mesma metodologia e equacionamento de Eldery et al. (2006). O problema de otimização foi resolvido por meio do Algoritmo Genético Compacto (Compact Genetic Algorithm (cGA)), obtendo soluções não-dominadas por meio do método da soma ponderada. A metodologia foi aplicada em redes de transmissão do IEEE de 14, 30 e 57 barras; resultando em cenários de monitoramento com quantidade reduzida de medidores e boa redundância na medição.

Wan et al. (2014) mesclaram a metodologia proposta por Eldery et al. (2006) com a definição do limiar de disparo do PQM (OLGUIN; VUINOVICH; BOLLEN, 2006). Dessa forma, o conceito de observabilidade é o mesmo apresentado por Eldery et al. (2006), porém, considerando apenas valores de tensão abaixo do limiar especificado. Wan et al. (2014) utilizaram o mesmo modelo de PLI de Eldery et al. (2006) e Olguin, Vuinovich e Bollen (2006), adicionando, contudo, mais uma restrição ao modelo, a qual vem a atacar o problema de localização das faltas. 
Os autores sugerem que os eventos manifestados na corrente e tensão devem ser diferenciados uns dos outros pelos PQMs instalados no sistema. Dessa forma, a localização da falta que causou cada um desses eventos pode ser obtida a partir das medições registradas pelos medidores. Wan et al. (2014) propõem que eventos diferentes devem ser capturados por PQMs diferentes. Portanto, o algoritmo de alocação vai adicionando medidores que capturam um determinado evento mas não registram um segundo, assim diferenciando os dois eventos que anteriormente eram registrados por um mesmo medidor. Os autores formularam então o problema de otimização inteira e o reduziram a vários problemas de decisão por meio da k-mediana. Cada problema foi resolvido com um algoritmo de busca local. Por consequência da modelagem proposta foram obtidos sistemas de monitoramento com elevado número de PQMs. Diferentemente de Pereira, Silva e Mantovani (2004) e Chen, Xu e Cao (2014) os autores não propõem uma metodologia para localizar as faltas, além do método de alocação de medidores. Ademais, o espaço de solução não é restringido, o que é feito por Pereira, Silva e Mantovani (2004) ao restringir a quantidade de medidores disponíveis, e por Chen, Xu e Cao (2014) ao pré-selecionar sistemas de monitoramento com base na metodologia de Olguin, Vuinovich e Bollen (2006).

Freitas et al. (2016) estudaram o problema de alocação de medidores de acordo com Eldery et al. (2006). Além do equacionamento original, os autores incluíram mais três restrições ao modelo de otimização. A primeira delas trata a possibilidade de já existirem medidores instalados em alguns pontos da rede elétrica. A segunda considera casos de barras onde ainda não existem medidores instalados, porém se deseja futuramente instalar. E a terceira restrição inclui casos onde a concessionária não possui interesse em instalar medidor em determinada barra. O problema de PLI proposto foi resolvido por meio do algoritmo Branch \& Bound em uma rede real de transmissão da CEMIG com 65 barras, onde foram testados vários cenários com restrições de instalação de medidores. O problema resultou em múltiplas soluções com mesmo custo do sistema de monitoramento. Os autores utilizaram um fator de redundância de dados para escolher a melhor solução. Esse mesmo índice foi utilizado por Oleskovicz et al. (2012), porém como um dos objetivos do problema de otimização.

\subsubsection{Metodologia baseada na divisão do sistema em clusters}

Um outro trabalho pioneiro no assunto foi o estudo desenvolvido por Ammer e Renner (2004). Este trabalho aplica técnicas de correlação e regressão ao problema de alocação ótima de PQMs. O distúrbio que se deseja monitorar é a tensão com distorções harmônicas. Para isso são determinadas as correntes do distúrbio em cada nó da rede em análise e, tendo como informação a matriz de impedância da rede, são calculadas as tensões com distorções harmônicas. Então, os nós com comportamento semelhantes em relação às tensões com distorções harmônicas são identificados para a redução do número de medidores necessários. As séries temporais calculadas dos parâmetros de qualidade em cada nó da rede são os dados de entrada para a análise da correlação e regressão. As análises são realizadas para todas as combinações de séries. 
São definidos limiares e os resultados armazenados em duas matrizes com zeros e uns para a regressão e correlação. Uma matriz resultante é gerada através de uma lógica AND elemento a elemento. Essa matriz é reorganizada com os elementos diferentes de zero próximos à diagonal. Assim são identificados clusters, e cada medidor é alocado no centro destes. A metodologia proposta pelos autores foi aplicada em três redes elétricas: uma rede de distribuição urbana de 10 $\mathrm{kV}$, distribuição rural de $30 \mathrm{kV}$ e de transmissão de $110 \mathrm{kV}$. Para estas três redes foi analisado o quinto componente harmônico. Eles identificaram a formação de clusters bem definidos para os 3 casos e, em alguns deles, ocorreram sobreposição de clusters. Os autores demonstraram que com essa metodologia é possível cobrir grandes áreas para monitoramento com PQMs, utilizando poucos e em alguns casos apenas 1 dispositivo de medição.

Hong e Chen (2011) seguiram uma abordagem parecida com a de Ammer e Renner (2004). Propuseram uma alocação de PQMs para o monitoramento das tensões com distorções harmônicas (regime permanente) e para o chaveamento de bancos de capacitores (regime transitório). Esse trabalho sugere um algoritmo $K$-means modificado para separar todas as barras da rede em $K$ conjuntos com características semelhantes, onde devem ser consideradas apenas barras que estão conectadas em cada grupo. Os medidores são alocados em posições correspondendo a aproximadamente o centro desses grupos. Esse problema foi resolvido por meio de um AG melhorado. Os resultados foram validados com uma rede de distribuição radial com 18 barras.

\subsubsection{Metodologia baseada na representação do sistema por meio de grafos}

Won e Moon (2008) trabalharam com redes de distribuição radiais, assim como Ammer e Renner (2004), Pereira, Silva e Mantovani (2004). Porém, exploraram a topologia da rede elétrica, e por meio de sua representação pela matriz de incidência elemento-nó, definiram o problema de alocação de PQMs através de um modelo mono-objetivo de PLI com uma restrição. O objetivo foi de maximizar a observabilidade do sistema. Em outras palavras, minimizar o número de elementos do sistema não observados. O conceito de observabilidade utilizado pelos autores é semelhante ao definido por Eldery et al. (2006), porém, levando em consideração apenas a lei de Kirchhoff das correntes. A restrição diz respeito à quantidade mínima e máxima de medidores disponíveis para instalação. Os autores definem uma matriz de cobertura com base na matriz de incidência, olhando para a posição em que o medidor está inserido no sistema e assumindo que os elementos a jusante deste ponto são cobertos pelo medidor. Essa matriz de cobertura também é interessante, pois consegue dar uma informação de direção do evento. Won e Moon (2008) afirmam que o medidor é capaz de informar se o evento ocorreu à montante e/ou a jusante do seu ponto de instalação, sendo esta informação da posição atrelada ao formato em árvore desse tipo de rede elétrica (redes radiais) analisada.

A característica de topologia radial dos sistemas de distribuição também foi explorada 
por Branco et al. (2018), analisando esses sistemas como grafos orientados onde os pontos candidatos à instalação de PQMs são os seus componentes (linhas, transformadores e cargas), assim como no trabalho de Won e Moon (2008). No entanto, Branco et al. (2018) abordaram o problema de alocação de PQMs como multi-objetivo, o qual possui 6 objetivos: reduzir o custo de instalação do sistema de monitoramento, maximizar o monitoramento das cargas, maximizar a área (quantidade de ramos) monitorada, minimizar a ambiguidade topológica (sendo que um componente ambíguo é o que não é possível determinar sua corrente), minimizar a quantidade de afundamentos de tensão que não estão sendo monitorados e, maximizar a redundância no monitoramento dos afundamentos de tensão. Vale ressaltar que os autores modelaram a parte da observabilidade de VTCDs como um dos objetivos do problema, e não como uma restrição, assim como no modelo clássico de Olguin, Vuinovich e Bollen (2006). A redundância também foi modelada como um dos objetivos, da mesma forma que (OLESKOVICZ et al., 2012). O método de alocação foi aplicado em 3 sistemas teste de distribuição do IEEE: de 13, 34 e 37 barras. Os curtos-circuitos foram simulados em todas as barras para a construção do conjunto de dados, sendo do tipo trifásicos e com impedância de falta variável. O modelo de otimização foi resolvido por meio do Multi-objective Evolutionary Algorithm with Tables (MEAT), obtendo diversas opções de alocações, cabendo ao tomador de decisão escolher a solução que melhor represente o custo/benefício para a concessionária que deseja instalar medidores na rede.

\subsubsection{Resumo dos trabalhos relatados}

O Quadro 2 apresenta todos os trabalhos discutidos neste capítulo, os quais estão divididos de acordo com o modo em que os autores abordaram o problema, reunindo as semelhanças identificadas entre as pesquisas. Cada coluna do Quadro 2 mostra os trabalhos mais próximos entre si em termos da metodologia empregada no problema de alocação.

Este trabalho segue a tendência dos trabalhos apresentados na primeira coluna do Quadro 2, visto que a sua metodologia também é baseada em simulação de faltas, assim como Olguin, Vuinovich e Bollen (2006). Além disso, este trabalho está fortemente relacionado com os trabalhos apresentados em (KEMPNER; OLESKOVICZ; GOMES, 2017) e (MARTINS et al., in press).

O Quadro 2 mostra uma quantidade maior de trabalhos seguindo a proposta de Olguin, Vuinovich e Bollen (2006), sendo estes bem distribuídos, desde o início das pesquisas dentro do problema de alocação de medidores até os trabalhos mais recentes.

A metodologia proposta por Eldery et al. (2006) também atraiu vários outros trabalhos na sequência, e a abordagem sugerida para o problema de alocação continuou sendo utilizada, segundo a revisão bibliográfica apresentada, até anos recentes à escrita desta monografia.

A ideia apresentada por Ammer e Renner (2004) não continuou sendo estudada, como mostra o Quadro 2. A utilização de grafos para abordar o problema também foi pouco explorada, 
sendo somente retomada dez anos depois, por Branco et al. (2018). Este trabalho, apesar de ter sido apresentado na quarta coluna do Quadro 2, também utiliza aspectos tanto da metodologia proposta por Olguin, Vuinovich e Bollen (2006) quanto da metodologia de Eldery et al. (2006).

Quadro 2 - Resumo dos trabalhos relatados e correlatos ao tema de alocação de medidores.

\begin{tabular}{|c|c|c|c|}
\hline $\begin{array}{c}\text { Metodologia baseada } \\
\text { em simulação de } \\
\text { faltas }\end{array}$ & $\begin{array}{c}\text { Metodologia baseada } \\
\text { na análise do circuito } \\
\text { elétrico }\end{array}$ & $\begin{array}{c}\text { Metodologia baseada } \\
\text { na divisão do sistema } \\
\text { em clusters }\end{array}$ & $\begin{array}{l}\text { Metodologia baseada } \\
\text { na representação do } \\
\text { sistema por meio de } \\
\text { grafos }\end{array}$ \\
\hline $\begin{array}{c}\text { Pereira, Silva e } \\
\text { Mantovani (2004) }\end{array}$ & Eldery et al. (2006) & $\begin{array}{c}\text { Ammer e Renner } \\
\text { (2004) }\end{array}$ & Won e Moon (2008) \\
\hline $\begin{array}{l}\text { Olguin, Vuinovich e } \\
\text { Bollen (2006) }\end{array}$ & Reis et al. (2008) & Hong e Chen (2011) & Branco et al. (2018) \\
\hline $\begin{array}{l}\text { Haghbin e Farjah } \\
\qquad(2009)\end{array}$ & $\begin{array}{c}\text { Kumar, Singh e Singh } \\
\text { (2012) }\end{array}$ & & \\
\hline $\begin{array}{c}\text { Espinosa-Juarez, } \\
\text { Hernandez e Olguin } \\
\text { (2009) }\end{array}$ & Almeida et al. (2012) & & \\
\hline $\begin{array}{l}\text { Almeida e Kagan } \\
\text { (2010) }\end{array}$ & Oleskovicz et al. (2012) & & \\
\hline Salim e Nor (2010) & Wan et al. (2014) & & \\
\hline $\begin{array}{l}\text { Cebrian, Almeida e } \\
\text { Kagan (2010) }\end{array}$ & Freitas et al. (2016) & & \\
\hline \multicolumn{4}{|l|}{$\begin{array}{l}\text { Ibrahim, Mohamed e } \\
\text { Shareef (2011) }\end{array}$} \\
\hline \multicolumn{4}{|l|}{$\begin{array}{l}\text { Haghbin, Farjah e } \\
\text { Mazaherifar (2013) }\end{array}$} \\
\hline \multicolumn{4}{|l|}{$\begin{array}{l}\text { Guerra, Cardoso e } \\
\text { Manso (2013) }\end{array}$} \\
\hline \multicolumn{4}{|l|}{ Kazemi et al. (2013) } \\
\hline \multicolumn{4}{|l|}{$\begin{array}{c}\text { Kempner, Oleskovicz e } \\
\text { Santos (2014) }\end{array}$} \\
\hline \multicolumn{4}{|l|}{ Chen, Xu e Cao (2014) } \\
\hline \multicolumn{4}{|l|}{ Martins et al. (2016) } \\
\hline \multicolumn{4}{|l|}{ Bertho et al. (2016) } \\
\hline \multicolumn{4}{|l|}{$\begin{array}{c}\text { Kempner, Oleskovicz e } \\
\text { Gomes (2017) }\end{array}$} \\
\hline Martins et al. (in press) & & & \\
\hline
\end{tabular}

Fonte: Elaborada pelo autor. 


\subsection{Considerações finais}

Esta pesquisa aborda o problema da alocação de medidores em sistemas de distribuição de energia, a princípio considerando a alocação de PQMs, mas não limitando a apenas esse tipo de equipamento, mas a qualquer outro capaz de registrar tensão em algum ponto do sistema. Aqui é dado um enfoque maior na medição dessa grandeza, visto que é o parâmetro de interesse em monitoramento pelas concessionárias de energia elétrica, dado que as agências reguladoras avaliam a QEE por meio da tensão fornecida (ANEEL, 2018). Além de atender aos requisitos de QEE, dado que esta pesquisa vem a atenuar/eliminar as possíveis condições de simetria, a tensão se mostrou uma grandeza satisfatória e de grande interesse. Portanto, o banco de dados derivado das simulações de falta é composto de valores de tensão medidos, o qual é utilizado pelo método de alocação de medidores. No entanto, isso não quer dizer que durante a instalação dos medidores estes devam estar limitados apenas à medição de tensão. Outras medições podem estar disponíveis, como a corrente, que é muito utilizada por métodos de localização de faltas. A metodologia proposta por esta pesquisa apenas decide os locais de instalação dos medidores, ficando os requisitos de cada medidor à cargo da concessionária de acordo com o seu interesse de monitoramento. Entretanto, independente das grandezas e aplicações, o método proposto é mais do que necessário para indicar o local e a quantidade de PQMs a serem instalados, já que as concessionárias, até o momento, não possuem nenhum encaminhamento neste sentido.

Este trabalho segue a tendência dos trabalhos de Olguin, Vuinovich e Bollen (2006), abordando a minimização de PQMs para o monitoramento de VTCDs. Porém, além da observação dos eventos, aqui é abordada também a questão da localização da fonte do distúrbio. Como serão simulados apenas curtos-circuitos, serão considerados os casos de VTCDs causadas por faltas, ou seja, a fonte do distúrbio é necessariamente um curto-circuito. Então, assume-se também que o sistema de monitoramento será composto de uma infraestrutura de comunicação, de tal forma que o sistema localizador de faltas seja capaz de obter em tempo real as medições de todos os PQMs otimamente instalados. A simulação das faltas elétricas é executada por meio de expressões analíticas visando chegar em matrizes que representem a tensão durante a falta, assim como em (OLGUIN; VUINOVICH; BOLLEN, 2006; HAGHBIN; FARJAH, 2009; ESPINOSA-JUAREZ; HERNANDEZ; OLGUIN, 2009; HAGHBIN; FARJAH; MAZAHERIFAR, 2013; KEMPNER; OLESKOVICZ; SANTOS, 2014; MARTINS et al., 2016; BERTHO et al., 2016; KEMPNER; OLESKOVICZ; GOMES, 2017; BRANCO et al., 2018; MARTINS et al., in press).

O problema da localização de faltas é tratado durante a alocação de PQMs, ou seja, dentro da metodologia de alocação são inseridas características inerentes do problema da localização de faltas de tal forma que a otimização valorize sistemas de monitoramento que irão facilitar posteriormente a localização das faltas. O conceito de simetria (e identificação de eventos), abordado por Martins et al. (in press), é retomado para representar as múltiplas estimações de falta que ocorrem nos sistemas de distribuição, sendo que diversos aspectos desse problema de múltiplas estimações são incorporados ao método de alocação proposto nesta pesquisa. 


\section{3}

METODOLOGIA

Neste capítulo são apresentados os métodos e técnicas utilizadas para abordar o problema de alocação de medidores deste trabalho, a fim de se obter uma modelagem matemática a ser resolvida por meio de um método de otimização adequado.

A metodologia foi dividida em 4 principais passos, os quais estão representados no fluxograma da Figura 2.

As quatro seções seguintes detalham cada um dos quatro passos representados no fluxograma. A seção 3.1 descreve os passos necessários para se chegar às impedâncias de sequência, necessárias para a construção das matrizes impedância de barras. A seção 3.2 aborda as considerações e o passo-a-passo para o cálculo de curto-circuito, incluindo a construção da matriz impedância de barras. A seção 3.3 apresenta como se utilizar dos cálculos de curto-circuito para obter um conjunto de dados que seja representativo, servindo como base para o algoritmo de alocação de PQMs. Por último, a seção 3.4 descreve o processamento desse conjunto de dados de maneira que o algoritmo de otimização consiga extrair as informações necessárias, sendo que estas deverão refletir o tratamento desejado ao problema de alocação de medidores. A seção 3.5 faz um fechamento do capítulo, ressaltando os pontos mais importantes abordados ao longo do mesmo.

\subsection{Passo 1: Leitura dos dados topológicos do sistema}

Nesta etapa são obtidas todas as informações sobre cada trecho da rede elétrica: comprimento, quantidade de fases, tipo de cabos, número de cabos por fase, e suas disposições e espaçamento geométrico entre os cabos.

As impedâncias próprias e mútuas são calculadas com base nas equações de Carson e, logo são obtidas as matrizes de impedância de fase para cada trecho do SEP. Mais detalhes sobre esses cálculos podem ser encontrados em (KERSTING, 2002, p. 81). 
Figura 2 - Fluxograma das 4 principais etapas da metodologia proposta para a alocação de PQMs.
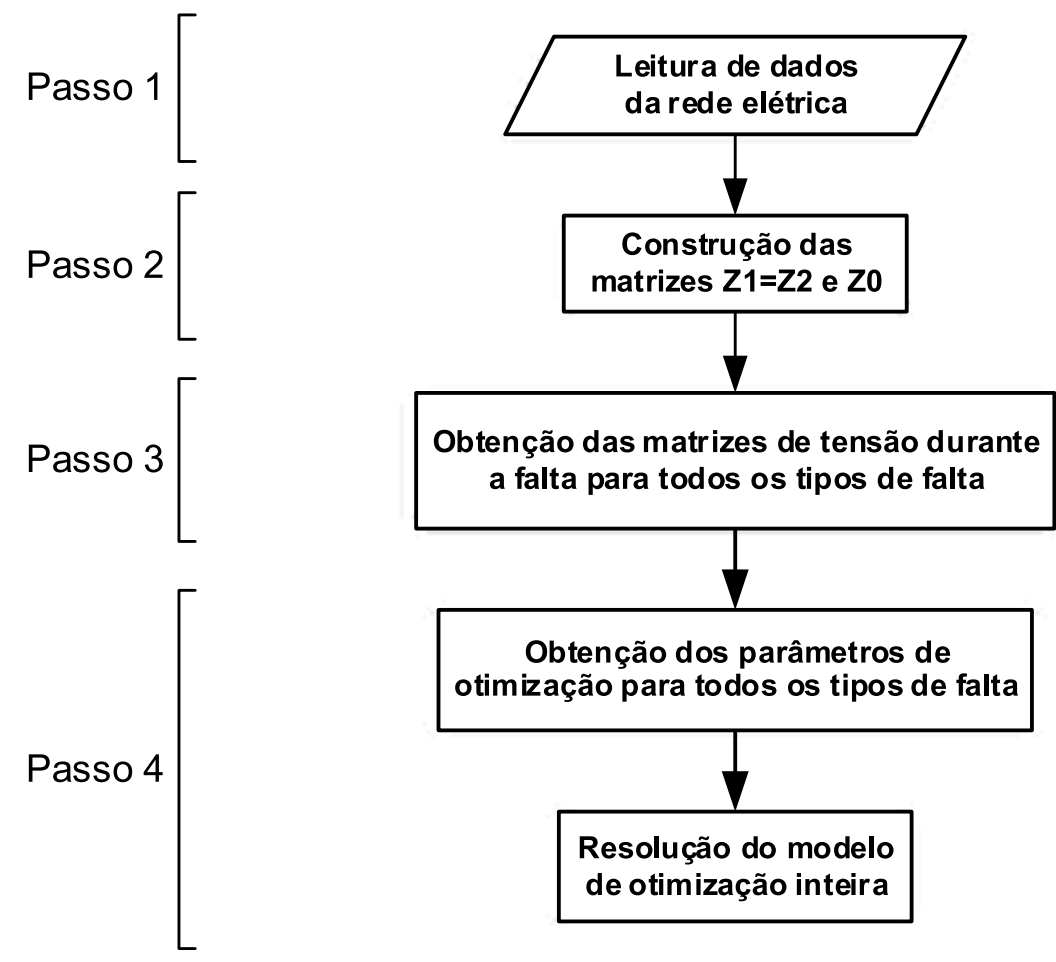

Fonte: $\mathrm{O}$ autor.

Neste estudo é considerada a transposição de todas as linhas. Portanto, o acoplamento mútuo entre as fases (termos fora da diagonal) é igual, assim como as impedâncias próprias das três fases (termos da diagonal). Essa consideração é feita substituindo os termos pertencentes e não pertencentes à diagonal pelos seus respectivos valores médios, como mostrado nas Equações (3.1), (3.2) e (3.3).

$$
\begin{aligned}
z_{s} & =\frac{1}{3} \cdot\left(z_{a a}+z_{b b}+z_{c c}\right) \\
z_{m} & =\frac{1}{3} \cdot\left(z_{a b}+z_{b c}+z_{c a}\right) \\
z_{a b c} & =\left[\begin{array}{lll}
z_{s} & z_{m} & z_{m} \\
z_{m} & z_{s} & z_{m} \\
z_{m} & z_{m} & z_{s}
\end{array}\right]
\end{aligned}
$$

Dessa forma, as impedâncias de sequência zero, positiva e negativa, podem ser calculadas na Equação (3.5):

$$
z_{012}=\frac{1}{3} \cdot\left[\begin{array}{ccc}
1 & 1 & 1 \\
1 & a & a^{2} \\
1 & a^{2} & a
\end{array}\right] \cdot\left[\begin{array}{ccc}
z_{s} & z_{m} & z_{m} \\
z_{m} & z_{s} & z_{m} \\
z_{m} & z_{m} & z_{s}
\end{array}\right] \cdot\left[\begin{array}{ccc}
1 & 1 & 1 \\
1 & a^{2} & a \\
1 & a & a^{2}
\end{array}\right]
$$




$$
z_{012}=\left[\begin{array}{ccc}
z_{s}+2 \cdot z_{m} & 0 & 0 \\
0 & z_{s}-z_{m} & 0 \\
0 & 0 & z_{s}-z_{m}
\end{array}\right]=\left[\begin{array}{ccc}
z_{00} & 0 & 0 \\
0 & z_{11} & 0 \\
0 & 0 & z_{22}
\end{array}\right]
$$

Esse último resultado é importante para o desenvolvimento desta pesquisa, visto que o desacoplamento das redes de sequência é necessário para se analisar faltas assimétricas utilizando o método da decomposição dos fasores em componentes simétricos.

A análise de curto-circuito realizada neste trabalho é baseada na matriz impedância de barras ( $Z$ ou $Z_{\text {barra }}$ ), a qual representa todo o sistema elétrico (Passo 2). Para analisar faltas trifásicas é necessária apenas a matriz impedância de barras de sequência positiva $\left(Z_{1}\right)$, enquanto o estudo de faltas desequilibradas requer também as matrizes de sequência negativa $\left(Z_{2}\right)$ e zero $\left(Z_{0}\right)$.

Por meio da Equação (3.5) é possível calcular $z_{00}, z_{11}$ e $z_{22}$ para todos os trechos do sistema. As matrizes $Z_{0}, Z_{1}$ e $Z_{2}$ são compostas por essas impedâncias, respectivamente.

\subsection{Passo 2: Construção das matrizes impedância de bar- ras}

Esta etapa tem como objetivo mostrar a construção da matriz impedância de barras. Analisando-se apenas as faltas trifásicas, na sequência será mostrado como obter a matriz $Z_{1}$. Neste caso, considera-se apenas as impedâncias $z_{11}$ de cada trecho. Por motivos de simplicidade, a matriz impedância de barras de sequência positiva será referida apenas como $Z_{\text {barra }}$ ou simplesmente $Z$.

A matriz $Z$ pode ser obtida por meio da inversão da matriz admitância de barras $Y$ ou construída diretamente, elemento a elemento. A desvantagem do primeiro método é que a matriz $Y$ pode não ter sua inversa (matriz singular), dependendo do sistema representado. Isso ocorre em caso de matrizes mal-condicionadas. Em razão deste estudo focar em sistemas radiais de distribuição, os quais apresentam poucas ou nenhuma conexão entre barras, optou-se pelo segundo método, a fim de se evitar o problema mencionado.

Para melhor compreensão, o processo de como obter a matriz $Z$ de forma direta será explicado em detalhes, utilizando-se como exemplo uma rede simples de distribuição. Como o cenário atual mostra sistemas de distribuição com crescente inserção de geração distribuída, será mostrada também a forma de considerar o gerador distribuído na matriz $Z$. Esse é um diferencial para esta pesquisa, visto que não foi encontrado em nenhum outro trabalho consultado até o momento, o estudo da influência da penetração da geração distribuída no problema de alocação de PQMs. 
Esta seção está dividida em duas subseções. A primeira introduz o sistema de distribuição que será utilizado como exemplo e define o tipo da geração distribuída considerada, bem como seu modelo. Ainda nesta subseção, o sistema em pauta é utilizado para introduzir o estudo de curto-circuito, com exemplos resolvidos por meio da análise de circuitos elétricos, visando mostrar a necessidade de uma metodologia mais geral para a análise de faltas. Na subseção 3.2.2 a matriz $Z_{\text {barra }}$ é sugerida para a solução deste problema. É estudada a construção desta matriz antes e após a inserção do Gerador Distribuído (GD), com o objetivo de mostrar quais mudanças são necessárias na $Z_{\text {barra }}$ para se incorporar o efeito do GD no sistema.

\subsubsection{Análise do sistema de distribuição durante a falta}

A Figura 3 mostra o sistema europeu de média tensão do (CIGRE Task Force C6.04, 2014, sec. 6.2). Esse sistema é alimentado por uma rede de subtransmissão de $110 \mathrm{kV}$, sendo a potência de curto-circuito na subestação de 5.000 MVA. As barras do sistema original foram renumeradas, e as chaves de interconexão foram consideradas todas abertas, caracterizando uma rede com topologia essencialmente radial. Além disso, foi acrescentado um gerador distribuído na barra 12, tratando-se de uma máquina síncrona acionada por uma turbina a vapor. O gerador síncrono possui uma potência nominal de 5 MVA e tensão de $6,6 \mathrm{kV}$. A resistência de armadura é de 0,004 p.u. e sua reatância subtransitória de eixo direto é de 0,119 p.u. (MOURA, 2011).

O gerador distribuído é uma máquina síncrona, conectada ao sistema original por meio de um transformador elevador. O modelo para o gerador foi o mesmo apresentado em (STREZOSKI; PRICA; LOPARO, 2018). As linhas e os transformadores foram modelados utilizando uma impedância série, sendo esse modelo suficiente para os estudos de curtos-circuitos.

Ao se aplicar uma falta trifásica franca no ponto de conexão do GD (barra 12), o circuito equivalente monofásico, que representa o sistema momentos antes da falta, é o mostrado na Figura 4. A tensão equivalente do sistema de subtransmissão que fornece energia à rede de distribuição é representada por $V_{e q}$, e $Z_{e q}$ representa a impedância vista desde a fonte de alimentação até a barra da subestação. Os valores desses elementos do circuito são calculados a partir dos dados (em MVA) de curto-circuito fornecidos (CIGRE Task Force C6.04, 2014, sec. 6.2). A impedância $Z_{1-12}$ é o equivalente série das impedâncias do transformador entre as barras 1 e 2; e das linhas entre as barras 2 e 12 . O gerador síncrono é representado pela sua tensão interna subtransitória $\left(E_{g d}\right)$ e pela impedância $Z_{g d}$, composta pela reatância subtransitória do gerador mais a impedância do transformador de conexão. Vale ressaltar que para outros tipos de GDs, como os baseados em inversores, modelos diferentes devem ser utilizados (STREZOSKI; PRICA; LOPARO, 2018). A fonte de tensão $V_{f}$ foi acrescentada no ponto de falta, tendo o mesmo valor da tensão na barra 12 antes da ocorrência da falta. A corrente $I_{L}$ é a corrente de carga que circula durante a operação do sistema em condições normais. A adição da fonte $V_{f}$ não altera o valor dessa corrente.

Para simular uma falta na barra 12 basta adicionar uma fonte com mesmo valor de $V_{f}$, 
Figura 3 - Sistema europeu de média tensão modificado de 15 barras.

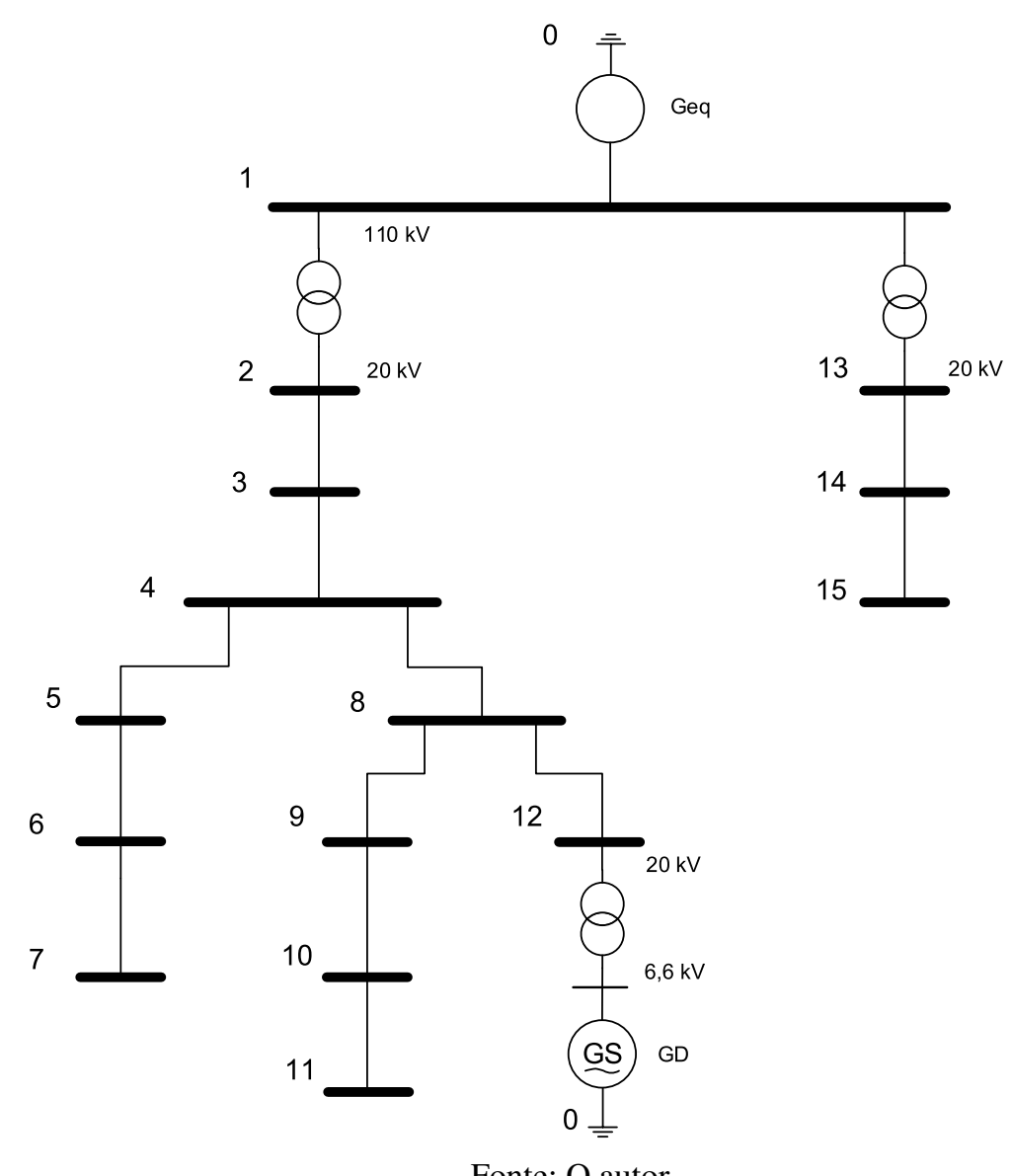

Fonte: $\mathrm{O}$ autor.

Figura 4 - Circuito equivalente representando o sistema antes da falta.

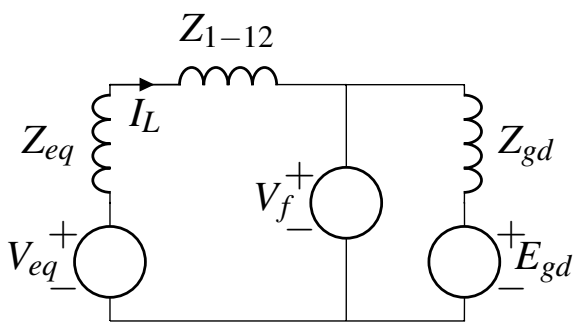

Fonte: $\mathrm{O}$ autor.

porém com a polaridade invertida (Figura 5). Então, pode-se aplicar o teorema da superposição, primeiro curto-circuitando as fontes $V_{e q}, V_{f}$ e $E_{g d}$ (Figura 6), e depois curto-circuitando $-V_{f}$ (Figura 7). O circuito da Figura 6 fornece as correntes que circulam devido à tensão com valor zero no ponto de falta, e o circuito da Figura 7 as correntes que circulam no sistema operando antes da falta.

Portanto, basta adicionar o valor da corrente de carga ao valor da corrente devido apenas à falta para se obter o valor total da corrente de falta. Normalmente, o valor da corrente de carga é desprezado, ou seja, admite-se que o sistema opera em vazio antes da falta. Assim, não 
Figura 5 - Circuito equivalente representando o sistema durante a falta.

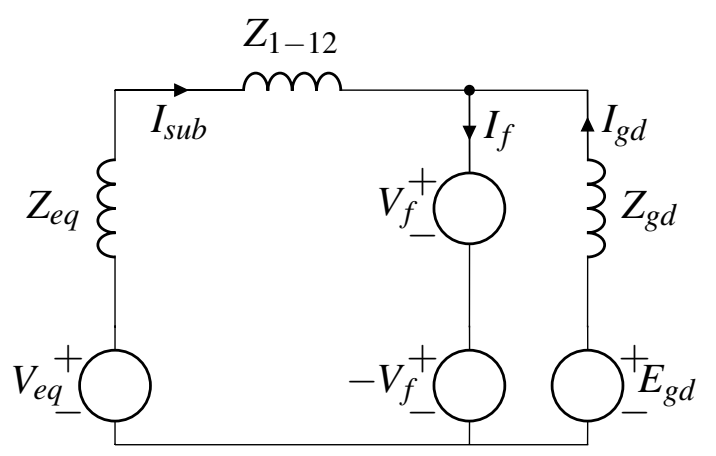

Fonte: $\mathrm{O}$ autor.

Figura 6 - Circuito equivalente 1 .

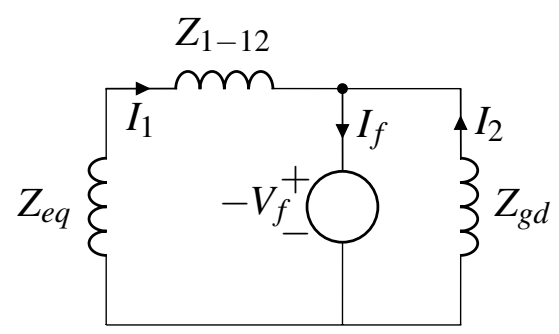

Fonte: $\mathrm{O}$ autor.

Figura 7 - Circuito equivalente 2.

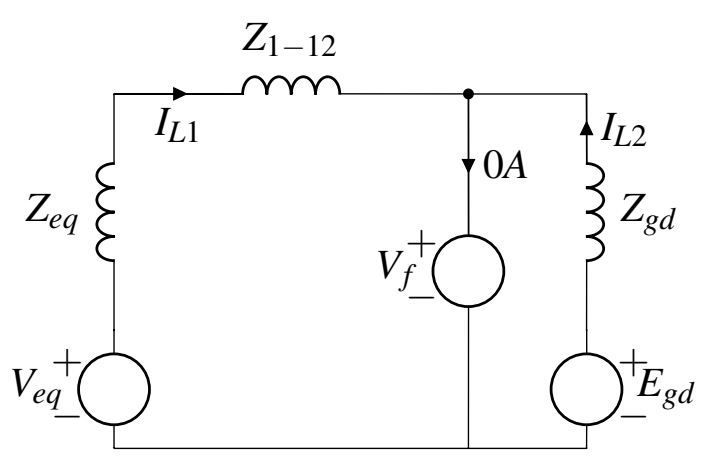

Fonte: $\mathrm{O}$ autor.

circulando corrente em nenhum ramo do sistema, todas as tensões nodais são iguais a 1 p.u.. Para esta pesquisa também foi feita essa consideração. O teorema de Thévenin pode ser utilizado para calcular o valor da corrente na falta, construindo o seu equivalente no ponto da falta. Nesse caso, a tensão de Thévenin é igual à tensão de pré-falta na barra $12\left(V_{t h}=V_{f}\right)$, e a impedância de Thévenin é dada por:

$$
Z_{t h}=\frac{\left(Z_{e q}+Z_{1-12}\right) \cdot Z_{g d}}{Z_{e q}+Z_{1-12}+Z_{g d}}
$$


Então, a corrente de falta é dada por:

$$
I_{f}=\frac{V_{f}}{Z_{t h}}
$$

\subsubsection{Análise de faltas usando a matriz impedância de barras}

A análise de curto-circuito é facilitada com o uso da matriz $Z$, principalmente em sistemas de grande porte. Essa matriz contém as impedâncias de Thévenin na sua diagonal principal (impedâncias próprias dos nós) e as impedâncias de transferência para cada barra.

\subsubsection{Matriz impedância de barras antes da inserção do GD}

Antes de inserir o GD no sistema, a rede elétrica é radial e o processo para construção da $Z$ é simples. $O$ primeiro elemento a ser adicionado na $Z$ é a impedância ligada à referência do sistema, formando uma matriz $1 x 1$ e adicionando a barra de número 1 à referência. Daí em diante, basta adicionar uma nova barra $p$ à uma barra $k$ já adicionada no sistema. A cada barra incorporada, é adicionada uma nova linha e uma nova coluna, e a matriz $Z_{b a r r a}$ é atualizada conforme a Equação 3.8 .

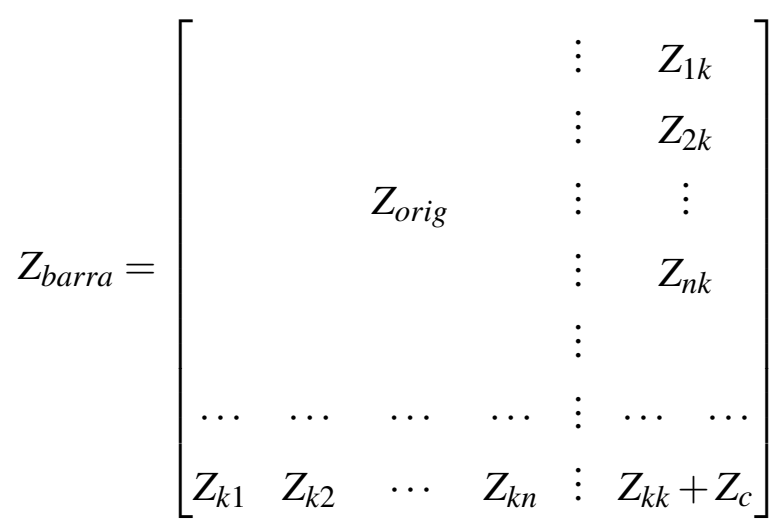

Dessa forma, se estiver sendo adicionado um trecho com impedância $Z_{c}$, o valor do elemento $Z_{p, p}$ será igual a $Z_{k, k}+Z_{c}$, ou seja, para cada nova barra $p$ adicionada, o elemento $Z_{p, p}$ sempre corresponderá ao valor da impedância de Thévenin vista naquele ponto. A nova linha $p$ adicionada na matriz é exatamente a mesma linha $k$, correspondente à barra na qual foi conectada o novo trecho. Analogamente, a nova coluna $p$ de $Z$ é a mesma coluna $k$.

A Figura 8 ilustra o diagrama de impedâncias do equivalente monofásico do sistema, durante uma falta trifásica franca ocorrendo na barra 7. Algumas impedâncias foram unidas para simplificar o diagrama. Vale frisar que como não está sendo considerado o efeito da corrente de carga na falta, não aparece no circuito a fonte que representa a alimentação vinda da subtransmissão, assim como no exemplo da Figura 6. 
Figura 8 - Diagrama de impedâncias do sistema europeu de 15 barras e de média tensão modificado.

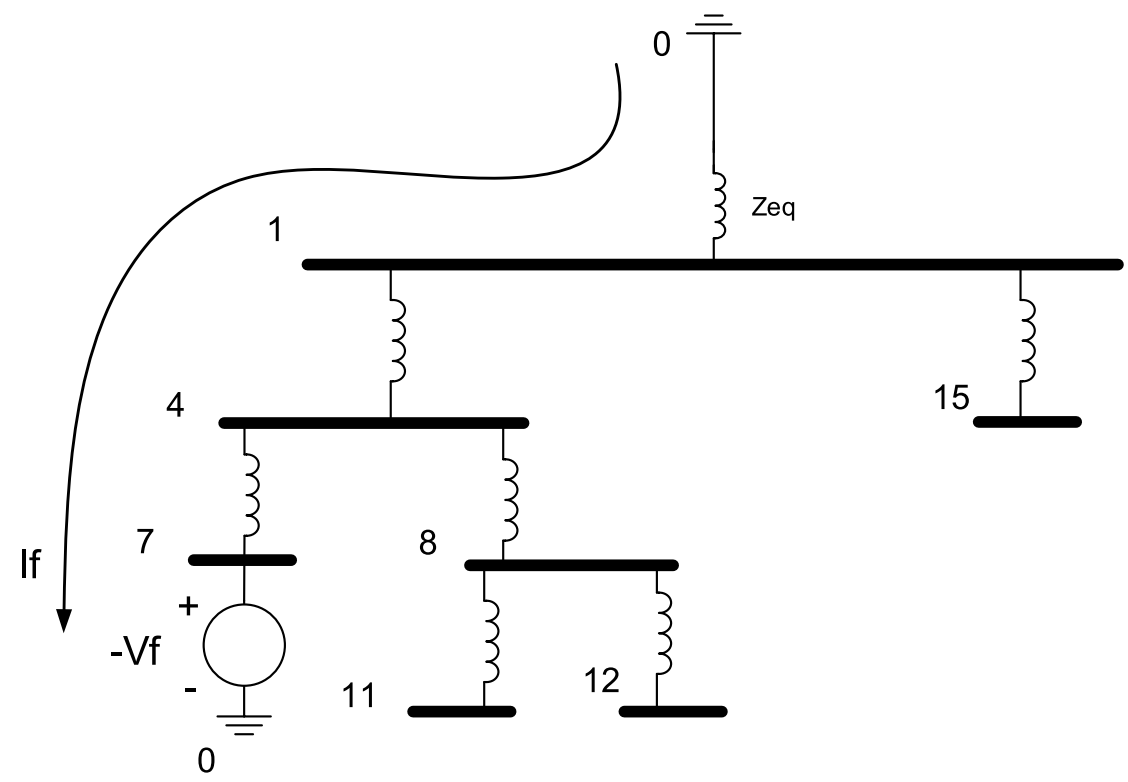

Fonte: $\mathrm{O}$ autor.

Assim, o valor da corrente de falta é dado por:

$$
I_{f}=\frac{V_{f}}{Z_{7,7}}
$$

As impedâncias de transferência de $Z$ permitem calcular o valor de tensão em qualquer barra do sistema devido ao gerador $-V_{f}$. Considerando que a tensão pré-falta na barra 7 é igual a 1 p.u., a tensão na barra 4, por exemplo, é dada por:

$$
\Delta V_{4}=-\frac{Z_{4,7}}{Z_{7,7}}
$$

A tensão na barra 4 antes da ocorrência da falta é a que existe quando $V_{f}$ e $V_{e q}$ estão no circuito, e $-V_{f}$ está curto-circuitado. Portanto, pelo princípio da superposição, a tensão na barra 4 é a soma dos efeitos antes e durante a ocorrência da falta. Como está sendo considerado o sistema operando à vazio antes da falta (tensão na barra 4 igual a 1 p.u.), a tensão na barra 4 após a ocorrência da falta é dada por:

$$
V_{4}=1+\Delta V_{4}=1-\frac{Z_{4,7}}{Z_{7,7}}
$$

De forma geral, a tensão em qualquer barra $m$ devido à uma falta na barra $k$ é fornecida pela Equação 3.12.

$$
V_{m}=1-\frac{Z_{m, k}}{Z_{k, k}}
$$


Quando se tem uma rede elétrica radial as impedâncias de transferência de $Z$ possuem um significado físico no circuito. De fato, $Z_{4,7}$ contém o valor, que ao ser multiplicado por $I_{f}$, fornece a queda de tensão desde a referência (barra 0) até a barra 4 . Seu valor é igual à impedância de Thévenin vista da barra 4 , ou seja, $Z_{4,4}$. Pelo circuito da Figura 8, como não circula corrente a partir da barra 8 , as tensões nas barras 8,11 e 12 são iguais à da barra 4 . Portanto, $Z_{8,7}=Z_{11,7}=Z_{12,7}=Z_{4,7}$.

\subsubsection{Matriz impedância de barras após a inserção do GD}

A matriz $Z$ deve ser modificada adequadamente para incorporar o efeito do GD inserido no sistema. A partir do exemplo da Figura 6, percebe-se que o GD deve ser considerado no circuito com sua impedância equivalente $Z_{g d}$ conectada da barra 12 à referência, ou seja, uma conexão de impedância entre duas barras já existentes. Isso é diferente do procedimento que vinha sendo executado, que era adicionar uma nova barra $p$ à uma barra $k$ já existente.

Sendo assim, primeiramente, adiciona-se a impedância $Z_{g d}$ à uma nova barra fictícia $p$, alterando a matriz $Z$ por meio do procedimento até então utilizado. Em seguida, curto-circuita-se a barra $p$ à referência, fazendo então $V_{p}$ igual a zero. Como ao término das alterações não foi adicionada nenhuma nova barra no sistema, a matriz $Z$ deve manter seu tamanho (15x15).

Segundo (KRON, 1951), é possível reduzir as linhas/colunas de barras nas quais não existe fluxo de corrente entrando ou saindo para a rede. Dessa forma, o nó fictício que foi criado pode ser eliminado via álgebra de redução de matrizes, ou seja, pode-se eliminar a linha e a coluna 16 da matriz $Z$. Cada elemento $h i$ da nova $Z_{(15 x 15)}$ pode ser calculado por meio da expressão:

$$
Z_{\text {nova }}=\text { Zorig }_{h i}-\frac{Z_{h p} \cdot Z_{p i}}{Z_{p p}}
$$

O procedimento descrito foi apresentado em (GRAINGER; STEVENSON JR., 1994, p. 196), com o objetivo de se incluir geradores de grande porte em sistemas de transmissão. Neste trabalho, tal procedimento foi utilizado para incluir o GD, visto que se considera a geração a partir de um mesmo tipo de máquina elétrica (síncrona).

A mesma situação de falta analisada na barra 7 agora é analisada com a presença do gerador distribuído (Figura 9). Percebe-se que agora o fluxo de potência do sistema já não é mais unidirecional, pois a impedância do GD forma uma malha pela terra com a barra da subestação. Isso significa que ao aplicar a mesma falta na barra 7 , a corrente vinda do gerador $-V_{f}$ terá dois caminhos no circuito $\left(I_{1}\right.$ e $\left.I_{2}\right)$, e a corrente de falta será a soma das duas.

O valor de $I_{f}$ ainda pode ser calculado por (3.7), sendo que nesse caso a impedância de Thévenin no ponto de falta não será apenas uma associação em série de impedâncias. Pode ser demonstrado que a redução de Kron recalcula os elementos de $Z$ de tal forma com que as impedâncias da diagonal ainda representam o equivalente de Thévenin no ponto dado. 
Figura 9 - Diagrama de impedâncias do sistema de 15 barras europeu de média tensão modificado após a inserção do GD.

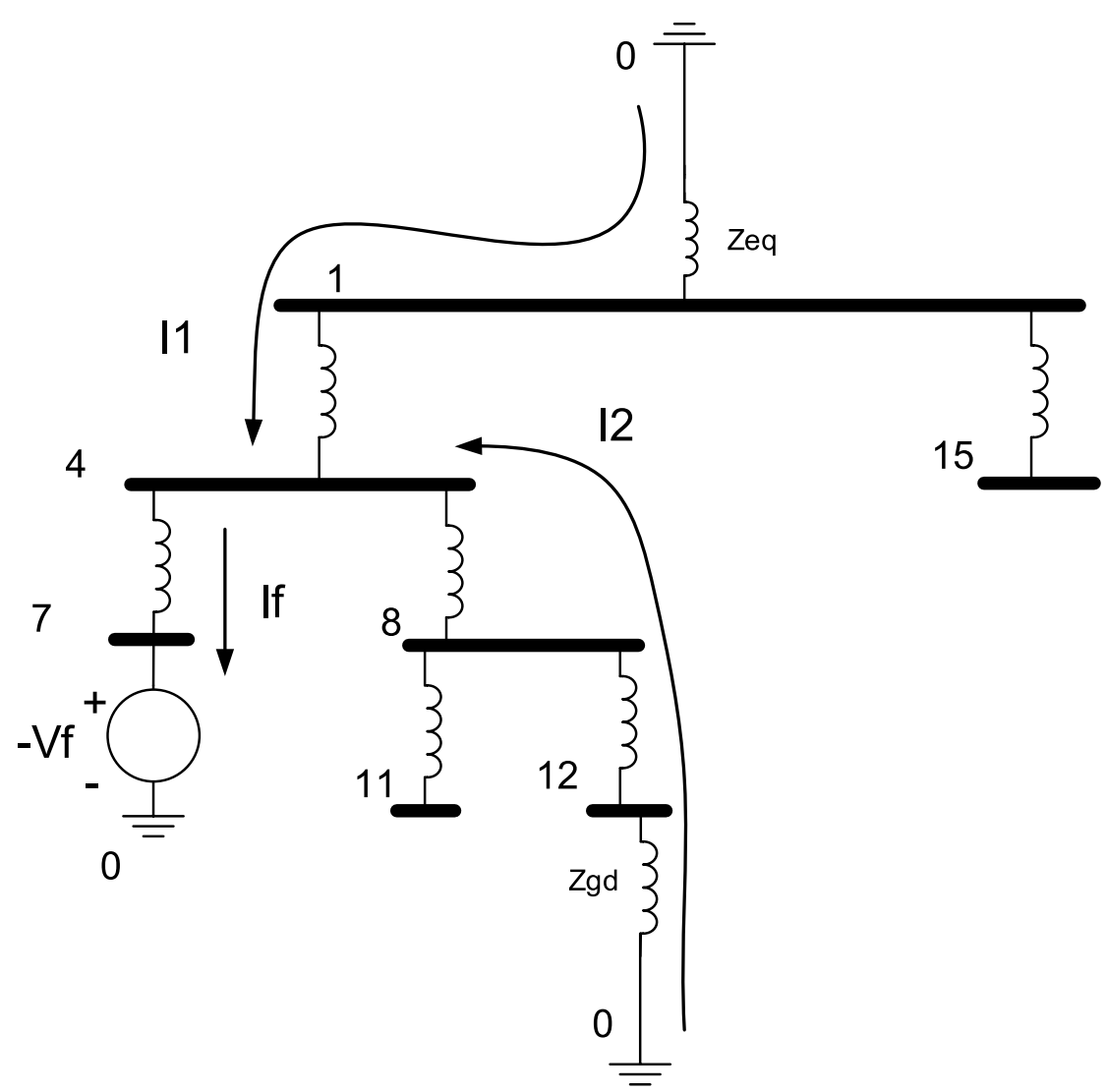

Fonte: $\mathrm{O}$ autor.

Considerando a matriz $Z_{(16 \times 16)}$, ou seja, após a inserção da impedância $Z_{g d}$ e antes da eliminação de Kron, o equivalente do circuito visto da barra 7 é dado pela combinação em série da impedância entre 4 e 7 com a associação em paralelo de 4 a 0 :

$$
\begin{aligned}
& Z_{t h}=\left(Z_{7,7}-Z_{4,4}\right)+\frac{Z_{4,4} \cdot\left(Z_{16,16}-Z_{4,4}\right)}{Z_{4,4}+\left(Z_{16,16}-Z_{4,4}\right)} \\
& Z_{t h}=Z_{7,7}-Z_{4,4}+\frac{Z_{4,4} \cdot Z_{16,16}-Z_{4,4} \cdot Z_{4,4}}{Z_{16,16}} \\
& Z_{t h}=Z_{7,7}-\frac{Z_{4,4} \cdot Z_{4,4}}{Z_{16,16}} \\
& Z_{t h}=Z_{7,7}-\frac{Z_{7,16} \cdot Z_{16,7}}{Z_{16,16}}
\end{aligned}
$$

A Expressão (3.17) é exatamente a aplicação da redução de Kron (Expressão (3.13)) para a obtenção do elemento $Z(7,7)$ da matriz, confirmando a validade do uso da matriz $Z$ para o cálculo de faltas mesmo com a inserção de um GD no sistema.

Embora as impedâncias próprias da $Z$ ainda mantenham seu significado físico, já não é mais possível obter um circuito passivo que represente cada impedância de transferência da 
$Z$. No entanto, seus valores devem ser interpretados como uma impedância equivalente tal que multiplicada pela corrente total $I_{f}$ represente a queda de tensão durante a falta.

Como exemplo, é mostrado o cálculo da variação de tensão na barra 9, devido à falta na barra 7. Primeiramente, deve ser calculado o valor de $I_{2}$, o qual pode ser obtido pelo divisor de correntes, como:

$$
I_{2}=\frac{Z_{4,4}^{1}}{Z_{16,16}-Z_{4,4}} \cdot I_{f}=\frac{Z_{4,4}^{1}}{Z_{16,16}-Z_{4,4}} \cdot \frac{1}{Z_{7,7}^{1}}
$$

Onde $Z_{4,4}^{1}$ e $Z_{7,7}^{1}$ representam elementos da matriz $Z$ após a redução de Kron. A Expressão (3.19) fornece o valor da variação de tensão na barra 9:

$$
\Delta V_{9}=I_{2} \cdot\left(Z_{16,16}-Z_{9,9}\right)=\frac{Z_{4,4}^{1}}{Z_{7,7}^{1}} \cdot \frac{Z_{16,16}-Z_{9,9}}{Z_{16,16}-Z_{4,4}}
$$

A partir da Expressão (3.19) pode ser encontrado o valor de $Z_{7,9}^{1}$. A Expressão (3.20) evidencia esse processo.

$$
\Delta V_{9}=Z_{4,4}^{1} \cdot \frac{Z_{16,16}-Z_{9,9}}{Z_{16,16}-Z_{4,4}} \cdot I_{f}
$$

Então, a impedância de transferência $Z_{7,9}^{1}$ é dada por:

$$
\begin{aligned}
& Z_{7,9}^{1}=\frac{Z_{4,4} \cdot Z_{16,16}-Z_{4,16} \cdot Z_{16,4}}{Z_{16,16}} \cdot \frac{Z_{16,16}-Z_{9,9}}{Z_{16,16}-Z_{4,4}} \\
& Z_{7,9}^{1}=\frac{Z_{4,4} \cdot Z_{16,16} \cdot Z_{16,16}-Z_{4,4} \cdot Z_{9,9} \cdot Z_{16,16}-Z_{4,16} \cdot Z_{16,4} \cdot Z_{16,16}+Z_{9,9} \cdot Z_{4,16} \cdot Z_{16,4}}{Z_{16,16} \cdot\left(Z_{16,16}-Z_{4,4}\right)} \\
& Z_{7,9}^{1}=\frac{Z_{4,4} \cdot Z_{16,16} \cdot Z_{16,16}-Z_{4,4} \cdot Z_{9,9} \cdot Z_{16,16}-Z_{4,4} \cdot Z_{4,4} \cdot Z_{16,16}+Z_{4,4} \cdot Z_{4,4} \cdot Z_{9,9}}{Z_{16,16} \cdot\left(Z_{16,16}-Z_{4,4}\right)} \\
& Z_{7,9}^{1}=\frac{Z_{4,4} \cdot Z_{16,16} \cdot\left(Z_{16,16}-Z_{4,4}\right)-Z_{4,4} \cdot Z_{9,9} \cdot\left(Z_{16,16}-Z_{4,4}\right)}{Z_{16,16} \cdot\left(Z_{16,16}-Z_{4,4}\right)} \\
& Z_{7,9}^{1}=Z_{4,4}-\frac{Z_{4,4} \cdot Z_{9,9}}{Z_{16,16}} \\
& Z_{7,9}^{1}=Z_{7,9}-\frac{Z_{7,16} \cdot Z_{16,9}}{Z_{16,16}}
\end{aligned}
$$

Assim como no exemplo de cálculo da impedância própria $Z_{7,7}^{1}$, foi mostrado que o valor da impedância de transferência $Z_{7,9}^{1}$ é fornecido corretamente pela redução de Kron.

Com base nessa análise, conclui-se que a expressão geral (3.12) ainda continua válida considerando o GD, e o cálculo das tensões durante a falta pode ser realizado diretamente da matriz Z. 


\subsection{Passo 3: Obtenção das matrizes de tensão durante a falta}

Uma forma de avaliar a melhor disposição dos PQMs com o objetivo de detectar afundamentos de tensão é submeter o sistema teste a diversas situações de curto-circuito, assim como proposto por Olguin, Vuinovich e Bollen (2006). Dessa maneira é possível identificar as áreas de alcance dos PQMs em cada posição do sistema de distribuição, e arranjá-los da melhor forma possível seguindo um determinado critério.

Diversos métodos foram utilizados na literatura para escolher esse conjunto de situações de falta. Olguin, Vuinovich e Bollen (2006) utilizaram o método das posições de falta (Method of Fault Positions), obtendo uma matriz quadrada que os autores denominaram dip-matrix, também chamada de Matriz de Tensão Durante a Falta (MTDF) (KEMPNER, 2016). Essa matriz relaciona as tensões remanescentes em todas as barras devidas a cada curto-circuito simulado também em todas as barras do sistema. Vale lembrar que, em casos de curtos-circuitos trifásicos, as tensões remanescentes para as 3 fases do sistema são iguais, bastando se referir a uma única MTDF. No entanto, ao simular faltas desequilibradas, devem ser consideradas três MTDFs, uma para cada fase, visto que nesses casos as tensões remanescentes não serão iguais para as três fases.

Neste trabalho essas matrizes são chamadas de $M T D F^{A}, M T D F^{B}$ e $M T D F^{C}$, com o objetivo de diferenciá-las, visto que foram analisados também casos de faltas desequilibradas. Tanto para os casos envolvendo uma das fases e a terra, quanto para os casos envolvendo duas fases com ou sem a terra, é necessário obter além de $Z_{1}$, também $Z_{2}$ e $Z_{0}$.

Olguin, Vuinovich e Bollen (2006) e Kempner, Oleskovicz e Gomes (2017) levaram em consideração apenas as barras como pontos de aplicação das faltas. Nesta pesquisa decidiu-se não limitar as situações de falta apenas às barras, visto que podem existir muitos casos de múltipla estimação de falta devido à faltas ocorrendo nas linhas. Em razão de se abordar faltas ocorrendo nas linhas, optou-se por não utilizar o método das posições de falta, visto que ele não inclui esses pontos de falta. Além disso, ele não inclui todos os tipos de falta. Por exemplo, para faltas monofásicas, considera-se apenas a que envolve a fase $A$ com a terra $(A T)$. Portanto, nesta pesquisa $M T D F^{A}, M T D F^{B}$ e $M T D F^{C}$ foram obtidas aplicando uma condição de falta por vez, utilizando as equações clássicas para calcular as tensões remanescentes em cada barra. Para o caso de faltas trifásicas (simétricas), a forma de calcular as tensões durante a falta já foi descrita na seção 3.2. A análise de faltas assimétricas foi feita utilizando a teoria de Fortescue (FORTESCUE, 1918) para decompor os fasores assimétricos em componentes simétricos, calculando as tensões de sequência, e retornando-as para o domínio $A B C$. Maiores detalhes sobre o equacionamento podem ser encontrados no Apêndice A. Embora tenha sido utilizado o método de componentes simétricas para o cálculo das tensões durante a falta, quaisquer outros métodos capazes de calcular essas tensões poderiam ser aplicados, como por exemplo o método descrito 
em (KERSTING, 2002, p. 290).

Para simular uma determinada falta em um ponto ao longo de uma linha utilizando a abordagem das matrizes de impedância de barras, é necessário adicionar uma barra fictícia no ponto de aplicação da falta, substituir a linha por dois trechos conectando a barra fictícia, e reconstruir $Z_{1}, Z_{2}$ e $Z_{0}$ para o cálculo das tensões. Contudo, reconstruir essas matrizes toda vez que for simulado um curto-circuito em um ponto diferente pode ser custoso computacionalmente para sistemas de grande porte. Por isso, foi utilizada a abordagem descrita em (ESPINOSAJUAREZ; HERNANDEZ; OLGUIN, 2009) para simulação de curtos-circuitos nas linhas de um sistema. Essa abordagem calcula as impedâncias próprias e de transferência de $Z_{1}, Z_{2}$ e $Z_{0}$ no ponto de falta em termos dos elementos originais dessas matrizes. Dessa forma, elas são construídas uma única vez, sendo necessário apenas recalcular os termos de interesse para uma determinada situação de falta.

\subsubsection{Definição do passo de aplicação das faltas}

Dado que não se utilizou um método direto para gerar todo o conjunto de condições de faltas (como o método das posições de falta), foi preciso definir uma metodologia para construir um banco de dados representativo, dispondo das ferramentas para cálculo de curtos-circuitos. Vale frisar que esse conjunto de faltas deve representar bem o problema abordado, ou seja, incluir casos de afundamentos de tensão, bem como casos de falta onde um localizador poderia enfrentar problemas de múltipla estimação do local da falta. Portanto, definiu-se a simulação de situações de falta ao longo de todas as linhas do sistema uniformemente distribuídas de acordo com um passo fixo de aplicação das faltas.

Esse passo precisa ser definido de forma que não seja muito grande, a ponto de se excluir casos importantes de múltipla estimação, e nem muito pequeno, para que não seja gerado uma quantidade excessiva e redundante de dados. Nesta pesquisa esse passo foi definido com base no problema da múltipla estimação de faltas, visto que a alocação de PQMs vem a ser direcionada para este problema.

$\mathrm{Na}$ prática, quando se tem um curto-circuito permanente, interrompendo o fornecimento da energia a uma dada região, é necessário que a concessionária envie uma equipe em campo para encontrar o local de defeito e efetuar os reparos para que se restabeleça o fornecimento. Dispondo de um localizador de faltas baseado em impedância, o qual está instalado na subestação, a equipe de manutenção conhece a que distância está o curto-circuito, e vai percorrendo esta distância a fim de encontrar o ponto de falta. No entanto, ao encontrar um ponto de bifurcação na rede elétrica, a equipe precisa decidir qual caminho tomar (múltipla estimação). Havendo dois caminhos disponíveis, pode ser que a equipe escolha o caminho onde não existe falta. Neste caso, ela terá que percorrer toda a distância até o suposto ponto de falta, e, não o encontrando, retornar ao ponto da bifurcação, e tomar o segundo caminho para então encontrar o ponto real de falta. Dessa forma a equipe irá percorrer 3 vezes a distância da bifurcação até o ponto de 
falta. Pensando sempre no pior caso (caminho errado), para uma falta localizada a uma distância (elétrica) da bifurcação equivalente a um terço do menor trecho, a equipe terá que percorrer uma distância equivalente a um comprimento de um trecho do sistema elétrico para encontrar a falta, sendo esta uma distância considerável. Portanto, nesta pesquisa o passo foi definido como um terço do comprimento (impedância) do menor trecho existente em todo o sistema de distribuição. Entende-se que uma distância menor que esta irá definir situações de falta muito próximas do ponto da bifurcação, que apesar de configurar um caso de múltipla estimação, na prática não oferece grandes dificuldades para a equipe localizar em campo o ponto de defeito. Os casos mais críticos de múltipla estimação são os que ocorrem nos finais dos ramais, aos quais deve ser dada maior atenção. Devido à possibilidade de existência de linhas não-homogêneas, neste trabalho foi tomada a distância elétrica (em $\Omega$ ) e não física $(\mathrm{em} \mathrm{Km})$, deixando a metodologia independente do tipo de configuração dos cabos de cada trecho do sistema.

\subsubsection{Exemplo de conjunto de dados para as faltas trifásicas}

O sistema do CIGRÉ de 15 barras, apresentado na Figura 3, foi redesenhado para evidenciar as proporções reais entre os comprimentos de todos os trechos do sistema. Para essa rede, o trecho com menor comprimento é a linha entre as barras 8 e 9 . Portanto, o passo de simulação das faltas foi definido com base nele, equivalendo a $1 / 3$ da impedância entre essas duas barras. A Figura 10 apresenta esse sistema redesenhado onde foram traçados em vermelho os pontos para a aplicação das situações de falta seguindo esse procedimento.

Foram simulados curtos-circuitos na barra da subestação (barra 1) e nas barras que correspondem aos secundários dos dois transformadores a partir dos quais derivam-se os dois alimentadores desse sistema. Então, tomando cada alimentador por vez, as faltas foram aplicadas seguindo uma sequência de busca em profundidade, motivo pelo qual as barras do sistema original foram renumeradas, para que a sequência de aplicação das faltas seguisse a ordem crescente e natural dos números das barras.

Na Figura 10 foi dado um zoom em uma região onde acontece a troca entre trechos nos quais estão sendo aplicadas as faltas, com o objetivo de evidenciar a uniformidade dos pontos ao longo do sistema. O que varia para cada trecho é apenas a porcentagem de aplicação das faltas, visto que esta é calculada com base no comprimento de cada trecho. Dessa forma, olhando para a porcentagem de aplicação das faltas, ela é maior para os menores trechos, por exemplo.

Outro ponto de destaque é o tratamento dado em pontos de bifurcação. Para esses casos de troca de trecho, mantendo o passo de aplicação, pode ocorrer a situação em que a primeira falta a ser aplicada no novo trecho esteja muito próxima da barra de bifurcação. Portanto, para essas situações específicas não se aplica falta na barra de bifurcação e conta-se um passo para se aplicar a primeira falta no novo trecho. Uma ressalva sobre esse tratamento é que uma barra só é considerada um ponto de bifurcação caso existe mais de um ramal à jusante dela onde exista a possibilidade de aplicação do tipo de falta em análise. 
Figura 10 - Conjunto de pontos de faltas definidos por meio da metodologia proposta.

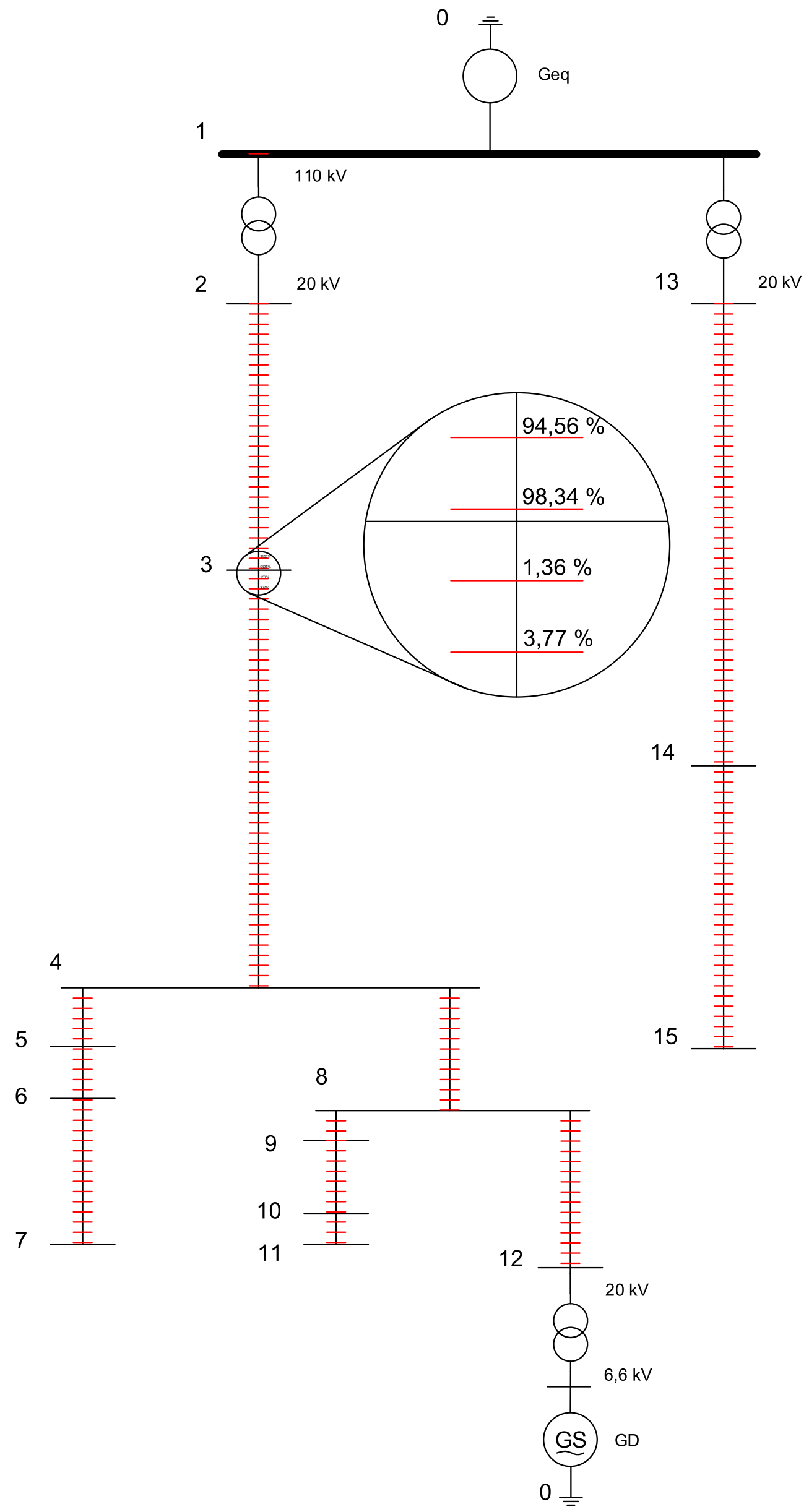

Fonte: Elaborada pelo autor. 
Por exemplo, no caso de aplicação de faltas monofásicas fase C-terra $(C T)$, uma barra na qual derivam dois ramais, sendo um deles trifásico e o outro contendo apenas a fase $A$, não é considerada um ponto de bifurcação no sistema, visto que não serão simuladas faltas $C T$ ao longo do ramal que contém somente a fase $A$.

Seguindo esta metodologia é possível construir um conjunto de dados para qualquer sistema, sem precisar definir novamente uma metodologia específica para cada novo sistema que se for analisar. A metodologia proposta nesta pesquisa é simples e se adequa à qualquer sistema de distribuição, bastando conhecer o menor trecho do mesmo. Para o sistema do CIGRÉ, por exemplo, esta metodologia resulta em um conjunto com 187 situações de falta.

O conjunto de dados de tensões durante a falta pode ser expresso em uma MTDF, considerando que as linhas da matriz indicam onde a situação de falta foi aplicada, e as colunas as barras onde estão sendo medidas as tensões. A Figura 11 representa através de uma matriz em escala de cores todas as tensões remanescentes medidas para cada falta simulada. A cor de cada elemento da MTDF está associada a um valor entre 0 e 1 p.u., representado pela barra vertical ao lado direito da matriz. As cores variam do preto até o branco, passando por cores quentes intermediárias. Assim, quanto mais escura for a cor, mais próximo de 0 p.u. é o valor da tensão remanescente (residual), e quanto mais clara, mais próximo de 1 p.u..

Cada linha da MTDF representa uma situação de falta aplicada (simulada) e, para cada uma delas, as tensões durante a falta são medidas nas barras de 1 a 15. Por exemplo, uma falta simulada na subestação (barra 1) leva a tensão a zero em todas as barras do sistema. Uma falta simulada na barra 13 (situação de falta 134) apenas zera as tensões nas barras 13, 14 e 15; visto que essas barras pertencem ao segundo alimentador que parte da subestação. As tensões nas barras que derivam do primeiro alimentador permanecem quase em 1 p.u., tendo apenas a queda de tensão na impedância $Z_{e q}$. Da mesma forma, as faltas aplicadas em barras do primeiro alimentador influenciam muito pouco a tensão nas barras do segundo alimentador. De fato, nesse caso, as tensões nas barras 13, 14 e 15 serão sempre iguais à tensão vista na barra 1 (colunas 1 , 13, 14 e 15 da MTDF).

A Figura 12 mostra a MTDF com o GD conectado ao sistema de fornecimento principal. Observa-se que os valores de tensão eficaz em alguns pontos do sistema são mais elevados, comparados aos do caso anterior à conexão do GD (Figura 11).

A razão para esse comportamento observado é o fato de se criar novos caminhos para a corrente de falta, o que foi explorado na subseção 3.2.2. Para o exemplo da falta na barra 7 (Figura 9), existe um aumento na tensão das barras que derivam da barra 8 (barras 8 a 11), comparando com o caso sem GD. Isso acontece porque a tensão nessas barras é dada por 1 p.u. menos a queda de tensão pela corrente $I_{2}$. Observando que essa corrente é menor do que $I_{f}$, a queda de tensão é relativamente pequena, e a tensão remanescente fica em um valor mais próximo da tensão de pré-falta. 
Figura 11 - MTDF resultante para o sistema de 15 barras durante a ocorrência de faltas trifásicas francas sem o GD.

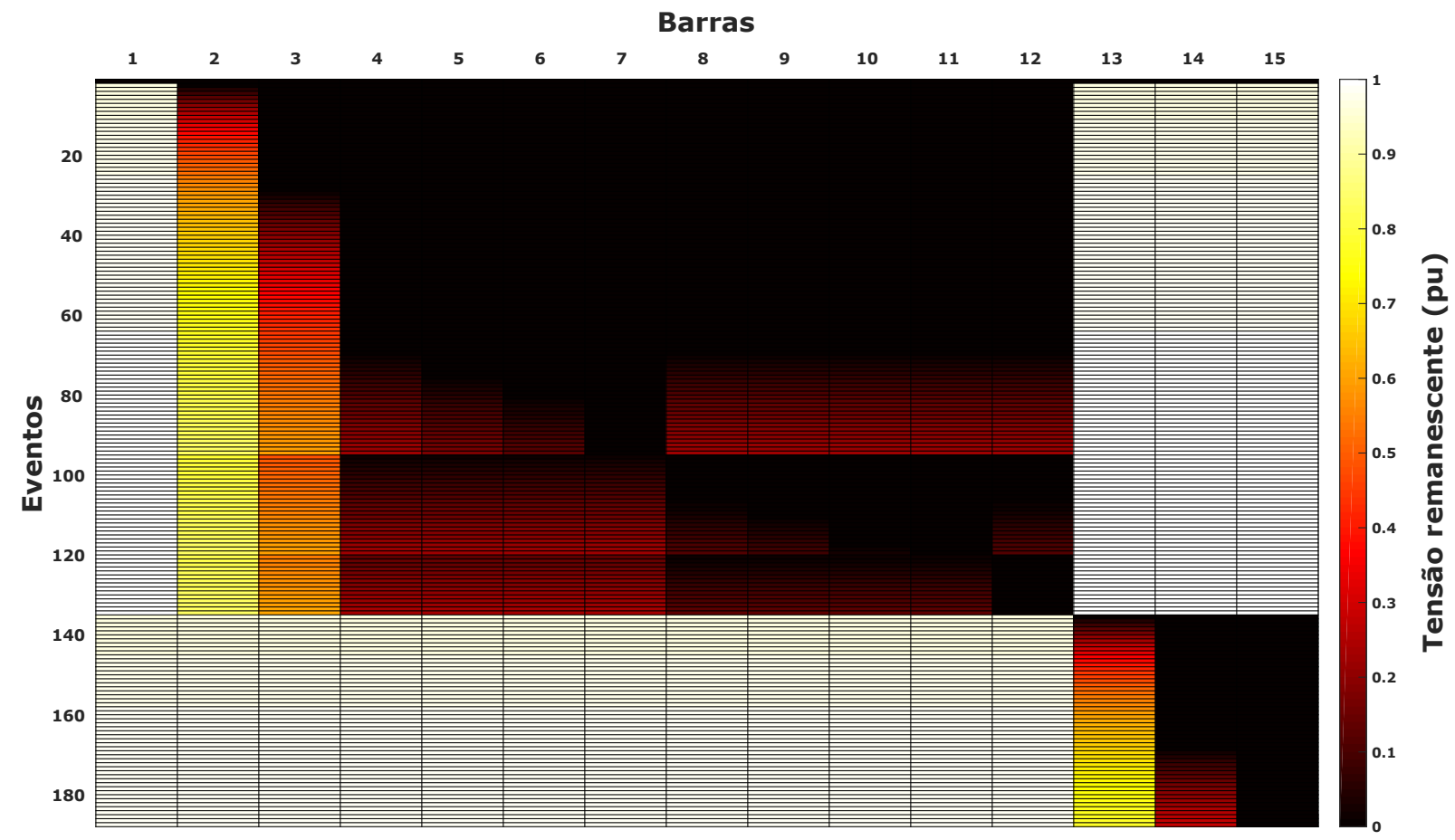

Fonte: Elaborada pelo autor.

Figura 12 - MTDF resultante para o sistema de 15 barras durante a ocorrência de faltas trifásicas francas com o GD.

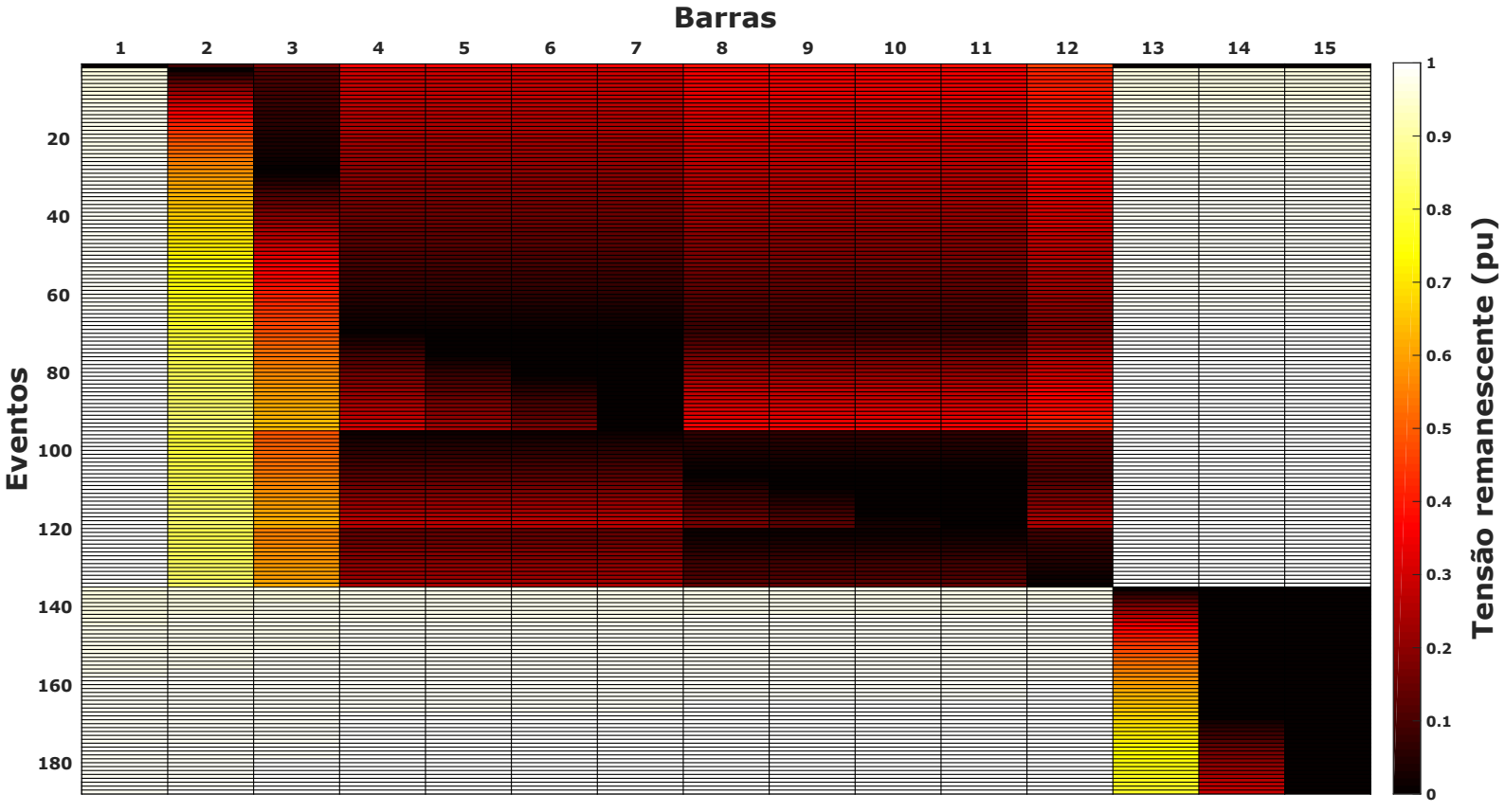

Fonte: Elaborada pelo autor.

Uma outra observação importante é que com a inserção do GD, uma falta na subestação já não leva a tensão a zero no restante do sistema. As únicas tensões em zero são as correspondentes 
às barras do segundo alimentador. As demais são diferentes de zero. Isso acontece porque a impedância de Thévenin na barra 1 se resume a uma associação em paralelo de um trecho muito longo do sistema com $Z_{e q}$. Como $Z_{e q}$ é uma impedância muito pequena, a corrente de falta se divide passando sua maior parte por essa impedância. Portanto, as quedas de tensão no outro ramo enxergam uma corrente muito pequena, o que justifica essas tensões mais altas.

As MTDFs para os outros tipos de falta aplicados no sistema de 15 barras são apresentadas no Apêndice B. Diferentemente do caso de faltas trifásicas, os outros tipos de falta são faltas desequilibradas. Portanto, no Apêndice B, são apresentadas 3 MTDFs para cada tipo de falta, visto que as tensões remanescentes não são iguais para esses tipos de falta.

\subsection{Passo 4: Modelagem do problema de otimização}

Nesta etapa a matriz (ou as matrizes) MTDF é utilizada para se extrair os parâmetros necessários para se obter o modelo de otimização e resolver o problema de alocação de PQMs.

Esta seção está dividida em duas subseções. A primeira aborda o modelo que visa à minimização da quantidade de PQMs, restrito à observabilidade total do sistema (abordagem clássica) (OLGUIN; VUINOVICH; BOLLEN, 2006). Já a segunda engloba o equacionamento considerando uma alocação voltada para o problema da localização de faltas (MARTINS et al., in press).

\subsubsection{Modelo clássico idealizado para sistemas de transmissão: Mo- delo 1}

Para chegar ao modelo de otimização para o monitoramento de afundamentos de tensão, deve-se definir um limiar de ativação para o PQM começar a registrar o afundamento de tensão.

Então, a partir da MTDF é possível definir uma matriz binária que irá guardar a informação de observabilidade de todos os afundamentos de tensão vistos por cada barra do sistema. Essa matriz, conhecida por MRA (OLGUIN; VUINOVICH; BOLLEN, 2006), ou Matriz de Observabilidade (MO) (ALMEIDA; KAGAN, 2010) possui cada elemento definido de acordo com a Equação (3.27):

$$
m o(i, j) \equiv \begin{cases}1, & \text { caso } m t d f(i, j) \leq \tau \\ 0, & \text { caso contrário }\end{cases}
$$

Sendo $\tau$ uma constante que representa o valor do limiar de tensão definido entre $0,1 \mathrm{e}$ 0,9 p.u. para o PQM começar a registrar o afundamento de tensão.

As Figuras 13 e 14 mostram as MOs para o exemplo de 15 barras antes da conexão do GD, e após a conexão do GD, respectivamente. Foi considerado um valor de $\tau=0,6$ p.u. para a construção dessas matrizes. 
Figura 13 - MO para o sistema de 15 barras com um valor de $\tau=0,6$ p.u. sem o GD.

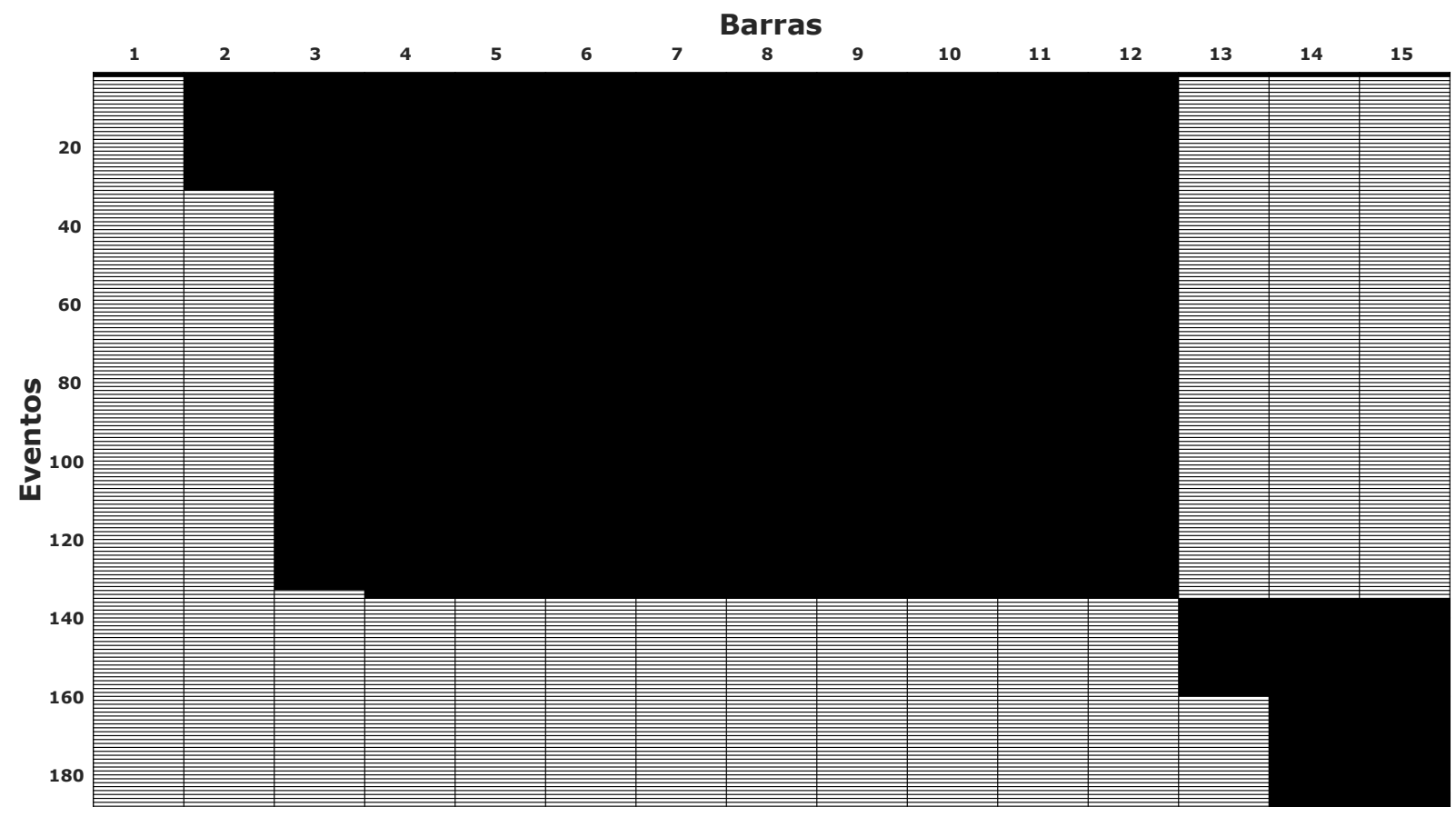

Fonte: Elaborada pelo autor.

Figura 14 - MO para o sistema de 15 barras com um valor de $\tau=0,6$ p.u. com o GD.

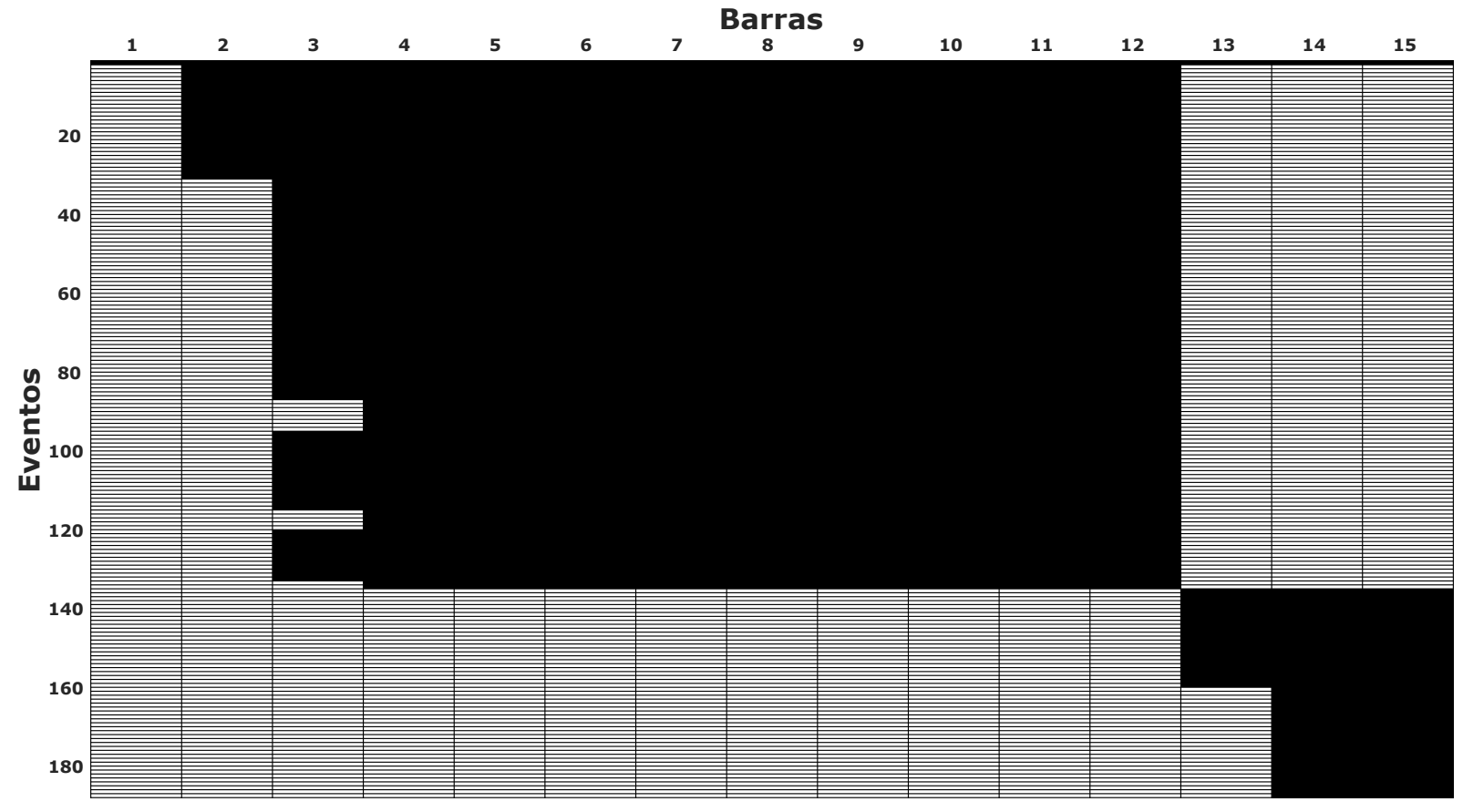

Fonte: Elaborada pelo autor.

Nessas figuras os elementos em preto representam as condições de falta aplicadas e que produziram afundamentos registrados por algum PQM com um limiar de tensão menor ou igual 
ao valor de 0,6 p.u. pré-fixado.

A variável de decisão que representa a decisão de instalar um PQM em determinada barra é dada pela Equação (3.28):

$$
x(j) \equiv \begin{cases}1, & \text { caso se deseje instalar um PQM na barra } j \in N \\ 0, & \text { caso contrário }\end{cases}
$$

Sendo $N$ o conjunto de barras candidatas à instalação de PQMs. Para o exemplo dado, esse conjunto possui cardinalidade 15 . No modelo clássico, o objetivo é minimizar a quantidade de PQMs necessários (custo), ou seja, minimizar a soma do vetor $X$, assim como mostra a Equação (3.29).

A restrição do modelo visa garantir que todas as condições de falta sejam observadas por pelo menos um PQM. Isto é representado matematicamente analisando os produtos $m o(i, j) \cdot x(j)$ e certificando que pelo menos um deles seja igual a "1"(3.30). O modelo clássico completo é dado por (3.29)-(3.31).

$$
\begin{array}{ccc} 
& \min \sum_{j \in N} x(j) & \\
\text { sujeito a: } & \sum_{j \in N} m o(i, j) \cdot x(j) \geq 1 & \forall i \in E \\
x(j) \in\{0,1\} & \forall j \in N
\end{array}
$$

Nas equações, $E$ é o conjunto de todos os eventos simulados, ou seja, cada linha da MO. A restrição (3.31) é uma restrição de conjunto, que visa garantir que as variáveis de decisão assumam apenas valores binários. Como a Equação (3.29) é linear, assim como a restrição (3.30), este é um problema de otimização classificado como de PLI.

\subsubsection{Ajuste no modelo clássico para sistemas de distribuição com linhas monofásicas e bifásicas}

O modelo definido por (3.29)-(3.31) responde bem no exemplo de 15 barras, pois este sistema é trifásico em toda a sua extensão. Em sistemas de distribuição onde esta situação não é verdade, que possuem ramais com somente a fase $A$, por exemplo, este modelo deve ser ajustado, para considerar duas questões em específico. A primeira diz respeito à medição de tensão em todas as fases dada uma certa situação de falta. Em ramais que possuem apenas a fase $A$, existirá somente uma medição. No entanto, o cálculo de curto-circuito retorna valores de tensão para as 3 fases, sendo que os valores para as fases $B$ e $C$ não correspondem à realidade do circuito físico. A segunda é que não será possível simular uma falta entre as fases $B$ e $C$, por exemplo, nesses ramais. 
Para corrigir o modelo para estes tipos de redes foram definidos três vetores, que representam a topologia do sistema: $T^{A}, T^{B}$ e $T^{C}$. Todos esses vetores possuem a dimensão do número total de barras do sistema, sendo que cada elemento binário representa a presença ou não da respectiva fase no barramento. Por exemplo, cada elemento do vetor $T^{A}$ é definido de acordo com a Equação (3.32):

$$
t^{A}(j) \equiv \begin{cases}1, & \text { se existe fisicamente a fase A na barra } j \in N \\ 0, & \text { caso contrário }\end{cases}
$$

Analogamente os elementos dos vetores $T^{B}$ e $T^{C}$ são definidos de acordo com (3.33) e (3.34), respectivamente:

$$
\begin{aligned}
& t^{B}(j) \equiv \begin{cases}1, & \text { se existe fisicamente a fase } B \text { na barra } j \in N \\
0, & \text { caso contrário }\end{cases} \\
& t^{C}(j) \equiv \begin{cases}1, & \text { se existe fisicamente a fase } C \text { na barra } j \in N \\
0, & \text { caso contrário }\end{cases}
\end{aligned}
$$

As matrizes de observabilidade das três fases devem ser tratadas separadamente, de forma a avaliar as VTCDs em cada fase. Para que uma determinada VTCD seja considerada passível de ocorrência no SEP é necessário que a tensão residual seja menor que o limiar préfixado $(m o(i, j)=1)$, e a fase na qual esse valor é determinado exista fisicamente no circuito $(t(j)=1)$. Dessa forma, para se avaliar as situações de falta observáveis deve-se checar os produtos $m o^{A}(i, j) \cdot t^{A}(j) \cdot x(j), m o^{B}(i, j) \cdot t^{B}(j) \cdot x(j)$ e $m o^{C}(i, j) \cdot t^{C}(j) \cdot x(j)$. Pelo menos um deles deve ser igual a "1", ou seja, a situação de falta $i$ deve ser observada por pelo menos uma das fases. Isto é representado matematicamente por meio de (3.35), resolvendo o primeiro problema mencionado. Nesse ponto, ao se adicionar na variável $m o(i, j)$ um modificador para designar as fases (A, B ou C), a restrição do modelo é generalizada para qualquer tipo de falta considerado.

$$
\sum_{j \in N} m o^{A}(i, j) \cdot t^{A}(j) \cdot x(j)+m o^{B}(i, j) \cdot t^{B}(j) \cdot x(j)+m o^{C}(i, j) \cdot t^{C}(j) \cdot x(j) \geq 1 \quad \forall i \in E
$$

O segundo problema pode ser resolvido ajustando (3.35) para cada condição de falta $i$. Uma falta trifásica simulada em uma barra que não possui as três fases não representa um caso passível de ocorrência no sistema real. Por isso, não é necessário que ela seja monitorada. Então, é suficiente trocar o "1"por "0"em (3.35). Assim, supondo que a barra 4, por exemplo, não seja trifásica, para $i=4$ teríamos uma inequação da forma: 


$$
\sum_{j \in N} m o^{A}(4, j) \cdot t^{A}(j) \cdot x(j)+m o^{B}(4, j) \cdot t^{B}(j) \cdot x(j)+m o^{C}(4, j) \cdot t^{C}(j) \cdot x(j) \geq 0
$$

Interpretando esta restrição como um conjunto com $i$ inequações, as que corresponderem a situações de falta impossíveis devem ser alteradas. Portanto, este conjunto de inequações seria ora maior que " 1 ", ora maior que " 0 ". Uma forma de generalizar para qualquer falta $i$ é considerar que todas as inequações devem ser maiores que $t^{A}(i) \cdot t^{B}(i) \cdot t^{C}(i)$. Esse produto somente resultará em "1"quando todas as fases estiverem presentes fisicamente na barra faltosa $i$. Se pelo menos uma delas não existir, esse produto será "0", o que consistirá no caso representado por (3.36). Portanto, o modelo mono-objetivo para minimização de medidores, considerando sistemas não totalmente trifásicos é dado por (3.37)-(3.39).

$$
\min \sum_{j \in N} x(j)
$$

sujeito a:

$$
\begin{array}{rlrl}
\sum_{j \in N} x(j) \cdot \sum_{k \in F} m o^{k}(i, j) \cdot t^{k}(j) & \geq t^{A}(i) \cdot t^{B}(i) \cdot t^{C}(i) & & \forall i \in E \\
x(j) & \in\{0,1\} & \forall j \in N
\end{array}
$$

Sendo $F$ o conjunto $\{A, B, C\}$.

\subsubsection{Modelo modificado considerando todos os tipos de falta}

Como nesta pesquisa são considerados outros tipos de falta, além da trifásica, é mostrado nesta subseção como generalizar o modelo para os outros tipos de falta.

Para uma falta monofásica do tipo $A T$ é suficiente verificar se a fase $A$ está presente na barra faltosa. Dessa forma, a restrição de observabilidade deve ser maior que $t^{A}$, como em (3.40).

$$
\sum_{j \in N} x(j) \cdot \sum_{k \in F} m o_{A T}^{k}(i, j) \cdot t^{k}(j) \geq t^{A}(i) \quad \forall i \in E
$$

Nesta restrição foi incluído um subíndice em cada MO para denotar o tipo de falta simulada que resultou nessas matrizes, diferenciando assim os diversos tipos de falta.

Um raciocínio análogo pode ser feito para construir as inequações de observabilidade para os outros tipos de falta. Por exemplo, faltas bifásicas envolvendo as fases $A$ e $C$, sem a conexão com a terra, são modeladas por meio da restrição (3.41).

$$
\sum_{j \in N} x(j) \cdot \sum_{k \in F} m o_{A C}^{k}(i, j) \cdot t^{k}(j) \geq t^{A}(i) \cdot t^{C}(i) \quad \forall i \in E
$$


Portanto, o modelo completo, incluindo todos os tipos de faltas é dado de (3.42) a (3.53).

$$
\min \sum_{j \in N} x_{j}
$$

sujeito a:

$$
\begin{array}{ll}
\sum_{j \in N} x(j) \cdot \sum_{k \in F} m o_{A T}^{k}(i, j) \cdot t^{k}(j) \geq t^{A}(i) & \forall i \in E \\
\sum_{j \in N} x(j) \cdot \sum_{k \in F} m o_{B T}^{k}(i, j) \cdot t^{k}(j) \geq t^{B}(i) & \forall i \in E \\
\sum_{j \in N} x(j) \cdot \sum_{k \in F} m o_{C T}^{k}(i, j) \cdot t^{k}(j) \geq t^{C}(i) & \forall i \in E \\
\sum_{j \in N} x(j) \cdot \sum_{k \in F} m o_{A B}^{k}(i, j) \cdot t^{k}(j) \geq t^{A}(i) \cdot t^{B}(i) & \forall i \in E \\
\sum_{j \in N} x(j) \cdot \sum_{k \in F} m o_{B C}^{k}(i, j) \cdot t^{k}(j) \geq t^{B}(i) \cdot t^{C}(i) & \forall i \in E \\
\sum_{j \in N} x(j) \cdot \sum_{k \in F} m o_{A C}^{k}(i, j) \cdot t^{k}(j) \geq t^{A}(i) \cdot t^{C}(i) & \forall i \in E \\
\sum_{j \in N} x(j) \cdot \sum_{k \in F} m o_{A B T}^{k}(i, j) \cdot t^{k}(j) \geq t^{A}(i) \cdot t^{B}(i) & \forall i \in E \\
\sum_{j \in N} x(j) \cdot \sum_{k \in F} m o_{B C T}^{k}(i, j) \cdot t^{k}(j) \geq t^{B}(i) \cdot t^{C}(i) & \forall i \in E \\
\sum_{j \in N} x(j) \cdot \sum_{k \in F} m o_{A C T}^{k}(i, j) \cdot t^{k}(j) \geq t^{A}(i) \cdot t^{C}(i) & \forall i \in E \\
\sum_{j \in N} x(j) \cdot \sum_{k \in F} m o_{A B C}^{k}(i, j) \cdot t^{k}(j) \geq t^{A}(i) \cdot t^{B}(i) \cdot t^{C}(i) & \forall i \in E \\
x(j) \in\{0,1\} & \forall j \in N
\end{array}
$$

A resolução deste problema de otimização, ou seja, considerando todas essas restrições ao mesmo tempo, garante uma disposição de PQMs capaz de observar qualquer tipo de falta acontecendo nas barras do sistema. Caso seja desejado um estudo direcionado para um determinado (ou determinados) tipo de falta, basta excluir as inequações de restrição que representam faltas que não se deseja monitorar.

\subsubsection{Modelagem matemática visando à localização de falta: Modelo 2}

Esta subseção descreve um modelo que vem a propiciar uma alocação de PQMs voltada para a localização física da falta.

O conceito de simetria apresentado por Martins et al. (in press) é retomado em uma aplicação no problema de localização de faltas em sistemas de distribuição. Essa simetria ocorre quando um PQM registra o mesmo (ou quase o mesmo) valor de tensão eficaz para duas condições de falta. Do ponto de vista do PQM é impossível determinar qual das duas condições de falta ocorreu no sistema. Portanto, esse fenômeno dificulta o problema da localização de faltas, sendo necessário tratá-lo de forma a reduzir a múltipla estimação da localização em função do processo de alocação dos PQMs. 
Para definir numericamente uma condição de simetria, deve-se estipular um intervalo em torno de um valor de tensão medido, devido à incerteza durante a medição. Por exemplo, considerando uma incerteza de \pm 0,05 p.u., as condições de curto-circuito 6 e 11 (Figura 15) são simétricas com relação a um PQM instalado na barra 8. Uma solução para esse problema de simetria é adicionar um outro PQM de tal forma que consiga diferenciar os eventos 6 e 11. Dessa forma, olhando para o sistema de monitoramento como um todo, essa simetria não existirá mais.

Figura 15 - Exemplo de um caso de simetria presente no sistema estudado sem o GD e sob a ocorrência de faltas trifásicas francas nas barras.

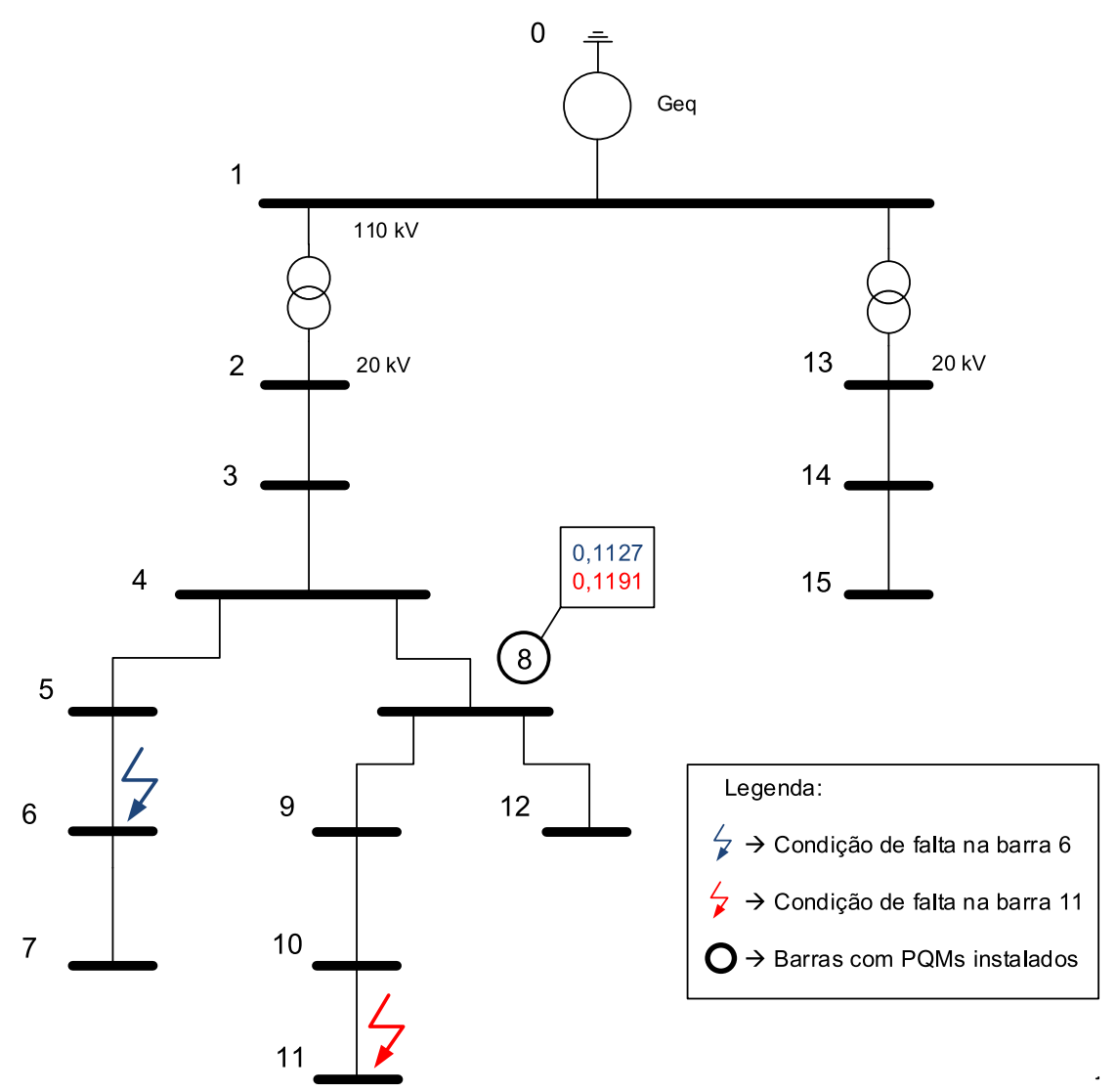

Fonte: $\mathrm{O}$ autor.

A instalação de um PQM na barra 4, por exemplo, já é suficiente para solucionar esse problema de simetria, visto que essa barra consegue diferenciar essas duas faltas (eventos 6 e 11) ocorrendo no sistema (Figura 16). Na situação representada, os valores estão fora da tolerância de 0,05 p.u., medindo na barra 8. Portanto, os eventos 6 e 11 não são simétricos com relação à barra 4 e, com esse conjunto de PQMs, não existe mais simetria no sistema.

\subsubsection{Definição de um intervalo de simetria adaptativo}

Ao se estudar sistemas de distribuição, definir condições de simetria a partir de um intervalo fixo para todas as combinações de possíveis situações de falta e barras, onde se efetua a medição, não é a melhor forma de se proceder. Isso acontece porque a sensibilidade da medição para duas faltas próximas varia de acordo com a distância a que essas duas faltas estão sendo aplicadas e com o local onde está sendo aferida a tensão. 
Figura 16 - Exemplo de como a disposição dos PQMs é capaz de resolver o problema da simetria.

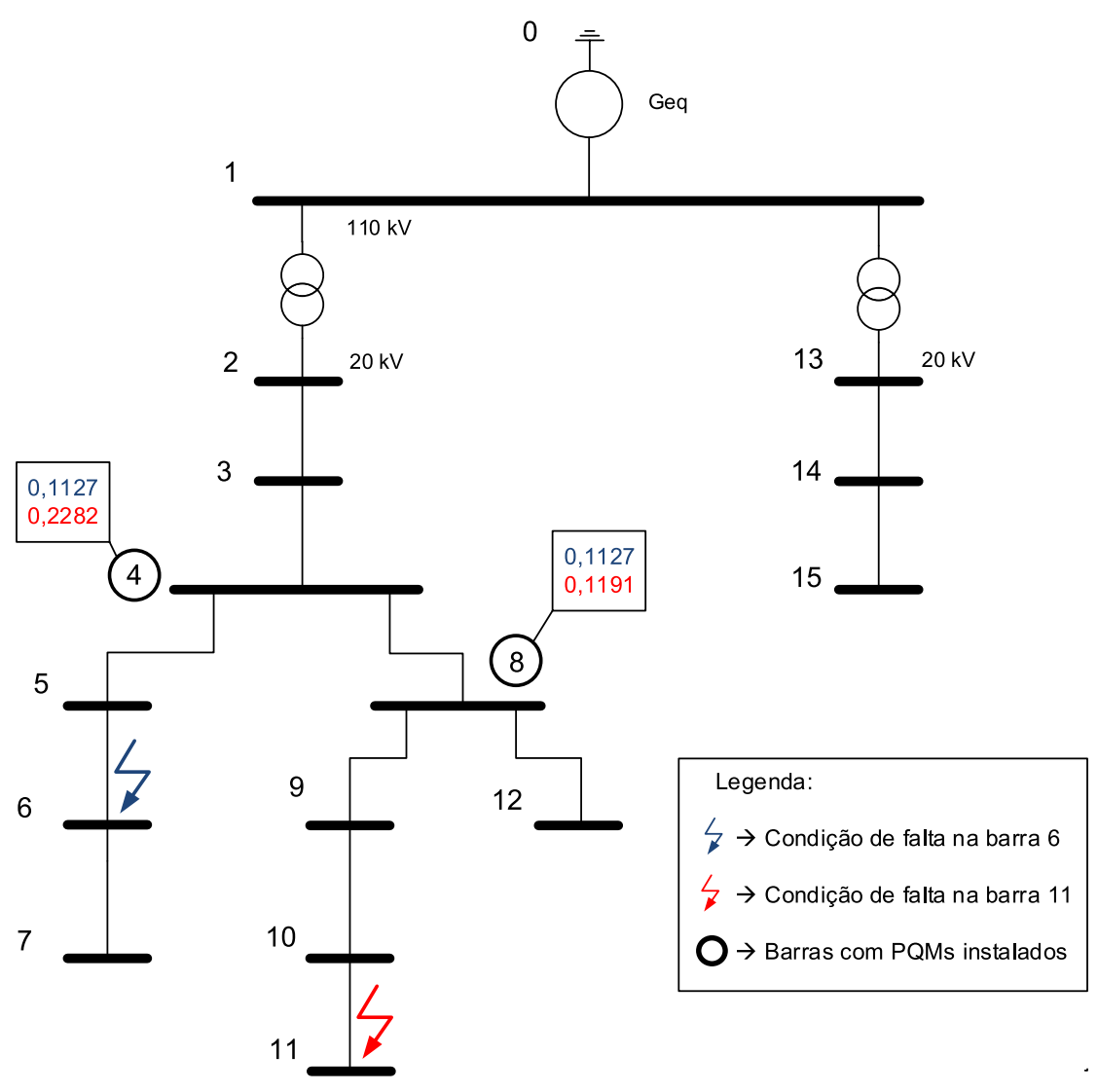

Fonte: $\mathrm{O}$ autor.

Por exemplo, para duas faltas trifásicas francas simuladas ao longo do trecho 3-4 (Figura 16), sendo uma delas sobre a barra 4 e a outra a 1 passo de simulação a montante dessa barra, a diferença da leitura de tensão durante a falta em um PQM instalado na barra 3 será de 0,0062 p.u.. E, considerando duas faltas ao longo do trecho 8-12, uma sobre a barra 12 e outra a 1 passo de simulação em direção à barra 8, a diferença de tensão entre essas duas faltas será de 0,0035 p.u.. Mantendo esses dois pares de falta e medindo na barra 1 a diferença será de 0,000116 p.u. para o primeiro par, e 0,0000665 p.u. para o segundo. Isso sugere que quanto mais distante forem os pontos de falta do medidor mais sensível será a medição, sendo que essa distância pode ser variada tomando um medidor mais longe (ou próximo), ou considerando dois pontos de faltas mais distantes (ou próximos).

Portanto, esta pesquisa propõe a definição de um intervalo de simetria que seja adaptativo. Nesse sentido, cada par de faltas será avaliado quanto à simetria segundo um intervalo específico para cada barra do sistema.

Neste sentido, para o sistema do CIGRÉ foram definidos 15 intervalos de simetria. Cada um deles foi definido como a menor diferença de tensão encontrada no sistema. Para isso, primeiramente, identifica-se o maior caminho existente no sistema a partir da subestação. Em seguida, toma-se o último trecho desse caminho e simula-se uma falta no último ponto e outra a 1 passo de simulação à montante. Então, o intervalo de simetria para cada medidor será definido como a diferença de tensão medida entre essas duas situações de falta. Para o sistema teste do CIGRÉ, o maior ramal a partir da subestação é o 
que termina na barra 12, o que pode ser identificado a partir da Figura 10, desenhada em escala. Portanto, os intervalos de simetria são determinados de acordo com duas faltas distantes entre si de um passo de simulação no fim do trecho 8-12. Dessa forma, tomando sempre os dois pontos mais distantes (pior caso), garante-se a maior sensibilidade que o medidor poderia ter em medição de tensão dentre todo o conjunto de faltas simuladas. Definir os intervalos de simetria dessa maneira evita, por exemplo, que duas faltas no início do trecho 8-12 distantes entre si de 1 passo de simulação, sejam tomadas como simétricas. Isso não é desejado, visto que se deseja direcionar o processo de alocação de PQMs para o problema da múltipla estimação. Portanto, essa metodologia visa evidenciar apenas os casos de simetria que correspondem à situações de falta localizadas em ramais distintos.

Existe um caso que merece cuidado durante a definição dos intervalos de simetria. Para o sistema CIGRÉ de 15 barras esse caso diz respeito à definição do intervalo de simetria para a barra 12. Um PQM nessa barra medirá 0 p.u. para uma situação de falta aplicada sobre a barra 12, e também 0 p.u. para uma falta aplicada à montante, resultando em um intervalo igual à zero. Isso dificultará a identificação dos casos de simetria do banco de dados. Portanto, para esse caso, foi escolhido o segundo maior ramal a partir da subestação para se aplicar o par de faltas.

A definição do intervalo de simetria adaptativo foi apresentada com base nos exemplos considerando faltas trifásicas francas. A mesma pode ser generalizada para se avaliar as condições de simetria em um banco de dados de faltas simuladas com qualquer característica. Para um conjunto de faltas monofásicas do tipo $A T$, simuladas com uma impedância de falta de $25 \Omega$, basta tomar dois curtos-circuitos com essas mesmas características durante a definição dos intervalos.

Para sistemas de distribuição inteiramente radiais a barra que corresponde ao último ponto do maior caminho pode ser identificada diretamente na diagonal da matriz $Z_{\text {barra }}$, correspondendo à posição que contém o maior valor de impedância. Para sistemas fracamente malhados, como é o caso do CIGRÉ, ao se considerar um GD conectado à rede principal, a metodologia se mantém. Para esse caso, a $Z_{\text {barra }}$ permite determinar o ponto mais distante (eletricamente) da subestação.

Para sistemas de distribuição onde existem ramais monofásicos e/ou bifásicos, deve-se tomar cuidado durante a identificação do maior ramal. Se o maior caminho do sistema terminar em uma ramificação monofásica, e o conjunto de dados for trifásico, esse caminho deve ser desconsiderado. Para esse caso deve-se tomar o maior ramal trifásico. O mesmo raciocínio deve ser feito para conjuntos de faltas de outros tipos. Para faltas monofásicas do tipo AT, por exemplo, deve-se descartar o caso de um caminho que termine em um trecho que contenha apenas a fase $C$.

Um outro caso que merece atenção é o de se avaliar simetrias para um banco de dados trifásico quando da definição do intervalo para barras localizadas em ramificações monofásicas a partir da última barra do maior ramal trifásico. Nesses casos, as diferenças de leitura de tensão também serão zero para as duas faltas trifásicas aplicadas no final desse ramal trifásico. Então, deve-se tomar também o segundo maior ramal durante a definição desses intervalos.

Quando avaliado bancos de dados de faltas desequilibradas, deve-se escolher em qual das fases deve ser aferida a tensão para o cálculo do intervalo de simetrias. Para faltas do tipo $A T$ sugere-se que se escolha a fase $A$, visto que é onde se manifestam os afundamentos de tensão. Caso a barra em questão não contenha a fase $A$, toma-se então a fase $B$ ou $C$ para se aferir a tensão. Seguindo o mesmo raciocínio, para 
faltas $B T$ sugere-se a seguinte ordem de prioridade: fase $B$, depois $A$, e então $C$. Para faltas $C T$ sugere-se tomar as fases $C, A$ e $B$, nessa ordem de prioridade. Para faltas do tipo $A B$ deve-se dar prioridade às fases $A$ e $B$, e por último a fase $C$. Nesse caso a tensão na fase $C$ vale sempre 1 p.u., o que resulta em zero no intervalo de simetria. Da mesma forma para faltas do tipo $A C$ é sugerida a prioridade para as fases $C, A \mathrm{e}$ $B$; e para faltas do tipo $B C$ sugere-se priorizar as fases $B, C$ e $A$. As faltas do tipo $A B T, A C T$ e $B C T$ podem seguir a mesma ordem de prioridade apresentada para as faltas sem o envolvimento com a terra.

\subsubsection{Modelo de otimização para identificação de eventos}

Essa informação sobre as condições simétricas presentes no sistema é representada através do parâmetro binário $\sigma(j, i, \bar{i})$, definido em (3.54).

$$
\sigma(j, i, \bar{i}) \equiv \begin{cases}1, & \text { em caso de os eventos } i, \bar{i} \in E \text { não serem simétricos com relação à barra } j \in N \\ 0, & \text { caso contrário }\end{cases}
$$

Esse parâmetro possui três dimensões (barras, eventos, eventos). Se fixarmos uma delas, a barra por exemplo, é possível representá-lo graficamente por meio de uma matriz binária. A Figura 17 representa todos os parâmetros $\sigma(8, i, \bar{i})$, ou seja, para todas as combinações de eventos trifásicos francos $i$ e $\bar{i}$ simulados nas 15 barras do sistema, com um ponto de medição instalado na barra 8 . Nela, os elementos em azul representam condições simétricas $(\sigma(8, i, \bar{i})=0)$ e em branco eventos que não são simétricos $(\sigma(8, i, \bar{i})=1)$. Por exemplo, os eventos 6 e 11 são simétricos com relação à barra 8 , e os eventos 7 e 9 não são simétricos com relação à barra 8 . Assumindo que um dado evento é simétrico a ele mesmo, a diagonal dessa matriz será sempre na cor azul. Além disso, essa matriz é simétrica com relação à diagonal principal, visto que os parâmetros $\sigma(8,2,1)$ e $\sigma(8,1,2)$, por exemplo, representam a mesma situação no sistema elétrico. Então, para esse sistema com 15 posições para alocação de PQMs, e considerando 15 eventos, existem $15 \times 15 \times 15=3.375$ sigmas, que podem ser representados em 15 matrizes como a da Figura 17, uma para cada barra.

Através da Figura 17 fica evidenciada a necessidade de se avaliar condições de falta nas linhas, visto que a maior parte dessas situações ocorrem ao longo das linhas do sistema e não sobre as barras.

Um conceito importante é então definido. Um evento é dito identificável se, e somente se, o conjunto de PQMs instalados for capaz de diferenciar os níveis de tensão eficaz durante esse evento de todos os demais eventos. Dessa forma, define-se uma variável binária para cada evento $i$ de acordo com (3.55).

$$
y(i) \equiv \begin{cases}1, & \text { se o evento } i \in E \text { é identificável } \\ 0, & \text { caso contrário }\end{cases}
$$

Quanto maior a quantidade de eventos identificáveis melhor será a disposição dos PQMs para propósitos de localização de falta. Portanto, pretende-se maximizar o número de eventos identificáveis. A Equação (3.56) representa esse objetivo, e as restrições representadas em (3.57) e (3.58) completam o modelo. 
Figura 17 - Representação do conjunto de parâmetros $\sigma(8, i, \bar{i})$ para faltas trifásicas francas nas barras do sistema europeu de média tensão sem o GD instalado.

\section{Eventos i}

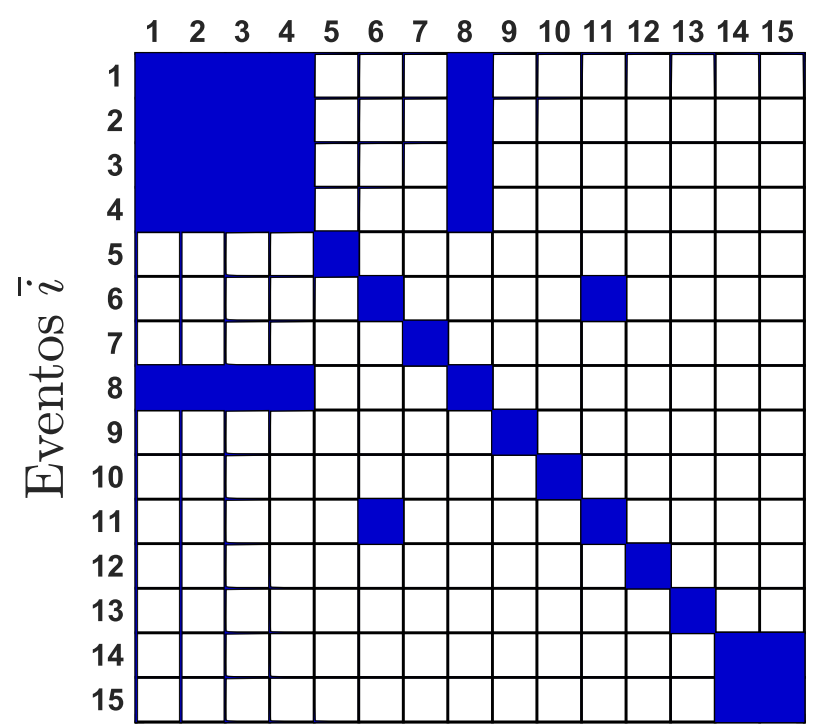

Fonte: $\mathrm{O}$ autor.

$$
\max \sum_{i \in E} y(i)
$$

sujeito a:

$$
\begin{aligned}
\sum_{j \in N} \sigma(j, i, \bar{i}) \cdot x(j) & \geq y(i) \quad \forall i, \bar{i} \in E, i \neq \bar{i} \\
y(i) & \in\{0,1\} \quad \forall i \in E
\end{aligned}
$$

A restrição (3.57) garante que existe quebra de simetria entre todas as combinações de eventos $i$ e $\bar{i}$ para uma dada alocação de PQMs. O produto $\sigma(j, i, \bar{i}) \cdot x(j)$ é igual a "1"apenas se existe um PQM instalado na barra $j$, e os eventos $i$ e $\bar{i}$ não são simétricos com relação a essa barra. Em outras palavras, a barra $j$ é capaz de quebrar a simetria entre essas duas condições de falta. Essa inequação garante que ao checar cada uma das barras $j \in N$ pelo menos uma delas consegue diferenciar as situações de falta $i$ e $\bar{i}$. Isto é testado para todas as combinações de eventos diferentes entre si. A restrição (3.58) apenas define o conjunto em que a variável de decisão $y(i)$ pode assumir valores.

Da mesma forma que para o Modelo 1 , podem ser atribuídos subíndices à variável $\sigma$ para evidenciar o tipo de falta presente no banco de dados avaliado pelo Modelo 2.

O modelo apresentado pode ser resolvido de forma isolada ou incorporado ao modelo clássico para a observabilidade de VTCDs. Dessa forma, é possível estabelecer um tratamento multi-objetivo ao problema de alocação, onde se pretende não só minimizar o número de PQMs, mas também maximizar a identificação única de eventos. Essa identificação é feita por meio da adição de PQMs em posições estratégicas de forma a conseguir diferenciar os eventos entre si. É importante ressaltar que essa abordagem multi-objetivo é adequada, visto que os dois objetivos são conflitantes entre si. Uma solução com maior quantidade de eventos identificados requer um número maior de PQMs, o qual se pretende minimizar. 


\subsection{Considerações finais}

A metodologia apresentada para resolver o problema de alocação de PQMs é baseada na simulação de situações de falta, sendo esta feita de forma analítica. Neste capítulo o foco foi dado às condições de falta trifásicas francas para fins didáticos. No entanto, foram apresentados os recursos para se generalizar toda a metodologia ao se analisar qualquer tipo de falta e com qualquer valor de impedância de falta.

O procedimento de estudo de curto-circuito foi desenvolvido em um sistema teste totalmente trifásico. No entanto, foi mostrado como adaptar a metodologia para abordar sistemas de distribuição com ramais bifásicos e/ou monofásicos.

Durante a análise de faltas foi estudada a influência de um GD na determinação das tensões durante a falta e a consequente implicação no problema de alocação de PQMs. Essa importante consideração não foi ainda incorporada aos estudos de alocação de PQMs, o que será feito buscando-se adequar cada vez mais à real composição dos sistemas de distribuição atuais.

Foi proposta uma metodologia para se construir um banco de dados representativo das situações de faltas para o problema da alocação de PQMs, com base na definição de um passo de aplicação das situações de faltas que mantém uma uniformidade na distribuição dos pontos ao longo do sistema, além de ser independente do tipo existente de configuração de cabo em cada trecho da rede e do sistema de distribuição em análise. Durante a definição desse passo de simulação já foram considerados aspectos que direcionaram a construção do banco de faltas simuladas para o problema da múltipla estimação da falta.

O modelo clássico para o problema de alocação de PQMs foi retomado conforme apresentado por Olguin, Vuinovich e Bollen (2006) e, em seguida, apresentou-se uma proposta para se considerar sistemas de distribuição com as impedâncias das linhas desequilibradas, permitindo generalizar o modelo clássico para qualquer sistema de distribuição real.

O modelo de identificação de eventos idealizado para sistemas de transmissão (MARTINS et al., in press) foi também retomado e aplicado em sistemas de distribuição, com foco no problema da múltipla estimação do local da falta. Foi mostrado que devido à topologia essencialmente radial desses sistemas, a definição de um intervalo adaptativo para tratar as simetrias é mais adequado. Além disso, foi discutido como as particularidades desses sistemas (como, por exemplo, a presença de GD, ramais monofásicos, etc.) influenciam nessa definição. 

Neste capítulo são apresentados os resultados obtidos nesta pesquisa, com o objetivo de mostrar a funcionalidade da metodologia proposta para alocação de PQMs em sistemas de distribuição.

Para ilustrar o processo de alocação de PQMs, a metodologia foi aplicada no sistema de distribuição utilizado como exemplo no Capítulo 3 (CIGRE Task Force C6.04, 2014, 6.2), por este se tratar de um sistema mais simplificado, o que facilita a análise dos resultados. Visto que este sistema apresenta um GD acoplado na barra 12, foram geradas instâncias considerando o GD conectado à rede principal de fornecimento e também considerando o GD fora de operação. Dessa forma, foi possível avaliar a influência da geração distribuída no problema de alocação de PQMs.

Além do sistema do CIGRÉ, o método de alocação também foi aplicado no sistema de distribuição IEEE de 123 barras (KERSTING, 1991). Esse sistema foi escolhido devido à sua maior quantidade de barras e ramificações, podendo evidenciar uma maior quantidade de casos de múltipla estimação da falta, o que se espera em um sistema de distribuição real. Ele também apresenta grande número de ramais monofásicos e bifásicos, justificando o ajuste no modelo clássico proposto nesta pesquisa (3.42) - (3.53).

Foram geradas instâncias abordando todos os tipos de faltas para os dois sistemas. Visto que o sistema CIGRÉ é trifásico em toda a sua extensão, foi considerado 1 tipo de falta monofásica, 1 tipo de falta bifásica e 1 tipo de falta bifásica com conexão com a terra. Cabe adiantar e afirmar que as demais variações desses casos resultaram em resultados idênticos. Portanto, são apresentados os resultados para as faltas AT, BC, BCT e ABC. Para cada tipo de falta o valor da impedância de falta foi variado em 0, 25 e $50 \Omega$.

No que segue, este capítulo foi dividido em cinco seções. A primeira apresenta os resultados para o Modelo 1 de otimização clássico e ajustado, e as implicações de se considerar a geração distribuída no sistema. A seção 4.2 mostra os resultados para o Modelo 2 voltado para o problema da localização de faltas. A seção 4.3 apresenta os resultados para a resolução destes dois Modelos (1 e 2) ao mesmo tempo, em uma abordagem multi-objetivo. Por fim, a seção 4.4 faz um fechamento do capítulo, resumindo os principais pontos observados durante a análise dos resultados até então obtidos. 


\subsection{Problema de minimização da quantidade de PQMs: Modelo 1}

Essa parte do problema da alocação de PQMs foi modelada como um problema de recobrimento (HOFFMAN; RALPHS, 2012), sendo facilmente resolvido por meio de algoritmos usuais de otimização linear inteira.

O modelo de otimização foi resolvido por um algoritmo Branch \& Bound de uso geral, e implementado em MATLAB utilizando um pacote de otimização para solução de problemas de PLI, YALMIP (LÖFBERG, 2004). As equações analíticas de curto-circuito para obtenção das MTDFs foram todas programadas por meio de scripts codificados usando o MATLAB 2015.

\subsubsection{Análise dos resultados para o sistema CIGRÉ}

O modelo clássico, descrito pelas equações de (3.29) a (3.31), foi resolvido para o sistema CIGRÉ considerando um limiar de 0,6 p.u.. Para uma situação de faltas trifásicas francas, o algoritmo mostra que com apenas dois PQMs é garantida a observabilidade de todas as condições de falta simuladas. A solução retornada pelo algoritmo determina a instalação dos PQMs nas barras 5 e 15, como mostra a Figura 18.

Os números das barras onde estão os PQMs foram circulados e destacados na Figura 18. Além disso, as respectivas áreas de cobertura (MRAs) foram representadas seguindo a mesma tonalidade de cor do índice do PQM. É possível perceber que a combinação das duas MRAs cobrem toda a rede, garantindo a observabilidade de todas as faltas simuladas. Isso é importante, visto que se houvesse uma barra não monitorada esta solução não seria factível. Em outras palavras, a restrição (3.30) seria violada.

Pode ser observado pela Figura 18 que a barra 1 é monitorada por ambos medidores. Essa redundância no monitoramento é interessante pois fornece mais confiança por parte do sistema de monitoramento em caso de falhas na detecção dos distúrbios. Em especial, esta é uma barra importante para o SEP, visto que é a barra da subestação, o que vem a valorizar esta solução obtida pelo algoritmo de alocação de PQMs.

As MRAs de cada PQM podem ser facilmente visualizadas a partir da MO (Figura 13). Por exemplo, a MRA do PQM instalado na barra 5 é identificada a partir da coluna 5 da MO. As linhas com elementos em preto nessa coluna representam os índices das situações de falta que pertencem à MRA, ou seja, os eventos 1-134. O evento 134 é a última situação de falta simulada na linha entre as barras 8 e 12 . O próximo evento (135) é a situação de falta simulada na barra 13, a qual já pertence à MRA do PQM da barra 15 (Figura 18). Da mesma forma a área do PQM instalado na barra 15 é identificada na coluna 15 dessa matriz (eventos 135-187).

Observando a MO é possível perceber outras combinações com dois PQMs que ainda cobrem todo o sistema, como: $\{4,14\},\{5,14\},\{6,14\},\{7,14\},\{8,14\},\{9,14\},\{10,14\},\{11,14\},\{12,14\},\{4,15\}$, $\{6,15\},\{7,15\},\{8,15\},\{9,15\},\{10,15\},\{11,15\}$ e $\{12,15\}$. Todas essas soluções são consideradas ótimas do ponto de vista do modelo de otimização, pois possuem o valor ótimo para a função objetivo (número de PQMs = 2). 
Figura 18 - Solução obtida para a resolução do Modelo 1 considerando o sistema CIGRÉ.

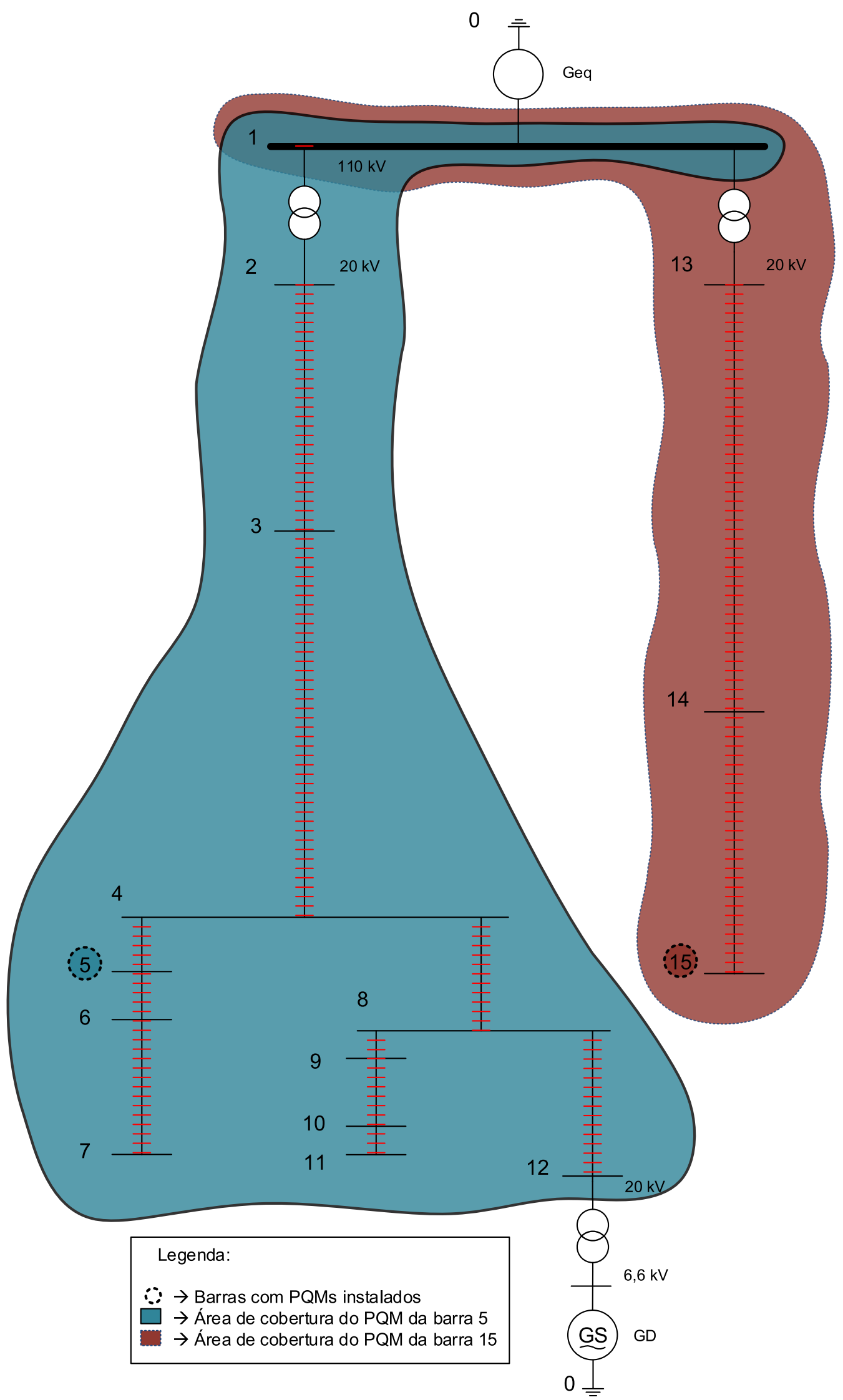

Fonte: Elaborada pelo autor. 
Esta possibilidade variada de combinações trás vantagens para a concessionária visando à instalação dos PQMs, já que, pelo impedimento ou dificuldade da instalação em uma determinada barra, outra poderá ser escolhida.

Nenhuma combinação com a barra 13, utilizando 2 PQMs, consegue cobrir todo o sistema. Isto é justificado pela dimensão do segundo alimentador. A Figura 13 mostra que a barra 13 não consegue observar os últimos eventos simulados (160-187), os quais foram aplicados no segundo alimentador. Como a distância entre o ponto de falta e o medidor vai aumentando, à medida em que estão sendo simuladas as faltas no segundo alimentador, chega a um ponto em que o medidor não é mais sensibilizado, para o limiar considerado. Isso acontece à exatamente 75,91\% do trecho entre as barras 13 e 14 .

Outras combinações são possíveis, porém, com uma quantidade maior de PQMs, não sendo portanto soluções ótimas. Então, esse é um problema que admite várias soluções ótimas globais, como foi observado por (OLGUIN; VUINOVICH; BOLLEN, 2006). Isso acontece porque se consegue dispor a mesma quantidade de PQMs em locais diferentes na rede elétrica de forma a ainda garantir a observabilidade total do sistema. Em particular para o caso estudado, a existência de múltiplas soluções se justifica por barras que possuem a mesma área de cobertura, como as barras $\{4,5,6,7,8,9,10,11$ e 12$\}$ e $\{14,15\}$.

Para os demais tipos de falta o algoritmo encontrou a mesma solução. Ademais, para todos os tipos de falta a solução $\{5,15\}$ foi encontrada não importando o GD estar conectado ou desconectado da rede principal.

Para valores mais altos de impedância de falta as tensões remanescentes nas barras são reduzidas, sendo necessário fazer uma análise da variação do limiar em função do valor de $Z_{f}$, a fim de conseguir soluções para este modelo 1, como mostrou Kempner et al. (2016).

\subsubsection{Análise dos resultados para o sistema IEEE 123 barras}

Neste trabalho o sistema teste do IEEE de 123 barras foi considerado da mesma forma apresentada em (KEMPNER, 2016, p. 118), desconsiderando as conexões entre barramentos por meio de chaves normalmente abertas e renumerando as barras de maneira idêntica (Figura 19).

Como esse sistema possui barras onde podem não existir 1 ou 2 fases, todas as instâncias foram geradas seguindo a adaptação para as MOs descrita na subseção 3.4.1.1. Dessa forma, evitou-se que o algoritmo erroneamente alocasse um medidor em uma barra que contém apenas a fase $A$ para a instância que contém apenas faltas do tipo $C T$.

A Tabela 1 mostra os resultados para todas as instâncias geradas para o sistema IEEE de 123 barras, considerando faltas francas e um limiar de 0,6 p.u..

Observa-se na Tabela 1 que para a maioria dos casos foram necessários apenas 2 PQMs para se garantir a observabilidade das faltas simuladas. As exceções são as instâncias para as faltas bifásicas $A B$, $A C$ e $B C$; as quais precisaram de $4 \mathrm{PQMs}$ para cobrir todo o sistema. Ainda assim uma quantidade muito pequena perto da quantidade total de locais para instalação dos medidores (118). Uma outra observação interessante dos resultados é que as soluções para as faltas bifásicas com a conexão com a terra estão contidas na solução análoga de 4 medidores para a falta bifásica sem conexão com a terra. 
Figura 19 - Sistema teste de distribuição do IEEE de 123 barras.

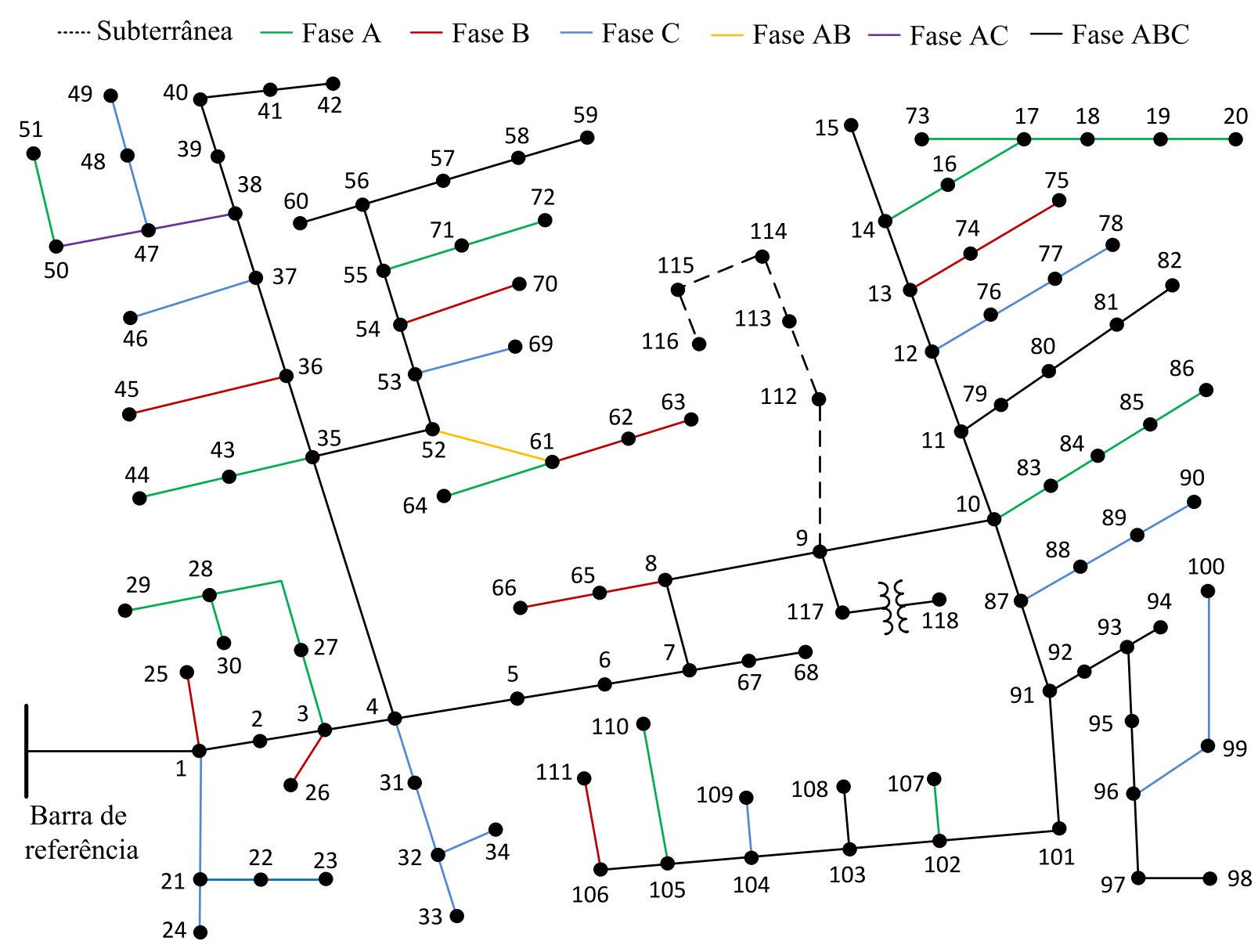

Fonte: Kempner (2016, p. 118).

Apesar de a Tabela 1 mostrar apenas 1 solução para cada instância, este problema de otimização admite múltiplas soluções igualmente ótimas. Por exemplo, para o cenário com faltas trifásicas, todas as soluções podem ser obtidas por meio da combinação das barras do conjunto $\{8-20,73-118\}$ com as barras do conjunto $\{35-64,69-72\}$.

São apresentadas alocações que cobrem o sistema para qualquer tipo de falta monofásica ( $A T, B T$ ou $C T$ ), bifásica $(A B, A C$ ou $B C$ ), e bifásica-terra $(A B T, A C T$ ou $B C T)$. $\mathrm{O}$ algoritmo sugere a instalação de PQMs nas barras 41 e 79 para o monitoramento de faltas monofásicas. Essa solução foi obtida ao se considerar o modelo 1 sujeito às restrições que correspondem a faltas monofásicas, ou seja, as equações (3.43) a (3.45). Da mesma forma, a solução para faltas bifásicas foi obtida considerando apenas o conjunto de restrições representado pelas equações (3.46) a (3.48), e para faltas bifásicas-terra considerando as restrições (3.49) a (3.51).

As barras 41 e 79 também foram selecionadas como solução para o monitoramento de todas as faltas bifásicas-terra. Já para as faltas do tipo bifásica foram necessários 4 PQMs para se garantir a observabilidade de todos os eventos simulados, sendo eles instalados nas barras 41, 60, 79 e 106. É importante ressaltar que o algoritmo de alocação retornou uma solução que veio a complementar a solução proposta para as faltas monofásicas e bifásicas. Em outras palavras, os PQMs alocados nas barras 41 e 79 
Tabela 1 - Resultados para todos os cenários de falta $\left(Z_{f}=0 \Omega\right.$ e $\tau=0,6$ p.u.).

\begin{tabular}{ccc}
\hline Tipo de falta & Número de PQMs & Barras onde os PQMs foram alocados \\
\hline ABC & 2 & 20,43 \\
AT & 2 & 20,57 \\
BT & 2 & 70,102 \\
CT & 2 & 58,113 \\
Faltas monofásicas & 2 & 41,79 \\
AB & 4 & $20,39,54,97$ \\
AC & 4 & $20,46,57,105$ \\
BC & 4 & $40,55,76,99$ \\
Faltas bifásicas & 4 & $41,60,79,106$ \\
ABT & 2 & 20,54 \\
ACT & 2 & 20,46 \\
BCT & 2 & 55,99 \\
Faltas bifásicas-terra & 2 & 41,79 \\
Todas as faltas & 4 & $41,60,79,106$ \\
\hline
\end{tabular}

Fonte: Elaborada pelo autor.

continuam válidos para o cenário com faltas bifásicas. Apesar de ter sido aumentado o número de PQMs necessários para este cenário, não houve a necessidade de realocação dos PQMs anteriormente alocados. Isto é vantajoso em termos dos custos de instalação, de manutenção e de gerenciamento das informações.

A última linha da Tabela 1 é a solução ótima para o modelo descrito pelas equações de (3.42) a (3.53), ou seja, impondo as restrições para todos os tipos de falta ao mesmo tempo. O algoritmo encontrou uma solução com apenas 4 medidores, com a qual é possível garantir a cobertura de todo o sistema para todos os tipos de falta. Esta solução é a mesma encontrada para as faltas bifásicas. De fato, esta solução já inclui o monitoramento das faltas monofásicas, bifásicas e bifásicas-terra; restando apenas a cobertura das faltas trifásicas. No entanto, a solução com PQMs nas barras 41 e 79 também é ótima para o cenário de faltas trifásicas, pois a barra 41 está contida no conjunto $\{35-64,69-72\}$ e a barra 79 está presente no conjunto $\{8-20,73-118\}$. Portanto, com a solução $\{41,60,79,106\}$ é garantido o monitoramento para todos os tipos de falta.

\subsection{Problema de maximização da quantidade de eventos identificados: Modelo 2}

Para resolver o Modelo 2, equações (3.56) a (3.58), que trata do problema de alocação de PQMs visando à localização de faltas, as soluções foram buscadas via a implementação de um AG, compilado em linguagem $C$. As soluções foram modeladas utilizando vetores binários. Foi utilizado elitismo e a quantidade menor de PQMs foi utilizada como critério de desempate em casos de duas soluções com a mesma quantidade de eventos identificados. Foi utilizada uma população com 20 indivíduos para instâncias do sistema CIGRÉ e com 120 indivíduos para instâncias do sistema do IEEE de 123 barras. A seleção foi feita por torneio de 3 elementos (tanto para o cruzamento quanto para a próxima geração), o crossover binário (tendo 1 ponto de corte nos vetores dos pais), e a mutação binária com uma probabilidade de 
ocorrência de $10 \%$ em cada filho gerado (para ambos os sistemas teste). O critério de parada do algoritmo foi a quantidade máxima de gerações, sendo que para todas as instâncias do sistema CIGRÉ notou-se que 30 gerações é um número suficiente para a convergência. Já para o sistema do IEEE de 123 barras foram necessárias 100 gerações. Como este é um algoritmo com uma presença de certa aleatoriedade, associada à geração da população inicial, o mesmo foi executado 10 vezes, a fim de se obter segurança nos resultados obtidos.

\subsubsection{Análise dos resultados para o sistema CIGRÉ}

Nesta seção são mostrados os resultados da resolução do Modelo 2 para o sistema CIGRÉ em cenários de faltas trifásicas, monofásicas do tipo $A T$, e bifásicas do tipo $B C$ e $B C T$. Para cada uma delas é apresentada uma análise da sensibilidade do método de alocação quanto à variação do valor da impedância de falta $\left(Z_{f}=0,25\right.$ e $\left.50 \Omega\right)$.

\subsubsection{Cenário para faltas trifásicas}

O algoritmo foi executado 10 vezes, e para cada uma delas foi salva a melhor solução da população após a convergência. Vale comentar que em alguns casos pode acontecer de o AG convergir para uma mesma solução já encontrada em execuções anteriores. Para o caso de faltas trifásicas francas, por exemplo, em 5 vezes o algoritmo convergiu para uma solução já previamente encontrada. Portanto, a Tabela 2 apresenta as 5 soluções distintas dentre as 10 retornadas. As outras 5 tratam de soluções idênticas às já mostradas e foram omitidas.

Tabela 2 - Resultados para o cenário de faltas trifásicas $\left(Z_{f}=0 \Omega\right)$.

\begin{tabular}{ccc}
\hline Número de PQMs & Barras onde os PQMs foram alocados & Número de eventos identificados \\
\hline 2 & 1,10 & 187 \\
2 & 1,11 & 187 \\
2 & 9,13 & 187 \\
2 & 10,13 & 187 \\
2 & 11,13 & 187 \\
\hline
\end{tabular}

Fonte: Elaborada pelo autor.

Todas as cinco soluções apresentadas possuem valor máximo de eventos identificados (187), mostrando que este problema de otimização, assim como o Modelo 1, é um problema que admite múltiplas soluções ótimas. O AG, devido à sua população inicial aleatória, pode chegar a soluções diferentes cada vez que for executado. Além disso, dentre os indivíduos da população após a convergência podem existir mais de um indivíduo distinto com mesmo valor ótimo de função objetivo. No entanto, aqui são apresentadas a melhor solução de cada última população, sendo que existem inúmeras soluções ótimas, não sendo viável enumerar todas elas. É interessante mencionar que para esse Modelo 2 a solução onde existem PQMs em todas as 15 barras é também uma solução ótima, visto que identifica todos os 187 eventos simulados. No entanto, não são necessários todos esses medidores instalados, e o critério de desempate empregado no algoritmo permite que ele mostre soluções com quantidade menor de PQMs dentre o conjunto de todas as soluções ótimas possíveis. De fato, para esse caso mais simples onde não é 
possível identificar 187 eventos com um único medidor, pode-se afirmar que 2 medidores é a quantidade mínima requerida para identificar o número máximo de eventos. Essa discussão sugere que o tratamento multi-objetivo é uma abordagem interessante para esse problema de alocação de PQMs.

Apesar de todas as 5 soluções propostas pelo algoritmo serem ótimas, talvez seja mais interessante a opção pelas soluções $\{1,10\}$ e $\{1,11\}$ em razão de que espera-se a existência de medição na barra da subestação (barra 1). Neste caso, restaria apenas a instalação de 1 único medidor na barra 10 ou 11. De qualquer maneira, a escolha de uma das 5 alocações apresentadas atenderia ao problema, e ficaria a encargo da concessionária verificar qual destas combinações ela daria preferência em função da acessibilidade e facilidade de instalação, e/ou, da presença em um destes barramentos de algum cliente em potencial que merecesse um monitoramento de forma continuada.

As soluções obtidas para as instâncias trifásicas com $Z_{f}=25$ e $50 \Omega$ são idênticas, por isso, todas foram resumidas na Tabela 3.

Tabela 3 - Resultados para o cenário de faltas trifásicas $\operatorname{com} Z_{f}=25$ e $50 \Omega$.

\begin{tabular}{ccc}
\hline Número de PQMs & Barras onde os PQMs foram alocados & Número de eventos identificados \\
\hline 4 & $7,11,12,13$ & 187 \\
4 & $7,11,12,14$ & 187 \\
4 & $7,11,12,15$ & 187 \\
\hline
\end{tabular}

Fonte: Elaborada pelo autor.

Essa tabela mostra que para esses casos o algoritmo ainda encontrou soluções que identificam todas as 187 situações de falta consideradas. No entanto, para isso foram necessários 4 medidores. A análise das duas tabelas mostra que a solução $\{7,11,12,13\}$ identifica todos os eventos para cada um dos 3 valores de impedância de falta.

\subsubsection{Cenário para faltas monofásicas AT}

Os resultados para a aplicação do Modelo 2 no conjunto de faltas $A T$ com impedância de falta $Z_{f}=0 \Omega$ são mostrados na Tabela 4 .

Tabela 4 - Resultados para o cenário de faltas do tipo $A T\left(Z_{f}=0 \Omega\right)$.

\begin{tabular}{ccc}
\hline Número de PQMs & Barras onde os PQMs foram alocados & Número de eventos identificados \\
\hline 2 & 9,13 & 187 \\
2 & 9,15 & 187 \\
2 & 10,14 & 187 \\
2 & 11,13 & 187 \\
2 & 11,14 & 187 \\
\hline
\end{tabular}

Fonte: Elaborada pelo autor.

Para esse cenário é possível também identificar todas as 187 situações de falta, sendo necessário para isso a instalação de 2 PQMs de acordo com cada uma das 5 soluções apresentadas.

Assim como para o cenário de faltas trifásicas, ao se variar a impedância de falta para 25 e $50 \Omega$ o algoritmo encontrou também 3 soluções, as quais atendem aos cenários com os dois valores de impedância 
de falta. Além disso, as barras que compõem estas 3 soluções são as mesmas já apresentadas para o cenário trifásico (Tabela 3). Por esse motivo essas soluções não serão repetidas aqui. Vale ressaltar que esse é um resultado importante, visto que com esses 4 medidores é garantida a identificação das 187 faltas trifásicas e monofásicas simuladas. E mais do que isso, caso seja escolhida a solução $\{7,11,12,13\}$, a identificação é garantida também para qualquer um dos 3 valores de impedância de falta considerados, visto que a solução $\{11,13\}$ também atende ao cenário de faltas monofásicas com impedância franca.

\subsubsection{Cenário para faltas bifásicas $B C$}

Para as faltas bifásicas $B C$ francas não foi possível identificar todos os 187 eventos, sendo que o método retornou como resposta a quantidade máxima de 171 eventos. Na Tabela 5 são apresentadas as 10 soluções diferentes encontradas, todas com 4 medidores. Nessa tabela também são mostrados, na última coluna, quais foram os eventos que não são identificáveis com essas soluções.

Tabela 5 - Resultados para o cenário de faltas do tipo $B C\left(Z_{f}=0 \Omega\right)$.

\begin{tabular}{cccc}
\hline Número de PQMs & $\begin{array}{c}\text { Barras onde os } \\
\text { PQMs foram } \\
\text { alocados }\end{array}$ & $\begin{array}{c}\text { Número de } \\
\text { eventos } \\
\text { identificados }\end{array}$ & Eventos não identificados \\
\hline 4 & $1,2,5,10$ & 171 & $70-72,95-97,107-111,120-124$ \\
4 & $1,2,5,11$ & 171 & $70-72,95-97,107-111,120-124$ \\
4 & $1,2,6,10$ & 171 & $70-72,95-97,107-111,120-124$ \\
4 & $1,2,6,11$ & 171 & $70-72,95-97,107-111,120-124$ \\
4 & $1,2,7,10$ & 171 & $70-72,95-97,107-111,120-124$ \\
4 & $1,2,7,11$ & 171 & $70-72,95-97,107-111,120-124$ \\
4 & $2,6,10,13$ & 171 & $70-72,95-97,107-111,120-124$ \\
4 & $2,6,11,13$ & 171 & $70-72,95-97,107-111,120-124$ \\
4 & $2,6,12,13$ & 171 & $70-72,95-97,107-111,120-124$ \\
4 & $2,7,11,13$ & 171 & $70-72,95-97,107-111,120-124$ \\
\hline
\end{tabular}

Fonte: Elaborada pelo autor.

Com as soluções apresentadas a quantidade mínima de eventos que não são identificados é 16, sendo estes os mesmos eventos para cada alocação encontrada pelo algoritmo. Isso acontece porque, para esta instância, qualquer que seja a quantidade e disposição dos PQMs (até no pior caso com PQMs em todas as 15 barras), não é possível identificar esses eventos em específico. Os eventos 70-72 são os 3 primeiros simulados no trecho 4-5, os eventos número 95-97 são os 3 primeiros simulados no trecho 4-8, os eventos 107-111 são os 5 primeiros simulados entre as barras 8 e 10, e os eventos 120-124 são os 5 primeiros simulados no trecho 8-12. Todos eles não são identificáveis devido à condições de simetria existentes entre eles. Por exemplo, os eventos 70-72 não foram identificados porque existe simetria entre estes e os eventos 95-97, seja qual for a barra de medição tomada como referência. Para esses dois conjuntos o evento 70 é simétrico com o 95, o evento 71 é simétrico com o 96, e o evento 72 é simétrico com o 97. Cada uma dessas 3 situações de simetria faz com que os dois eventos envolvidos não sejam identificáveis. Da mesma forma, os eventos 107-111 formam pares simétricos com os correspondentes do outro ramal (120-124). 
Porém, ao se variar a impedância de falta para os dois valores mais altos, o algoritmo encontra soluções que conseguem identificar todos os eventos. Essas soluções atendem os dois cenários de valores de impedância e, assim como no caso das faltas AT, são as mesmas já apresentadas para o caso trifásico (Tabela 3).

As faltas do tipo bifásicas sem envolvimento com a terra possuem características próprias que, a depender do valor da impedância de falta, podem criar situações de simetria no sistema. O Quadro 3 ilustra essas características, olhando para o caso da condição de simetria entre os eventos 70 e 95 , tomados com relação à barra 11. São apresentados os valores de tensão das 3 fases durante a falta número $70 \mathrm{e}$ 95 (linhas 1 e 2 do quadro) para os 3 valores de impedância de falta. Na terceira linha é apresentada a diferença entre as tensões de cada fase para as duas situações de falta, e na última linha é mostrado o intervalo de simetria da barra 11 calculado para cada um dos valores de impedância de falta.

Quadro 3 - Valores de tensão durante uma falta do tipo BC medidos na barra 11 do sistema do CIGRÉ.

\begin{tabular}{|c|c|c|c|c|c|c|c|c|c|}
\hline & \multicolumn{3}{|c|}{$Z_{f}=0 \Omega$} & \multicolumn{3}{c|}{$Z_{f}=25 \Omega$} & \multicolumn{3}{c|}{$Z_{f}=50 \Omega$} \\
\cline { 2 - 11 } & $V_{a}(\mathrm{pu})$ & $V_{b}(\mathrm{pu})$ & $V_{c}(\mathrm{pu})$ & $V_{a}(\mathrm{pu})$ & $V_{b}(\mathrm{pu})$ & $V_{c}(\mathrm{pu})$ & $V_{a}(\mathrm{pu})$ & $V_{b}(\mathrm{pu})$ & $V_{c}(\mathrm{pu})$ \\
\hline 70 & 1 & 0,5014 & 0,4987 & 1 & 0,9337 & 0,6147 & 1 & 0,9820 & 0,7806 \\
\hline 95 & 1 & 0,5000 & 0,5000 & 1 & 0,9332 & 0,6102 & 1 & 0,9818 & 0,7780 \\
\hline Diferença & 0 & 0,0014 & 0,0013 & 0 & 0,0005 & 0,0045 & 0 & 0,0002 & 0,0026 \\
\hline Intervalo & \multicolumn{3}{|c|}{0,0066} & \multicolumn{3}{c|}{0,0018} & \multicolumn{3}{c|}{0,0007} \\
\hline
\end{tabular}

Fonte: Elaborada pelo autor.

O Quadro 3 mostra que as tensões nas fases B e C (fases envolvidas na falta) são ambas próximas de 0,5 p.u. quando $Z_{f}=0 \Omega$. Para valores mais altos de impedância essas tensões possuem valores mais altos, sendo que a tensão na fase $\mathrm{B}$ se eleva bem mais que a fase $\mathrm{C}$. A análise desse quadro mostra para este caso específico de simetria a influência da fase $\mathrm{C}$, e pode explicar para os demais casos de simetria observados com as faltas francas a razão dos mesmos não existiram ao se variar a impedância de falta.

Quando se avalia a simetria entre duas situações de falta desequilibradas é necessário que a diferença entre os valores de tensão das 3 fases estejam dentro do intervalo de simetria para que essas duas situações de falta sejam simétricas. Ao analisar o caso dos eventos 70 e 95 com impedância de falta franca o intervalo da barra 11 é 0,0066 p.u. e o Quadro 3 mostra que a diferença para as 3 fases estão dentro da faixa que determina a simetria. Portanto, os eventos 70 e 95 com impedância franca são simétricos. Já para $Z_{f}=25 \Omega$ a diferença de tensão para as fases A e B estão dentro do intervalo de simetria, porém a fase $\mathrm{C}$ está de fora $(0,0045>0,0018)$. Então, as condições de falta 70 e $95 \mathrm{com} Z_{f}=25 \Omega$ não são simétricas com relação à barra 11 . Como essa situação de simetria foi quebrada, esses dois eventos são identificáveis caso a barra 11 seja um ponto de instalação de PQM. Analogamente, a diferença de tensão da fase $\mathrm{C}$ é maior que o comprimento do intervalo de simetria para o caso $Z_{f}=50 \Omega$, o que faz com que os dois eventos não sejam simétricos.

A discussão acima ajuda a explicar o porquê, para este tipo de falta, o total de eventos simulados é identificado somente para conjuntos de falta com impedâncias mais altas. Todas as 3 soluções obtidas para os cenários com $Z_{f}=25$ e $50 \Omega$ (Tabela 3) possuem a barra 11, a qual consegue quebrar pelo menos uma das condições de simetria que fazem com que os eventos mostrados para o cenário com faltas francas não sejam identificáveis. Em particular, a solução $\{7,11,12,13\}$ que atende a todos os cenários para as 
faltas trifásicas e monofásicas AT, identifica 169 eventos BC francos. Além dos eventos não identificados mostrados na Tabela 5, esta solução não identifica os eventos 133 e 134, devido à uma simetria existente entre eles. No entanto, esses dois eventos estão localizados no mesmo ramal (dois últimos simulados no trecho 8-12) e, portanto, a simetria existente entre eles não é tão crítica para o problema estudado, visto que não se trata de um caso de múltipla estimação. Em outras palavras, caso uma das duas situações de falta ocorressem no sistema, a equipe de manutenção seria direcionada para o local correto da falta.

\subsubsection{Cenário para faltas bifásicas BCT}

As Tabelas 6, 7 e 8 mostram os resultados para a resolução do Modelo 2 frente a ocorrência de faltas bifásicas $B C T$.

Tabela 6 - Resultados para o cenário de faltas do tipo $B C T\left(Z_{f}=0 \Omega\right)$.

\begin{tabular}{ccc}
\hline Número de PQMs & Barras onde os PQMs foram alocados & Número de eventos identificados \\
\hline 2 & 1,10 & 187 \\
2 & 1,12 & 187 \\
2 & 9,13 & 187 \\
2 & 9,14 & 187 \\
2 & 10,14 & 187 \\
2 & 11,13 & 187 \\
2 & 11,14 & 187 \\
2 & 12,14 & 187 \\
\hline
\end{tabular}

Fonte: Elaborada pelo autor.

Tabela 7 - Resultados para o cenário de faltas bifásicas $B C T\left(Z_{f}=25 \Omega\right)$.

\begin{tabular}{cccc}
\hline Número de PQMs & $\begin{array}{c}\text { Barras onde os } \\
\text { PQMs foram } \\
\text { alocados }\end{array}$ & $\begin{array}{c}\text { Número de } \\
\text { eventos } \\
\text { identificados }\end{array}$ & Eventos não identificados \\
\hline 3 & $1,5,12$ & 169 & $70-72,95-97,107-109,118-122,131-134$ \\
3 & $5,11,13$ & 169 & $70-72,95-97,107-109,118-122,131-134$ \\
3 & $5,12,13$ & 169 & $70-72,95-97,107-109,118-122,131-134$ \\
3 & $6,10,13$ & 169 & $70-72,95-97,107-109,118-122,131-134$ \\
3 & $6,10,14$ & 169 & $70-72,95-97,107-109,118-122,131-134$ \\
3 & $6,11,15$ & 169 & $70-72,95-97,107-109,118-122,131-134$ \\
\hline
\end{tabular}

Fonte: Elaborada pelo autor.

A Tabela 6 mostra 8 soluções distintas para o cenário de faltas bifásicas do tipo $B C T$ francas. Nesses casos, foram identificadas a quantidade máxima de eventos com 2 PQMs. Algumas das soluções dentre essas estão presentes para os casos de faltas trifásicas e $A T$ francas, como por exemplo, as soluções $\{9,13\}$ e $\{11,13\}$.

Ao se variar a impedância de falta para $25 \Omega$, alguns eventos passam a não ser identificados, como mostra a Tabela 7. Também se observa que a quantidade requerida de medidores aumentou para 3 para as soluções apresentadas. Para todas as alocações encontradas os eventos não identificados são os 
Tabela 8 - Resultados para o cenário de faltas bifásicas $B C T\left(Z_{f}=50 \Omega\right)$.

\begin{tabular}{cccc}
\hline Número de PQMs & $\begin{array}{c}\text { Barras onde os } \\
\text { PQMs foram } \\
\text { alocados }\end{array}$ & $\begin{array}{c}\text { Número de } \\
\text { eventos } \\
\text { identificados }\end{array}$ & Eventos não identificados \\
\hline 3 & $1,2,10$ & 161 & $70-74,95-99,107-113,120-126,133,134$ \\
3 & $2,10,13$ & 161 & $70-74,95-99,107-113,120-126,133,134$ \\
3 & $2,10,15$ & 161 & $70-74,95-99,107-113,120-126,133,134$ \\
3 & $2,11,13$ & 161 & $70-74,95-99,107-113,120-126,133,134$ \\
3 & $2,11,14$ & 161 & $70-74,95-99,107-113,120-126,133,134$ \\
\hline
\end{tabular}

Fonte: Elaborada pelo autor.

mesmos, sendo que: os eventos 70-72 são os 3 primeiros simulados no trecho entre as barras 4 e 5 , os eventos 95-97 são os 3 primeiros simulados no trecho 4-8, os eventos 107-109 são os 3 do trecho 8-9, os eventos número 118-122 são os 2 últimos simulados no trecho 10-11 e os 3 primeiros do trecho 8-12, e os eventos 131-134 são os 4 últimos do trecho 8-12. Vale lembrar que os eventos 70-72 e 95-97 também não foram identificados para o caso de faltas $B C$ francas.

Com a impedância de falta em $50 \Omega$ a quantidade máxima de eventos identificados reduz mais um pouco, chegando a 161. As soluções encontradas também possuem 3 PQMs, mas são todas diferentes do caso anterior. Algumas barras aparecem nas soluções para os dois casos de variação de impedância, como as barras 11 e 13. Também é notada uma preferência da barra 2 ao invés da barra 5 ou 6 . Alguns dos eventos não identificados são comuns aos dois casos de variação de $Z_{f}$. Os 26 eventos não identificados são: os eventos 70-74, localizados no trecho entre as barras 4 e 5; os eventos 95-99, 5 primeiros simulados no trecho 4-8; os eventos 107-113, os 3 simulados no trecho 8-9 juntamente com os 4 primeiros do trecho 9-10; os eventos 120-126, que são os 7 primeiros simulados no trecho 8-12; e por último os eventos 133 e 134; dois últimos simulados no trecho 8-12.

Todos os eventos não identificados apresentados (para $Z_{f}=25$ e $50 \Omega$ ) estão localizados logo após um ponto de bifurcação no sistema e a não-identificação ocorre devido a uma simetria existente entre um par de eventos equidistantes da subestação situados em ramais diferentes, com exceção dos últimos eventos simulados no trecho 8-12, os quais não configuram casos de múltipla estimação da falta. A dificuldade na quebra de todos esses casos de simetria, ao se aumentar o valor da impedância de falta, ocorre em razão das características do curto-circuito bifásico-terra. Uma análise das tensões durante esse tipo de falta pode mostrar a causa dessa dificuldade. Como os eventos 70 e 95 também configuram caso de simetria para este curto-circuito (e para permitir uma comparação), eles são utilizados para exemplificar, assim como na falta bifásica BC, a influência da variação da impedância de falta. O Quadro 4 mostra as tensões para as 3 fases da barra 11 durante um curto do tipo BCT com os 3 valores de impedância de falta considerados.

Esse tipo de curto-circuito apresenta afundamentos de tensão nas fases B e C, e elevação de tensão na fase $\mathrm{A}$. Os valores de tensão nas fases $\mathrm{B}$ e $\mathrm{C}$ são mais próximos, comparados ao curto-circuito BC. Além disso, essas tensões chegam a 0 p.u. com a impedância de falta franca, como pode ser visto nas tensões medidas para o evento 95 . O medidor da barra 11 registra o mesmo valor de tensão no ponto da falta 95 , e um valor ligeiramente mais alto para a falta 70 , visto que ele mede a mesma tensão da barra 
Quadro 4 - Valores de tensão durante uma falta do tipo BCT medidos na barra 11 do sistema do CIGRÉ.

\begin{tabular}{|c|c|c|c|c|c|c|c|c|c|}
\hline & \multicolumn{3}{|c|}{$Z_{f}=0 \Omega$} & \multicolumn{3}{c|}{$Z_{f}=25 \Omega$} & \multicolumn{3}{c|}{$Z_{f}=50 \Omega$} \\
\cline { 2 - 10 } & $V_{a}(\mathrm{pu})$ & $V_{b}(\mathrm{pu})$ & $V_{c}(\mathrm{pu})$ & $V_{a}(\mathrm{pu})$ & $V_{b}(\mathrm{pu})$ & $V_{c}(\mathrm{pu})$ & $V_{a}(\mathrm{pu})$ & $V_{b}(\mathrm{pu})$ & $V_{c}(\mathrm{pu})$ \\
\hline 70 & 1,1760 & 0,0120 & 0,0113 & 1,0213 & 0,4431 & 0,4443 & 1,0094 & 0,4730 & 0,4724 \\
\hline 95 & 1,1786 & 0,0000 & 0,0000 & 1,0216 & 0,4429 & 0,4429 & 1,0096 & 0,4722 & 0,4722 \\
\hline Diferença & 0,0026 & 0,0120 & 0,0113 & 0,0003 & 0,0002 & 0,0014 & 0,0002 & 0,0008 & 0,0002 \\
\hline Intervalo & \multicolumn{3}{|c|}{0,0079} & \multicolumn{3}{c}{0,0069} & \multicolumn{3}{c}{0,0067} \\
\hline
\end{tabular}

Fonte: Elaborada pelo autor.

4 (que está um pouco acima do ponto de falta). Essa diferença entre as tensões das fases B e C para as duas faltas é grande o suficiente para extrapolar os limites do intervalo de simetria, permitindo assim a identificação desses dois eventos. O Quadro 4 mostra, entretanto, que para valores mais altos de $Z_{f}$ essa diferença não é tão expressiva, o que faz com que essas duas faltas sejam simétricas com relação à barra 11. Como nenhuma outra barra consegue quebrar a simetria existente entre esses dois eventos, eles não conseguem ser identificados. Situação semelhante ocorre para os demais casos de eventos não identificados.

A razão da preferência da barra 2 nas soluções da instância com $Z_{f}=50 \Omega$ é que esta barra permite a identificação do evento 132. Por exemplo, a solução $\{5,11,13\}$ (Tabela 7) seria o mesmo que trocar a barra 2 pela barra 5 na quarta solução apresentada para $Z_{f}=50 \Omega$. Esta alocação identifica apenas 160 eventos, não sendo uma solução ótima para o Modelo 2. Dentre os 27 eventos não identificados, 26 são os mostrados na Tabela 8 e o evento adicional é o 132, que não é identificado devido a uma simetria existente com o evento 133. A solução $\{7,11,12,13\}$, discutida para os outros tipos de falta, identifica os mesmos 160 eventos. Para a instância com curtos BCT e impedância de falta de $25 \Omega$ esta solução identifica os mesmos 169 eventos, valor ótimo.

Portanto, apesar de terem sido apresentados vários sistemas de monitoramento para todos os tipos de falta e cada variação na impedância de falta, sendo que todos eles atendem igualmente bem cada cenário apresentado, sugere-se a opção pela alocação $\{7,11,12,13\}$, visto que ela consegue atender muito bem a todos os cenários apresentados. Os poucos casos em que esta solução não identificou a quantidade ótima de eventos, os não identificados foram sempre casos de simetria que não correspondiam a situações de múltipla estimação da falta. Então, este sistema de monitoramento pode ser uma excelente opção para dar suporte a um localizador de faltas.

\subsubsection{Cenário para faltas trifásicas considerando o GD conectado}

Ao se considerar o GD conectado ao sistema, nota-se mudanças nas respostas do método, como mostra a Tabela 9.

A quantidade máxima de eventos identificados é 183, sendo necessários pelo menos 3 medidores para identificá-los. Dessa forma, reduziu-se a quantidade de eventos identificados e aumentou-se a quantidade de PQMs. Os eventos não identificados não são casos de múltipla estimação, porém estarem localizados no final do ramal 8-12. A presença do GD faz com que as tensões na barra 12 devido a cada um desses curtos não identificados seja diferente de 0 p.u., sendo a tensão mais baixa é observada na barra 
Tabela 9 - Resultados para o cenário de faltas trifásicas considerando o GD conectado à rede principal $\left(Z_{f}=0 \Omega\right)$.

\begin{tabular}{cccc}
\hline Número de PQMs & $\begin{array}{c}\text { Barras onde os } \\
\text { PQMs foram } \\
\text { alocados }\end{array}$ & $\begin{array}{c}\text { Número de } \\
\text { eventos } \\
\text { identificados }\end{array}$ & Eventos não identificados \\
\hline 3 & $1,5,11$ & 183 & $131,132,133,134$ \\
3 & $4,10,13$ & 183 & $131,132,133,134$ \\
3 & $4,11,13$ & 183 & $131,132,133,134$ \\
3 & $5,9,13$ & 183 & $131,132,133,134$ \\
3 & $5,10,13$ & 183 & $131,132,133,134$ \\
3 & $5,11,13$ & 183 & $131,132,133,134$ \\
3 & $6,11,13$ & 183 & $131,132,133,134$ \\
\hline
\end{tabular}

Fonte: Elaborada pelo autor.

11 (0,1245 p.u. para o evento 133). A diferença de tensão é suficiente pequena para impedir a quebra de simetria entre esses eventos.

Entretanto, para valores de impedância de falta de 25 e $50 \Omega$, a geração distribuída não impactou na quantidade de eventos identificáveis (Tabela 10). Além disso, o GD impactou positivamente no número requerido de medidores, reduzindo de 4 para 3. Comparando as 3 soluções mostradas, percebe-se a não necessidade da presença da barra 12 no conjunto de PQMs, sendo esta a barra onde está ligado o GD. Para esses valores de impedância de falta as tensões remanescentes são bem mais elevadas, e as diferenças de tensão entre possíveis casos de simetria são sempre maiores que os limites dos intervalos para cada barra.

Tabela 10 - Resultados para o cenário de faltas trifásicas considerando o GD conectado à rede principal $\left(Z_{f}=25 \mathrm{e}\right.$ $50 \Omega$ ).

\begin{tabular}{ccc}
\hline Número de PQMs & Barras onde os PQMs foram alocados & Número de eventos identificados \\
\hline 3 & $7,11,13$ & 187 \\
3 & $7,11,14$ & 187 \\
3 & $7,11,15$ & 187 \\
\hline
\end{tabular}

Fonte: Elaborada pelo autor.

\subsubsection{Cenário para faltas monofásicas AT considerando o GD conectado}

A Tabela 11 mostra as soluções encontradas para a instância de faltas $A T$ francas ao se considerar a presença da geração distribuída.

Este é um caso de curto-circuito menos severo, comparado ao curto trifásico, e por isso os afundamentos de tensão são mais brandos. Essa característica facilita a quebra das simetrias entre os eventos.

Os resultados mostram que para este cenário não existe diferença na quantidade de eventos identificados, quando comparada ao caso em que o GD não estava presente. No entanto, a quantidade de PQMs das soluções apresentadas é maior em relação ao caso sem GD.

Ao se variar a impedância de falta para 25 e $50 \Omega$ as soluções encontradas são as mesmas para a instância de faltas trifásicas (Tabela 10). 
Tabela 11 - Resultados para o cenário de faltas do tipo $A T$ considerando o GD conectado à rede principal $\left(Z_{f}=0 \Omega\right)$.

\begin{tabular}{ccc}
\hline Número de PQMs & Barras onde os PQMs foram alocados & Número de eventos identificados \\
\hline 3 & $1,4,12$ & 187 \\
3 & $3,12,13$ & 187 \\
3 & $3,12,14$ & 187 \\
3 & $4,12,13$ & 187 \\
3 & $4,12,15$ & 187 \\
\hline
\end{tabular}

Fonte: Elaborada pelo autor.

\subsubsection{Cenário para faltas bifásicas $B C$ considerando o GD conectado}

Ao se considerar o GD conectado no cenário de faltas $B C$ a quantidade de eventos identificados reduz de 171 para 170. No entanto, excluindo os eventos 120-124 não existe correspondência entre os eventos não identificados. A Tabela 12 mostra duas soluções distintas que identificam essa quantidade de eventos, sendo que elas apresentam 3 medidores ao invés de 4, como era o caso desconsiderando a presença do GD.

Tabela 12 - Resultados para o cenário de faltas do tipo $B C$ considerando o GD conectado à rede principal $\left(Z_{f}=0 \Omega\right)$.

\begin{tabular}{cccc}
\hline Número de PQMs & $\begin{array}{c}\text { Barras onde os PQMs } \\
\text { foram alocados }\end{array}$ & $\begin{array}{c}\text { Número de eventos } \\
\text { identificados }\end{array}$ & Eventos não identificados \\
\hline 3 & $1,2,12$ & 170 & $93,94,120-134$ \\
3 & $2,12,13$ & 170 & $93,94,120-134$ \\
\hline
\end{tabular}

Fonte: Elaborada pelo autor.

Resolvendo o Modelo 2 para a instância com $Z_{f}=25 \Omega$ o algoritmo encontrou as mesmas soluções já mostradas para as faltas trifásicas e monofásicas $A T$ (Tabela 10).

Porém, como para a instância com $Z_{f}=50 \Omega$ o algoritmo encontrou outras 3 soluções distintas. Essas soluções para $Z_{f}=25 \Omega$ são repetidas na Tabela 13 .

Tabela 13 - Resultados para o cenário de faltas bifásicas $B C$ considerando o GD conectado à rede principal $\left(Z_{f}=50 \Omega\right)$.

\begin{tabular}{ccc}
\hline Número de PQMs & Barras onde os PQMs foram alocados & Número de eventos identificados \\
\hline 3 & $7,10,13$ & 187 \\
3 & $7,10,14$ & 187 \\
3 & $7,10,15$ & 187 \\
3 & $7,11,13$ & 187 \\
3 & $7,11,14$ & 187 \\
3 & $7,11,15$ & 187 \\
\hline
\end{tabular}

Fonte: Elaborada pelo autor.

A Tabela 13 mostra outras 3 soluções que podem ser obtidas simplesmente trocando a barra 11 pela barra 10 em cada uma delas. Todas essas soluções identificam os 187 eventos. 


\subsubsection{Cenário para faltas bifásicas BCT considerando o GD conectado}

As Tabelas 14, 15 e 16 mostram os resultados da solução do modelo 2 para faltas bifásicas BCT onde é considerada a presença da geração distribuída no sistema CIGRÉ.

Tabela 14 - Resultados para o cenário de faltas do tipo BCT considerando o GD conectado à rede principal $\left(Z_{f}=0 \Omega\right)$.

\begin{tabular}{ccc}
\hline Número de PQMs & Barras onde os PQMs foram alocados & Número de eventos identificados \\
\hline 3 & $1,10,12$ & 187 \\
3 & $8,12,13$ & 187 \\
3 & $9,12,13$ & 187 \\
3 & $9,12,14$ & 187 \\
3 & $9,12,15$ & 187 \\
3 & $10,12,14$ & 187 \\
3 & $11,12,13$ & 187 \\
\hline
\end{tabular}

Fonte: Elaborada pelo autor.

Tabela 15 - Resultados para o cenário de faltas bifásicas BCT considerando o GD conectado à rede principal $\left(Z_{f}=25 \Omega\right)$.

\begin{tabular}{cccc}
\hline Número de PQMs & $\begin{array}{c}\text { Barras onde os PQMs } \\
\text { foram alocados }\end{array}$ & $\begin{array}{c}\text { Número de eventos } \\
\text { identificados }\end{array}$ & Eventos não identificados \\
\hline 2 & 1,12 & 166 & $70,92-95,107,120-134$ \\
2 & 12,13 & 166 & $70,92-95,107,120-134$ \\
2 & 12,14 & 166 & $70,92-95,107,120-134$ \\
2 & 12,15 & 166 & $70,92-95,107,120-134$ \\
\hline
\end{tabular}

Fonte: Elaborada pelo autor.

Tabela 16 - Resultados para o cenário de faltas bifásicas $B C T$ considerando o GD conectado à rede principal $\left(Z_{f}=50 \Omega\right)$.

\begin{tabular}{cccc}
\hline Número de PQMs & $\begin{array}{c}\text { Barras onde os PQMs } \\
\text { foram alocados }\end{array}$ & $\begin{array}{c}\text { Número de eventos } \\
\text { identificados }\end{array}$ & Eventos não identificados \\
\hline 3 & $1,2,12$ & 170 & $93,94,120-134$ \\
3 & $2,12,13$ & 170 & $93,94,120-134$ \\
3 & $2,12,14$ & 170 & $93,94,120-134$ \\
\hline
\end{tabular}

Fonte: Elaborada pelo autor.

Para o cenário com faltas francas (Tabela 14), também são identificados todos os 187 eventos, quando comparado ao caso em que o GD estava desconectado. Porém, são necessários $3 \mathrm{PQMs}$ ao invés de 2. A comparação dos dois conjuntos de soluções mostra que a maioria das soluções com 2 PQMs estão contidas em soluções com 3 PQMs, o que sugere utilizar-se de uma delas de modo a atender a incerteza da presença da geração distribuída.

A resolução da instância com impedância de falta em $25 \Omega$ mostra uma redução na quantidade de eventos identificados, de 169 (sem GD) para 166 (com GD). São apresentadas 4 soluções distintas na Tabela 15, sendo que estas também estão contidas nas soluções da Tabela 14. 
Para a instância com $Z_{f}=50 \Omega$ considerando o GD conectado à rede principal foram identificados 170 eventos, sendo que para o cenário análogo desconsiderando o GD foram identificados apenas 161. A Tabela 16 apresenta 3 soluções distintas, sendo que as 3 primeiras soluções da Tabela 15 estão contidas nesse conjunto, bastando adicionar a barra $2 \mathrm{em}$ cada uma delas para se chegar às 3 soluções encontradas para $Z_{f}=50 \Omega$. Os 17 eventos não identificados da Tabela 16 estão todos contidos nos 21 eventos não identificados da Tabela 15.

\subsubsection{Análise dos resultados para o sistema IEEE 123 barras}

Nesta seção são apresentados os resultados para a aplicação do Modelo 2 de maximização da quantidade de eventos identificados no sistema do IEEE de 123 barras. Os resultados estão divididos para cada um dos 10 tipos de falta: $A B C, A T, B T, C T, A B, A C, B C, A B T, A C T$ e $B C T$. Assim como para os resultados do sistema CIGRÉ, é feita uma análise sobre a variação da impedância de falta com base em três valores.

\subsubsection{Cenário para faltas trifásicas}

A Tabela 17 apresenta os resultados para faltas trifásicas francas no sistema do IEEE de 123 barras. O algoritmo retornou as 10 soluções distintas, contendo todas 6 PQMs e identificando 667 eventos, sendo essa a quantidade máxima, visto que para o cenário de faltas trifásicas foram simuladas 667 situações de curto-circuito. É importante ressaltar que para este sistema a quantidade de faltas simuladas varia para cada tipo, devido à presença de ramais monofásicos e bifásicos, onde não é possível simular uma falta trifásica, por exemplo. Isso faz com que o banco de dados trifásico seja o menor de todos.

Tabela 17 - Resultados para o cenário de faltas trifásicas $\left(Z_{f}=0 \Omega\right)$.

\begin{tabular}{ccc}
\hline Número de PQMs & Barras onde os PQMs foram alocados & Número de eventos identificados \\
\hline 6 & $13,24,59,94,110,116$ & 667 \\
6 & $18,21,57,94,110,116$ & 667 \\
6 & $20,22,59,96,106,114$ & 667 \\
6 & $22,59,76,100,105,117$ & 667 \\
6 & $22,60,75,97,106,116$ & 667 \\
6 & $22,60,81,100,110,117$ & 667 \\
6 & $23,57,80,100,111,118$ & 667 \\
6 & $23,57,81,97,104,114$ & 667 \\
6 & $24,58,76,96,109,117$ & 667 \\
6 & $25,58,80,95,111,116$ & 667 \\
\hline
\end{tabular}

Fonte: Elaborada pelo autor.

As soluções para as instâncias trifásicas com $Z_{f}=25$ e $50 \Omega$ são idênticas, e estão resumidas na Tabela 18. As oito soluções mostradas identificam todos os 667 eventos. No entanto, conforme observado, o número de PQMs aumentou de 6 para 10. 
Tabela 18 - Resultados para o cenário de faltas trifásicas $\left(Z_{f}=25\right.$ e $\left.50 \Omega\right)$.

\begin{tabular}{ccc}
\hline Número de PQMs & Barras onde os PQMs foram alocados & Número de eventos identificados \\
\hline 10 & $15,57,68,82,94,98,106,108,116,118$ & 667 \\
10 & $15,57,68,82,94,98,108,111,116,118$ & 667 \\
10 & $15,58,68,82,94,98,106,108,116,118$ & 667 \\
10 & $15,58,68,82,94,98,108,111,116,117$ & 667 \\
10 & $15,58,68,82,94,98,108,111,116,118$ & 667 \\
10 & $15,59,68,82,94,98,106,108,116,118$ & 667 \\
10 & $15,60,68,82,94,98,106,108,116,118$ & 667 \\
10 & $15,60,68,82,94,98,108,111,116,118$ & 667 \\
\hline
\end{tabular}

Fonte: Elaborada pelo autor.

\subsubsection{Cenário para faltas monofásicas AT}

A resolução do Modelo 2 para faltas monofásicas do tipo $A T$ francas também encontra o valor ótimo igual à quantidade de faltas simuladas (902). A Tabela 19 mostra 7 alocações de medidores distintas com mesmo valor ótimo. Todas as soluções obtidas contendo 7 medidores.

Tabela 19 - Resultados para o cenário de faltas do tipo $A T\left(Z_{f}=0 \Omega\right)$.

\begin{tabular}{ccc}
\hline Número de PQMs & Barras onde os PQMs foram alocados & Número de eventos identificados \\
\hline 7 & $18,21,29,49,58,99,106$ & 902 \\
7 & $19,21,30,41,57,94,106$ & 902 \\
7 & $19,22,29,39,60,100,106$ & 902 \\
7 & $19,23,29,42,60,100,106$ & 902 \\
7 & $19,23,29,50,60,100,106$ & 902 \\
7 & $21,29,50,57,73,99,106$ & 902 \\
7 & $23,30,48,58,73,94,106$ & 902 \\
\hline
\end{tabular}

Fonte: Elaborada pelo autor.

Ao se variar o valor da impedância de falta obteve-se soluções que ainda conseguiram identificar os 902 eventos, tanto para $25 \Omega$ como para $50 \Omega$. Todas essas soluções são mostradas nas Tabelas 20 e 21 , respectivamente, contendo 14 medidores.

Tabela 20 - Resultados para o cenário de faltas do tipo $A T\left(Z_{f}=25 \Omega\right)$.

\begin{tabular}{ccc}
\hline Número de PQMs & Barras onde os PQMs foram alocados & $\begin{array}{c}\text { Número de } \\
\text { eventos } \\
\text { identificados }\end{array}$ \\
\hline 14 & $20,29,30,48,58,68,73,86,96,106,107,108,111,117$ & 902 \\
14 & $20,29,30,48,59,68,73,77,86,100,107,108,111,117$ & 902 \\
14 & $20,29,30,48,59,68,73,86,96,106,107,108,111,118$ & 902 \\
14 & $20,29,30,48,60,68,73,86,95,106,107,108,111,118$ & 902 \\
14 & $20,29,30,49,59,68,73,76,86,100,107,108,111,117$ & 902 \\
14 & $20,29,30,49,59,68,73,86,98,106,107,108,111,117$ & 902 \\
\hline
\end{tabular}


Tabela 21 - Resultados para o cenário de faltas do tipo $A T\left(Z_{f}=50 \Omega\right)$.

Número de PQMs Barras onde os PQMs foram alocados

Número de

eventos

\begin{tabular}{ccc} 
& & identificados \\
\hline 14 & $20,29,30,48,57,68,73,78,86,99,107,108,111,117$ & 902 \\
14 & $20,29,30,48,58,68,73,77,86,99,107,108,111,117$ & 902 \\
14 & $20,29,30,48,59,68,73,78,86,100,107,108,111,117$ & 902 \\
14 & $20,29,30,48,60,68,73,78,86,100,107,108,111,118$ & 902 \\
14 & $20,29,30,49,60,68,73,86,95,106,107,108,111,118$ & 902 \\
\hline
\end{tabular}

Fonte: Elaborada pelo autor.

\subsubsection{Cenário para faltas monofásicas BT}

Para as faltas monofásicas $B T$ a metodologia de aplicação das situações de falta resultou em um conjuntos com 783 curtos-circuitos. Considerando as faltas francas o algoritmo encontrou soluções com 5 PQMs que identificam todos os 783 eventos (Tabela 22).

Tabela 22 - Resultados para o cenário de faltas do tipo $B T\left(Z_{f}=0 \Omega\right)$.

\begin{tabular}{ccc}
\hline Número de PQMs & Barras onde os PQMs foram alocados & Número de eventos identificados \\
\hline 5 & $1,18,60,94,106$ & 783 \\
5 & $1,20,57,97,106$ & 783 \\
5 & $20,23,60,96,106$ & 783 \\
5 & $21,58,74,97,106$ & 783 \\
5 & $21,60,73,96,106$ & 783 \\
5 & $23,60,75,97,106$ & 783 \\
\hline
\end{tabular}

Fonte: Elaborada pelo autor.

Tabela 23 - Resultados para o cenário de faltas do tipo $B T\left(Z_{f}=25 \Omega\right)$.

\begin{tabular}{ccc}
\hline Número de PQMs & Barras onde os PQMs foram alocados & Número de eventos identificados \\
\hline 8 & $19,25,26,47,60,100,108,111$ & 783 \\
8 & $19,25,27,41,59,96,108,111$ & 783 \\
8 & $19,25,27,45,59,95,108,111$ & 783 \\
8 & $19,25,29,45,60,94,108,111$ & 783 \\
8 & $20,25,28,51,57,97,108,111$ & 783 \\
8 & $20,25,30,48,59,98,108,111$ & 783 \\
8 & $25,28,46,57,73,96,108,111$ & 783 \\
8 & $25,30,49,60,75,99,108,111$ & \\
\hline
\end{tabular}

Fonte: Elaborada pelo autor.

Para variações da impedância de falta em 25 e $50 \Omega$ a quantidade de eventos identificados não se alterou, no entanto as soluções apresentadas pelas Tabelas 23 e 24 contém 8 medidores. Apesar da quantidade de medidores ter aumentado, em relação ao caso com situações de falta monofásicas BT francas, esta ainda é uma quantidade pequena comparada com a quantidade total de barras candidatas à instalação de medidores (118). Apesar de o algoritmo ter encontrado soluções com 8 medidores para 
Tabela 24 - Resultados para o cenário de faltas do tipo $B T\left(Z_{f}=50 \Omega\right)$.

\begin{tabular}{ccc}
\hline Número de PQMs & Barras onde os PQMs foram alocados & Número de eventos identificados \\
\hline 8 & $16,25,28,51,60,96,108,111$ & 783 \\
8 & $17,25,28,46,58,100,108,111$ & 783 \\
8 & $17,25,28,47,60,99,108,111$ & 783 \\
8 & $18,25,26,51,58,97,108,111$ & 783 \\
8 & $19,25,26,47,60,97,108,111$ & 783 \\
8 & $19,25,26,50,60,99,108,111$ & 783 \\
8 & $19,25,27,45,59,95,108,111$ & 783 \\
8 & $20,25,27,50,59,99,108,111$ & 783 \\
8 & $25,27,45,60,75,100,108,111$ & 783 \\
8 & $25,30,45,58,73,98,108,111$ & 783 \\
\hline
\end{tabular}

Fonte: Elaborada pelo autor.

ambos os casos de variação da impedância de falta, as alocações encontradas diferem entre si. É possível que existam soluções comuns às duas instâncias, porém devido ao comportamento do AG e à quantidade enorme de combinações ótimas possíveis com 8 medidores, seria muito improvável que ele retornasse soluções comuns aos dois casos.

\subsubsection{Cenário para faltas monofásicas CT}

Para caso de faltas monofásicas do tipo $C T$, o algoritmo encontrou o valor de 889 eventos identificados. Sendo que esta é a quantidade de faltas simuladas, pode-se afirmar que o algoritmo convergiu para o valor ótimo global da função objetivo. A Tabela 25 , mostra 9 soluções distintas contendo 7 medidores para o cenário com faltas francas, ou seja, das dez vezes que o algoritmo foi executado houve uma delas em que ele encontrou uma solução idêntica a outra obtida em execuções anteriores.

Tabela 25 - Resultados para o cenário de faltas do tipo $C T\left(Z_{f}=0 \Omega\right)$.

\begin{tabular}{ccc}
\hline Número de PQMs & Barras onde os PQMs foram alocados & Número de eventos identificados \\
\hline 7 & $13,22,34,51,57,99,106$ & 889 \\
7 & $14,22,33,49,60,97,105$ & 889 \\
7 & $19,22,33,37,59,99,105$ & 889 \\
7 & $19,22,34,40,60,99,106$ & 889 \\
7 & $19,23,33,51,59,97,111$ & 889 \\
7 & $20,22,33,46,59,97,105$ & 889 \\
7 & $20,24,34,49,57,98,111$ & 889 \\
7 & $22,33,41,59,76,97,106$ & 889 \\
7 & $23,34,51,57,80,97,111$ & 889 \\
\hline
\end{tabular}

Fonte: Elaborada pelo autor.

As Tabelas 26 e 27 mostram as soluções encontradas para as instâncias com $Z_{f}=25$ e $50 \Omega$, respectivamente. As soluções para ambos os cenários apresentam 8 medidores. 
Tabela 26 - Resultados para o cenário de faltas do tipo $C T\left(Z_{f}=25 \Omega\right)$.

\begin{tabular}{ccc}
\hline Número de PQMs & Barras onde os PQMs foram alocados & Número de eventos identificados \\
\hline 8 & $22,25,34,51,59,78,100,111$ & 889 \\
8 & $23,25,33,49,60,78,100,111$ & 889 \\
8 & $23,25,34,48,59,78,100,111$ & 889 \\
8 & $24,25,33,50,58,78,100,111$ & 889 \\
\hline
\end{tabular}

Fonte: Elaborada pelo autor.

Tabela 27 - Resultados para o cenário de faltas do tipo $C T\left(Z_{f}=50 \Omega\right)$.

\begin{tabular}{ccc}
\hline Número de PQMs & Barras onde os PQMs foram alocados & Número de eventos identificados \\
\hline 8 & $23,25,34,49,57,74,100,111$ & 889 \\
8 & $23,25,34,49,60,78,100,111$ & 889 \\
\hline
\end{tabular}

Fonte: Elaborada pelo autor.

\subsubsection{Cenário para faltas bifásicas $A B$}

As Tabelas 28 e 29 mostram as soluções retornadas pelo AG, contendo 9 e 10 PQMs, respectivamente, para os cenários com variação de $Z_{f}$.

Tabela 28 - Resultados para o cenário de faltas do tipo $A B\left(Z_{f}=25 \Omega\right)$.

\begin{tabular}{ccc}
\hline Número de PQMs & Barras onde os PQMs foram alocados & Número de eventos identificados \\
\hline 9 & $12,57,67,82,98,106,108,116,118$ & 686 \\
9 & $12,58,67,81,97,106,108,115,117$ & 686 \\
9 & $13,59,67,79,96,106,108,116,117$ & 686 \\
9 & $13,60,68,79,95,108,111,115,118$ & 686 \\
9 & $14,57,68,81,96,108,111,115,118$ & 686 \\
9 & $14,60,68,82,96,108,111,115,118$ & 686 \\
9 & $15,59,67,81,96,106,108,116,117$ & 686 \\
9 & $15,59,68,81,94,106,108,115,117$ & 686 \\
9 & $15,60,67,82,96,106,108,116,117$ & 686 \\
9 & $15,60,68,80,97,106,108,115,117$ & 686 \\
\hline
\end{tabular}

Fonte: Elaborada pelo autor.

Tabela 29 - Resultados para o cenário de faltas do tipo $A B\left(Z_{f}=50 \Omega\right)$.

\begin{tabular}{ccc}
\hline Número de PQMs & Barras onde os PQMs foram alocados & Número de eventos identificados \\
\hline 8 & $13,58,67,80,97,106,116,118$ & 686 \\
8 & $13,60,68,80,97,106,116,117$ & 686 \\
8 & $16,58,67,79,97,106,116,118$ & 686 \\
8 & $16,58,67,80,98,106,116,118$ & 686 \\
8 & $16,58,67,81,96,106,116,118$ & 686 \\
8 & $17,59,68,81,95,106,116,118$ & 686 \\
\hline
\end{tabular}

Fonte: Elaborada pelo autor.

Para faltas francas a Tabela 30 mostra que foram identificados 576 eventos. 
Tabela 30 - Resultados para o cenário de faltas bifásicas $A B\left(Z_{f}=0 \Omega\right)$.

\begin{tabular}{|c|c|c|c|}
\hline $\begin{array}{l}\text { Número } \\
\text { de PQMs }\end{array}$ & $\begin{array}{l}\text { Barras onde os } \\
\text { PQMs foram } \\
\text { alocados }\end{array}$ & $\begin{array}{l}\text { Número de } \\
\text { eventos } \\
\text { identificados }\end{array}$ & Eventos não identificados \\
\hline 6 & $\begin{array}{c}1,12,60,67 \\
106,117\end{array}$ & 576 & $\begin{array}{c}28,51,52,87-91,98-103,106-112,167,194,195, \\
255,256,267,298-300,322-324,326,345,346, \\
363-369,426-431,441-448,457-470,503-518,558, \\
566-582,669-673\end{array}$ \\
\hline 6 & $\begin{array}{c}1,15,60,67 \\
106,117\end{array}$ & 576 & $\begin{array}{c}28,51,52,87-91,98-103,106-112,167,194,195, \\
255,256,267,298-300,322-324,326,345,346, \\
363-369,426-431,441-448,457-470,503-518,558, \\
566-582,669-673\end{array}$ \\
\hline 6 & $\begin{array}{c}1,16,60,67 \\
106,117\end{array}$ & 576 & $\begin{array}{c}28,51,52,87-91,98-103,106-112,167,194,195, \\
255,256,267,298-300,322-324,326,345,346, \\
363-369,426-431,441-448,457-470,503-518,558, \\
566-582,669-673\end{array}$ \\
\hline 6 & $\begin{array}{c}1,19,57,68 \\
106,118\end{array}$ & 576 & $\begin{array}{c}28,51,52,87-91,98-103,106-112,167,194,195, \\
255,256,267,298-300,322-324,326,345,346, \\
363-369,426-431,441-448,457-470,503-518,558, \\
566-582,669-673\end{array}$ \\
\hline 6 & $\begin{array}{c}1,19,59,68 \\
106,117\end{array}$ & 576 & $\begin{array}{c}28,51,52,87-91,98-103,106-112,167,194,195, \\
255,256,267,298-300,322-324,326,345,346, \\
363-369,426-431,441-448,457-470,503-518,558, \\
566-582,669-673\end{array}$ \\
\hline 6 & $\begin{array}{c}1,58,68,80 \\
106,117\end{array}$ & 576 & $\begin{array}{c}28,51,52,87-91,98-103,106-112,167,194,195, \\
255,256,267,298-300,322-324,326,345,346, \\
363-369,426-431,441-448,457-470,503-518,558, \\
566-582,669-673\end{array}$ \\
\hline 6 & $\begin{array}{c}1,60,68,73 \\
106,117\end{array}$ & 576 & $\begin{array}{c}28,51,52,87-91,98-103,106-112,167,194,195, \\
255,256,267,298-300,322-324,326,345,346, \\
363-369,426-431,441-448,457-470,503-518,558, \\
566-582,669-673\end{array}$ \\
\hline 6 & $\begin{array}{c}16,25,57,68 \\
106,117\end{array}$ & 576 & $\begin{array}{c}28,51,52,87-91,98-103,106-112,167,194,195, \\
255,256,267,298-300,322-324,326,345,346, \\
363-369,426-431,441-448,457-470,503-518,558, \\
566-582,669-673\end{array}$ \\
\hline 6 & $\begin{array}{c}17,25,60,68 \\
106,117\end{array}$ & 576 & $\begin{array}{c}28,51,52,87-91,98-103,106-112,167,194,195, \\
255,256,267,298-300,322-324,326,345,346, \\
363-369,426-431,441-448,457-470,503-518,558, \\
566-582,669-673\end{array}$ \\
\hline 6 & $\begin{array}{c}25,57,68,74 \\
106,117\end{array}$ & 576 & $\begin{array}{c}28,51,52,87-91,98-103,106-112,167,194,195, \\
255,256,267,298-300,322-324,326,345,346, \\
363-369,426-431,441-448,457-470,503-518,558, \\
566-582,669-673\end{array}$ \\
\hline
\end{tabular}


A discussão feita para os curtos-circuitos bifásicos sem conexão com terra no sistema do CIGRÉ ajuda a explicar essa quantidade de eventos não identificados para as faltas AB francas.

\subsubsection{Cenário para faltas bifásicas $A C$}

Para esse cenário as instâncias possuem um total de 684 faltas simuladas, sendo que este tipo de curto-circuito só pode ser simulado em trechos bifásicos AC e trechos trifásicos. Como o sistema IEEE de 123 barras possui apenas um trecho bifásico AC, o qual está situado entre as barras 38 e 50 (Figura 19), esse conjunto de dados ficou pouco maior que o para as faltas trifásicas.

Este curto-circuito bifásico também apresentou a mesma característica de não-identificação de alguns eventos para o caso de faltas francas, os quais conseguem ser identificados ao se aumentar o valor da impedância de falta. As Tabelas 31 e 32 apresentam todas as soluções encontradas, contendo 10 e 9 medidores, respectivamente.

Tabela 31 - Resultados para o cenário de faltas do tipo $A C\left(Z_{f}=25 \Omega\right)$.

\begin{tabular}{ccc}
\hline Número de PQMs & Barras onde os PQMs foram alocados & Número de eventos identificados \\
\hline 10 & $12,42,58,68,79,96,106,108,116,117$ & 684 \\
10 & $12,47,58,68,82,95,106,108,116,118$ & 684 \\
10 & $14,39,57,67,82,95,106,108,115,117$ & 684 \\
10 & $15,39,57,67,79,98,106,108,115,118$ & 684 \\
10 & $39,59,67,76,82,96,106,108,116,117$ & 684 \\
10 & $41,57,68,77,80,95,106,108,116,117$ & 684 \\
10 & $47,57,68,77,81,96,106,108,115,118$ & 684 \\
10 & $49,59,68,77,82,97,106,108,116,118$ & 684 \\
\hline
\end{tabular}

Fonte: Elaborada pelo autor.

Tabela 32 - Resultados para o cenário de faltas do tipo $A C\left(Z_{f}=50 \Omega\right)$.

\begin{tabular}{ccc}
\hline Número de PQMs & Barras onde os PQMs foram alocados & Número de eventos identificados \\
\hline 9 & $12,49,58,67,79,97,106,115,117$ & 684 \\
9 & $13,39,57,67,82,94,106,115,117$ & 684 \\
9 & $13,40,57,68,80,96,106,116,118$ & 684 \\
9 & $13,51,58,68,80,96,106,115,118$ & 684 \\
9 & $14,39,57,68,80,98,106,115,117$ & 684 \\
9 & $15,48,57,67,81,95,106,115,118$ & 684 \\
9 & $15,48,60,68,82,97,106,116,117$ & 684 \\
9 & $15,51,57,68,79,97,106,115,118$ & 684 \\
9 & $48,59,68,76,82,98,106,116,118$ & 684 \\
\hline
\end{tabular}

Fonte: Elaborada pelo autor.

Considerando curtos francos, foram identificadas 574 situações de curto-circuito. A Tabela 33 apresenta todas as 10 soluções obtidas para essa situação, todas elas contendo 7 PQMs. Apesar de valores mais altos de impedância de falta facilitar a identificação dos eventos simulados, pode ser notado que a quantidade de medidores requerida para essa identificação é um pouco maior, comparada com o caso em que os curtos-circuitos foram simulados $\operatorname{com} Z_{f}=0 \Omega$. 
Tabela 33 - Resultados para o cenário de faltas bifásicas $A C\left(Z_{f}=0 \Omega\right)$.

\begin{tabular}{|c|c|c|c|}
\hline $\begin{array}{l}\text { Número } \\
\text { de PQMs }\end{array}$ & $\begin{array}{l}\text { Barras onde os } \\
\text { PQMs foram } \\
\text { alocados }\end{array}$ & $\begin{array}{l}\text { Número de } \\
\text { eventos } \\
\text { identificados }\end{array}$ & Eventos não identificados \\
\hline 7 & $\begin{array}{l}1,16,41,59 \\
67,106,118\end{array}$ & 574 & $\begin{array}{c}28,51,52,87-91,98-103,106-112,167,194,195 \\
220,254,272,273,315-317,339-341,343,344, \\
361-367,424-429,439-446,455-468,501-516,556, \\
564-580,667-671\end{array}$ \\
\hline 7 & $\begin{array}{c}13,22,42,60 \\
68,106,117\end{array}$ & 574 & $\begin{array}{c}28,51,52,87-91,98-103,106-112,167,194,195 \\
220,254,272,273,315-317,339-341,343,344, \\
361-367,424-429,439-446,455-468,501-516,556 \\
564-580,667-671\end{array}$ \\
\hline 7 & $\begin{array}{c}13,23,41,60 \\
67,106,118\end{array}$ & 574 & $\begin{array}{c}28,51,52,87-91,98-103,106-112,167,194,195 \\
220,254,272,273,315-317,339-341,343,344 \\
361-367,424-429,439-446,455-468,501-516,556 \\
564-580,667-671\end{array}$ \\
\hline 7 & $\begin{array}{c}13,23,41,60 \\
68,106,117\end{array}$ & 574 & $\begin{array}{c}28,51,52,87-91,98-103,106-112,167,194,195 \\
220,254,272,273,315-317,339-341,343,344, \\
361-367,424-429,439-446,455-468,501-516,556, \\
564-580,667-671\end{array}$ \\
\hline 7 & $\begin{array}{c}13,24,42,59 \\
67,106,117\end{array}$ & 574 & $\begin{array}{c}28,51,52,87-91,98-103,106-112,167,194,195 \\
220,254,272,273,315-317,339-341,343,344 \\
361-367,424-429,439-446,455-468,501-516,556 \\
564-580,667-671\end{array}$ \\
\hline 7 & $\begin{array}{c}14,23,39,60 \\
68,106,118\end{array}$ & 574 & $\begin{array}{c}28,51,52,87-91,98-103,106-112,167,194,195 \\
220,254,272,273,315-317,339-341,343,344 \\
361-367,424-429,439-446,455-468,501-516,556 \\
564-580,667-671\end{array}$ \\
\hline 7 & $\begin{array}{c}14,24,41,59 \\
67,106,117\end{array}$ & 574 & $\begin{array}{c}28,51,52,87-91,98-103,106-112,167,194,195 \\
220,254,272,273,315-317,339-341,343,344 \\
361-367,424-429,439-446,455-468,501-516,556 \\
564-580,667-671\end{array}$ \\
\hline 7 & $\begin{array}{c}21,42,59,68 \\
79,106,118\end{array}$ & 574 & $\begin{array}{c}28,51,52,87-91,98-103,106-112,167,194,195 \\
220,254,272,273,315-317,339-341,343,344 \\
361-367,424-429,439-446,455-468,501-516,556 \\
564-580,667-671\end{array}$ \\
\hline 7 & $\begin{array}{c}22,42,58,68 \\
78,106,118\end{array}$ & 574 & $\begin{array}{c}28,51,52,87-91,98-103,106-112,167,194,195 \\
220,254,272,273,315-317,339-341,343,344 \\
361-367,424-429,439-446,455-468,501-516,556 \\
564-580,667-671\end{array}$ \\
\hline 7 & $\begin{array}{c}24,39,59,68 \\
80,106,117\end{array}$ & 574 & $\begin{array}{c}28,51,52,87-91,98-103,106-112,167,194,195 \\
220,254,272,273,315-317,339-341,343,344 \\
361-367,424-429,439-446,455-468,501-516,556, \\
564-580,667-671\end{array}$ \\
\hline
\end{tabular}




\subsubsection{Cenário para faltas bifásicas $B C$}

Para esta instância foram simuladas 667 situações de falta, mesmo número que para o conjunto de dados trifásico. Isso ocorre porque o sistema IEEE de 123 barras não possui nenhum ramal bifásico BC (Figura 19), sendo que este tipo de curto-circuito foi simulado apenas nos ramais trifásicos.

Da mesma forma que para os outros dois casos de faltas bifásicas sem conexão com a terra, a identificação de todos os eventos simulados só é conseguida ao se variar a impedância de falta para valores mais altos. As Tabelas 34 e 35 mostram as soluções retornadas pelo algoritmo para 25 e $50 \Omega$, respectivamente.

Tabela 34 - Resultados para o cenário de faltas do tipo $B C\left(Z_{f}=25 \Omega\right)$.

\begin{tabular}{ccc}
\hline Número de PQMs & Barras onde os PQMs foram alocados & Número de eventos identificados \\
\hline 9 & $12,58,67,81,95,106,108,115,118$ & 667 \\
9 & $12,59,67,82,94,106,108,116,118$ & 667 \\
9 & $13,57,68,80,94,106,108,116,117$ & 667 \\
9 & $13,59,67,80,94,106,108,116,117$ & 667 \\
9 & $14,57,68,80,95,106,108,116,118$ & 667 \\
9 & $14,60,67,80,97,106,108,115,118$ & 667 \\
9 & $15,57,68,79,98,106,108,115,118$ & 667 \\
9 & $15,58,67,82,94,106,108,116,117$ & 667 \\
9 & $15,58,68,80,98,106,108,116,117$ & 667 \\
\hline
\end{tabular}

Fonte: Elaborada pelo autor.

Tabela 35 - Resultados para o cenário de faltas do tipo $B C\left(Z_{f}=50 \Omega\right)$.

\begin{tabular}{ccc}
\hline Número de PQMs & Barras onde os PQMs foram alocados & Número de eventos identificados \\
\hline 8 & $12,57,68,82,95,106,116,118$ & 667 \\
8 & $12,58,67,80,97,106,116,117$ & 667 \\
8 & $12,58,68,79,94,106,116,118$ & 667 \\
8 & $12,59,68,81,97,106,116,117$ & 667 \\
8 & $14,59,68,80,96,106,116,118$ & 667 \\
8 & $14,59,68,81,94,106,116,117$ & 667 \\
8 & $15,58,67,79,95,106,115,118$ & 667 \\
8 & $15,58,68,81,97,106,115,117$ & 667 \\
8 & $15,60,68,80,96,106,115,118$ & 667 \\
8 & $60,67,74,82,95,106,116,118$ & 667 \\
\hline
\end{tabular}

Fonte: Elaborada pelo autor.

A quantidade de eventos identificados para o cenário com faltas francas foi de 559, dentre o total simulado de 667 eventos. A Tabela 36 mostra as soluções obtidas para esta instância, contendo 6 medidores cada uma. Da mesma forma que no tipo de curto-circuito que foi analisado anteriormente, apesar da não identificação de alguns eventos, foram apresentadas soluções com uma quantidade inferior de medidores, quando comparadas às soluções retornadas para valores mais altos de impedância de falta. 
Tabela 36 - Resultados para o cenário de faltas bifásicas $B C\left(Z_{f}=0 \Omega\right)$.

\begin{tabular}{|c|c|c|c|}
\hline $\begin{array}{l}\text { Número } \\
\text { de PQMs }\end{array}$ & $\begin{array}{l}\text { Barras onde os } \\
\text { PQMs foram } \\
\text { alocados }\end{array}$ & $\begin{array}{l}\text { Número de } \\
\text { eventos } \\
\text { identificados }\end{array}$ & Eventos não identificados \\
\hline 6 & $\begin{array}{c}1,57,67,76 \\
106,117\end{array}$ & 559 & $\begin{array}{c}28,51,52,87-91,98-103,106-112,167,194,195 \\
255,256,298-300,322-324,326,327,344-350, \\
407-412,422-429,438-451,484-499,539,547-563, \\
650-654\end{array}$ \\
\hline 6 & $\begin{array}{c}14,23,59,67 \\
106,118\end{array}$ & 559 & $\begin{array}{c}28,51,52,87-91,98-103,106-112,167,194,195 \\
255,256,298-300,322-324,326,327,344-350 \\
407-412,422-429,438-451,484-499,539,547-563 \\
650-654\end{array}$ \\
\hline 6 & $\begin{array}{c}21,58,67,76 \\
106,117\end{array}$ & 559 & $\begin{array}{c}28,51,52,87-91,98-103,106-112,167,194,195 \\
255,256,298-300,322-324,326,327,344-350, \\
407-412,422-429,438-451,484-499,539,547-563, \\
650-654\end{array}$ \\
\hline
\end{tabular}

6

22, 60, 68, 74, 106, 117

559

23, 59, 67, 79, 106, 118

559

6

24, 58, 68, 74, 106, 117

559

6

$24,59,67,74$, 106, 118

559

6

$24,59,67,79$, 106, 117

559

6

$25,57,67,78$, 106, 117

559

6

$25,57,68,78$ 106, 118
$28,51,52,87-91,98-103,106-112,167,194,195$, 255, 256, 298-300, 322-324, 326, 327, 344-350, 407-412, 422-429, 438-451, 484-499, 539, 547-563, 650-654

28, 51, 52, 87-91, 98-103, 106-112, 167, 194, 195, 255, 256, 298-300, 322-324, 326, 327, 344-350, 407-412, 422-429, 438-451, 484-499, 539, 547-563, 650-654

$28,51,52,87-91,98-103,106-112,167,194,195$, 255, 256, 298-300, 322-324, 326, 327, 344-350, 407-412, 422-429, 438-451, 484-499, 539, 547-563, 650-654

28, 51, 52, 87-91, 98-103, 106-112, 167, 194, 195, $255,256,298-300,322-324,326,327,344-350$, 407-412, 422-429, 438-451, 484-499, 539, 547-563, 650-654

28, 51, 52, 87-91, 98-103, 106-112, 167, 194, 195, 255, 256, 298-300, 322-324, 326, 327, 344-350, 407-412, 422-429, 438-451, 484-499, 539, 547-563, $650-654$

$28,51,52,87-91,98-103,106-112,167,194,195$, 255, 256, 298-300, 322-324, 326, 327, 344-350, 407-412, 422-429, 438-451, 484-499, 539, 547-563, 650-654

28, 51, 52, 87-91, 98-103, 106-112, 167, 194, 195, 255, 256, 298-300, 322-324, 326, 327, 344-350, 407-412, 422-429, 438-451, 484-499, 539, 547-563, $650-654$ 


\subsubsection{Cenário para faltas bifásicas $A B T$}

A Tabela 37 apresenta 10 soluções distintas para o cenário de faltas bifásicas $A B T$ francas. Todas as soluções encontradas possuem 5 medidores e conseguem identificar todos os 686 eventos.

Tabela 37 - Resultados para o cenário de faltas do tipo $A B T\left(Z_{f}=0 \Omega\right)$.

\begin{tabular}{ccc}
\hline Número de PQMs & Barras onde os PQMs foram alocados & Número de eventos identificados \\
\hline 5 & $1,59,77,98,105$ & 686 \\
5 & $14,22,59,100,105$ & 686 \\
5 & $20,25,58,97,110$ & 686 \\
5 & $21,57,80,94,110$ & 686 \\
5 & $21,58,79,95,110$ & 686 \\
5 & $22,58,78,98,108$ & 686 \\
5 & $23,58,78,99,104$ & 686 \\
5 & $23,59,75,99,111$ & 686 \\
5 & $24,60,82,96,104$ & 686 \\
5 & $25,59,73,96,111$ & 686 \\
\hline
\end{tabular}

Fonte: Elaborada pelo autor.

Vale colocar que agora é observado um efeito contrário em relação às faltas bifásicas com conexão com a terra: ao aumentar o valor da impedância de falta começaram a aparecer eventos não identificados. Para a instância onde se considera $Z_{f}=25 \Omega$ as soluções apresentam 28 eventos não identificados (Tabela 38), e para $Z_{f}=50 \Omega$ são 30 eventos não identificados (Tabela 39). Os 28 eventos estão contidos nos 30 , sendo que aumenta-se a não identificação com os eventos 300 e 324.

Tabela 38 - Resultados para o cenário de faltas bifásicas $A B T\left(Z_{f}=25 \Omega\right)$.

\begin{tabular}{cccc}
\hline $\begin{array}{c}\text { Número de } \\
\text { PQMs }\end{array}$ & $\begin{array}{c}\text { Barras onde os PQMs } \\
\text { foram alocados }\end{array}$ & $\begin{array}{c}\text { Número de } \\
\text { eventos } \\
\text { identificados }\end{array}$ & Eventos não identificados \\
\hline 6 & $1,57,69,76,99,109$ & 658 & $298,299,322,323,503-510,566-581$ \\
6 & $1,57,69,78,99,109$ & 658 & $298,299,322,323,503-510,566-581$ \\
6 & $1,59,69,78,99,109$ & 658 & $298,299,322,323,503-510,566-581$ \\
6 & $25,57,69,76,99,109$ & 658 & $298,299,322,323,503-510,566-581$ \\
6 & $25,57,69,76,100,109$ & 658 & $298,299,322,323,503-510,566-581$ \\
6 & $25,58,69,77,99,109$ & 658 & $298,299,322,323,503-510,566-581$ \\
6 & $25,58,69,77,100,109$ & 658 & $298,299,322,323,503-510,566-581$ \\
6 & $25,59,69,76,99,109$ & 658 & $298,299,322,323,503-510,566-581$ \\
6 & $25,59,69,77,99,109$ & 658 & $298,299,322,323,503-510,566-581$ \\
6 & $25,60,69,76,100,109$ & 658 & $298,299,322,323,503-510,566-581$ \\
\hline
\end{tabular}

Fonte: Elaborada pelo autor.

Todas as soluções para as instâncias com $Z_{f}=25$ e $50 \Omega$ apresentam uma quantidade de 6 medidores. Além disso, pode-se observar que a solução $\{25,59,69,77,99,109\}$ atende às duas situações. 
Tabela 39 - Resultados para o cenário de faltas bifásicas $A B T\left(Z_{f}=50 \Omega\right)$.

\begin{tabular}{cccc}
\hline $\begin{array}{c}\text { Número de } \\
\text { PQMs }\end{array}$ & $\begin{array}{c}\text { Barras onde os PQMs } \\
\text { foram alocados }\end{array}$ & $\begin{array}{c}\text { Número de } \\
\text { eventos } \\
\text { identificados }\end{array}$ & Eventos não identificados \\
\hline 6 & $1,57,69,78,99,109$ & 656 & $298-300,322-324,503-510,566-581$ \\
6 & $1,58,69,78,100,109$ & 656 & $298-300,322-324,503-510,566-581$ \\
6 & $1,60,69,77,99,109$ & 656 & $298-300,322-324,503-510,566-581$ \\
6 & $1,60,69,77,100,109$ & 656 & $298-300,322-324,503-510,566-581$ \\
6 & $1,60,69,77,100,109$ & 656 & $298-300,322-324,503-510,566-581$ \\
6 & $25,57,69,77,99,109$ & 656 & $298-300,322-324,503-510,566-581$ \\
6 & $25,57,69,78,99,109$ & 656 & $298-300,322-324,503-510,566-581$ \\
6 & $25,59,69,77,99,109$ & 656 & $298-300,322-324,503-510,566-581$ \\
6 & $25,59,69,78,99,109$ & 656 & $298-300,322-324,503-510,566-581$ \\
\hline
\end{tabular}

Fonte: Elaborada pelo autor.

\subsubsection{Cenário para faltas bifásicas $A C T$}

Analogamente ao caso anterior, para as faltas bifásicas ACT só foram identificados todos os 684 eventos para a instância onde $Z_{f}=0 \Omega$. Para os outros dois valores de impedância de falta houveram casos de eventos não identificados. Essa é a mesma característica deste tipo de curto-circuito bifásico com conexão com a terra também observada durante a análise dos resultados para o cenário com faltas do tipo BCT no sistema do CIGRÉ de 15 barras.

Analisando as situações de faltas $\operatorname{com} Z_{f}=0 \Omega$, o algoritmo retornou 2 soluções distintas, contendo 5 medidores cada uma (Tabela 40). Todas as outras 8 soluções encontradas são iguais a essas duas ou contém quantidade maior de medidores, por isso não foram apresentadas nesta tabela.

Tabela 40 - Resultados para o cenário de faltas do tipo ACT $\left(Z_{f}=0 \Omega\right)$.

\begin{tabular}{ccc}
\hline Número de PQMs & Barras onde os PQMs foram alocados & Número de eventos identificados \\
\hline 5 & $25,58,76,95,106$ & 684 \\
5 & $25,60,80,98,109$ & 684 \\
\hline
\end{tabular}

Fonte: Elaborada pelo autor.

A Tabela 41 mostra 10 soluções distintas com 7 medidores para a instância com $Z_{f}=25 \Omega$. Cada uma dessas soluções é capaz de identificar 658 dos 684 eventos simulados, restando 26 não identificados. Com valor mais alto de impedância de falta a diferença entre as tensões para dois eventos tomados pode ser menor que os limites do intervalo de simetria de uma determinada barra, configurando casos de simetria que impedem a identificação de alguns eventos, como os apresentados na Tabela 41.

Para $Z_{f}=50 \Omega$, as soluções encontradas identificam 4 eventos a menos, sendo eles: 317, 341, 461 e 468. A Tabela 42 apresenta 5 alocações distintas contendo 5 PQMs. Portanto, ao se elevar um pouco mais a impedância de falta, a dificuldade aumenta na identificação de eventos deste tipo de curto-circuito. 
Tabela 41 - Resultados para o cenário de faltas bifásicas $A C T\left(Z_{f}=25 \Omega\right)$.

\begin{tabular}{|c|c|c|c|}
\hline $\begin{array}{l}\text { Número } \\
\text { de PQMs }\end{array}$ & $\begin{array}{c}\text { Barras onde os PQMs foram } \\
\text { alocados }\end{array}$ & $\begin{array}{l}\text { Número de } \\
\text { eventos } \\
\text { identificados }\end{array}$ & Eventos não identificados \\
\hline 7 & $1,39,57,62,75,95,111$ & 658 & $\begin{array}{c}220,254,315,316,339,340,455-460, \\
462-467,501-508\end{array}$ \\
\hline 7 & $1,40,57,70,75,95,111$ & 658 & $\begin{array}{c}220,254,315,316,339,340,455-460, \\
462-467,501-508\end{array}$ \\
\hline 7 & $21,39,57,63,75,97,111$ & 658 & $\begin{array}{c}220,254,315,316,339,340,455-460, \\
462-467,501-508\end{array}$ \\
\hline 7 & $21,42,57,63,74,97,111$ & 658 & $\begin{array}{c}220,254,315,316,339,340,455-460 \\
462-467,501-508\end{array}$ \\
\hline 7 & $22,39,57,63,74,97,111$ & 658 & $\begin{array}{c}220,254,315,316,339,340,455-460, \\
462-467,501-508\end{array}$ \\
\hline 7 & $22,41,60,70,75,98,111$ & 658 & $\begin{array}{c}220,254,315,316,339,340,455-460, \\
462-467,501-508\end{array}$ \\
\hline 7 & $23,40,59,62,75,97,111$ & 658 & $\begin{array}{c}220,254,315,316,339,340,455-460 \\
462-467,501-508\end{array}$ \\
\hline 7 & $23,41,59,62,75,97,111$ & 658 & $\begin{array}{c}220,254,315,316,339,340,455-460 \\
462-467,501-508\end{array}$ \\
\hline 7 & $23,42,57,70,75,96,111$ & 658 & $\begin{array}{c}220,254,315,316,339,340,455-460, \\
462-467,501-508\end{array}$ \\
\hline 7 & $24,42,59,63,74,97,111$ & 658 & $\begin{array}{c}220,254,315,316,339,340,455-460, \\
462-467,501-508\end{array}$ \\
\hline
\end{tabular}

Fonte: Elaborada pelo autor.

Tabela 42 - Resultados para o cenário de faltas bifásicas $A C T\left(Z_{f}=50 \Omega\right)$.

\begin{tabular}{cccc}
\hline $\begin{array}{c}\text { Número } \\
\text { de PQMs }\end{array}$ & $\begin{array}{c}\text { Barras onde os PQMs } \\
\text { foram alocados }\end{array}$ & $\begin{array}{c}\text { Número de } \\
\text { eventos } \\
\text { identificados }\end{array}$ & Eventos não identificados \\
\hline 5 & $22,45,58,74,111$ & 654 & $220,254,315-317,339-341,455-468,501-508$ \\
5 & $23,45,57,75,111$ & 654 & $220,254,315-317,339-341,455-468,501-508$ \\
5 & $23,45,60,74,111$ & 654 & $220,254,315-317,339-341,455-468,501-508$ \\
5 & $24,45,58,75,111$ & 654 & $220,254,315-317,339-341,455-468,501-508$ \\
5 & $24,45,60,74,111$ & 654 & $220,254,315-317,339-341,455-468,501-508$ \\
\hline
\end{tabular}

\subsubsection{Cenário para faltas bifásicas BCT}

A Tabela 43 mostra todas as soluções obtidas para o cenários com faltas $B C T$ francas. As soluções apresentadas contém 5 medidores e conseguem identificar todos os 667 eventos simulados.

Ao se variar a impedância de falta para 25 e $50 \Omega$ aparecem eventos que não são identificáveis, assim como foi observado para os dois tipos de falta analisados anteriormente. Para $Z_{f}=25 \Omega$ as soluções obtidas contém 6 PQMs e identificam 633 eventos, restando 34 (Tabela 44). Com $Z_{f}=50 \Omega$ aumenta-se de 5 para 6 PQMs e reduz-se a quantidade de eventos identificados de 633 para 629 (Tabela 45). Os 34 
Tabela 43 - Resultados para o cenário de faltas do tipo $B C T\left(Z_{f}=0 \Omega\right)$.

\begin{tabular}{ccc}
\hline Número de PQMs & Barras onde os PQMs foram alocados & Número de eventos identificados \\
\hline 5 & $1,14,57,97,106$ & 667 \\
5 & $1,14,58,99,111$ & 667 \\
5 & $17,21,58,97,105$ & 667 \\
5 & $17,22,60,95,106$ & 667 \\
5 & $20,23,59,99,106$ & 667 \\
5 & $21,58,81,95,106$ & 667 \\
5 & $23,60,75,99,105$ & 667 \\
5 & $23,60,77,98,108$ & 667 \\
5 & $24,58,74,100,104$ & 667 \\
5 & $24,60,79,94,108$ & 667 \\
\hline
\end{tabular}

Fonte: Elaborada pelo autor.

eventos não identificados para $Z_{f}=25 \Omega$ estão contidos no conjunto de eventos não identificados para $Z_{f}=50 \Omega$. Além desses 34, aumenta-se a lista com os eventos 300, 324, 444 e 451 .

Tabela 44 - Resultados para o cenário de faltas bifásicas $B C T\left(Z_{f}=25 \Omega\right)$.

\begin{tabular}{|c|c|c|c|}
\hline $\begin{array}{l}\text { Número } \\
\text { de PQMs }\end{array}$ & $\begin{array}{c}\text { Barras onde os PQMs foram } \\
\text { alocados }\end{array}$ & $\begin{array}{l}\text { Número de } \\
\text { eventos } \\
\text { identificados }\end{array}$ & Eventos não identificados \\
\hline 6 & $1,17,51,59,99,110$ & 633 & $\begin{array}{c}298,299,322,323,438-443,445-450, \\
484-491,553-562\end{array}$ \\
\hline 6 & $1,17,58,64,96,110$ & 633 & $\begin{array}{c}298,299,322,323,438-443,445-450, \\
484-491,553-562\end{array}$ \\
\hline 6 & $16,23,51,60,94,110$ & 633 & $\begin{array}{c}298,299,322,323,438-443,445-450, \\
484-491,553-562\end{array}$ \\
\hline 6 & $16,25,57,64,99,110$ & 633 & $\begin{array}{c}298,299,322,323,438-443,445-450, \\
484-491,553-562\end{array}$ \\
\hline 6 & $18,23,60,64,99,110$ & 633 & $\begin{array}{c}298,299,322,323,438-443,445-450, \\
484-491,553-562\end{array}$ \\
\hline 6 & $19,24,51,58,97,110$ & 633 & $\begin{array}{c}298,299,322,323,438-443,445-450, \\
484-491,553-562\end{array}$ \\
\hline 6 & $19,25,51,60,95,110$ & 633 & $\begin{array}{c}298,299,322,323,438-443,445-450, \\
484-491,553-562\end{array}$ \\
\hline 6 & $21,58,64,73,99,110$ & 633 & $\begin{array}{c}298,299,322,323,438-443,445-450, \\
484-491,553-562\end{array}$ \\
\hline 6 & $25,59,64,73,99,110$ & 633 & $\begin{array}{c}298,299,322,323,438-443,445-450, \\
484-491,553-562\end{array}$ \\
\hline
\end{tabular}

Fonte: Elaborada pelo autor. 
Tabela 45 - Resultados para o cenário de faltas bifásicas $B C T\left(Z_{f}=50 \Omega\right)$.

\begin{tabular}{cccc}
\hline $\begin{array}{c}\text { Número } \\
\text { de PQMs }\end{array}$ & $\begin{array}{c}\text { Barras onde os PQMs } \\
\text { foram alocados }\end{array}$ & $\begin{array}{c}\text { Número de } \\
\text { eventos } \\
\text { identificados }\end{array}$ & Eventos não identificados \\
\hline 5 & $1,17,59,64,110$ & 629 & $298-300,322-324,438-451,484-491,553-562$ \\
5 & $1,20,59,64,110$ & 629 & $298-300,322-324,438-451,484-491,553-562$ \\
5 & $16,24,59,71,110$ & 629 & $298-300,322-324,438-451,484-491,553-562$ \\
5 & $17,21,51,59,110$ & 629 & $298-300,322-324,438-451,484-491,553-562$ \\
5 & $17,22,59,72,110$ & 629 & $298-300,322-324,438-451,484-491,553-562$ \\
5 & $18,24,57,71,110$ & 629 & $298-300,322-324,438-451,484-491,553-562$ \\
5 & $19,22,59,64,110$ & 629 & $298-300,322-324,438-451,484-491,553-562$ \\
5 & $19,23,58,72,110$ & 629 & $298-300,322-324,438-451,484-491,553-562$ \\
5 & $20,21,59,72,110$ & 629 & $298-300,322-324,438-451,484-491,553-562$ \\
5 & $20,25,51,57,110$ & 629 & $298-300,322-324,438-451,484-491,553-562$ \\
\hline
\end{tabular}

Fonte: Elaborada pelo autor.

\subsection{Abordagem multiobjetivo: Modelo $1+$ Modelo 2}

Nesta seção são apresentados os resultados obtidos para a resolução do problema de otimização multi-objetivo, contendo dois objetivos: minimizar a quantidade de PQMs e maximizar a quantidade de eventos identificados. Esses dois objetivos são conflitantes, visto que a medida que se reduz o número de medidores a quantidade de eventos identificados também se reduz. O contrário também é válido: ao se aumentar o número de PQMs se aumenta a quantidade de eventos identificados.

Esse modelo multi-objetivo foi resolvido aplicando o método ABCDO proposto em (SAYIN; KOUVELIS, 2005). Este método é capaz de obter todas as soluções não dominadas ${ }^{1}$ para um problema de otimização discreta com dois objetivos. O algoritmo ABCDO foi implementado em Python 2.7, e os subproblemas de otimização mono-objetivo foram resolvidos utilizando o CPLEX 12.6 (IBM-ILOG CPLEX, 2014) por meio de uma API para Python. O CPLEX utiliza um algoritmo baseado no Branch \& Cut para resolver problemas de otimização linear inteiro discreto.

\subsubsection{Análise dos resultados para o sistema CIGRÉ}

Assim como para o Modelo 1 foram geradas instâncias com faltas francas, considerando os tipos de falta $A B C, A T, B C$ e $B C T$.

1 Soluções que não são dominadas por nenhuma outra dentro de um conjunto $X$ de soluções factíveis (DEB, 2001, p. 28). Uma solução $x^{1}$ domina uma outra solução $x^{2}$, se as condições a seguir são satisfeitas:

1. A solução $x^{1}$ não é pior que a solução $x^{2}$ para todos os objetivos, ou seja, $f_{k}\left(x^{1}\right) \leq f_{k}\left(x^{2}\right), k=1, \ldots, p$.

2. A solução $x^{1}$ é estritamente melhor que a solução $x^{2}$ em pelo menos uma componente $\bar{k} \in\{1, \ldots, p\}$, ou seja, $f_{\bar{k}}\left(x^{1}\right)<f_{\bar{k}}\left(x^{2}\right)$. 


\subsubsection{Análise considerando o GD desconectado}

A Tabela 46 mostra as soluções não dominadas para cada tipo de falta e, na última linha, para todos os tipos de falta, considerando o GD desconectado da rede de fornecimento principal.

Tabela 46 - Resultados para todos os cenários de falta considerando o sistema CIGRÉ e o GD desconectado da rede principal $\left(Z_{f}=0 \Omega\right)$.

\begin{tabular}{|c|c|c|c|c|}
\hline Tipo de Falta & Número de PQMs & $\begin{array}{l}\text { Barras onde os } \\
\text { PQMs foram } \\
\text { alocados }\end{array}$ & $\begin{array}{l}\text { Número de } \\
\text { eventos } \\
\text { identificados }\end{array}$ & $\begin{array}{l}\text { Eventos não } \\
\text { identificados }\end{array}$ \\
\hline \multirow{2}{*}{$\mathrm{ABC}$} & 2 & 11,14 & 154 & $135-167$ \\
\hline & 3 & $11,13,15$ & 187 & - \\
\hline AT & 2 & 11,14 & 187 & - \\
\hline \multirow{4}{*}{$\mathrm{BC}$} & 2 & 10,15 & 115 & $\begin{array}{c}70-73,95-98,107-111 \\
120-124,134-187\end{array}$ \\
\hline & 3 & $12,13,15$ & 168 & $\begin{array}{c}70-73,95-98,107-111 \\
120-124,134\end{array}$ \\
\hline & 4 & $5,12,13,15$ & 170 & $\begin{array}{c}70-72,95-97,107-111 \\
120-124,134\end{array}$ \\
\hline & 5 & $1,2,5,10,15$ & 171 & $\begin{array}{c}70-72,95-97,107-111 \\
120-124\end{array}$ \\
\hline BCT & 2 & 12,14 & 187 & - \\
\hline \multirow[t]{2}{*}{ Todas as faltas } & 2 & 10,14 & 664 & $\begin{array}{l}\text { 135-167, 444-447, } \\
469-472,481-485 \\
494-498,509-541\end{array}$ \\
\hline & 3 & $11,13,15$ & 730 & $\begin{array}{l}444-447,469-472 \\
481-485,494-498\end{array}$ \\
\hline
\end{tabular}

Fonte: Elaborada pelo autor.

Para as faltas trifásicas foi obtido um conjunto ótimo de pareto $^{2}$ com duas soluções não dominadas, contendo 2 e 3 medidores. A solução com 2 medidores identifica 154 eventos e sugere a instalação dos PQMs nas barras 11 e 14. Essa solução não consegue identificar os eventos de 135 a 167, porém é a solução que melhor atende aos dois Modelos 1 e 2 simultaneamente. As soluções obtidas para o Modelo 2 (Tabela 2) identificam os 187 eventos com apenas 2 PQMs. Entretanto, nenhuma delas são soluções factíveis para o problema multi-objetivo, pois todas elas não passam na restrição de observabilidade do Modelo 1. Para que se observe todos os eventos é necessário que haja um medidor na barra 14 ou 15, como foi discutido na subseção 4.1.1. Dentre todas as soluções factíveis com 2 PQMs a que identifica a maior quantidade de eventos é a solução $\{11,14\}$. Aumentando-se 1 PQM já é possível identificar todas as 187 faltas simuladas, bastando tomar qualquer uma das soluções da Tabela 2 e adicionar um medidor na barra 15 ou 14 para garantir a observabilidade. Por exemplo, para se obter a solução retornada pelo

2 Conjunto não dominado (ou fronteira de Pareto) de todo o espaço de busca factível (DEB, 2001, p. 31). Dentre um conjunto de soluções $X$, o conjunto não dominado $\bar{X}$ é o que contém todas as soluções que não são dominadas por nenhuma outra dentro do conjunto $X$. 
ABCDO basta pegar a solução $\{11,13\}$ do Modelo 2 e adicionar um medidor na barra 15. Como pode ser observado existem mais soluções que podem representar o mesmo ponto ótimo da curva de pareto. Como o ABCDO usa um algoritmo de enumeração para encontrar as soluções para cada subproblema ele sempre encontra apenas uma solução não dominada.

A curva de pareto para a instância com faltas monofásicas do tipo $A T$ contém apenas um ponto (solução), como mostra a Tabela 46. Nesse caso a solução com 2 medidores nas barras 11 e 14 já permite a identificação da quantidade máxima de eventos, não sendo necessário aumentar 1 medidor para se alcançar esse objetivo. E como uma solução qualquer com um único medidor não é factível (restrição de observabilidade), este único ponto representa toda a curva de pareto para essa instância.

O cenário para faltas bifásicas $B C$, por sua vez, apresenta 4 pontos na curva de pareto, contendo: 2, 3, 4 e 5 medidores. Como a solução deste cenário de faltas para o modelo 2 não apresentou nenhuma solução que identificasse todos os 187 eventos, para o problema multi-objetivo a quantidade máxima de eventos identificáveis também foi 171. Da mesma forma, nenhuma das soluções apresentadas na Tabela 5 garante a observabilidade total do sistema frente às VTCDs, pois nenhuma delas contém a barra 14 ou 15 em seu conjunto de locais para instalação dos PQMs. No entanto, ao se adicionar um medidor na barra 15, por exemplo, tem-se uma solução factível com 5 PQMs que identifica a quantidade máxima possível para esta instância (171 eventos).

O pareto para as faltas bifásicas $B C T$ também possui apenas um ponto, visto que a solução apresentada (com 2 PQMs) já identifica todos os 187 eventos.

Para a instância considerando todos os 4 tipos de falta (748 eventos) o algoritmo encontrou duas soluções não dominadas, com 2 e 3 medidores. Em nenhuma delas se consegue identificar todos os 748 eventos. Na solução com 3 medidores ainda restam 18 eventos não identificados. Nesse caso, aumentar ainda mais a quantidade de medidores não faz com que se aumente a quantidade de eventos identificados. Portanto, o pareto se resume a apenas esses dois pontos.

\subsubsection{Análise considerando o GD conectado}

A Tabela 47 resume os resultados da resolução do problema multi-objetivo para as instâncias considerando o GD conectado no sistema.

Para o cenário de faltas trifásicas o algoritmo retornou uma fronteira de pareto com três soluções, contendo 2, 3 e 4 medidores. Observa-se em todas elas a presença da barra 14 ou 15 (restrição de observabilidade). A quantidade máxima de eventos identificados é atingida na solução com 4 medidores, mas mesmo assim ainda existe 3 eventos que não são identificados.

Considerando o GD conectado na instância contendo faltas do tipo AT não é possível identificar todos os 187 eventos com apenas 2 PQMs. Portanto, a fronteira de pareto agora contém 2 soluções, sendo necessária uma solução com 3 medidores para se alcançar a identificação de todos os eventos simulados. A solução com 3 PQMs apresentada é diferente de todas as encontradas pelo AG quando da solução do Modelo 2.

O cenário de faltas bifásicas do tipo $B C$ apresentou um pareto com 4 soluções, sendo elas com 3, 4, 5 e 6 PQMs. As soluções encontradas pelo AG com quantidade mínima (3) de PQMs identificam 
Tabela 47 - Resultados para todos os cenários de falta no sistema CIGRÉ considerando o GD conectado à rede principal $\left(Z_{f}=0 \Omega\right)$.

\begin{tabular}{|c|c|c|c|c|}
\hline Tipo de Falta & Número de PQMs & $\begin{array}{l}\text { Barras onde os } \\
\text { PQMs foram } \\
\text { alocados }\end{array}$ & $\begin{array}{l}\text { Número de } \\
\text { eventos } \\
\text { identificados }\end{array}$ & $\begin{array}{l}\text { Eventos não } \\
\text { identificados }\end{array}$ \\
\hline \multirow{3}{*}{$\mathrm{ABC}$} & 2 & 9,14 & 150 & $94,132-167$ \\
\hline & 3 & $1,9,14$ & 183 & $94,132-134$ \\
\hline & 4 & $6,11,13,15$ & 184 & $132-134$ \\
\hline \multirow{2}{*}{ AT } & 2 & 12,14 & 179 & $94,98-104$ \\
\hline & 3 & $4,12,14$ & 187 & - \\
\hline \multirow{4}{*}{$\mathrm{BC}$} & 3 & $3,5,15$ & 106 & $\begin{array}{c}70-72,93-98,107-110 \\
120-187\end{array}$ \\
\hline & 4 & $1,3,5,15$ & 159 & $\begin{array}{c}70-72,93-98,107-110 \\
120-134\end{array}$ \\
\hline & 5 & $1,3,5,12,15$ & 171 & $93,94,121-134$ \\
\hline & 6 & $1,2,3,5,12,15$ & 172 & $94,121-134$ \\
\hline \multirow{2}{*}{$\mathrm{BCT}$} & 2 & 11,14 & 185 & 133,134 \\
\hline & 3 & $8,12,14$ & 187 & - \\
\hline \multirow{3}{*}{ Todas as faltas } & 2 & 12,14 & 674 & $\begin{array}{c}135-167,281,285-291, \\
509-541\end{array}$ \\
\hline & 3 & $1,12,14$ & 740 & $281,285-291$ \\
\hline & 4 & $4,12,13,15$ & 748 & - \\
\hline
\end{tabular}

Fonte: Elaborada pelo autor.

uma quantidade maior de eventos (170 versus 106), porém não garantem a observabilidade das VTCDs. Aumentando-se o número de medidores a quantidade máxima atingida de eventos identificados é 172, com 6 medidores.

Para as faltas $B C T$, após a consideração do GD conectado, não é possível identificar todos os 187 eventos com apenas 2 medidores. Portanto, é necessário aumentar o número para que se consiga encontrar um ponto em que se identifique uma quantidade maior de eventos. Com 3 medidores se consegue identificar todos os 187 eventos. Então, a curva de pareto para essa instância é composta de duas soluções.

Considerando o caso de todas as faltas ao mesmo tempo existem 3 soluções ótimas de pareto, com 2, 3 e 4 medidores. A última delas identifica todos os 748 eventos do banco de faltas simuladas.

\subsubsection{Análise dos resultados para o sistema do IEEE 123 barras}

Para o sistema do IEEE de 123 barras foram geradas instâncias considerando os 10 tipos de falta: $A B C, A T, B T, C T, A B, A C, B C, A B T, A C T$ e $B C T$. Todas as faltas aplicadas são francas. Vale adiantar que o algoritmo não encontrou nenhuma solução para os cenários de faltas $A T$ e $B T$. Não foi possível identificar com exatidão a razão para este fato, porém imagina-se que as soluções analisadas dentro do 
espaço de busca de soluções factíveis para um dos problemas mono-objetivo não representam soluções factíveis para o outro problema mono-objetivo. Para estes dois cenários em específico sugere-se tomar a análise dos dois problemas mono-objetivo separadamente, os quais apresentaram soluções boas para cada caso.

\subsubsection{Cenário para faltas trifásicas}

A Tabela 48 mostra todas as soluções não dominadas encontradas pelo ABCDO para a instância com faltas trifásicas.

Tabela 48 - Resultados para o cenário de faltas trifásicas $\left(Z_{f}=0 \Omega\right)$.

\begin{tabular}{cccc}
\hline $\begin{array}{c}\text { Número } \\
\text { de PQMs }\end{array}$ & $\begin{array}{c}\text { Barras onde os PQMs } \\
\text { foram alocados }\end{array}$ & $\begin{array}{c}\text { Número de } \\
\text { eventos } \\
\text { identificados }\end{array}$ & Eventos não identificados \\
\hline 2 & 60,94 & 501 & $1-27,106-166,323-325,344-404,539-544$, \\
& $12,57,94$ & 626 & $1-27,539-544,563-569,650$ \\
3 & $1,12,57,94$ & 653 & $539-544,563-569,650$ \\
4 & $1,12,57,94,104$ & 665 & 569,650 \\
5 & $1,15,59,94,104,112$ & 667 & - \\
6 & \multicolumn{3}{c}{ Fonte: Elaborada pelo autor. }
\end{tabular}

As soluções variam de 2 a 6 medidores, sendo que com 6 é possível identificar todos os 667 eventos simulados. Para esta solução, os PQMs nas barras 59 e 112 já garantem a observabilidade das VTCDs, pois pertencem aos dois conjuntos de barras mencionados na subseção 4.1.2. Qualquer uma das soluções geradas pelo AG na solução do Modelo 2 (Tabela 17) podem representar esse ponto da curva de pareto, visto que todas elas são soluções factíveis para o problema multi-objetivo com 6 medidores e 667 eventos identificados. Podem existir inúmeras soluções ótimas de pareto, tanto para esse como para os demais pontos da curva. Ao se reduzir a quantidade de medidores obtém-se os demais pontos, até chegar em 2 PQMs, que identificam 501 eventos. Com 1 PQM perde-se a restrição de observabilidade das VTCDs.

\subsubsection{Cenário para faltas monofásicas CT}

Para a instância com faltas do tipo $C T$ foram encontradas soluções variando entre 2 e 7 medidores, como mostra a Tabela 49.

A última solução (com 7 PQMs) garante a identificação de todos os eventos simulados, da mesma forma que todas as outras soluções obtidas pelo AG durante a solução do problema mono-objetivo. As demais soluções não dominadas da curva identificam quantidades menores de eventos, chegando a 746 para o caso com 2 medidores. 
Tabela 49 - Resultados para o cenário de faltas monofásicas do tipo $C T\left(Z_{f}=0 \Omega\right)$.

\begin{tabular}{|c|c|c|c|}
\hline $\begin{array}{l}\text { Número } \\
\text { de PQMs }\end{array}$ & $\begin{array}{c}\text { Barras onde os PQMs foram } \\
\text { alocados }\end{array}$ & $\begin{array}{l}\text { Número de } \\
\text { eventos } \\
\text { identificados }\end{array}$ & Eventos não identificados \\
\hline 2 & $57,97,105$ & 746 & $\begin{array}{c}1-27,106-114,120-132,157-167, \\
173-178,190-195,198,201,203-212, \\
214-223,279,288,330,357,457-459, \\
494-503,508-520,545-553,755,761-763, \\
780,781,786-789\end{array}$ \\
\hline 3 & $16,57,97$ & 812 & $\begin{array}{c}1-27,166,167,173-178,190-195,198 \\
201,203-212,214-223,279,288,330 \\
357,753,754,760,761,777,778,780 \\
783,784,786\end{array}$ \\
\hline 4 & $22,57,74,97$ & 855 & $\begin{array}{l}203-212,214-223,279,288,330,357 \\
753,754,760,761,777-779,783-785\end{array}$ \\
\hline 5 & $16,22,33,57,97$ & 875 & $\begin{array}{c}279,288,330,357,753,754,760,761 \\
777,778,780,783,784,786\end{array}$ \\
\hline 6 & $13,22,33,57,97,105$ & 885 & $279,288,330,357$ \\
\hline 7 & $13,23,33,39,57,97,105$ & 889 & - \\
\hline
\end{tabular}

Fonte: Elaborada pelo autor.

\subsubsection{Cenário para faltas bifásicas $A B$}

A Tabela 50 apresenta todas as alocações de medidores obtidas para o cenário com faltas do tipo $A B$, as quais formam a fronteira de pareto para esta instância analisada.

A primeira solução contém 4 medidores, alocados nas barras 12, 37, 57 e 106. Esta solução identifica 529 eventos dentre o total de 686 eventos simulados, correspondendo a uma taxa de identificação de $77,11 \%$. Com 5 medidores a quantidade de eventos identificados sobe para 575, correspondendo a uma taxa de 83,82\%. Com 6 medidores mais alguns eventos conseguem ser identificados, elevando essa taxa de identificação para 84,11\%. E, por último, com 7 medidores, é conseguida uma taxa de identificação de $84,40 \%$.

Pode ser observado na última coluna da Tabela 50 que os eventos não identificados para cada alocação de medidores estão todos contidos no conjunto maior de eventos não identificados, que é o caso da solução com 4 medidores. Os resultados mostram que a instalação de medidores em posições estratégicas pode fazer com que alguns eventos desse conjunto maior sejam identificáveis, reduzindo então essa quantidade de eventos não identificados e melhorando a taxa de identificação do sistema de monitoramento.

Para esse caso, as soluções factíveis (Modelo 1) podem ser obtidas por meio da combinação das barras dos conjuntos $\{11-20,73-75,79-82\},\{37-42,47,50,51\},\{53-60,70-72\}$ e $\{87,91-98101-$ $106,108,111\}$. Portanto, todas as soluções obtidas pelo ABCDO respeitam a restrição de observabilidade, 
Tabela 50 - Resultados para o cenário de faltas bifásicas do tipo $A B\left(Z_{f}=0 \Omega\right)$.

\begin{tabular}{|c|c|c|c|}
\hline $\begin{array}{l}\text { Número } \\
\text { de } \\
\text { PQMs }\end{array}$ & $\begin{array}{l}\text { Barras onde os PQMs } \\
\text { foram alocados }\end{array}$ & $\begin{array}{l}\text { Número de } \\
\text { eventos } \\
\text { identificados }\end{array}$ & Eventos não identificados \\
\hline 4 & $12,37,57,106$ & 529 & $\begin{array}{c}1-28,51-53,87-92,98-103,106-112,164-169, \\
194,195,255,256,267,298-300,322-324, \\
326,345-347,363-369,421-431,441-448, \\
57-470,498-502,504-518,558,562-564, \\
566-571,573-582,669-674\end{array}$ \\
\hline 5 & $25,37,57,80,106$ & 575 & $\begin{array}{c}28,51-53,87-92,98-103,106-112,167,194, \\
195,255,256,267,298-300,322-324,326, \\
345-347,363-369,426-431,441-448,457-470, \\
504-518,558,567-571,573-582,669-674\end{array}$ \\
\hline 6 & $1,37,57,68,82,106$ & 577 & $\begin{array}{c}28,51,52,87-92,98-103,106-112,167,194, \\
195,255,256,267,298-300,322-324,326, \\
345,346,363-369,426-431,441-448,457-470, \\
504-518,558,567-571,573-582,669-674\end{array}$ \\
\hline 7 & $25,47,60,68,79,106,117$ & 579 & $\begin{array}{c}28,51,52,87-91,98-103,106-112,167,194, \\
195,255,256,267,298-300,322-324,326, \\
345,346,363-369,426-431,441-448,457-470, \\
504-518,558,567-571,573-582,669-673\end{array}$ \\
\hline
\end{tabular}

Fonte: Elaborada pelo autor.

como era esperado.

\subsubsection{Cenário para faltas bifásicas $A C$}

Os resultados para a resolução da instância de faltas $A C$ são mostrados na Tabela 51. Nela são mostradas as soluções que compõem o conjunto não dominado para esta instância.

Assim como para o caso de situações de falta bifásicas $\mathrm{AB}$, as alocações obtidas para este cenário possuem de 4 a 7 medidores, sendo que com 7 medidores é possível identificar 577 eventos dentre os 684 simulados. Esse valor corresponde a uma taxa de identificação de $84,36 \%$, valor máximo conseguido para este tipo de falta. Com 4 PQMs se consegue identificar 527 deles, correspondendo a 77,05\% do total. Com 5 medidores é possível identificar 575 eventos simulados, sendo uma taxa de identificação de 84,06 $\%$. E com 6 medidores a Tabela 51 mostra que a solução encontrada identifica um total de 577 situações de falta, o que corresponde a uma taxa de $84,36 \%$.

A opção a ser tomada cabe à concessionária interessada na instalação do sistema de monitoramento, e vem a depender da quantidade de recursos disponíveis para o investimento e do interesse na qualidade da identificação dos curtos-circuitos. No entanto, nota-se pela Tabela 51 que a solução com 5 medidores é uma excelente opção, pois com o aumento de um único medidor é conseguida uma elevação considerável na taxa de identificação de eventos. Após esse ponto da curva de Pareto a quantidade de 
Tabela 51 - Resultados para o cenário de faltas bifásicas do tipo $A C\left(Z_{f}=0 \Omega\right)$.

\begin{tabular}{|c|c|c|c|}
\hline $\begin{array}{l}\text { Número } \\
\text { de } \\
\text { PQMs }\end{array}$ & $\begin{array}{l}\text { Barras onde os PQMs } \\
\text { foram alocados }\end{array}$ & $\begin{array}{l}\text { Número de } \\
\text { eventos } \\
\text { identificados }\end{array}$ & Eventos não identificados \\
\hline 4 & $12,39,57,106$ & 527 & $\begin{array}{c}1-28,51-53,87-92,98-103,106-112,164-169, \\
194,195,220,254,272,273,315-317, \\
339-341,343-345,361-367,419-429,439-446, \\
455-468,496-500,502-516,556,560-562, \\
564-569,571-580,667-672\end{array}$ \\
\hline 5 & $16,21,40,60,106$ & 573 & $\begin{array}{c}28,51-53,87-92,98-103,106-112,167,194, \\
195,220,254,272,273,315-317,339-341, \\
343-345,361-367,424-429,439-446,455-468, \\
502-516,556,565-569,571-580,667-672\end{array}$ \\
\hline 6 & $21,40,58,67,82,106$ & 575 & $\begin{array}{c}28,51,52,87-92,98-103,106-112,167,194, \\
195,220,254,272,273,315-317,339-341, \\
343,344,361-367,424-429,439-446,455-468, \\
502-516,556,565-569,571-580,667-672\end{array}$ \\
\hline 7 & $21,41,60,68,79,106,117$ & 577 & $\begin{array}{c}28,51,52,87-91,98-103,106-112,167,194, \\
195,220,254,272,273,315-317,339-341, \\
343,344,361-367,424-429,439-446,455-468, \\
502-516,556,565-569,571-580,667-671\end{array}$ \\
\hline
\end{tabular}

Fonte: Elaborada pelo autor.

identificação de eventos começa a saturar, sendo que o aumento no investimento reflete em uma baixa melhoria na taxa de identificação.

\subsubsection{Cenário para faltas bifásicas BC}

O conjunto de soluções não dominadas para o cenário de faltas do tipo $B C$ contém 4 alocações, as quais são mostrados na Tabela 52.

A quantidade de medidores das soluções varia de 4 a 7, assim como para os casos das faltas do tipo AB e AC. A solução com 4 medidores sugere como pontos de instalação as barras 12, 37, 57 e 106. Esses são os mesmos pontos sugeridos pelo algoritmo para a instância com faltas do tipo AB (Tabela 50). Para o caso das situações de faltas bifásicas AC, a única diferença é a troca da barra 37 pela 39 (Tabela 51).

Assim como foi observado para as demais faltas bifásicas sem o envolvimento da terra, não é possível identificar todos os eventos simulados, nem mesmo com a quantidade máxima de medidores sugerida. Para este caso, a solução com 7 PQMs identifica 562 eventos dentre os 667 simulados. Essa quantidade vai decrescendo até 512 eventos identificados com 4 PQMs. 
Tabela 52 - Resultados para o cenário de faltas bifásicas do tipo $B C\left(Z_{f}=0 \Omega\right)$.

\begin{tabular}{|c|c|c|c|}
\hline $\begin{array}{l}\text { Número } \\
\text { de } \\
\text { PQMs }\end{array}$ & $\begin{array}{l}\text { Barras onde os PQMs } \\
\quad \text { foram alocados }\end{array}$ & $\begin{array}{l}\text { Número de } \\
\text { eventos } \\
\text { identificados }\end{array}$ & Eventos não identificados \\
\hline 4 & $12,37,57,106$ & 512 & $\begin{array}{c}1-28,51-53,87-92,98-103,106-112,164-169, \\
194,195,255,256,298-300,322-324, \\
326-328,344-350,402-412,422-429,438-451, \\
479-483,485-499,539,543-545,547-552, \\
554-563,650-655\end{array}$ \\
\hline 5 & $25,39,57,80,106$ & 558 & $\begin{array}{c}28,51-53,87-92,98-103,106-112,167,194, \\
195,255,256,298-300,322-324,326-328, \\
344-350,407-412,422-429,438-451,485-499, \\
539,548-552,554-563,650-655\end{array}$ \\
\hline 6 & $1,37,57,68,82,106$ & 560 & $\begin{array}{c}28,51,52,87-92,98-103,106-112,167,194, \\
195,255,256,298-300,322-324,326,327, \\
344-350,407-412,422-429,438-451,485-499, \\
539,548-552,554-563,650-655\end{array}$ \\
\hline 7 & $25,47,60,68,76,106,117$ & 562 & $\begin{array}{c}28,51,52,87-91,98-103,106-112,167,194, \\
195,255,256,298-300,322-324,326,327, \\
344-350,407-412,422-429,438-451,485-499, \\
539,548-552,554-563,650-654\end{array}$ \\
\hline
\end{tabular}

Fonte: Elaborada pelo autor.

\subsubsection{Cenário para faltas bifásicas $A B T$}

Para esta instância o algoritmo encontrou 4 soluções não dominadas, as quais são apresentadas na Tabela 53.

Tabela 53 - Resultados para o cenário de faltas bifásicas do tipo $A B T\left(Z_{f}=0 \Omega\right)$.

\begin{tabular}{cccc}
\hline $\begin{array}{c}\text { Número } \\
\text { de PQMs }\end{array}$ & $\begin{array}{c}\text { Barras onde os PQMs foram } \\
\text { alocados }\end{array}$ & $\begin{array}{c}\text { Número de } \\
\text { eventos } \\
\text { identificados }\end{array}$ & Eventos não identificados \\
\hline 2 & $60,95,104$ & 526 & $1-27,559-562,584-587$ \\
3 & $12,57,99$ & 656 & $1-27,558,582,583$ \\
4 & $1,12,57,99$ & 683 & $558,582,583$ \\
5 & $16,25,58,94,104$ & 686 & - \\
\hline
\end{tabular}

Fonte: Elaborada pelo autor.

A alocação com 5 PQMs consegue identificar todos os 686 eventos simulados. A mesma quantidade foi observada nas soluções obtidas para este mesmo cenário durante a solução do modelo 2 mono-objetivo. 


\subsubsection{Cenário para faltas bifásicas ACT}

A Tabela 54 apresenta as soluções que formam o pareto para esta instância com faltas ACT.

Tabela 54 - Resultados para o cenário de faltas bifásicas do tipo $A C T\left(Z_{f}=0 \Omega\right)$.

\begin{tabular}{cccc}
\hline $\begin{array}{c}\text { Número } \\
\text { de PQMs }\end{array}$ & $\begin{array}{c}\text { Barras onde os PQMs foram } \\
\text { alocados }\end{array}$ & $\begin{array}{c}\text { Número de } \\
\text { eventos } \\
\text { identificados }\end{array}$ & Eventos não identificados \\
\hline 2 & $60,94,104$ & 524 & $1-27,220,254,558-560,583-585$ \\
3 & $57,74,94$ & 650 & $1-27,220,254,556,557,580-582$ \\
4 & $25,60,82,98$ & 679 & $556,557,580-582$ \\
5 & $16,25,57,94,104$ & 684 & - \\
\hline
\end{tabular}

Fonte: Elaborada pelo autor.

Assim como para a instância de faltas $A B T$ obteve-se 4 soluções variando de 2 a 5 PQMs, sendo que com 5 medidores conseguiu-se identificar a quantidade total de eventos simulados (684).

\subsubsection{Cenário para faltas bifásicas BCT}

Para o cenário com faltas bifásicas do tipo $B C T$, também foram encontradas 4 soluções não dominadas (Tabela 55).

Tabela 55 - Resultados para o cenário de faltas bifásicas do tipo $B C T\left(Z_{f}=0 \Omega\right)$.

\begin{tabular}{cccc}
\hline $\begin{array}{c}\text { Número } \\
\text { de PQMs }\end{array}$ & $\begin{array}{c}\text { Barras onde os PQMs foram } \\
\text { alocados }\end{array}$ & $\begin{array}{c}\text { Número de } \\
\text { eventos } \\
\text { identificados }\end{array}$ & Eventos não identificados \\
\hline 2 & 60,94 & 504 & $1-27,539,540,563-565$ \\
3 & $16,57,94$ & 635 & $1-27,539,540,563-565$ \\
4 & $1,16,57,94$ & 662 & $539,540,563-565$ \\
5 & $16,25,58,94,104$ & 667 & - \\
\hline \multicolumn{4}{r}{ Fonte: Elaborada pelo autor. }
\end{tabular}

Da mesma forma que para os dois casos anteriores, com a solução apresentada com quantidade maior de PQMs (5) foi possível identificar todo o conjunto de faltas simuladas (667). As soluções com 2, 3 e 4 medidores identificam uma quantidade menor, porém ainda elevada de situações de falta.

\subsection{Considerações finais}

Neste capítulo foram abordados 3 modelos de otimização para o problema de alocação de PQMs. O primeiro deles (Modelo 1) é o problema de minimização da quantidade de PQMs (1 objetivo), sujeito à observabilidade do conjunto de VTCDs simuladas. O segundo (Modelo 2) é o problema de maximização da quantidade de eventos (situações de falta) identificados (1 objetivo). E o último deles (Modelo $1+$ Modelo 2) analisa esses dois objetivos simultaneamente, tornando o problema multi-objetivo. 
Os três modelos foram avaliados em dois sistemas de distribuição, o sistema CIGRÉ de 15 barras, e o sistema do IEEE de 123 barras, ambos sistemas de distribuição. No primeiro deles foi incorporado um GD a fim de se analisar a influência do mesmo durante o processo de alocação dos PQMs. Foram geradas instâncias para todos os tipos de falta e, para cada uma delas foram analisados 3 valores distintos de impedância de falta.

Os resultados mostraram que para todos os problemas de otimização formulados existem inúmeras, porém finitas soluções ótimas, visto que é possível escolher a mesma quantidade de PQMs, dispondo-os em locais diferentes na rede de forma a obter ainda o mesmo valor para a função objetivo. O AG, empregado na solução do Modelo 2, apresentou sempre mais do que uma solução ótima, devido à sua característica populacional. Para esse problema, visto desse ponto, esta se mostrou uma ferramenta interessante durante a obtenção de soluções ótimas para o problema.

Quanto à quantidade de eventos identificados, para as situações de falta bifásicas sem a conexão com a terra não foram encontradas soluções que identificassem a quantidade total de eventos simulados. No entanto, a quantidade máxima atingida ainda foi grande, mostrando serem boas soluções para o problema. 



\section{CONSIDERAÇÕES FINAIS}

Esta pesquisa abordou o problema da alocação de PQMs em sistemas de distribuição, sendo este modelado por meio de 3 problemas de otimização combinatória. O primeiro deles, Modelo 1, teve como objetivo a minimização da quantidade de PQMs sujeito à restrição de se garantir a observabilidade das VTCDs decorrentes das situações de curtos-circuitos simuladas no sistema. O segundo, Modelo 2, objetiva à maximização da quantidade de eventos (faltas) identificadas dentre o conjunto de situações de faltas simuladas. E o último, Modelo 1 + Modelo 2, reúne os dois primeiros problemas de otimização em uma perspectiva multi-objetivo.

A metodologia proposta foi adequada para a aplicação dos modelos de otimização discreta em sistemas de distribuição com diversas características, como: linhas não-homogêneas, presença de geração distribuída, linhas monofásicas e/ou bifásicas, etc. Nesse sentido, o modelo clássico de minimização de PQMs foi generalizado para sua aplicação em qualquer sistema elétrico de potência, e aplicado nos sistemas de distribuição avaliados nesta pesquisa.

Os três modelos foram testados considerando dois sistemas de distribuição com diferentes características e tamanhos. O primeiro deles é o sistema europeu de média tensão do CIGRÉ com 15 barras ao qual foi incluído um gerador distribuído. O segundo é o sistema teste do IEEE de 123 barras de distribuição. Para ambos os sistemas foram geradas instâncias levando em consideração a variação do ponto de falta, tipo da falta e da impedância da falta.

Os resultados mostraram que para vários sistemas de monitoramento as situações de faltas podem ser observadas mas não necessariamente identificadas, quando da resolução do Modelo 1 ou do modelo multi-objetivo ( Modelo 1 + Modelo 2). Da mesma forma, durante a aplicação do Modelo 2, os resultados mostraram casos onde elas podem ser identificadas, porém não observadas por nenhum medidor. As condições de simetria presentes no sistema podem impedir a identificação de alguns eventos.

O método da alocação de PQMs conseguiu encontrar soluções com baixo número de medidores, inclusive para o sistema de grande porte analisado nesta pesquisa (IEEE de 123 barras). Isso facilita a implantação do sistema de monitoramento por parte da concessionária, pois reduz os custos de investimento em equipamentos e estrutura de comunicação entre os elementos do sistema de monitoramento. Dessa forma, é possível implantar a monitoração de VTCDs em toda a rede e garantir a identificação da maioria 
das situações de falta passíveis de ocorrência no sistema com um baixo investimento.

De forma geral, as alocações dos medidores obtidas pela metodologia proposta obtiveram uma taxa de identificação acima de $83 \%$. Os casos de situações de falta não identificadas pelo conjunto de medidores são devidos às simetrias existentes entre pares de eventos que não foram possíveis de serem quebradas. Da maneira em que o problema de alocação foi tratado nesta pesquisa, essas condições de simetria correspondem à situações de múltipla estimação da falta, as quais tomou-se como um dos objetivos nesta pesquisa minimizar. A alta taxa de identificação obtida pelo método proposto mostra que os sistemas de monitoramento sugeridos podem ser usados, assumindo uma infraestrutura de comunicação, para dar suporte à um sistema localizador de faltas, usualmente implementado nas subestações.

As menores taxas de identificação foram obtidas para as faltas bifásicas sem conexão com a terra, o que contribuiu para reduzir a taxa de identificação para todas as faltas de forma geral. No entanto, esse tipo de falta possui baixa taxa de ocorrência em sistemas de distribuição. Vale então frisar que para as faltas monofásicas o método obteve $100 \%$ de identificação dos eventos, sendo este o tipo de falta mais recorrente em sistemas de distribuição (HÄNNINEN; LEHTONEN, 1998), e que, consequentemente, é o grande motivo de preocupação por parte das concessionárias, e o que mais gera as situações de VTCDs.

Para o sistema do CIGRÉ estudado, a inserção da geração distribuída não impactou na observabilidade das VTCDs (Modelo 1), considerando o limiar de ativação ajustado. Tanto a quantidade, quanto a disposição dos medidores no sistema não se alteraram ao se considerar o GD conectado à rede de fornecimento principal. No entanto, a presença do GD introduziu uma dificuldade na identificação dos eventos para o Modelo 2 e, consequentemente, impactou nos resultados para a abordagem multi-objetivo (Modelo 1 + Modelo 2). Ao se considerar o GD conectado à rede, apareceram eventos não identificáveis, não importando a quantidade de PQMs utilizada. Também foram observados casos em que para se identificar todos os eventos simulados foi necessário aumentar a quantidade de PQMs requerida. Devido à não incerteza quanto à presença do GD no sistema, sugere-se que seja assumido que este esteja sempre conectado. Portanto, é desejável que se escolha um sistema de monitoramento dentre os apresentados para o caso da conexão do GD à rede, visto que este contém uma quantidade maior de PQMs. Ademais sugere-se que esta alocação inclua uma solução dentre as apresentadas para o caso em que o GD não está presente no sistema. Dessa forma, garante-se um monitoramento eficiente levando em conta as incertezas características desse tipo de elemento da rede.

Para finalizar, vale apontar alguns aspectos que podem ser considerados no sentido de dar continuidade a esta pesquisa, os quais são: incorporar outras características inerentes ao problema da localização de faltas dentro do Modelo 2; analisar a presença e a interação de múltiplos GDs; considerar a ocorrência de faltas simultâneas; fazer uma abordagem estatística para tratar a incerteza e os erros nas medições; e priorizar a frequência de ocorrência de cada tipo de falta dentro dos modelos de otimização, entre outros.

\subsection{Publicações decorrentes desta pesquisa}

1. MARTINS, P. E. T.; OLESKOVICZ, M.; PESSOA, A. L. S.; FARIA, I. M. Optimized Allocation of Power Quality Monitors in Distribution Systems Considering Fault Location no XVIII Internacional 
Conference on Harmonics and Quality of Power - ICHQP 2018, realizada nos dias 13 à 16 de Maio de 2018 em Ljubljana, Eslôvenia.

2. MARTINS, P. E. T.; OLESKOVICZ, M.; PESSOA, A. L. S.; FARIA, I. M. Bi-objective Approach For Power Quality Monitors Allocation Problem no XXII Congresso Brasileiro de Automática CBA 2018, realizado nos dias 09 à 12 de Setembro de 2018 em João Pessoa, PB, Brasil.

\subsection{Publicações correlatas a esta pesquisa}

Os seguintes trabalhos foram desenvolvidos em parceria com outros pesquisadores e, mesmo não estando diretamente relacionados ao problema da alocação de PQMs, estão inseridos no contexto das redes elétricas inteligentes:

1. PESSOA, A. L. S.; OLESKOVICZ, M.; MARTINS, P. E. T. A multi-stage methodology for fault location in radial distribution systems no XVIII Internacional Conference on Harmonics and Quality of Power - ICHQP 2018, realizada nos dias 13 a 16 de Maio de 2018 em Ljubljana, Eslôvenia.

2. FARIA, I. M.; FURLAN, R. H.; MARTINS, P. E. T.; MENEZES, T. S.; OLESKOVICZ, M.; COURY, D. V. The Proposition of a Multiagent System for Adaptive Protection of a Distribution System no VII Simpósio Brasileiro de Sistemas Elétricos - SBSE 2018, realizado nos dias 12 a 16 de Maio de 2018 em Niterói, RJ, Brasil.

3. CAMPOS, G. P.; OLESKOVICZ, M.; MARTINS, P. E. T.; BICZKOWSKI, M. Curva de Carga Otimizada para Armazenadores de Energia em um Sistema de Distribuição com a Presença de Geração Fotovoltaica no XXII Congresso Brasileiro de Automática - CBA 2018, realizado nos dias 09 à 12 de Setembro de 2018 em João Pessoa, PB, Brasil.

4. TORREZAN, G. F.; OLESKOVICZ, M.; PESSOA, A. L. S.; MARTINS, P. E. T. Estudo do Desequilíbrio de Tensão em um Sistema de Distribuição no XXII Congresso Brasileiro de Automática CBA 2018, realizado nos dias 09 à 12 de Setembro de 2018 em João Pessoa, PB, Brasil. 

ALMEIDA, C. F. M.; KAGAN, N. Aplicação de algoritmos genéticos e teoria dos conjuntos fuzzy no dimensionamento de sistemas de monitoração para redes de transmissão de energia elétrica. Revista Controle \& Automação, v. 21, n. 4, p. 363-378, jul./ago. 2010. Citado 4 vezes nas páginas 4, 10, 21 e 40 .

ALMEIDA, C. F. M.; KAGAN, N.; SOUZA, T. P.; MATSUO, N. M.; DUARTE, S. X.; NETO, A. B.; SUEMATSU, A. K. Locating Power Quality Meters in Order to Perform Harmonic State Estimation. In: 2012 IEEE 15th International Conference on Harmonics and Quality of Power. Hong Kong, China: IEEE, 2012. p. 662-667. Citado 2 vezes nas páginas 17 e 21.

AMMER, C.; RENNER, H. Determination of the optimum measuring positions for power quality monitoring. In: 2004 11th International Conference on Harmonics and Quality of Power. Lake Placid, Estados Unidos: IEEE, 2004. p. 684-689. Citado 4 vezes nas páginas 18, 19, 20 e 21.

ANEEL. Procedimentos de Distribuição de Energia Elétrica no Sistema Elétrico Nacional, PRODIST, Módulo 8: Qualidade da Energia Elétrica. Revisão 10 - Resolução Normativa n 794/2017, 2018. Citado na página 22.

BERTHO, R.; KEMPNER, T. R.; VIEIRA, J. C. M.; OLESKOVICZ, M.; COURY, D. V.; CARLOS, S.; BRAZIL, S. P. Optimized Power Quality Monitor Placement Based on a Particle Swarm Optimization Algorithm. In: 2016 17th International Conference on Harmonics and Quality of Power (ICHQP). Belo Horizonte, Brasil: IEEE, 2016. p. 115-119. Citado 3 vezes nas páginas 14, 21 e 22.

BHATTACHARYA, K.; BOLlEN, M. H. J.; DAALDER, J. E. Operation of Restructured Power Systems. Boston: Kluwer Academic Publishers, 2001. Citado na página 2.

BRANCO, H. M.; OLESKOVICZ, M.; COURY, D. V.; DELBEM, A. C. Multiobjective optimization for power quality monitoring allocation considering voltage sags in distribution systems. International Journal of Electrical Power and Energy Systems, Elsevier, v. 97, p. 1-10, nov 2018. Citado 3 vezes nas páginas 20, 21 e 22.

CEBRIAN, J. C.; ALMEIDA, C. F. M.; KAGAN, N. Genetic Algorithms applied for the Optimal Allocation of Power Quality Monitors in Distribution Networks. In: ICHQP 2010 - 14th International Conference on Harmonics and Quality of Power. Bérgamo, Itália: IEEE, 2010. p. 1-10. Citado 2 vezes nas páginas 11 e 21.

CHEN, L. P.; XU, W. T.; CAO, K. J. Optimal Placement of Voltage Sag Monitors Based on Fault Location Principle. In: POWERCON 2014 - 2014 International Conference on Power System Technology: Towards Green, Efficient and Smart Power System, Proceedings. Chengdu, China: IEEE, 2014. p. 2069-2074. Citado 4 vezes nas páginas 13, 14, 18 e 21.

CIGRE Task Force C6.04. Technical Brochure 575: Benchmark Systems for Network Integration of Renewable and Distributed Energy Resources. [S.1.]: CIGRE, 2014. Citado 2 vezes nas páginas 26 e 53.

DEB, K. Multi-Objective Optimization using Evolutionary Algorithms. 1st. ed. New York: John Wiley \& Sons, 2001. (Wiley-Interscience series in systems and optimization). Citado 2 vezes nas páginas 83 e 84 . 
DUGAN, R. C.; MCGRANAGHAN, M. F.; SANTOSO, S.; BEATY, H. W. Electrical Power Systems Quality. Third. New York: McGraw-Hill, 2012. Citado 3 vezes nas páginas 1, 2 e 4.

DZAFIC, I.; JABR, R.; HENSELMEYER, S.; DONLAGIC, T. Fault Location in Distribution Networks through Graph Marking. IEEE Transactions on Smart Grid, v. 9, n. 2, p. 1345-1353, mar. 2018. Citado na página 4.

ELDERY, M.; EL-SAADANY, E.; SALAMA, M.; VANNELLI, A. A Novel Power Quality Monitoring Allocation Algorithm. IEEE Transactions on Power Delivery, v. 21, n. 2, p. 768-777, abr. 2006. Citado 9 vezes nas páginas $4,10,11,16,17,18,19,20$ e 21.

ESPINOSA-JUAREZ, E.; HERNANDEZ, A.; OLGUIN, G. An Approach Based on Analytical Expressions for Optimal Location of Voltage Sags Monitors. IEEE Transactions on Power Delivery, v. 24, n. 4, p. 2034-2042, 2009. Citado 7 vezes nas páginas 9, 10, 13, 14, 21, 22 e 35.

FORTESCUE, C. L. Method of Symmetrical Coordinates Applied to the Solution of Polyphase Networks. Transactions of the American Institute of Electrical Engineers, IEEE, v. 37, p. 1027-1140, 1918. Citado 2 vezes nas páginas 34 e 105 .

FREITAS, A. F. de; AMARAL, F. V.; SILVA, J. A. L.; SALDANHA, R. R.; SILVA, S. M. a. Optimum Allocation of Power Quality Monitors in Electric Power Systems - A Case Study. In: 2016 17th International Conference on Harmonics and Quality of Power (ICHQP). Belo Horizonte, Brasil: IEEE, 2016. p. 768-773. Citado 2 vezes nas páginas 18 e 21.

GRAINGER, J. J.; STEVENSON JR., W. D. Power system analysis. In: . New York: McGraw-Hill, 1994. p. 784. Citado na página 31.

GUERRA, W. Z.; CARDOSO, E. M.; MANSO, J. C. G. Optimal allocation of meters for monitoring voltage sags and swells using the grasp-vns optimization algorithm. In: Proc. of 2th Conference on Innovative Smart Grid Technologies (ISGT Latin America). São Paulo, Brasil: IEEE, 2013. p. 1-5. Citado 2 vezes nas páginas 12 e 21 .

HAGHBIN, M.; FARJAH, E. Optimal Placement of Monitors in Transmission Systems Using Fuzzy Boundaries for Voltage Sag Assessment. In: 2009 IEEE Bucharest PowerTech: Innovative Ideas Toward the Electrical Grid of the Future. Bucareste, Romênia: IEEE, 2009. p. 1-6. Citado 6 vezes nas páginas $8,10,12,13,21$ e 22 .

HAGHBIN, M.; FARJAH, E.; MAZAHERIFAR, H. Improved power quality monitor placement using innovative indices. In: PEDSTC 2013 - 4th Annual International Power Electronics, Drive Systems and Technologies Conference. Teerã, Irã: IEEE, 2013. p. 501-509. Citado 4 vezes nas páginas 12, 13, 21 e 22 .

HÄNNINEN, S.; LEHTONEN, M. Characteristics of earth faults in electrical distribution networks with high impedance earthing. Electric Power Systems Research, v. 1, n. 44, p. 155-161, 1998. Citado na página 96.

HOFFMAN, K. L.; RALPHS, T. K. Integer and Combinatorial Optimization. [S.1.]: COR@L Technical Report 12T-020, 2012. Citado na página 54.

HONG, Y.-Y.; CHEN, Y. Placement of power quality monitors using enhanced genetic algorithm and wavelet transform. IET Generation, Transmission \& Distribution, v. 5, n. 4, p. 461-466, 2011. Citado 2 vezes nas páginas 19 e 21.

IBM-ILOG CPLEX. 12.6 User’s Manual. [S.1.], 2014. Citado na página 83. 
IBRAHIM, A. A.; MOHAMED, A.; SHAREEF, H. Optimal Placement of Power Quality Monitors in Distribution Systems Using the Topological Monitor Reach Area. In: 2011 IEEE International Electric Machines and Drives Conference, IEMDC 2011. Niagara Falls, ON, Canadá: IEEE, 2011. p. 394-399. Citado 2 vezes nas páginas 11 e 21.

A Novel Quantum-inspired Binary Gravitational Search Algorithm in Obtaining Optimal Power Quality Monitor Placement. Journal of Applied Sciences, v. 12, n. 9, p. 822-830, 2012. Citado 2 vezes nas páginas 11 e 12.

Power Quality Monitor Placement Method Using Adaptive Quantum-Inspired Binary Gravitational Search Algorithm. In: 10th International Power and Energy Conference, IPEC 2012. Cidade de Ho Chi Minh, Vietnã: IEEE, 2012. p. 363-368. Citado 2 vezes nas páginas 11 e 12.

Optimal power quality monitor placement in power systems using an adaptive quantum-inspired binary gravitational search algorithm. International Journal of Electrical Power \& Energy Systems, Elsevier, v. 57, p. 404-413, 2014. Citado 2 vezes nas páginas 11 e 12.

IBRAHIM, A. A.; MOHAMED, A.; SHAREEF, H.; GHOSHAL, S. P. An Effective Power Quality Monitor Placement Method Utilizing Quantum-Inspired Particle Swarm Optimization. In: Proceedings of the 2011 International Conference on Electrical Engineering and Informatics, ICEEI 2011. Bandung, Indonésia: IEEE, 2011. p. 1-6. Citado 3 vezes nas páginas 11, 12 e 17.

IBRAHIM, A. A. et al. Optimal Power Quality Monitor Placement in Power Systems Based on Particle Swarm Optimization and Artificial Immune System. In: Proc. of 3th Conference on Data Mining and Optimization (DMO). Selangor, Malásia: IEEE, 2011. p. 141-145. Citado 2 vezes nas páginas 11 e 12.

A New Approach for Optimal Power Quality Monitor Placement in Power System Considering System Topology. Przeglad Elektrotechniczny, v. 88, n. 1, p. 272-276, 2012. Citado na página 11.

IEEE. IEEE Recommended Practice for Powering and Grounding Electronic Equipment. New York, 2005. Citado na página 1.

IEEE Recommended Practice for Monitoring Electric Power Quality. New York, 2009. Citado 2 vezes nas páginas 1 e 2 .

KAZEMI, A. et al. Optimal power quality monitor placement using genetic algorithm and Mallow's Cp. International Journal of Electrical Power \& Energy Systems, Elsevier, v. 53, p. 564-575, 2013. Citado 2 vezes nas páginas 13 e 21.

KEMPNER, T. R. Análise da Robustez e da Sensibilidade de Sistemas de Distribuição para a Alocação Otimizada de Medidores frente às Variações de Tensão de Curta Duração. Tese (Doutorado) Univ. de São Paulo, São Carlos, Brasil, 2016. Citado 3 vezes nas páginas 34, 56 e 57.

KEMPNER, T. R.; MOURINHO, F. A.; BOTTURA, F. B.; OLESKOVICZ, M.; VIEIRA, J. C. M.; FILHO, J. R. L. Optimal voltage sags monitoring considering different loading profiles in distribution systems. In: Proc. of 16th International Conference on Renewable Energies and Power Quality. Madrid, Spain: EA4EPQ, 2016. p. 306-311. Citado na página 56.

KEMPNER, T. R.; OLESKOVICZ, M.; GOMES, D. P. Optimal monitoring of voltage sags through simultaneous analysis of short-circuits in distribution systems. IET Generation, Transmission \& Distribution, v. 11, n. 7, p. 1801-1808, 2017. Citado 6 vezes nas páginas 14, 15, 20, 21, 22 e 34.

KEMPNER, T. R.; OLESKOVICZ, M.; SANTOS, A. Q. Optimal Allocation of Monitors by Analyzing the Vulnerability Area Against Voltage Sags. In: 2014 16th International Conference on Harmonics and Quality of Power (ICHQP). Bucareste, Romênia: IEEE, 2014. p. 536-540. Citado 5 vezes nas páginas $13,14,15,21$ e 22. 
KERSTING, W. H. Radial Distribution Test Feeders. IEEE Transactions on Power Systems, IEEE, v. 6, n. 3, p. 975-985, aug 1991. Citado na página 53.

Distribution system modeling and analysis. In: . Nova Yorque, EUA: CRC Press, 2002. p. 314. Citado 2 vezes nas páginas 23 e 35 .

KINDERMANN, G. Curto-circuito. Porto Alegre: Sagra Luzzatto, 1997. 214 p. Citado na página 4.

KRISHNATHEVAR, R.; ENG, N. Generalized Impedance-Based Fault Location for Distribution Systems. IEEE Transactions on Power Delivery, v. 27, n. 1, p. 449-451, 2012. Citado na página 5.

KRON, G. Tensorial Analysis of Integrated Transmission Systems, Part I, The Six Basic Reference Frames. Transactions of the American Institute of Electrical Engineers, IEEE, v. 70, n. 2, p. 1239-1248, July 1951. Citado na página 31.

KUMAR, P.; SINGH, A. K.; SINGH, N. Fuzzy Expert System Based Power Quality Meter Placement. In: 2012 IEEE 15th International Conference on Harmonics and Quality of Power (ICHQP). Hong Kong, China: IEEE, 2012. p. 523-530. Citado 2 vezes nas páginas 16 e 21.

LÖFBERG, J. Yalmip : A toolbox for modeling and optimization in matlab. In: In Proceedings of the CACSD Conference. Taipei, Taiwan: [s.n.], 2004. Citado na página 54.

MARTINS, P. E. T.; ZVIETCOVICH, W. G.; SILVA, T. A. d. O.; JESUS, B. J. de. Allocation of power quality monitors by clonal algorithm. In: Proc. of 17th International Conference on Harmonics and Quality of Power (ICHQP). Belo Horizonte, Brasil: IEEE, 2016. p. 980-985. Citado 4 vezes nas páginas 14, 15, 21 e 22.

MARTINS, P. E. T.; ZVIETCOVICH, W. G.; SILVA, T. A. de O.; OLIVEIRA, F. B. de. Multi-objective Approach for Power Quality Monitor Allocation with Symmetry in Short-Duration Voltage Variations. in press. IEEE Transactions on Power Delivery. Citado 8 vezes nas páginas 4, 15, 20, 21, 22, 40, 45 e 51 .

MORA-FLÓREZ, J.; MORALES-ESPAÑA, G.; PÉREZ-LONDOÑO, S. Learning-based strategy for reducing the multiple estimation problem of fault zone location in radial power systems. IET Generation, Transmission \& Distribution, v. 3, n. 4, p. 346-356, 2009. Citado na página 5.

MORALES-ESPANAA, G.; MORA-FLÓREZ, J.; VARGAS-TORRES, H. Elimination of Multiple Estimation for Fault Location in Radial Power Systems by Using Fundamental Single-End Measurements. IEEE Transactions on Power Delivery, IEEE, v. 24, n. 3, p. 1382-1389, jul. 2009. Citado na página 5.

MOURA, F. A. M. Geração distribuída - impactos e contribuições para a qualidade da energia elétrica e dinâmica dos sistemas elétricos - uma análise através do ATP-EMTP. Tese (Doutorado) Universidade Federal de Uberlândia, Uberlândia, Brasil, 2011. Citado na página 26.

OLESKOVICZ, M.; BRANCO, H. M. G. C.; SILVA, R. P. M. da; COURY, D. V.; DELBEM, A. C. B. A Compact Genetic Algorithm Structure Used for the Optimum Allocation of Power Quality Monitors Based on Electrical Circuit Topology. In: 2012 IEEE 15th International Conference on Harmonics and Quality of Power (ICHQP). Hong Kong, China: IEEE, 2012. p. 34-39. Citado 4 vezes nas páginas 17, 18, 20 e 21.

OLGUIN, G. Voltage Dip (Sag) Estimation in Power Systems based on Stochastic Assessment and Optimal Monitoring. Tese (Doutorado) — Chalmers University of Technology, Gotemburgo, Suécia, 2005. Citado 2 vezes nas páginas 3 e 4 .

OLGUIN, G.; VUINOVICH, F.; BOLLEN, M. H. J. An Optimal Monitoring Program for Obtaining Voltage Sag System Indexes. IEEE Transactions on Power Systems, v. 21, n. 1, p. 378-384, fev. 2006. Citado 18 vezes nas páginas $8,9,10,11,12,13,14,15,16,17,18,20,21,22,34,40,51$ e 56. 
PEREIRA, R. A. F.; SILVA, L. G. W. D.; MANTOVANI, J. R. S. PMUs Optimized Allocation Using a Tabu Search Algorithm for Fault Location in Electric Power Distribution System. In: 2004 IEEE/PES Transmission and Distribution Conference and Exposition: Latin America. São Paulo, Brasil: IEEE, 2004. p. 143-148. Citado 6 vezes nas páginas 7, 14, 16, 18, 19 e 21.

REIS, D. C. S.; VILLELA, P.; DUQUE, C.; RIBEIRO, P. Transmission Systems Power Quality Monitors Allocation. In: Proc. of IEEE Power and Energy Society General Meeting - Conversion and Delivery of Electrical Energy in the 21st Century. Pittsburgh, PA: IEEE, 2008. p. 20-24. Citado 2 vezes nas páginas 16 e 21.

ROSSINI, J. P.; FARIAS, P. E.; MORAIS, A. P. de; CARDOSO, G.; COSTA, G. B. da. An alternative solution for the multiple estimation problem using fuzzy sets. In: 2017 IEEE International Conference on Environment and Electrical Engineering and 2017 IEEE Industrial and Commercial Power Systems Europe (EEEIC / I CPS Europe). Milan, Italy: IEEE, 2017. p. 1-5. Citado na página 5.

SALIM, F.; NOR, K. M. Voltage Sags Observation through Optimal Monitor Locations. In: ICHQP 2010 - 14th International Conference on Harmonics and Quality of Power. Bérgamo, Itália: IEEE, 2010. p. 1-6. Citado 2 vezes nas páginas 10 e 21.

SAYIN, S.; KOUVELIS, P. The multiobjective discrete optimization problem: A weighted min-max twostage optimization approach and a bicriteria algorithm. Management Science, v. 51, n. 10, p. 1572-1581, out. 2005. Citado na página 83 .

STREZOSKI, L.; PRICA, M.; LOPARO, K. A. Sequence domain calculation of active unbalanced distribution systems affected by complex short circuits. IEEE Transactions on Power Systems, v. 33, n. 2, p. 1891-1902, March 2018. Citado na página 26.

TRINDADE, F. C. L.; FREITAS, W. Low Voltage Zones to Support Fault Location in Distribution Systems With Smart Meters. IEEE Trans. Smart Grid, v. 8, n. 6, p. 2765-2774, 2017. Citado na página 5.

TRINDADE, F. C. L.; FREITAS, W.; VIEIRA, J. C. M. Fault location in distribution systems based on smart feeder meters. IEEE Transactions on Power Delivery, v. 29, n. 1, p. 251-260, 2014. Citado na página 5.

WAN, Y. et al. Optimization of the power quality monitor number in smart grid. In: Proc. of 2014 IEEE International Conference on Smart Grid Communications. Veneza, Itália: IEEE, 2014. p. 230-235. Citado 3 vezes nas páginas 17, 18 e 21.

WON, D.; MOON, S. Optimal Number and Locations of Power Quality Monitors Considering System Topology. IEEE Transactions on Power Delivery, v. 23, n. 1, p. 288-295, jan. 2008. Citado 3 vezes nas páginas 19, 20 e 21.

WONG, L. A.; SHAREEF, H.; MOHAMED, A.; IBRAHIM, A. A. Novel quantum-inspired firefly algorithm for optimal power quality monitor placement. Frontiers in Energy, Springer, v. 8, n. 2, p. 254-260, 2014. Citado 2 vezes nas páginas 11 e 12.

ZAMBRANO, X.; HERNáNDEZ, A.; IZZEDDINE, M.; CASTRO, R. M. de. Estimation of voltage sags from a limited set of monitors in power systems. IEEE Transactions on Power Delivery, v. 32, n. 2, p. 656-665, April 2017. Citado na página 3.

ZHU, J.; LUBKEMAN, D.; GIRGIS, A. Automated fault location and diagnosis on electric power distribution feeders. IEEE Transactions on Power Delivery, v. 12, n. 2, p. 801-809, 1997. Citado na página 5. 

APÊNDICE

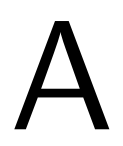

\section{ANÁLISE DE FALTAS ASSIMÉTRICAS}

A análise de situações de falta assimétricas foi realizada com base na teoria dos componentes simétricos (FORTESCUE, 1918). Aplicando essa teoria nos circuitos trifásicos, qualquer conjunto de 3 fasores desequilibrados pode ser decomposto em 3 sistemas trifásicos equilibrados: os componentes de sequência positiva, os componentes de sequência negativa e os componentes de sequência zero. Os circuitos equivalentes monofásicos desses sistemas (redes de sequência) podem ser associados para representar as diversas situações de falta desequilibradas. Portanto, a estratégia se resume a encontrar os componentes simétricos da corrente de falta, com base neles calcular as tensões durante a falta (ainda no domínio da sequência), e então retornar para o domínio $\mathrm{ABC}$.

\section{A.1 Matrizes de transformação}

Para cada situação de falta analisada deve-se utilizar uma matriz de transformação adequada quando for feita a conversão do conjunto de fasores de um domínio para o outro. Essa escolha depende dos circuitos equivalentes monofásicos adotados em cada situação: equivalente da fase A, B ou C. Nesta seção são apresentadas as matrizes de transformação para os 3 casos, as quais são utilizadas posteriormente nas demais seções deste apêndice.

\section{A.1.1 Circuito equivalente monofásico da fase $A$}

Considerando 3 fasores de corrente desequilibrados $\left(I_{a}, I_{b}\right.$ e $\left.I_{c}\right)$, cada um deles pode ser decomposto em seus componentes simétricos, como mostrado nas Equações (A.1), (A.2) e (A.3):

$$
\begin{aligned}
& I_{a}=I_{a 0}+I_{a 1}+I_{a 2} \\
& I_{b}=I_{b 0}+I_{b 1}+I_{b 2} \\
& I_{c}=I_{c 0}+I_{c 1}+I_{c 2}
\end{aligned}
$$


onde $I_{a 0}$ é o componente de sequência zero da fase A, $I_{a 1}$ é o componente de sequência positiva da fase A e $I_{a 2}$ é o componente de sequência negativa da fase A.

Analogamente para as demais fases.

Com base na definição dos sistemas de componentes simétricos é possível reescrever os componentes de sequência das fases $\mathrm{B}$ e $\mathrm{C}$ em termos dos componentes da fase $\mathrm{A}$ :

$$
\begin{array}{ll}
I_{b 0}=I_{a 0} & I_{c 0}=I_{a 0} \\
I_{b 1}=a^{2} \cdot I_{a 1} & I_{c 1}=a \cdot I_{a 1} \\
I_{b 2}=a \cdot I_{a 2} & I_{c 2}=a^{2} \cdot I_{a 2}
\end{array}
$$

onde $a$ é um operador que equivale a $1 \angle 120^{\circ}$.

Reescrevendo as Equações (A.1), (A.2) e (A.3) em termos dos componentes da fase A, tem-se:

$$
\begin{aligned}
& I_{a}=I_{a 0}+I_{a 1}+I_{a 2} \\
& I_{b}=I_{a 0}+a^{2} \cdot I_{a 1}+a \cdot I_{a 2} \\
& I_{c}=I_{a 0}+a \cdot I_{a 1}+a^{2} \cdot I_{a 2}
\end{aligned}
$$

Ou em formato matricial:

$$
\left[\begin{array}{c}
I_{a} \\
I_{b} \\
I_{c}
\end{array}\right]=\left[\begin{array}{ccc}
1 & 1 & 1 \\
1 & a^{2} & a \\
1 & a & a^{2}
\end{array}\right] \cdot\left[\begin{array}{c}
I_{a 0} \\
I_{a 1} \\
I_{a 2}
\end{array}\right]
$$

A matriz evidenciada na Equação (A.10) realiza a conversão dos fasores da fase A do domínio da sequência para o domínio $\mathrm{ABC}$ e é destacada na Equação (A.11).

$$
A=\left[\begin{array}{lll}
1 & 1 & 1 \\
1 & a^{2} & a \\
1 & a & a^{2}
\end{array}\right]
$$

A inversa desta matriz permite realizar a conversão do domínio $\mathrm{ABC}$ para o domínio da sequência, a qual é mostrada na Equação (A.12).

$$
A^{-1}=\frac{1}{3} \cdot\left[\begin{array}{ccc}
1 & 1 & 1 \\
1 & a & a^{2} \\
1 & a^{2} & a
\end{array}\right]
$$




\section{A.1.2 Circuito equivalente monofásico da fase $B$}

Para encontrar as matrizes de transformação ao se considerar os componentes simétricos da fase B primeiramente deve-se encontrar as relações dos componentes simétricos das fases $\mathrm{A}$ e $\mathrm{C}$ em termos dos componentes da fase B, como mostra as Equações (A.13), (A.14) e (A.15).

$$
\begin{array}{ll}
I_{a 0}=I_{b 0} & I_{c 0}=I_{b 0} \\
I_{a 1}=a \cdot I_{b 1} & I_{c 1}=a^{2} \cdot I_{b 1} \\
I_{a 2}=a^{2} \cdot I_{b 2} & I_{c 2}=a \cdot I_{b 2}
\end{array}
$$

Então, as Equações (A.1), (A.2) e (A.3) podem ser reescritas em termos dos componentes de sequência da fase B:

$$
\begin{aligned}
& I_{a}=I_{b 0}+a \cdot I_{b 1}+a^{2} \cdot I_{b 2} \\
& I_{b}=I_{b 0}+I_{b 1}+I_{b 2} \\
& I_{c}=I_{b 0}+a^{2} \cdot I_{b 1}+a \cdot I_{b 2}
\end{aligned}
$$

Das Equações (A.16), (A.17) e (A.18) obtém-se a matriz de transformação ao se reescrevê-las no formato matricial:

$$
\left[\begin{array}{c}
I_{a} \\
I_{b} \\
I_{c}
\end{array}\right]=\left[\begin{array}{ccc}
1 & a & a^{2} \\
1 & 1 & 1 \\
1 & a^{2} & a
\end{array}\right] \cdot\left[\begin{array}{c}
I_{b 0} \\
I_{b 1} \\
I_{b 2}
\end{array}\right]
$$

Portanto, a matriz de transformação do domínio da sequência para o domínio ABC é dada pela Equação (A.20).

$$
B=\left[\begin{array}{lll}
1 & a & a^{2} \\
1 & 1 & 1 \\
1 & a^{2} & a
\end{array}\right]
$$

A inversa dessa matriz realiza a transformação do domínio $\mathrm{ABC}$ para o domínio da sequência:

$$
B^{-1}=\frac{1}{3} \cdot\left[\begin{array}{ccc}
1 & 1 & 1 \\
\frac{1}{a} & 1 & -\frac{(1+a)}{a} \\
-\frac{(1+a)}{a} & 1 & \frac{1}{a}
\end{array}\right]
$$




\section{A.1.3 Circuito equivalente monofásico da fase $C$}

Para obter as matrizes de transformação para esse caso deve-se repetir o mesmo processo, porém escrevendo os componentes de sequência das fases A e B em termos dos componentes da fase $\mathrm{C}$. As relações entre esses componentes são mostradas nas Equações (A.22), (A.23) e (A.24).

$$
\begin{array}{ll}
I_{a 0}=I_{c 0} & I_{b 0}=I_{c 0} \\
I_{a 1}=a^{2} \cdot I_{c 1} & I_{b 1}=a \cdot I_{c 1} \\
I_{a 2}=a \cdot I_{c 2} & I_{b 2}=a^{2} \cdot I_{c 2}
\end{array}
$$

Então, com base nos componentes simétricos da fase C é possível obter os valores de $I_{a}, I_{b}$ e $I_{c}$ segundo a Equação (A.25).

$$
\left[\begin{array}{c}
I_{a} \\
I_{b} \\
I_{c}
\end{array}\right]=\left[\begin{array}{ccc}
1 & a^{2} & a \\
1 & a & a^{2} \\
1 & 1 & 1
\end{array}\right] \cdot\left[\begin{array}{c}
I_{c 0} \\
I_{c 1} \\
I_{c 2}
\end{array}\right]
$$

Portanto, as matrizes de transformação em termos dos componentes simétricos da fase $\mathrm{C}$ são dadas pelas Equações (A.26) e (A.27).

$$
\begin{gathered}
C=\left[\begin{array}{ccc}
1 & a^{2} & a \\
1 & a & a^{2} \\
1 & 1 & 1
\end{array}\right] \\
C^{-1}=\frac{1}{3} \cdot\left[\begin{array}{ccc}
1 & 1 & 1 \\
\frac{a+1}{a} & \frac{1}{a} & 1 \\
\frac{1}{a} & \frac{a+1}{a} & 1
\end{array}\right]
\end{gathered}
$$

\section{A.2 Curtos-circuitos monofásicos}

Essa primeira classe de curtos-circuitos desequilibrados é caracterizada pelo contato (direta ou indiretamente) do condutor de uma das fases com a terra. A Figura 20 representa a situação onde a fase A entra em contato com a terra. Os demais casos também estão representados nessa figura, bastando trocar a conexão da terra com o ponto $V_{b}$ ou $V_{c}$. Nas 3 subseções seguintes são mostradas a aplicação da teoria de componentes simétricos para a análise desses 3 casos de curtos-circuitos monofásicos.

\section{A.2.1 Curto-circuito monofásico AT}

Na situação do condutor da fase A em contato com o solo tem-se, durante a falta, as seguintes condições: 
Figura 20 - Curto-circuito monofásico AT.

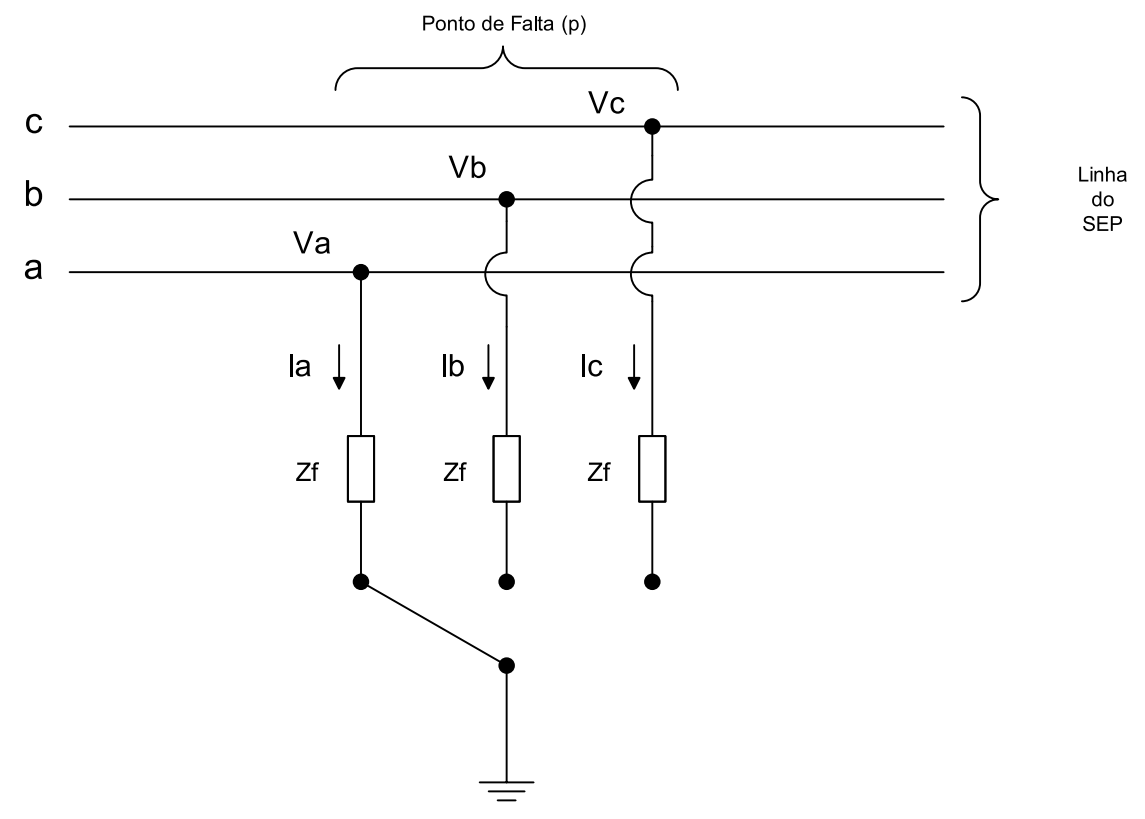

$$
V_{a}=I_{a} \cdot Z_{f}, \quad I_{b}=I_{c}=0
$$

Nessas condições, e utilizando-se da Equação (A.12), os componentes simétricos da corrente da fase A podem ser calculados:

$$
\left[\begin{array}{c}
I_{a 0} \\
I_{a 1} \\
I_{a 2}
\end{array}\right]=\frac{1}{3} \cdot\left[\begin{array}{ccc}
1 & 1 & 1 \\
1 & a & a^{2} \\
1 & a^{2} & a
\end{array}\right] \cdot\left[\begin{array}{c}
I_{a} \\
0 \\
0
\end{array}\right]
$$

Ao se expandir a Equação (A.29) obtém-se a condição representada na Equação (A.30).

$$
I_{a 0}=I_{a 1}=I_{a 2}=\frac{I_{a}}{3}
$$

Os componentes simétricos da tensão no ponto de falta são dadas pela Equação (A.31).

$$
\left[\begin{array}{c}
V_{a 0} \\
V_{a 1} \\
V_{a 2}
\end{array}\right]=\left[\begin{array}{c}
0 \\
E_{a} \\
0
\end{array}\right]-\left[\begin{array}{ccc}
Z_{0} & 0 & 0 \\
0 & Z_{1} & 0 \\
0 & 0 & Z_{2}
\end{array}\right] \cdot\left[\begin{array}{c}
I_{a 1} \\
I_{a 1} \\
I_{a 1}
\end{array}\right],
$$

onde $E_{a}$ é a tensão pré-falta no ponto de falta e $Z_{1}, Z_{2}$ e $Z_{0}$ são os equivalentes de Thévenin na falta de cada rede de sequência.

Desenvolvendo a Equação (A.31) obtém-se a Equação (A.34). 


$$
\begin{aligned}
V_{a 0}+V_{a 1}+V_{a 2} & =E_{a}-Z_{1} \cdot I_{a 1}-Z_{2} \cdot I_{a 1}-Z_{0} \cdot I_{a 1} \\
V_{a} & =E_{a}-\left(Z_{1}+Z_{2}+Z_{0}\right) \cdot I_{a 1}
\end{aligned}
$$

Substituindo o valor de $V_{a}$ dado pela Equação A.28 na Equação A.33, obtém-se:

$$
I_{a} \cdot Z_{f}=E_{a}-\left(Z_{1}+Z_{2}+Z_{0}\right) \cdot I_{a 1}
$$

Como $I_{a}=3 \cdot I_{a 1}$, a Equação A.34 pode ser simplificada, e o componente de sequência positiva da corrente de falta pode ser calculado através da Equação A.35.

$$
I_{a 1}=\frac{E_{a}}{Z_{1}+Z_{2}+Z_{0}+3 \cdot Z_{f}}
$$

Após obtidos $I_{a 1}=I_{a 2}=I_{a 0}$, os componentes simétricos da tensão na fase A em qualquer barra podem ser calculados pela Equação (A.36).

$$
\left[\begin{array}{c}
V_{a 0}^{m} \\
V_{a 1}^{m} \\
V_{a 2}^{m}
\end{array}\right]=\left[\begin{array}{c}
0 \\
V_{p r e}^{m} \\
0
\end{array}\right]-\left[\begin{array}{ccc}
Z_{m, p}^{0} & 0 & 0 \\
0 & Z_{m, p}^{1} & 0 \\
0 & 0 & Z_{m, p}^{2}
\end{array}\right] \cdot\left[\begin{array}{c}
I_{a 1} \\
I_{a 1} \\
I_{a 1}
\end{array}\right],
$$

onde $V_{a 0}^{m}$ é o componente de sequência zero da tensão na barra $m, V_{p r e}^{m}$ é a tensão pré-falta na barra $m$, e $Z_{m, p}^{0}$ é o elemento $(m, p)$ da matriz impedância de barras de sequência zero, sendo $p$ o ponto de falta. Essas definições são análogas para as variáveis das demais sequências.

Por fim, tendo os componentes simétricos da tensão, basta então obter as tensões no domínio ABC aplicando a Equação (A.37).

$$
\left[\begin{array}{c}
V_{a}^{m} \\
V_{b}^{m} \\
V_{c}^{m}
\end{array}\right]=\left[\begin{array}{lll}
1 & 1 & 1 \\
1 & a^{2} & a \\
1 & a & a^{2}
\end{array}\right] \cdot\left[\begin{array}{c}
V_{a 0}^{m} \\
V_{a 1}^{m} \\
V_{a 2}^{m}
\end{array}\right]
$$

\section{A.2.2 Curto-circuito monofásico BT}

A expressão para as tensões durante a falta monofásica do tipo BT pode ser obtida seguindo um procedimento semelhante ao apresentado para a falta AT. No entanto, os cálculos devem ser efetuados descrevendo todos os componentes simétricos das grandezas envolvidas em termos da fase $\mathrm{B}$, sendo que ao final os valores obtidos são passados de volta ao domínio $\mathrm{ABC}$ por meio da matriz de transformação adequada. Então, para esse caso de curto-circuito o componente da corrente de falta é obtido por meio da Equação A.38. 


$$
I_{b 1}=\frac{E_{b}}{Z_{1}+Z_{2}+Z_{0}+3 \cdot Z_{f}}
$$

Conhecendo os componentes simétricos da corrente de falta, os componentes da tensão em qualquer barra podem ser calculados pela Equação (A.39).

$$
\left[\begin{array}{c}
V_{b 0}^{m} \\
V_{b 1}^{m} \\
V_{b 2}^{m}
\end{array}\right]=\left[\begin{array}{c}
0 \\
V_{p r e}^{m} \\
0
\end{array}\right]-\left[\begin{array}{ccc}
Z_{m, p}^{0} & 0 & 0 \\
0 & Z_{m, p}^{1} & 0 \\
0 & 0 & Z_{m, p}^{2}
\end{array}\right] \cdot\left[\begin{array}{c}
I_{b 1} \\
I_{b 1} \\
I_{b 1}
\end{array}\right]
$$

E então as tensões no domínio ABC podem ser obtidas aplicando a Equação (A.40).

$$
\left[\begin{array}{c}
V_{a}^{m} \\
V_{b}^{m} \\
V_{c}^{m}
\end{array}\right]=\left[\begin{array}{ccc}
1 & a & a^{2} \\
1 & 1 & 1 \\
1 & a^{2} & a
\end{array}\right] \cdot\left[\begin{array}{c}
V_{b 0}^{m} \\
V_{b 1}^{m} \\
V_{b 2}^{m}
\end{array}\right]
$$

\section{A.2.3 Curto-circuito monofásico CT}

Para este tipo de falta também é possível obter as equações para a corrente e as tensões durante o curto seguindo raciocínio análogo ao caso da falta monofásica AT. Dessa forma, o componente simétrico da corrente no ponto de falta é dado por:

$$
I_{c 1}=\frac{E_{c}}{Z_{1}+Z_{2}+Z_{0}+3 \cdot Z_{f}}
$$

Então, os componentes simétricos da tensão em uma barra $m$ podem ser calculados pela Equação (A.42).

$$
\left[\begin{array}{c}
V_{c 0}^{m} \\
V_{c 1}^{m} \\
V_{c 2}^{m}
\end{array}\right]=\left[\begin{array}{c}
0 \\
V_{p r e}^{m} \\
0
\end{array}\right]-\left[\begin{array}{ccc}
Z_{m, p}^{0} & 0 & 0 \\
0 & Z_{m, p}^{1} & 0 \\
0 & 0 & Z_{m, p}^{2}
\end{array}\right] \cdot\left[\begin{array}{c}
I_{c 1} \\
I_{c 1} \\
I_{c 1}
\end{array}\right]
$$

E por fim, utilizando a matriz de transformação para o circuito da fase $C$, são obtidas as tensões no domínio $\mathrm{ABC}$.

$$
\left[\begin{array}{c}
V_{a}^{m} \\
V_{b}^{m} \\
V_{c}^{m}
\end{array}\right]=\left[\begin{array}{ccc}
1 & a^{2} & a \\
1 & a & a^{2} \\
1 & 1 & 1
\end{array}\right] \cdot\left[\begin{array}{c}
V_{c 0}^{m} \\
V_{c 1}^{m} \\
V_{c 2}^{m}
\end{array}\right]
$$




\section{A.3 Curtos-circuitos bifásicos}

Esse tipo de situação de falta é caracterizada pela conexão dos condutores de duas fases entre si. A Figura 21 ilustra o caso de um curto-circuito entre as fases B e C, sem a conexão com a terra. Este caso e mais os outros dois curtos bifásicos serão descritos ao longo desta seção.

Figura 21 - Curto-circuito bifásico BC.

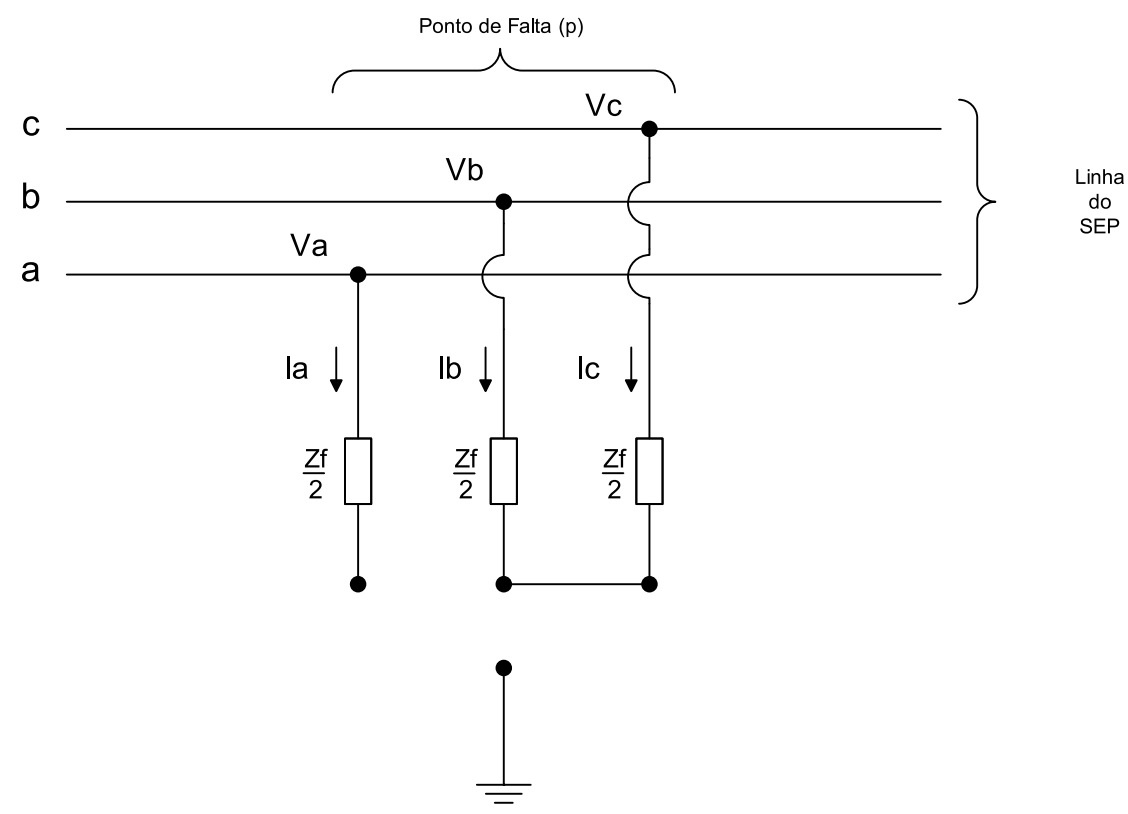

\section{A.3.1 Curto-circuito bifásico BC}

Observando a Figura 21, durante a falta, tem-se as seguintes condições:

$$
V_{c}=V_{b}-I_{b} \cdot Z_{f}, \quad I_{a}=0, \quad I_{b}=-I_{c}
$$

Os componentes simétricos da corrente na fase A são calculados pela Equação (A.45).

$$
\left[\begin{array}{c}
I_{a 0} \\
I_{a 1} \\
I_{a 2}
\end{array}\right]=\frac{1}{3} \cdot\left[\begin{array}{ccc}
1 & 1 & 1 \\
1 & a & a^{2} \\
1 & a^{2} & a
\end{array}\right] \cdot\left[\begin{array}{c}
0 \\
-I_{c} \\
I_{c}
\end{array}\right]
$$

O desenvolvimento da Equação (A.45) implica nas seguintes condições:

$$
I_{a 0}=0, \quad I_{a 2}=-I_{a 1}
$$

Assumindo $Z_{0}$ um valor finito, ou seja, existe uma conexão do neutro do gerador com a terra, $I_{a 0}=0$ implica em: 


$$
V_{a 0}=0
$$

Tomando $V_{c}=V_{b}-I_{b} \cdot Z_{f}$, os componentes simétricos da tensão na fase A são dados por:

$$
\left[\begin{array}{c}
V_{a 0} \\
V_{a 1} \\
V_{a 2}
\end{array}\right]=\frac{1}{3} \cdot\left[\begin{array}{ccc}
1 & 1 & 1 \\
1 & a & a^{2} \\
1 & a^{2} & a
\end{array}\right] \cdot\left[\begin{array}{c}
V_{a} \\
V_{b} \\
V_{b}-I_{b} \cdot Z_{f}
\end{array}\right]
$$

Desenvolvendo para $V_{a 1}$ e $V_{a 2}$ :

$$
\begin{aligned}
& 3 \cdot V_{a 1}=V_{a}+\left(a+a^{2}\right) \cdot V_{b}-a^{2} \cdot I_{b} \cdot Z_{f} \\
& 3 \cdot V_{a 2}=V_{a}+\left(a+a^{2}\right) \cdot V_{b}-a \cdot I_{b} \cdot Z_{f}
\end{aligned}
$$

Então,

$$
3 \cdot\left(V_{a 1}-V_{a 2}\right)=\left(a-a^{2}\right) \cdot I_{b} \cdot Z_{f}=j \cdot \sqrt{3} \cdot I_{b} \cdot Z_{f}
$$

Dado que $I_{a 1}=-I_{a 2}$,

$$
\begin{aligned}
& I_{b}=a^{2} \cdot I_{a 1}+a \cdot I_{a 2} \\
& I_{b}=\left(a^{2}-a\right) \cdot I_{a 1}=-j \cdot \sqrt{3} \cdot I_{a 1}
\end{aligned}
$$

Substituindo a Equação (A.53) na Equação (A.51):

$$
V_{a 1}-V_{a 2}=I_{a 1} \cdot Z_{f}
$$

Os componentes da tensão no ponto de falta são dados pela Equação (A.55).

$$
\left[\begin{array}{c}
0 \\
V_{a 1} \\
V_{a 2}
\end{array}\right]=\left[\begin{array}{c}
0 \\
E_{a} \\
0
\end{array}\right]-\left[\begin{array}{ccc}
Z_{0} & 0 & 0 \\
0 & Z_{1} & 0 \\
0 & 0 & Z_{2}
\end{array}\right] \cdot\left[\begin{array}{c}
0 \\
I_{a 1} \\
-I_{a 1}
\end{array}\right]
$$

Então,

$$
V_{a 1}-V_{a 2}=E_{a}-I_{a 1} \cdot Z_{1}-I_{a 1} \cdot Z_{2}
$$


Substituindo a Equação (A.54) na Equação (A.56) obtém-se o valor de $I_{a 1}$ :

$$
\begin{aligned}
I_{a 1} \cdot Z_{f} & =E_{a}-I_{a 1} \cdot Z_{1}-I_{a 1} \cdot Z_{2} \\
I_{a 1} & =\frac{E_{a}}{Z_{1}+Z_{2}+Z_{f}}
\end{aligned}
$$

Portanto, os componentes simétricos da tensão em uma barra genérica $m$ do sistema são descritos pela Equação (A.59).

$$
\left[\begin{array}{c}
V_{a 0}^{m} \\
V_{a 1}^{m} \\
V_{a 2}^{m}
\end{array}\right]=\left[\begin{array}{c}
0 \\
V_{p r e}^{m} \\
0
\end{array}\right]-\left[\begin{array}{ccc}
Z_{m, p}^{0} & 0 & 0 \\
0 & Z_{m, p}^{1} & 0 \\
0 & 0 & Z_{m, p}^{2}
\end{array}\right] \cdot\left[\begin{array}{c}
0 \\
I_{a 1} \\
-I_{a 1}
\end{array}\right]
$$

E no domínio $\mathrm{ABC}$ as tensões na barra $m$ podem ser obtidas a partir da Equação (A.37), que já foi mostrada para o curto-circuito fase A-terra.

\section{A.3.2 Curto-circuito bifásico AC}

O mesmo procedimento demonstrado para o curto-circuito BC pode ser aplicado para este caso, tomando o circuito equivalente monofásico para a fase B. Aplicando o mesmo raciocínio é possível determinar a expressão para a sequência positiva da corrente de falta:

$$
I_{b 1}=\frac{E_{b}}{Z_{1}+Z_{2}+Z_{f}}
$$

Então, as tensões no domínio da sequência podem ser calculadas da Equação (A.61).

$$
\left[\begin{array}{c}
V_{b 0}^{m} \\
V_{b 1}^{m} \\
V_{b 2}^{m}
\end{array}\right]=\left[\begin{array}{c}
0 \\
V_{p r e}^{m} \\
0
\end{array}\right]-\left[\begin{array}{ccc}
Z_{m, p}^{0} & 0 & 0 \\
0 & Z_{m, p}^{1} & 0 \\
0 & 0 & Z_{m, p}^{2}
\end{array}\right] \cdot\left[\begin{array}{c}
0 \\
I_{b 1} \\
-I_{b 1}
\end{array}\right]
$$

E a conversão para o domínio ABC pode ser feita por meio da Equação (A.40).

\section{A.3.3 Curto-circuito bifásico $A B$}

A análise desse terceiro curto bifásico segue raciocínio semelhante aos demais, porém considerando no desenvolvimento dos cálculos o circuito monofásico equivalente da fase C. Analogamente, o componente de sequência positiva da corrente de falta é dado pela Equação A.62.

$$
I_{c 1}=\frac{E_{c}}{Z_{1}+Z_{2}+Z_{f}}
$$


Portanto, as tensões no domínio da sequência são dadas por:

$$
\left[\begin{array}{c}
V_{c 0}^{m} \\
V_{c 1}^{m} \\
V_{c 2}^{m}
\end{array}\right]=\left[\begin{array}{c}
0 \\
V_{p r e}^{m} \\
0
\end{array}\right]-\left[\begin{array}{ccc}
Z_{m, p}^{0} & 0 & 0 \\
0 & Z_{m, p}^{1} & 0 \\
0 & 0 & Z_{m, p}^{2}
\end{array}\right] \cdot\left[\begin{array}{c}
0 \\
I_{c 1} \\
-I_{c 1}
\end{array}\right]
$$

E no domínio $\mathrm{ABC}$ são obtidas por meio da Equação (A.43).

\section{A.4 Curtos-circuitos bifásicos-terra}

Este tipo de curto-circuito desequilibrado ocorre com o contato de condutores de duas fases mais a terra, o qual é representado na Figura 22 quando o contato envolve as fases B e C com a terra.

Figura 22 - Curto-circuito BCT.

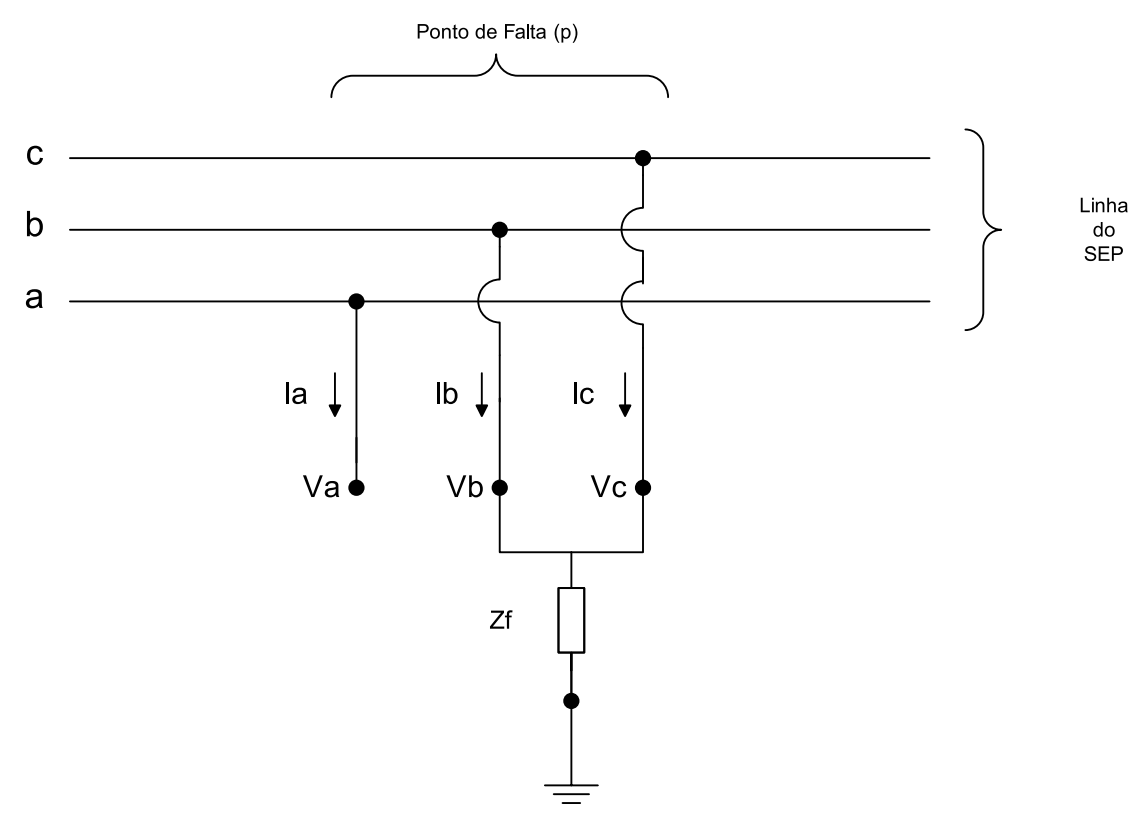

\section{A.4.1 Curto-circuito BCT}

As condições durante a falta são:

$$
V_{b}=V_{c}=\left(I_{b}+I_{c}\right) \cdot Z_{f}, \quad I_{a}=0
$$

Os componentes simétricos da corrente na fase A podem ser calculados por meio da Equação A.65.

$$
\left[\begin{array}{c}
I_{a 0} \\
I_{a 1} \\
I_{a 2}
\end{array}\right]=\frac{1}{3} \cdot\left[\begin{array}{ccc}
1 & 1 & 1 \\
1 & a & a^{2} \\
1 & a^{2} & a
\end{array}\right] \cdot\left[\begin{array}{c}
0 \\
I_{b} \\
I_{c}
\end{array}\right]
$$


Desenvolvendo a Equação A.65 para $I_{a 0}$ obtém-se:

$$
I_{a 0}=\frac{\left(I_{b}+I_{c}\right)}{3}
$$

Os componentes simétricos da tensão na fase A são dados pela Equação (A.67).

$$
\left[\begin{array}{l}
V_{a 0} \\
V_{a 1} \\
V_{a 2}
\end{array}\right]=\frac{1}{3} \cdot\left[\begin{array}{ccc}
1 & 1 & 1 \\
1 & a & a^{2} \\
1 & a^{2} & a
\end{array}\right] \cdot\left[\begin{array}{c}
V_{a} \\
V_{b} \\
V_{b}
\end{array}\right]
$$

De onde obtém-se:

$$
\begin{aligned}
& V_{a 1}=V_{a 2} \\
& V_{a 0}=\frac{V_{a}+2 \cdot V_{b}}{3}
\end{aligned}
$$

Da definição dos componentes simétricos, e tomando $V_{a 1}=V_{a 2}, V_{a}$ pode ser calculado pela Equação A.70.

$$
V_{a}=V_{a 0}+2 \cdot V_{a 1}
$$

Substituindo Equação A.70 e o valor de $V_{b}$ dado pela Equação A.64 na Equação A.69, temos que:

$$
V_{a 0}=\frac{V_{a 0}+2 \cdot V_{a 1}+2 \cdot\left(I_{b}+I_{c}\right) \cdot Z_{f}}{3}
$$

Aplicando a Equação A.66 na Equação A.71 obtém-se uma expressão para $V_{a 0}$ :

$$
\begin{aligned}
& V_{a 0}=\frac{V_{a 0}+2 \cdot V_{a 1}}{3}+2 \cdot I_{a 0} \cdot Z_{f} \\
& V_{a 0}=V_{a 1}+3 \cdot I_{a 0} \cdot Z_{f}
\end{aligned}
$$

A corrente que circula na rede de sequência zero é dada por:

$$
I_{a 0}=-\frac{V_{a 0}}{Z_{0}}
$$

Substituindo a Equação A.74 na Equação A.73 obtém-se: 


$$
\begin{aligned}
& V_{a 0}=V_{a 1}-\frac{3 \cdot V_{a 0} \cdot Z_{f}}{Z_{0}} \\
& V_{a 0}=\frac{Z_{0}}{Z_{0}+3 \cdot Z_{f}} \cdot V_{a 1}
\end{aligned}
$$

A queda de tensão no circuito de sequência positiva é dada pela Equação A.77.

$$
V_{a 1}=E_{a}-I_{a 1} \cdot Z_{1}
$$

Substituindo o valor de $V_{a 1}$ na Equação A.76 chega-se na Equação A.78.

$$
V_{a 0}=\frac{Z_{0}}{Z_{0}+3 \cdot Z_{f}} \cdot E_{a}-\frac{Z_{0} \cdot Z_{1}}{Z_{0}+3 \cdot Z_{f}} \cdot I_{a 1}
$$

As quedas de tensão em cada uma das redes de sequência podem ser calculadas pela Equação A.79.

$$
\left[\begin{array}{c}
V_{a 0} \\
V_{a 1} \\
V_{a 2}
\end{array}\right]=\left[\begin{array}{c}
0 \\
E_{a} \\
0
\end{array}\right]-\left[\begin{array}{ccc}
Z_{0} & 0 & 0 \\
0 & Z_{1} & 0 \\
0 & 0 & Z_{2}
\end{array}\right] \cdot\left[\begin{array}{c}
I_{a 0} \\
I_{a 1} \\
I_{a 2}
\end{array}\right]
$$

Considerando $V_{a 1}$ e $V_{a 2}$ como $E_{a}-I_{a 1} \cdot Z_{1}$ e $V_{a 0}$ dado pela Equação A.78, obtém-se:

$$
\left[\begin{array}{c}
\frac{Z_{0}}{Z_{0}+3 \cdot Z_{f}} \cdot E_{a}-\frac{Z_{0} \cdot Z_{1}}{Z_{0}+3 \cdot Z_{f}} \cdot I_{a 1} \\
E_{a}-I_{a 1} \cdot Z_{1} \\
E_{a}-I_{a 1} \cdot Z_{1}
\end{array}\right]=\left[\begin{array}{c}
0 \\
E_{a} \\
0
\end{array}\right]-\left[\begin{array}{ccc}
Z_{0} & 0 & 0 \\
0 & Z_{1} & 0 \\
0 & 0 & Z_{2}
\end{array}\right] \cdot\left[\begin{array}{c}
I_{a 0} \\
I_{a 1} \\
I_{a 2}
\end{array}\right]
$$

Multiplicando ambos os lados por $Z^{-1}$, sendo:

$$
Z^{-1}=\left[\begin{array}{ccc}
\frac{1}{Z_{0}} & 0 & 0 \\
0 & \frac{1}{Z_{1}} & 0 \\
0 & 0 & \frac{1}{Z_{2}}
\end{array}\right]
$$

obtém-se:

$$
\left[\begin{array}{ccc}
\frac{1}{Z_{0}} & 0 & 0 \\
0 & \frac{1}{Z_{1}} & 0 \\
0 & 0 & \frac{1}{Z_{2}}
\end{array}\right] \cdot\left[\begin{array}{c}
\frac{Z_{0}}{Z_{0}+3 \cdot Z_{f}} \cdot E_{a}-\frac{Z_{0} \cdot Z_{1}}{Z_{0}+3 \cdot Z_{f}} \cdot I_{a 1} \\
E_{a}-I_{a 1} \cdot Z_{1} \\
E_{a}-I_{a 1} \cdot Z_{1}
\end{array}\right]=\left[\begin{array}{ccc}
\frac{1}{Z_{0}} & 0 & 0 \\
0 & \frac{1}{Z_{1}} & 0 \\
0 & 0 & \frac{1}{Z_{2}}
\end{array}\right] \cdot\left[\begin{array}{c}
0 \\
E_{a} \\
0
\end{array}\right]-\left[\begin{array}{c}
I_{a 0} \\
I_{a 1} \\
I_{a 2}
\end{array}\right]
$$


Somando as 3 equações e considerando que $I_{a 1}+I_{a 2}+I_{a 0}=I_{a}=0$, tem-se que:

$$
\begin{aligned}
& \frac{E_{a}}{Z_{0}+3 \cdot Z_{f}}-I_{a 1} \cdot \frac{Z_{1}}{Z_{0}+3 \cdot Z_{f}}+\frac{E_{a}}{Z_{1}}-I_{a 1}+\frac{E_{a}}{Z_{2}}-I_{a 1} \cdot \frac{Z_{1}}{Z_{2}}=\frac{E_{a}}{Z_{1}} \\
& \frac{E_{a}}{Z_{0}+3 \cdot Z_{f}}+\frac{E_{a}}{Z_{2}}=I_{a 1} \cdot\left(\frac{Z_{1}}{Z_{0}+3 \cdot Z_{f}}+1+\frac{Z_{1}}{Z_{2}}\right) \\
& I_{a 1} \cdot\left(\frac{Z_{1} \cdot Z_{2}+Z_{2} \cdot\left(Z_{0}+3 \cdot Z_{f}\right)+Z_{1} \cdot\left(Z_{0}+3 \cdot Z_{f}\right)}{Z_{2} \cdot\left(Z_{0}+3 \cdot Z_{f}\right)}\right)=\left(\frac{Z_{2}+Z_{0}+3 \cdot Z_{f}}{Z_{2} \cdot\left(Z_{0}+3 \cdot Z_{f}\right)}\right) \cdot E_{a} \\
& I_{a 1}=\frac{Z_{2}+Z_{0}+3 \cdot Z_{f}}{Z_{1} \cdot Z_{2}+Z_{1} \cdot\left(Z_{0}+3 \cdot Z_{f}\right)+Z_{2} \cdot\left(Z_{0}+3 \cdot Z_{f}\right)} \cdot E_{a}
\end{aligned}
$$

Levando em conta que $V_{a 1}=V_{a 2}, I_{a 2}$ pode ser calculado por:

$$
\begin{aligned}
& I_{a 2}=-\frac{V_{a 1}}{Z_{2}} \\
& I_{a 2}=-\frac{E_{a}-I_{a 1} \cdot Z_{1}}{Z_{2}}
\end{aligned}
$$

E $I_{a 0}$ pode ser calculado substituindo a Equação A.73 na Equação A.74 e reduzindo os termos:

$$
\begin{aligned}
I_{a 0} & =-\frac{V_{a 1}+3 \cdot I_{a 0} \cdot Z_{f}}{Z_{0}} \\
I_{a 0} & =-\frac{V_{a 1}}{Z_{0}+3 \cdot Z_{f}}
\end{aligned}
$$

Então, conhecendo todos os componentes simétricos da corrente de falta, calcula-se os componentes da tensão em uma barra $m$ :

$$
\left[\begin{array}{c}
V_{a 0}^{m} \\
V_{a 1}^{m} \\
V_{a 2}^{m}
\end{array}\right]=\left[\begin{array}{c}
0 \\
V_{p r e}^{m} \\
0
\end{array}\right]-\left[\begin{array}{ccc}
Z_{m, p}^{0} & 0 & 0 \\
0 & Z_{m, p}^{1} & 0 \\
0 & 0 & Z_{m, p}^{2}
\end{array}\right] \cdot\left[\begin{array}{c}
I_{a 0} \\
I_{a 1} \\
I_{a 2}
\end{array}\right]
$$

Por fim, para retornar ao domínio ABC basta aplicar a Equação (A.37).

\section{A.4.2 Curto-circuito ACT}

O mesmo procedimento descrito para o cálculo do curto-circuito BCT pode ser aplicado para este curto ACT, considerando o circuito equivalente da fase B. Seguindo este procedimento a corrente de sequência positiva é dada pela Equação A.92.

$$
I_{b 1}=\frac{Z_{2}+Z_{0}+3 \cdot Z_{f}}{Z_{1} \cdot Z_{2}+Z_{1} \cdot\left(Z_{0}+3 \cdot Z_{f}\right)+Z_{2} \cdot\left(Z_{0}+3 \cdot Z_{f}\right)} \cdot E_{b}
$$


Observando que $V_{b 1}=V_{b 2}, I_{b 2}$ pode ser calculado por:

$$
\begin{aligned}
I_{b 2} & =-\frac{V_{b 1}}{Z_{2}} \\
I_{b 2} & =-\frac{E_{b}-I_{b 1} \cdot Z_{1}}{Z_{2}}
\end{aligned}
$$

Da mesma forma $I_{b 0}$ é dado por:

$$
I_{b 0}=-\frac{V_{b 1}}{Z_{0}+3 \cdot Z_{f}}
$$

Os componentes simétricos da tensão em uma barra genérica $m$ são dados pela Equação (A.96).

$$
\left[\begin{array}{c}
V_{b 0}^{m} \\
V_{b 1}^{m} \\
V_{b 2}^{m}
\end{array}\right]=\left[\begin{array}{c}
0 \\
V_{p r e}^{m} \\
0
\end{array}\right]-\left[\begin{array}{ccc}
Z_{m, p}^{0} & 0 & 0 \\
0 & Z_{m, p}^{1} & 0 \\
0 & 0 & Z_{m, p}^{2}
\end{array}\right] \cdot\left[\begin{array}{c}
I_{b 0} \\
I_{b 1} \\
I_{b 2}
\end{array}\right]
$$

E as tensões no domínio $\mathrm{ABC}$ podem ser calculadas com a Equação (A.40).

\section{A.4.3 Curto-circuito ABT}

De maneira semelhante, considerando o circuito equivalente monofásica da fase $\mathrm{C}$, o componente de sequência positiva da corrente de falta para este curto é dado pela Equação A.97.

$$
I_{c 1}=\frac{Z_{2}+Z_{0}+3 \cdot Z_{f}}{Z_{1} \cdot Z_{2}+Z_{1} \cdot\left(Z_{0}+3 \cdot Z_{f}\right)+Z_{2} \cdot\left(Z_{0}+3 \cdot Z_{f}\right)} \cdot E_{c}
$$

Então, $I_{c 2}$ e $I_{c 0}$ são obtidos pelas Equações (A.98) e (A.99), respectivamente.

$$
\begin{aligned}
I_{c 2} & =-\frac{E_{c}-I_{c 1} \cdot Z_{1}}{Z_{2}} \\
I_{c 0} & =-\frac{V_{c 1}}{Z_{0}+3 \cdot Z_{f}}
\end{aligned}
$$

Portanto, os componentes simétricos da tensão em qualquer barra do sistema podem ser calculados pela Equação (A.100).

$$
\left[\begin{array}{c}
V_{c 0}^{m} \\
V_{c 1}^{m} \\
V_{c 2}^{m}
\end{array}\right]=\left[\begin{array}{c}
0 \\
V_{p r e}^{m} \\
0
\end{array}\right]-\left[\begin{array}{ccc}
Z_{m, p}^{0} & 0 & 0 \\
0 & Z_{m, p}^{1} & 0 \\
0 & 0 & Z_{m, p}^{2}
\end{array}\right] \cdot\left[\begin{array}{c}
I_{c 0} \\
I_{c 1} \\
I_{c 2}
\end{array}\right]
$$

E as tensões no domínio ABC a partir da Equação (A.43). 

APÊNDICE

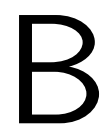

\section{MATRIZES DE TENSÃO DURANTE A FALTA}

Neste apêndice são apresentadas as MTDFs das 3 fases para as faltas desequilibradas aplicadas no sistema teste do CIGRÉ. As matrizes são representadas em uma escala de cor, assim como foi feito para as faltas trifásicas apresentadas no Capítulo 3. Como não existem ramais monofásicos ou bifásicos nesse sistema teste, não são apresentados todos os tipos de falta. Para as faltas monofásicas-terra são apresentadas as faltas do tipo AT. Para as bifásicas, faltas do tipo BC. Finalizando, para as bifásicas com conexão com a terra, as faltas do tipo BCT são apresentadas.

Figura 23 - MTDF da fase A para o sistema de 15 barras durante a ocorrência de faltas monofásicas AT francas sem o GD.

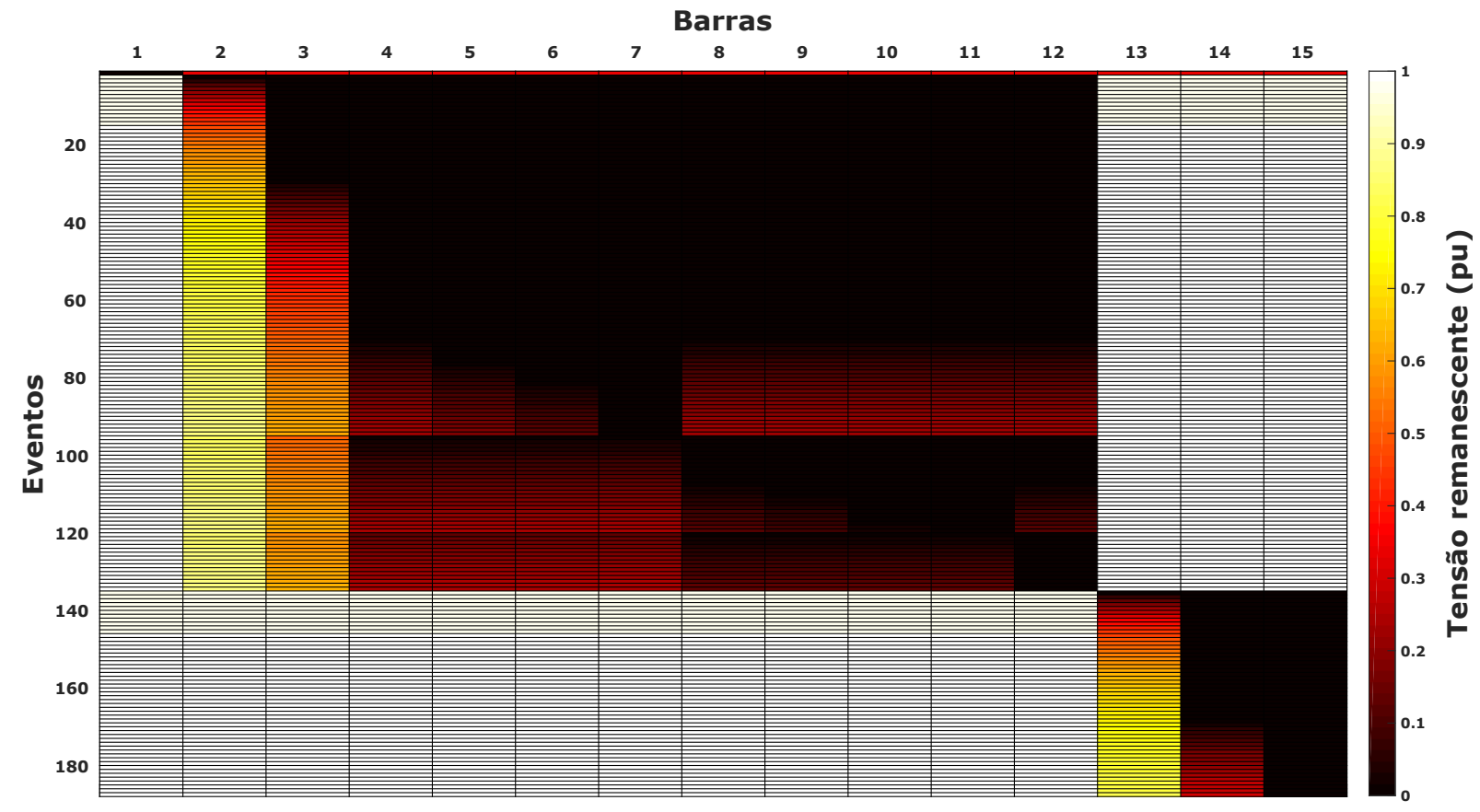


Figura 24 - MTDF da fase B para o sistema de 15 barras durante a ocorrência de faltas monofásicas AT francas sem o GD.

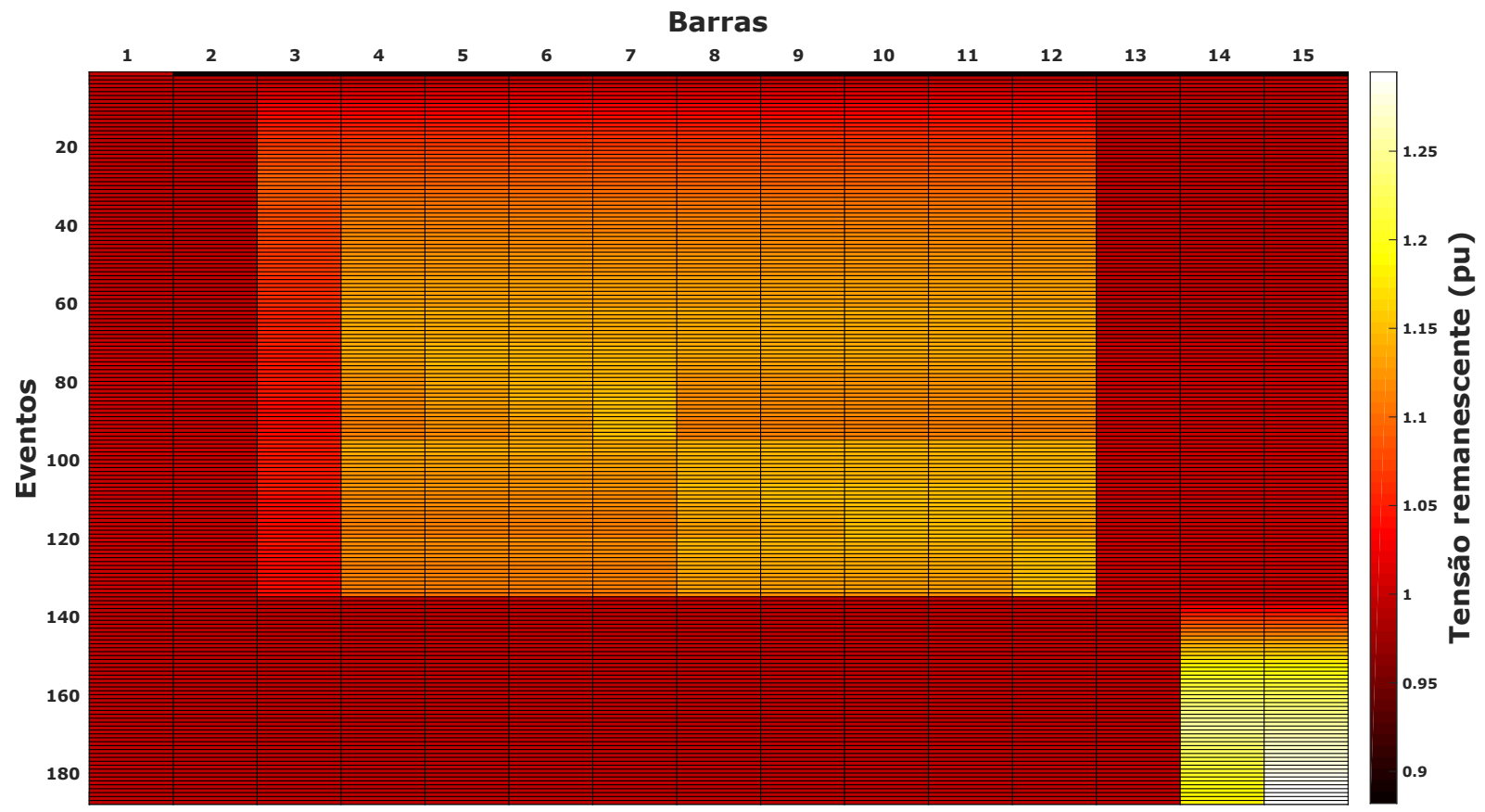

Figura 25 - MTDF da fase C para o sistema de 15 barras durante a ocorrência de faltas monofásicas AT francas sem o GD.

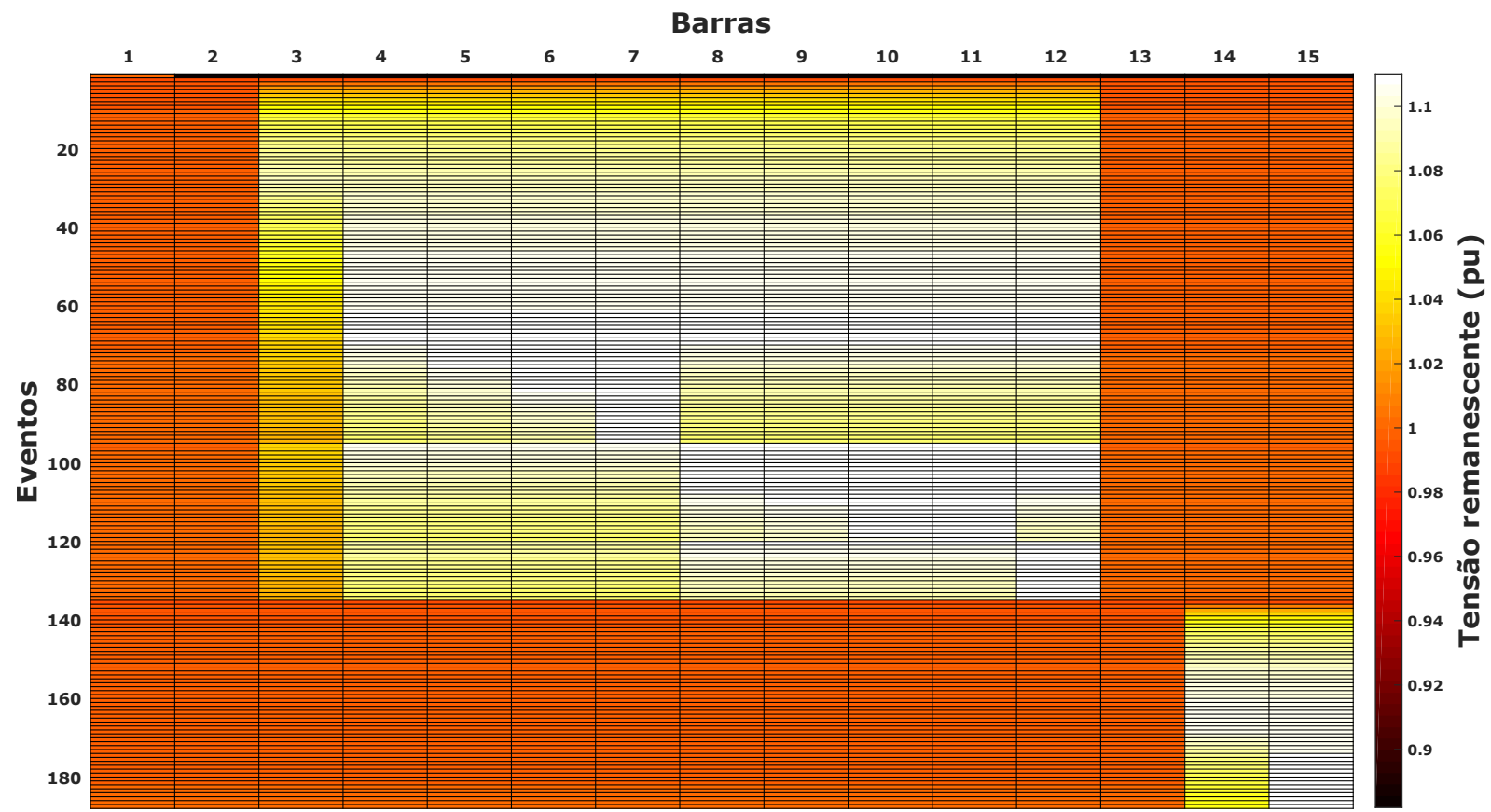


Figura 26 - MTDF da fase A para o sistema de 15 barras durante a ocorrência de faltas bifásicas BC francas sem o GD.

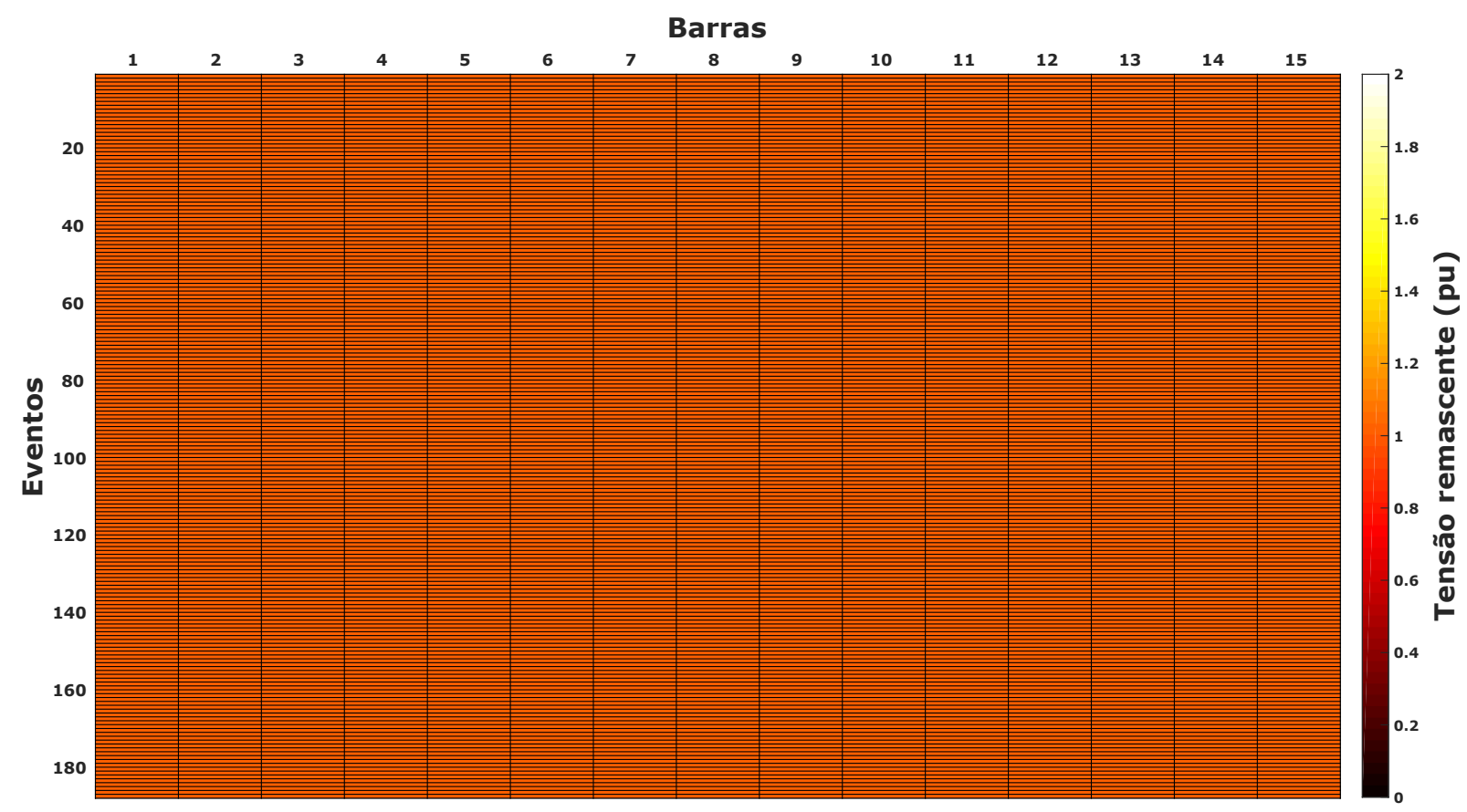

Figura 27 - MTDF da fase B para o sistema de 15 barras durante a ocorrência de faltas bifásicas BC francas sem o GD.

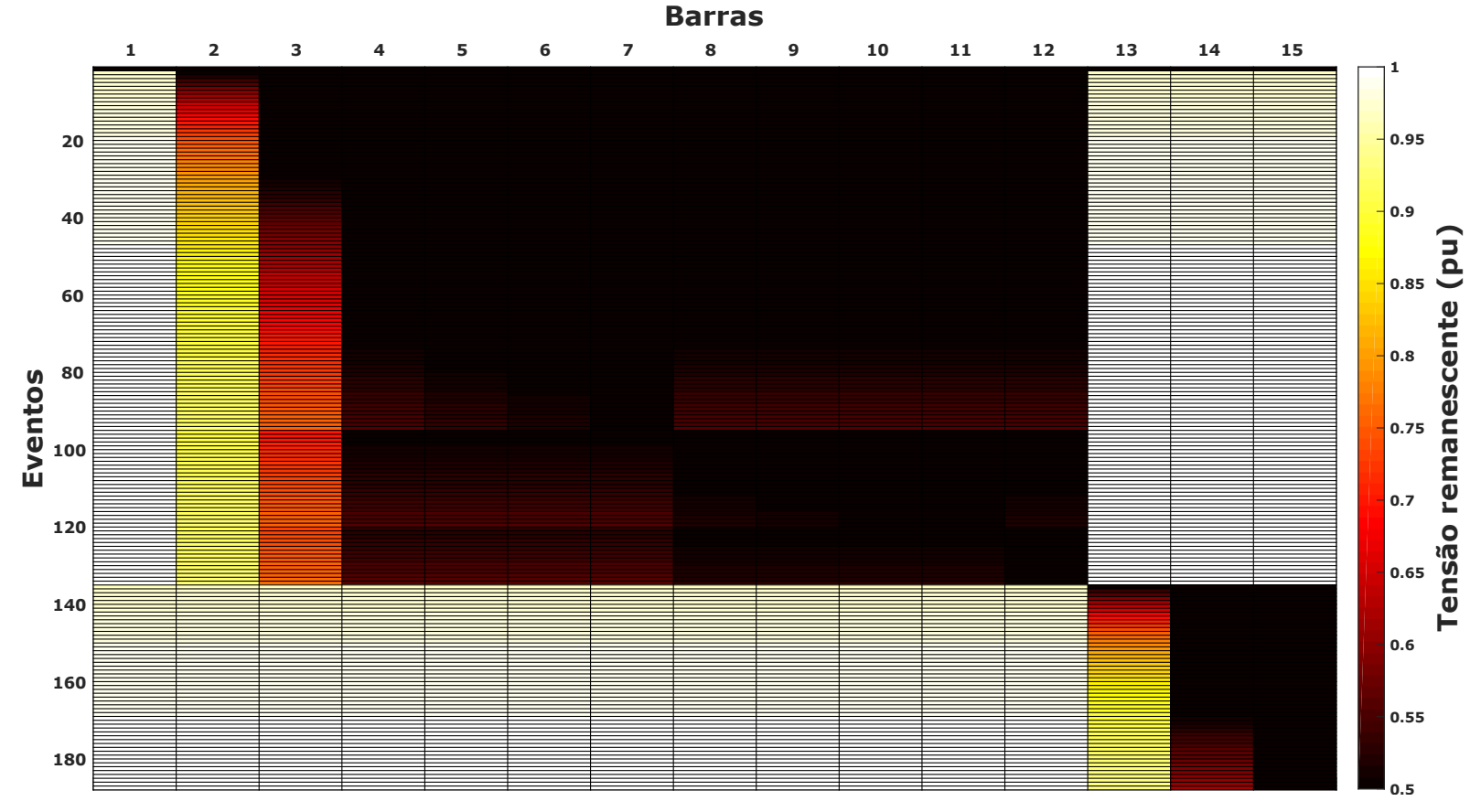


Figura 28 - MTDF da fase C para o sistema de 15 barras durante a ocorrência de faltas bifásicas BC francas sem o GD.

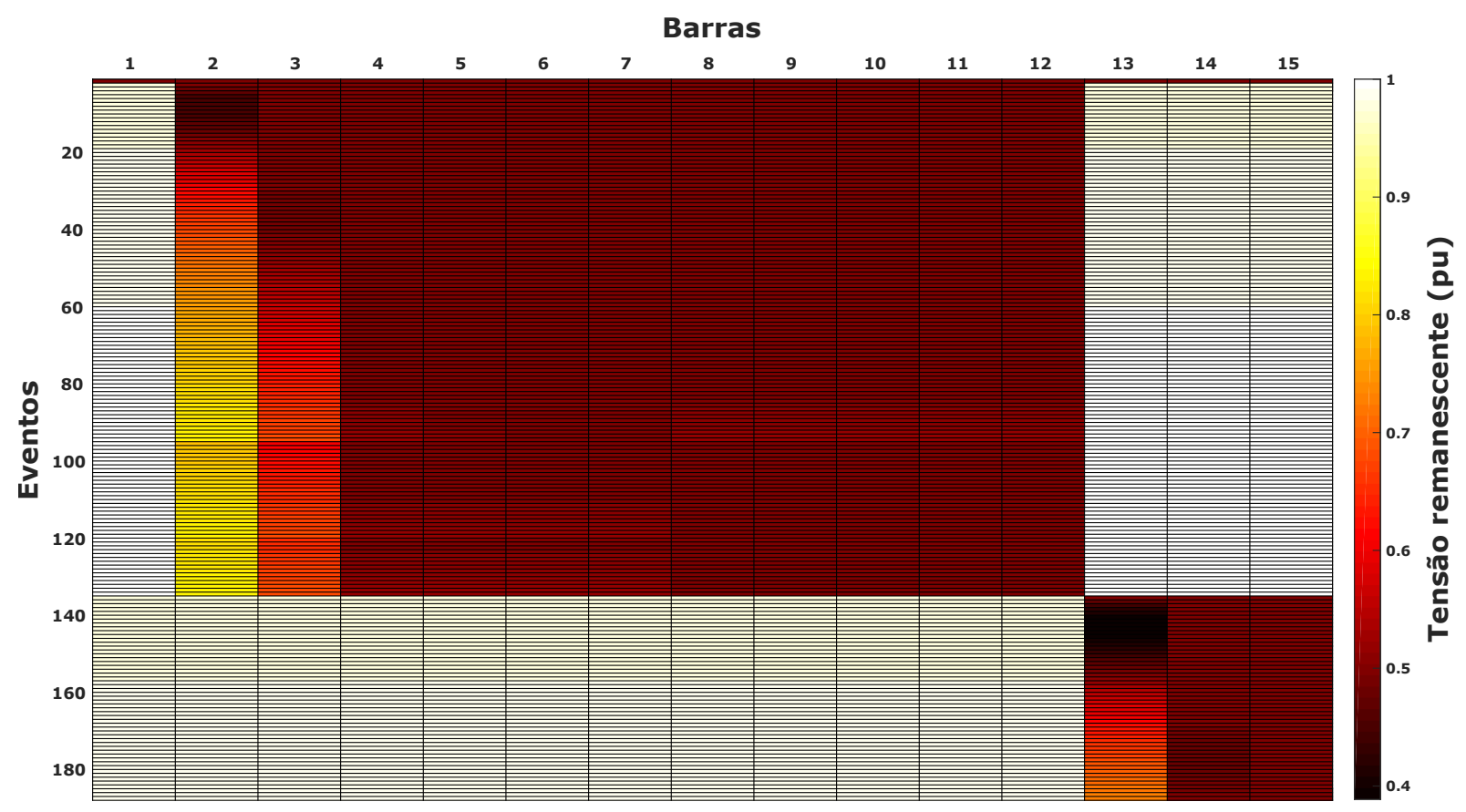

Figura 29 - MTDF da fase A para o sistema de 15 barras durante a ocorrência de faltas bifásicas BCT francas sem o GD.

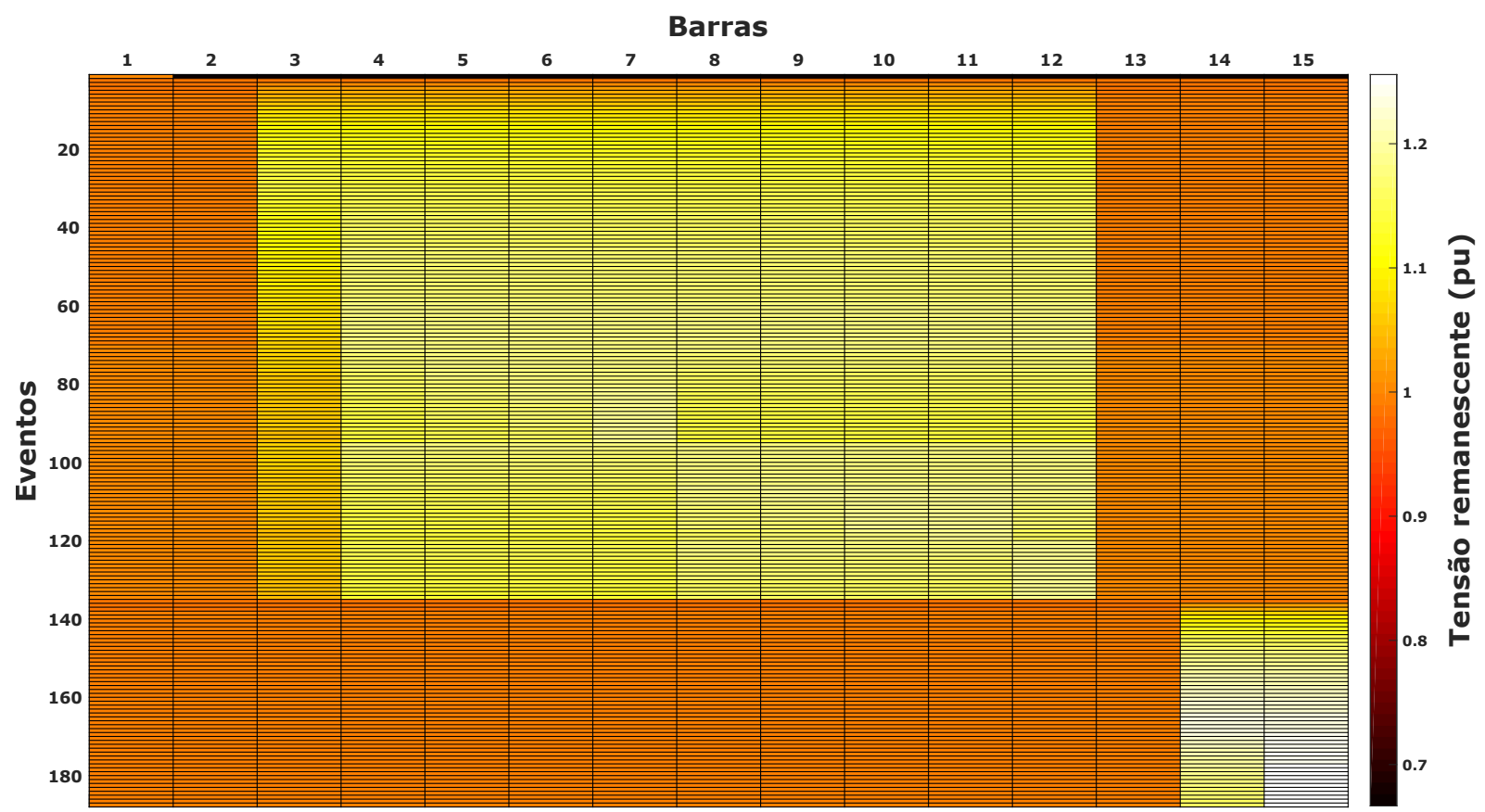


Figura 30 - MTDF da fase B para o sistema de 15 barras durante a ocorrência de faltas bifásicas BCT francas sem o GD.

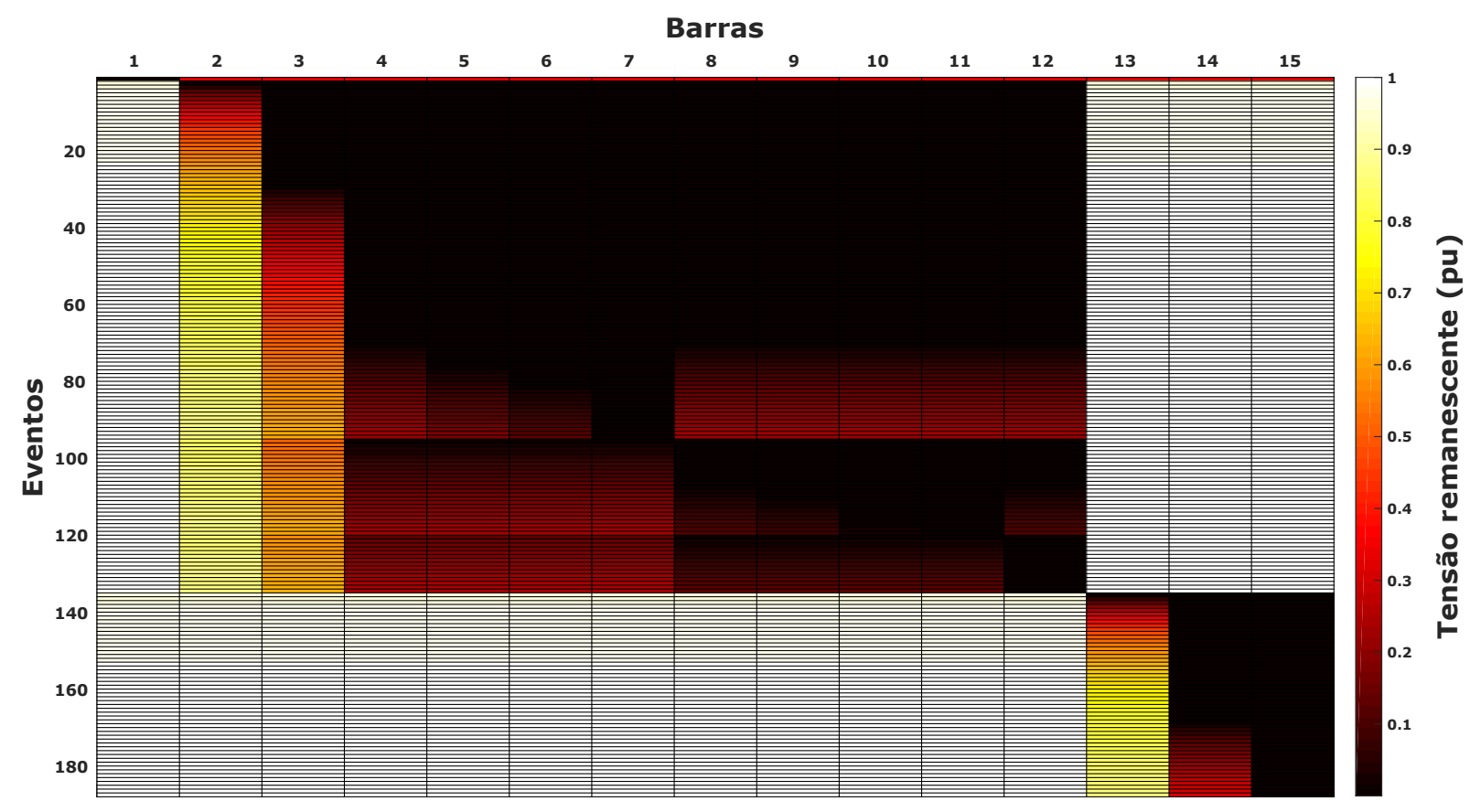

Figura 31 - MTDF da fase C para o sistema de 15 barras durante a ocorrência de faltas bifásicas BCT francas sem o GD.

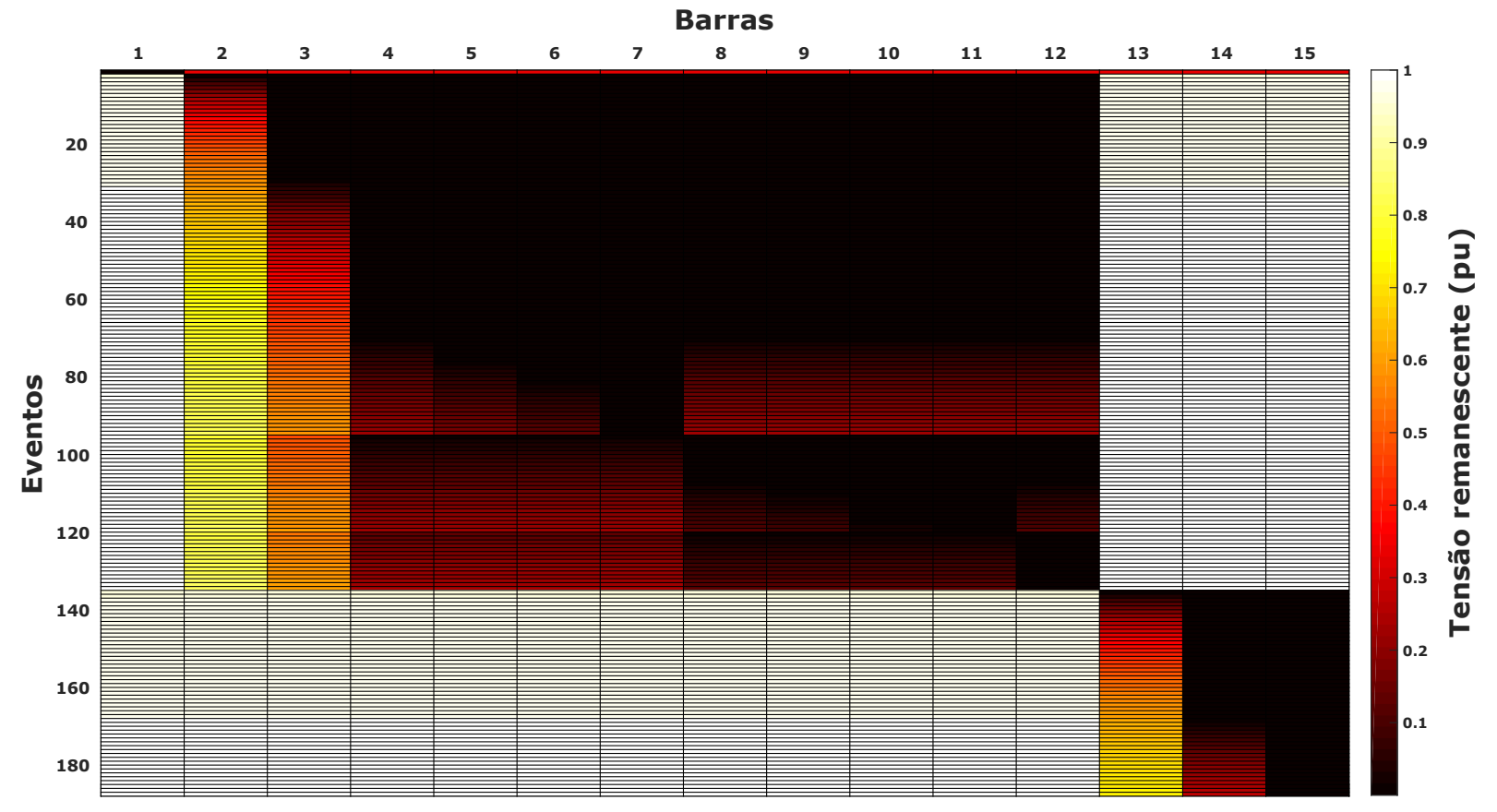

